\title{
MULTIPLE CHOICE:
}

$\infty \infty$

\section{LEVERAGING INSTRUCTIVE CULTURE MODELS TO IMPROVE CARTILAGE TISSUE ENGINEERING}

Nicole Georgi

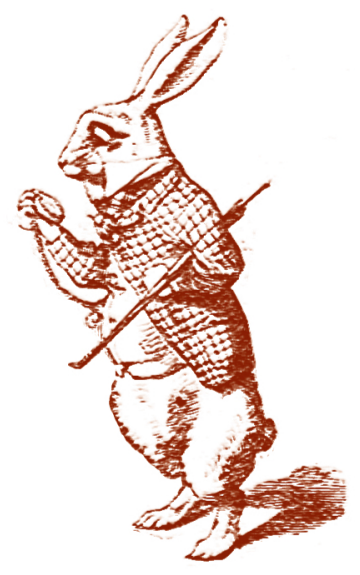




\section{Multiple Choice: \\ Leveraging instructive culture models to improve cartilage tissue engineering}

Nicole Georgi

2013 


\title{
Members of the Graduation Committee
}

\section{Chairman:}

Prof. Dr. G. van der Steenhoven (University of Twente)

\section{Promoter:}

Prof. Dr. C. A. van Blitterswijk (University of Twente)

\section{Co-promoter:}

Prof. Dr. M. Karperien (University of Twente)

\section{Members:}

Prof. Dr. Andre van Wijnen (Mayo Clinic, Rochester)

Prof. Dr. Ron Heeren (FOM Institute AMOLF, Amsterdam)

Prof. Dr. Harrie Weinans (Erasmus MC, Rotterdam)

Prof. Dr. Wouter Dhert (UMC, Utrecht)

Dr. Marco Helder (UUmc, Amsterdam)

Prof. Dr. Leon Terstappen (University of Twente)

Prof. Dr. Dirk Grijpma (University of Twente)

\section{MULTIPLE CHOICE: \\ LEVERAGING INSTRUCTIVE CULTURE MODELS TO IMPROVE CARTILAGE TISSUE ENGINEERING}

\author{
Nicole Georgi
}

PhD Thesis, University of Twente, Enschede, The Netherlands

ISBN: 978-90-365-3520-5

The research described in this thesis was supported by:

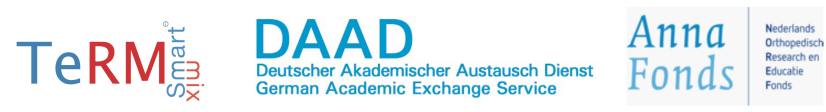

This publication was supported:

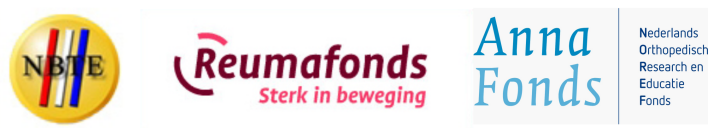

(c) N. Raiss-Georgi 2013, Enschede, The Netherlands. Neither this thesis nor its parts may be reproduced without written permission of the author.

Cover design: Time management and decision making processes. Alice in Wonderland (Lewis Carrol) was linked by the author to the process of obtaining a $\mathrm{PhD}$. 


\title{
MULTIPLE CHOICE: \\ LEVERAGING INSTRUCTIVE CULTURE \\ MODELS TO IMPROVE CARTILAGE TISSUE ENGINEERING
}

\author{
DISSERTATION \\ to obtain \\ the degree of doctor at the University of Twente, \\ on the authority of the rector magnificus, \\ Prof. Dr. H. Brinksma \\ on the account of decision of the graduation committee, \\ to be publicly defended \\ on Friday, March $22^{\text {nd }} 2013$ at 14.45 hours
}

by

Nicole Raiss-Georgi

Born on March 22 ${ }^{\text {nd }}, 1983$

in Schlema, Germany 
iv

Promoter:

Prof. Dr. C. A. van Blitterswijk (University of Twente)

Co-promoter:

Prof. Dr. M. Karperien (University of Twente)

(c) N. Raiss-Georgi 2013, Enschede, The Netherlands.

ISBN: 978-90-365-3520-5 


\section{Summary}

In the recent years, multipotent cells, like mesenchymal stromal/stem cells (MSCs), gained considerable interest in cell based cartilage tissue engineering strategies. MSCs abilities to differentiate into chondrocytes as well as to act as a trophic mediators makes them a promising cell source for the use in cartilage repair. In general, this thesis addresses three major aspects for the use of MSCs in cartilage tissue engineering: i) the role of low oxygen tension to improve MSC performance during cellular expansion ii) the role of low oxygen tension to alter chondrogenic differentiation quantity and quality and iii) revealing MSCs role in co-culture approaches with human chondrocytes.

Chapter two gives a state of the art overview of various aspects in cartilage tissue engineering. The importance and varying qualities of cell sources in cartilage tissue engineering, in particular MSCs, are addressed in the literature review in chapter three.

In chapter four, we reveal the limited chondrogenic differentiation potential of twenty bone marrow-derived MSC donors. Identification of good and bad responding MSC donors and their associated genetic fingerprint indicates a first step in improving the use of MSC in tissue engineering strategies.

In the human body, homing of MSCs in hypoxic niches is essential to retain their multipotent potential. Expansion and differentiation of MSC in low oxygen tension/ hypoxia was employed in chapters five and six. Hypoxic cell expansion leads to a delay in cellular senescence, improvement of proliferation and differentiation potential as well as to an altered RNA/ miRNA expression level and methylation signature. Hypoxic MSC differentiation is associated with improved chondrogenesis, the increased expression of the recently identified articular cartilage markers GREM, FRZB and DKK1 as well as prevention of implant calcification in-vivo. This indicates the importance of strict oxygen regulation for cellular differentiation and tissue formation.

As an alternative to low oxygen tension, o-Phenanthroline, a mimicking agent of the hypoxic response as well as an inhibitor of matrix metalloproteinase, was evaluated in chapter seven. o-Phenanthroline activates the hypoxic signalling pathways and reduced the catabolic response in cartilage degradation models. Still, its side effects need to be addressed for medical applications.

Chapter eight and nine investigate the co-culture of MSCs and chondrocytes for improvement of chondrogenesis. Mass spectrometry based imaging strategies employed in chapter eight prove cholesterol and phosphocholine to be regulated in 
MSCs and chondrocytes during co-culture of these cell types. The biomaterial-based application of the co-culture of MSCs and chondrocytes in chapter nine leads to advantageous chondrogenic matrix deposition and gives thereby an outlook for future medical applications of this strategy. 


\section{Samenvatting}

De laatste jaren is de belangstelling voor multipotente cellen, zoals mesenchymale stromale/stam cellen (MSCs), voor het gebruik in kraakbeen regeneratie strategieën toegenomen. De capaciteit van MSCs om te differentiëren tot chondrocyten en te fungeren als trofische mediatoren, maakt deze cellen geschikt voor het herstel van kraakbeen. Algemeen worden in dit proefschrift drie belangrijke pijlers uitgelicht: i) de rol van lage zuurstofdruk ter verbetering van de prestatie van MSCs in celgroei, ii) de invloed van lage zuurstofdruk op de kwaliteit en kwantiteit van chondrogene differentiatie, and iii) de betrokkenheid van MSCs in co-kweek met chondrocyten.

Hoofdstuk twee geeft een uitgebreid overzicht van verschillende aspecten die een rol spelen in kraakbeen regeneratie. Het belang van de verschillende oorsprong en kwaliteiten van cellen, met name MSCs, wordt uitgelicht middels een literatuurstudie in hoofdstuk drie.

In hoofdstuk vier wordt de beperkte mogelijkheid tot chondrogene differentiatie van twintig van beenmerg afkomstige MSC donoren beschreven. De identificatie van goed en slecht reagerende MSC donoren en de bijbehorende genetische profielen, inpliceren een eerste stap tot het verbeteren van het gebruik van MSCs in kraakbeen regeneratie.

In het menselijk lichaam is de homing van MSCs in hypoxische niches essentieel voor het behoud van de multipotente capaciteit. De expansie en differentiatie van MSCs bij lage zuurstofdruk/hypoxia worden bestudeerd in hoofdstukken vijf en zes. De expansie van cellen in hypoxia heeft geleid tot een vertraagde cel senescence en verbeterde proliferatie en differentiatie, evenals een aangepast RNA, miRNA en methylatie profiel. Differentiatie van MSCs in hypoxia wordt geassocieerd met verbeterde chondrogenese, verhoogde expressie van articulair kraakbeen markers GREM, FRZB en DKK1 en voorkomt daarnaast de verkalking van het implantaat emphin vivo. Dit impliceert dat een strikte regulatie van zuurstof essentieel is voor de differentiatie van cellen en de formatie van weefsels.

Als een alternatief voor lage zuurstofdruk, wordt o-Phenanthroline, een nabootser van de hypoxische respons en tegelijkertijd een remmer van matrix metalloproteinase, bestudeerd in hoofdstuk zeven. o-Phenanthroline activeert de hypoxia signaleringsroute en reduceert de katabole respons in modellen voor kraakbeenafbraak. De ongewenste neveneffecten dienen onderzocht te worden om medische toepassing mogelijk te maken.

Hoofdstukken acht en negen belichten de co-kweek van MSCs en chondrocyten 
ter verbetering van de chondrogenese. De visualisatie strategieën gebaseerd op massaspectrometrie, die gebruikt zijn in hoofdstuk acht, bewijzen dat cholesterol en phosphocholine worden gereguleerd in MSCs en chondrocyten tijdens de co-kweek van deze celtypen. De toepassing van de co-kweek van MSCs en chondrocyten op basis van biomaterialen in hoofdstuk negen, heeft een gunstig effect op de opbouw van kraakbeen matrix en geeft daarmee uitzicht op het gebruik van deze strategie voor toekomstige medische toepassingen. 


\section{Zusammenfassung}

Die Bedeutung von multipotententen körpereigenen Zellen, wie zum Beispiel mesenchymalen stromale Zellen (MSZ), hat im Gebiet der Knorpelregenerationstherapie in den letzten Jahren beachtlich zugenommen. Die Fähigkeit der MSZs zu Chondrozyten zu differenzieren oder trophische Faktoren zu sekretieren macht sie zu einer vielversprechenden Zellressource für die Knorpelregenerationstherapie. Diese Promotionsarbeit beschäftigt sich mit drei Ansätzen für die Verwendung von MSZs in der Knorpelregenerationstherapie: i) die Rolle von Hypoxie während der Zellvermehrung in Laborkultur, ii) die Rolle von Hypoxie während der chondrogenen Differenzierung von MSZ und iii) die Erforschung des Einflusses von MSZ in Ko-kultur mit von Knorpel isolierten Chondrozyten.

Das zweite Kapitel ist eine Zusammenfassung verschiedener Aspekte der Knorpelregenerationstherapie nach aktuellem Stand der Wissenschaft. Die Bedeutung und die Vorzüge von unterschiedlichen Zellressourcen in der Knorpelgewebekultur, im speziellen MSZ, werden in der Literaturrecherche des dritten Kapitels zusammengefasst.

Im vierten Kapitel wird das teilweise eingeschränkte Differenzierungspotential von MSZs anhand von zwanzig Knochenmarkspendern verdeutlicht. Der Ansatz einer Einteilung in gut- und schlecht-differenzierende MSZ Spendern in Verbindung mit der Identifizierung des entsprechenden genetischen Profils markiert einen ersten Schritt zur Verbesserung der Verwendung von MSZ in der Gewebekultur.

Im menschlichen Körper findet man MSZs in sauerstoffarmen Gewebsnischen, welche grundlegend an der Erhaltung derer multipotenten Differenzierungspotentiale beteiligt sind. In Kapitel fünf und sechs wird die MSZ Zellvermehrung und differenzierung unter Hypoxie beschrieben. Die kontinuierliche Zellvermehrung unter Hypoxie führt zur Verzögerung des zellulären Alterungsprozess (Seneszenz), Erhöhung der Zellproliferation und der Zelldifferenzierung, sowie zu Veränderung der RNA-, microRNA-Expression und des Methylierungszustandes der DNA.

Die hypoxische MSZ-Differenzierung resultiert in gesteigerter Chondrogenese, unter anderem durch positive Regulierung von kürzlich identifizierter artikulärer Knorpelmarker: GREM, FRZB und DKK1. Zusätzlich konnte Verknöcherung des Knorpelimplantats im Mausmodell verhindert werden. Diese Ergebnisse verdeutlichen die Bedeutung einer strikten Regulierung der Sauerstoffzufuhr während Zelldifferenzierung und Zellkultur.

In Kapitel sieben wurde o-Phenanthrolin als Hypoxieimitator und Inhibitor von 
Metallopoteinasen getestet. Dieses Derivat des Phenanthrens aktiviert den hypoxischen Signalweg und reduziert den Abbau von Knorpel im Modellsystem. Jedoch besteht die Notwendigkeit ungewollte Nebenwirkungen vor der medizinischen Anwendung zu reduzieren.

In Kapitel acht und neun wird die verbesserte Knorpelbildung nach der Kokultur von MSZ und Chondrozyten weiterführend untersucht. Mit Hilfe von bildgebender Massenspektrometrie wurden Cholesterol und Phosphocholine als regulierte Lipide in der Ko-kultur identifiziert. Die biomaterial-basierte Ko-kultur von MSZ und Chondrozyten wird in Kapitel neun beschrieben. Die Kombination von GelatinMicroträgermaterial und Zellkultur führt zu einer vorteilhaften Knorpelgewebebildung und stellt somit eine Methode für zukünftige medizinische Anwendungen dar. 


\section{Table of Contents}

1 General introduction and thesis outline 1

1.1 Role of low oxygen tension in mesenchymal stromal cell culture . . . . 3

1.2 The role of low oxygen tension during chondrogenic differentiation . . 4

1.3 Aim and outline of this thesis . . . . . . . . . . . . . 5

2 Cartilage tissue engineering $\quad 9$

2.1 Introduction . . . . . . . . . . . . . . . . . . . . 11

2.2 Development of cartilage . . . . . . . . . . . . . . . . . . . 11

2.2 .1 Joint formation . . . . . . . . . . . . . . . . . . . 11

2.2.2 Growth plate cartilage . . . . . . . . . . . . . . . . . 12

2.2 .3 Articular cartilage . . . . . . . . . . . . . . . . . . . 13

2.3 History of clinical applications in cartilage repair . . . . . . . . . . 13

2.4 Cell sources of cartilage engineering _ . . . . . . . . . . . . . 15

2.5 Biomaterials for cartilage repair . . . . . . . . . . . . . . . 16

2.5.1 Chondro-conducting scaffolds: natural and synthetic biomaterials 17

2.5.2 Emerging "smart" biomaterials . . . . . . . . . . . . . 20

2.6 Future of cartilage tissue engineering . . . . . . . . . . . . . . . . 21

3 Cell sources for articular cartilage repair strategies: shifting from mono-cultures to co-cultures $\quad 25$

3.1 Introduction . . . . . . . . . . . . . . . . . . . . . 27

3.2 Autologous articular chondrocytes: cell number versus dedifferentiation 27

3.3 Non-autologous articular chondrocytes: morbidity versus immune re-

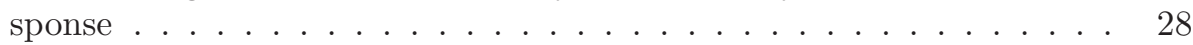

3.4 Non-articular chondrocytes: morbidity versus phenotype . . . . . . . . 29

3.5 Non-chondrocyte cell sources: morbidity versus control of differentiation 30

3.6 Co-cultures: combinatorial advantages versus current knowledge . . . 33

3.7 Conclusion . . . . . . . . . . . . . . . . . . . 36

4 microRNA levels as prognostic markers for chondrogenesis of MSC donors 43

4.1 Introduction . . . . . . . . . . . . . . . . . . . . 45

4.2 Materials and Methods . . . . . . . . . . . . . . . . 45

4.2 .1 Cell expansion and differentiation . . . . . . . . . . . 45 
4.2.2 Chondrogenic differentiation . . . . . . . . . . . . . 46

4.2.3 Alcian Blue staining . . . . . . . . . . . . . . . 46

4.2.4 RNA isolation and quantitative polymerase chain reaction . . . 46

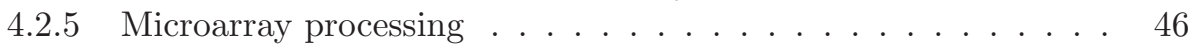

4.2.6 miRNA isolation and quantitative analysis . . . . . . . . . 47

4.2 .7 Statistical analysis .................. . . 48

4.3 Results.......................... . . 48

4.3.1 Limited chondrogenic potential in MSCs donors . . . . . . . . 48

4.3.2 microarray mRNA analysis reveals limited seperation of different chondrogenic groups . . . . . . . . . . . . . . 50

4.3.3 Differential expression of miRNAs between groups with distinct chondrogenic potential ............ . . 50

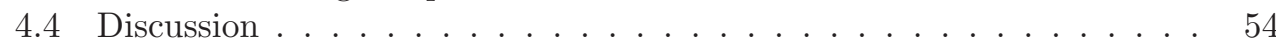

5 Epigenetic changes associate with improved performance of MSCs expanded in hypoxia

5.1 Introduction . . . . . . . . . . . . . . . . . . 63

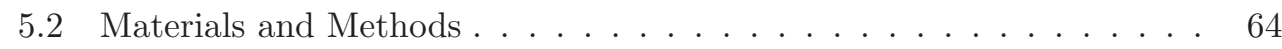

5.2.1 Cell expansion and differentiation . . . . . . . . . . . . 64

5.2.2 Immunophenotyping of adherence selected MSCs . . . . . . . 64

5.2.3 Chondrogenic differentiation .............. . 64

5.2.4 Adipogenic differentiation ......................... 64

5.2 .5 Osteogenic differentiation ................ 65

5.2.6 Senescence-associated $\beta$-galactosidase expression (SA- $\beta$ gal) . . 65

5.2.7 Staining .................... 65

5.2.8 RNA, DNA, small RNA isolation and qRT-PCR . . . . . . 66

5.2.9 Microarray processing ..................... 67

5.2.10 Illumina ${ }^{\circledR}$ Methylation Array Infinium450k . . . . . . . . . . . 67

5.2 .11 Statistical analysis . . . . . . . . . . . . . . . . . . 67

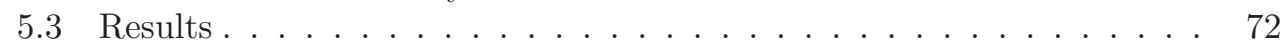

5.3.1 Hypoxic MSC expansion maintains cellular morphology and growth rate ..................... 72

5.3.2 Hypoxia slightly improves CD marker expression in culture expanded MSCs . . . . . . . . . . . . . 72

5.3.3 Expansion in hypoxia improves the differentiation potential of MSCs ..................... 72

5.3.4 Regulation of glycolytic and transcriptional genes in different oxygen tensions . . . . . . . . . . . . 73

5.3.5 Hypoxia induces epigenetic changes in DNA methylation . . . . 73

5.3.6 Changes in miRNA expression are associated with cell passage and oxygen tension . . . . . . . . . . . . . . . 74

5.4 Discussion . . . . . . . . . . . . . . . . . . 74

6 Hypoxia steers chondrogenically differentiating human mesenchymal stromal cells towards an articular cartilage phenotype 
6.1 Introduction . . . . . . . . . . . . . . . . . . 85

6.2 Materials and Methods. . . . . . . . . . . . . . . . 85

6.2.1 Patient material ................... 85

6.2.2 Chondrogenic differentiation of MSCs . . . . . . . . . . 86

6.2.3 Total RNA extraction . . . . . . . . . . . . . . 86

6.2.4 Microarray processing and statistical analysis . . . . . . . . . 86

6.2.5 Quantitative real-time reverse transcriptase-polymerase chain reaction (qRT-PCR) . . . . . . . . . . . . 87

6.2.6 Subcutaneous implantation .............. 87

6.2.7 Histological analysis . . . . . . . . . . . . . . . . . 87

6.2.8 Quantitative glycosaminoglycan and DNA assay ...... . 87

6.2.9 Quantification of GREM1, FRZB and DKK1 protein levels in conditioned media ................. . . 88

6.2.10 Statistical analysis . . . . . . . . . . . . . . . . . . . . . . . . . . 88

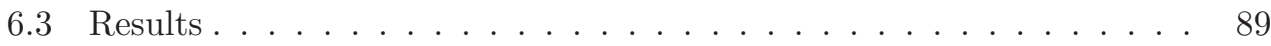

6.3.1 Hypoxia stimulates chondrogenic differentiation of MSCs . . . 89

6.3.2 Effect of oxygen on gene expression profile of chondrogenically differentiating MSCs ............... . . 90

6.3.3 Gene networks regulated by oxygen levels . . . . . . . . . . 92

6.3.4 Hypoxia induces an articular cartilage-like profile in chondrogenically differentiated MSCs ............. . 93

6.3.5 Continued hypoxia is needed to retain chondrogenic stimulus . 94

6.3.6 Hypoxic chondrogenic differentiation of MSCs strongly reduces calcification upon implantation . . . . . . . . . . . . . . 94

6.4 Discussion . . . . . . . . . . . . . . . . . 95

7 The effect of o-Phenanthroline as mediator of the hypoxic response in cartilage tissue engineering models 99

7.1 Introduction . . . . . . . . . . . . . . . . . . . . . . . . . . . . . . . . . . . . . .

7.2 Materials and Methods . . . . . . . . . . . . . . . 102

7.2.1 Human cell culture . . . . . . . . . . ...... 102

7.2.2 HIF1 $\alpha$ immunofluorescence staining . . . . . . . . . . . . 103

7.2 .3 Pellet culture . . . . . . . . . . . . . . . . 103

7.2.4 Mouse fetal metatarsals . . . . . . . . . . . . . . . 103

7.2 .5 Histological analysis . . . . . . . . . . . . . . . . . 104

7.2 .6 Gene expression analysis . . . . . . . . . . . . . . . . 104

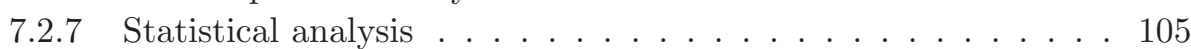

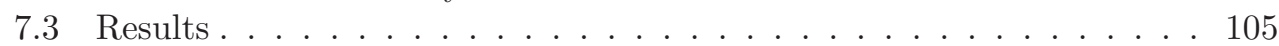

7.3.1 Dose-response effect of $o$-Phenanthroline on HIF1 $\alpha$ expression and cell count . . . . . . . . . . . . . . 105

7.3.2 O-Phenanthroline induces HIF1 $\alpha$ expression less effectively than hypoxia or $\mathrm{CoCl}_{2}$. . . . . . . . . . . . . . 105

7.3.3 O-Phenanthroline increased SOX9 mRNA expression in chondrogenic pellets, without affecting cartilage matrix deposition . 109 
7.3.4 O-Phenanthroline blocks IL1 $\beta / \mathrm{TNF} \alpha$ induced cartilage degradation ................... . 109

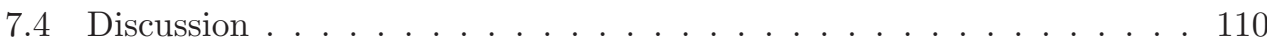

8 Cholesterol and phosphocholine as regulators of the chondrogenic response in co-cultures of MSCs and primary chondrocytes 115

8.1 Introduction . . . . . . . . . . . . . . . . . 117

8.2 Materials and Methods . . . . . . . . . . . . . . . 118

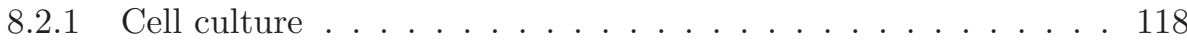

8.2.2 Alcian Blue staining . . . . . . . . . . . . . . . 118

8.2.3 Sample preparation .................. 119

8.2.4 TOF-SIMS experiments . . . . . . . . . . . . 119

8.2.5 MALDI-IMS experiments ................ 119

8.2 .6 Data interpretation . . . . . . . . . . . . . . . 119

8.2 .7 Lipid staining . . . . . . . . . . . . . . . . 120

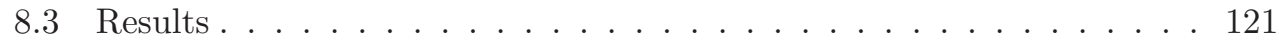

8.3.1 Co-culture leads to improved chondrogenesis under normoxia

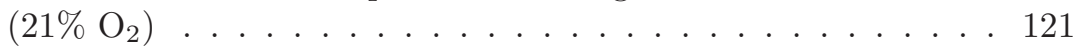

8.3.2 Molecular profile of normoxic pellet cultures separates clearly from hypoxic pellet cultures . . . . . . . . . . . . . 123

8.3.3 Co-culture lipid profiles are more different from MSC monoculture in normoxia profiles than in hypoxia . . . . . . . . . . . 125

8.3.4 Spatial mapping of specific masses reveals location and difference in expression between conditions . . . . . . . . . . . . . 125

8.3.5 Higher lipid deposition in normoxic cultured conditions . . . . 126

8.4 Discussion . . . . . . . . . . . . . . . 126

9 MSC or chondrocyte seeded microcarriers as building blocks for cartilage tissue engineering

9.1 Introduction . . . . . . . . . . . . . . . . . . . 135

9.2 Materials and Methods . . . . . . . . . . . . . . 136

9.2.1 Cell culture . . . . . . . . . . . . . . . . 136

9.2.2 Microcarrier construct culture . . . . . . . . . . . . 137

9.2.3 Live dead staining . . . . . . . . . . . . . . . . . 137

9.2.4 Scanning electron microscopy . . . . . . . . . . . 137

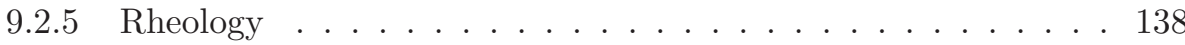

9.2 .6 Histology . . . . . . . . . . . . . . . . . . . 138

9.2.7 Wet weight, dry weight and quantitative GAG, DNA assay . . 138

9.2.8 RNA isolation, and quantitative polymerase chain reaction . . 138

9.2 .9 Statistical analysis . . . . . . . . . . . . . . . 138

9.3 Results......................... . . . . . . . . . . . . . . . . .

9.3.1 Cells expanded on microcarriers can be used as building units for cartilage TE-constructs . . . . . . . . . . . . . . 140

9.3.2 Microcarrier based tissue constructs show cartilaginous tissue formation .................. 144 
9.3.3 Reduced markers of de-differentiation and hypertrophy in microcarrier seeded constructs . . . . . . . . . . . . 145

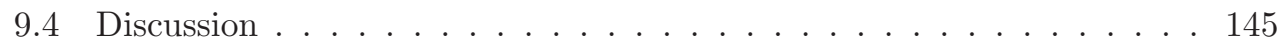

10 Conclusion and Outlook 153

10.1 Abstract . . . . . . . . . . . . . . . . . . 154

10.2 Mesenchymal stromal cells and their position in the field in cartilage

tissue engineering . . . . . . . . . . . . . . 155

10.3 Hypoxia to improve MSC performance and chondrogenic differentiation 156

10.4 Co-culture of MSCs and chondrocytes for improved chondrogenesis . . 157

10.5 Linking microRNA levels to MSC differentiation potential . . . . . . 158

10.6 Concluding remarks and future perspectives . . . . . . . . . . . 158

$\begin{array}{lr}\text { Curriculum Vitae } & 161\end{array}$

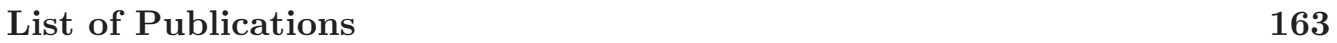

$\begin{array}{lr}\text { Acknowledgement } & 167\end{array}$ 


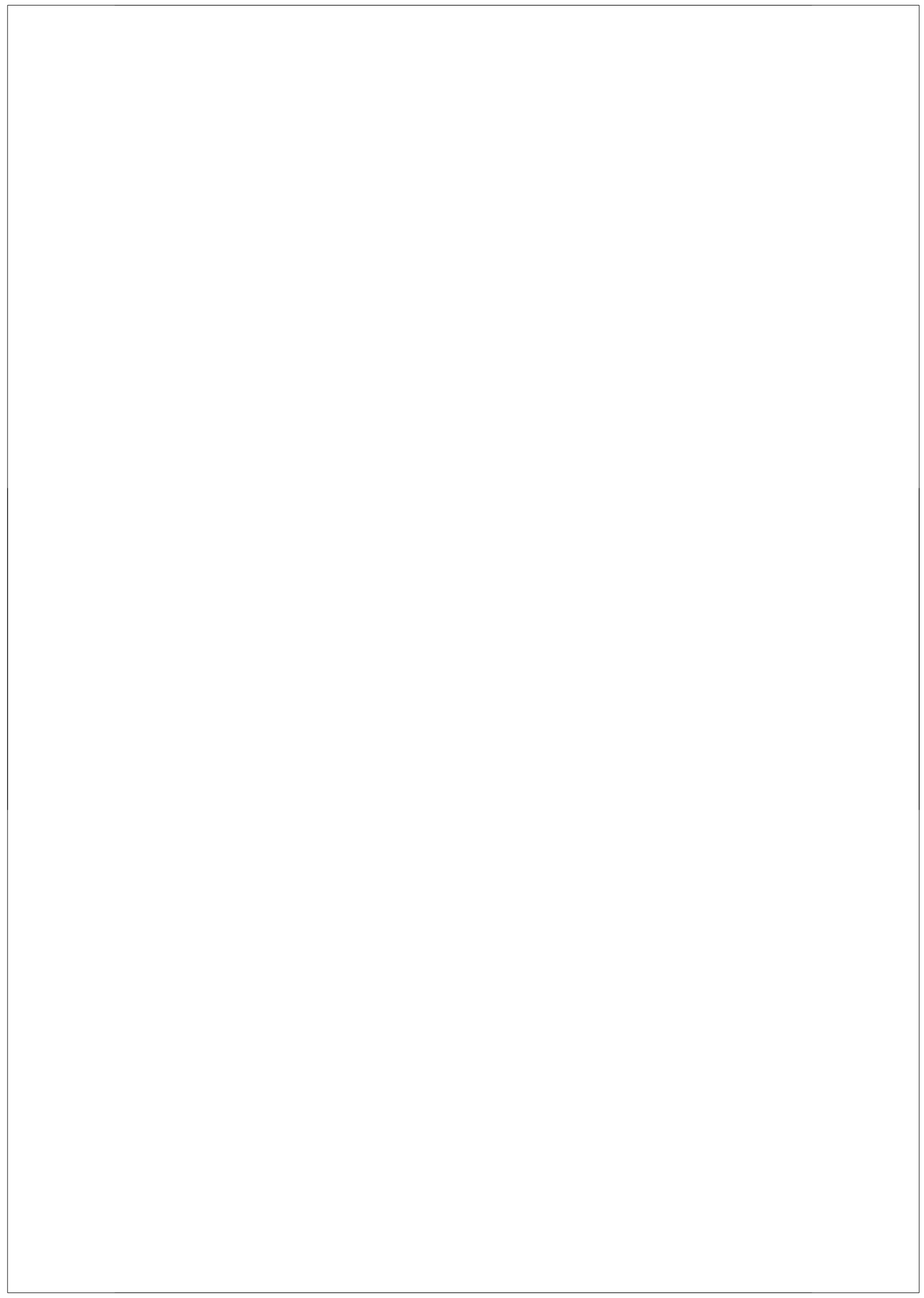


Chapter 1

\section{General introduction and thesis outline}

"Begin at the beginning," the King said gravely, "and go on till you come to the end: then stop." (Alice's Adventures in Wonderland, Chapter 12) 
Articular cartilage is avascular and aneural. Therefore chondrocytes, the native cell population of cartilage, are most times in cellular arrest. After injury chondrocytes have limited ability to respond and to contribute to tissue repair. Consequently, it is important to develop and optimise strategies for cartilage repair. Currently the strategies for cartilage repair include osteochondral grafting, bone marrow stimulation techniques and ultimately cellular therapies [1-3]. The most described cellular therapy is autologous chondrocyte implantation (ACI). For ACI, autologous chondrocytes are first isolated from an autologous biopsy and expanded ex vivo before re-implantation in a subsequent second surgical procedure. Ex vivo chondrocytes expansion is associated with the loss of the differentiated phenotype of the cells, resulting in altered chondrogenic performance. Thus, it is important to limit and optimise the use of chondrocytes in cartilage repair strategies and to consider different cell sources as well as alternative culture methods.

In recent years, multipotent cells, like mesenchymal stromal/stem cells (MSCs), gained considerable interest in tissue engineering. MSCs ability to differentiate into chondrocytes as well as to act as a trophic mediator make them a promising cell source for the use in cartilage repair strategies. Nevertheless, MSCs potential to undergo chondrogenic differentiation can be limited. The potential of MSCs to differentiate into cells of the mesenchymal lineage is strongly dependent on donor age, harvest site, method of harvesting and the ex vivo culture method to select the MSCs and to obtain sufficient cells for therapeutic application $[4,5]$. The next paragraphs will focus on ways to improve MSC differentiation potential. 


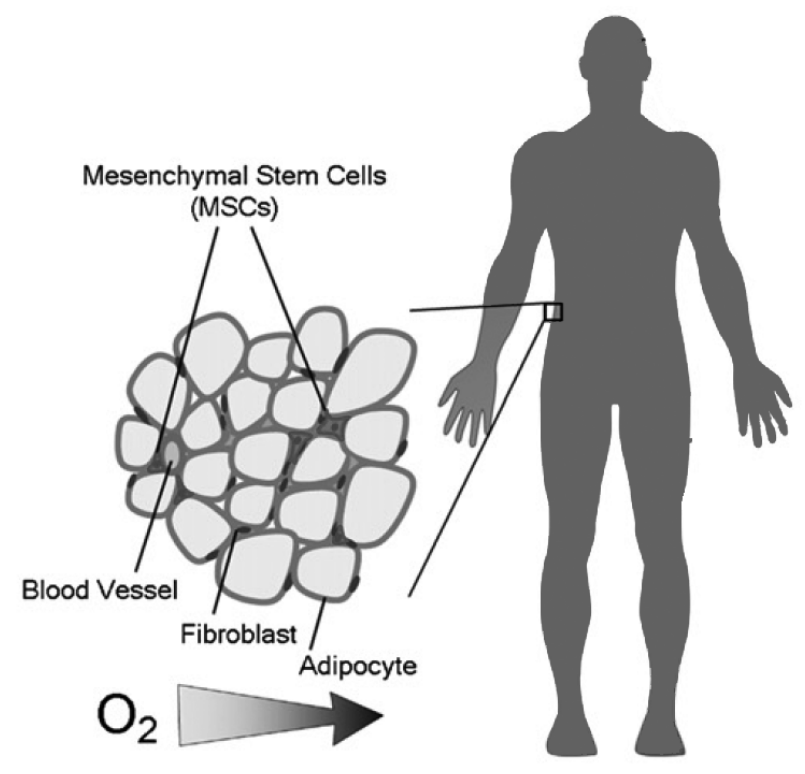

Figure 1.1: Hypoxic mesenchymal niches in the human body (adapted from $[17])$

\subsection{Role of low oxygen tension in mesenchymal stromal cell culture}

Stem cells or progenitor cells are described to reside in a complex microenvironment, so called cellular niches [6]. Next to complex structural and humeral factors, low oxygen tension persists in these niches. Low oxygen tension is involved in maintaining the undifferentiated state of multipotent or pluripotent cell sources in these niches $[7,8]$. Furthermore it has been hypothesized that low oxygen tension offers a selective advantage for multipotent cells, since metabolism under atmospheric oxygen concentration is known to introduce more reactive oxygen species and thereby leads to more DNA damage [9]. As visible in figure 1.1, MSCs inhabit various oxygen low niches in the body: (i) the perivascular niche, experiencing the highest oxygen levels of about $8 \%$, (ii) the bone marrow niche and the (iii) adipose tissue niche with the lowest abundance of oxygen [10-12]. In their respective environment MSCs interact with a myriad of different cell types, soluble factors as well as with proteins from the surrounding extracellular matrix (Fig 1.2). Until now low oxygen tension, or so 


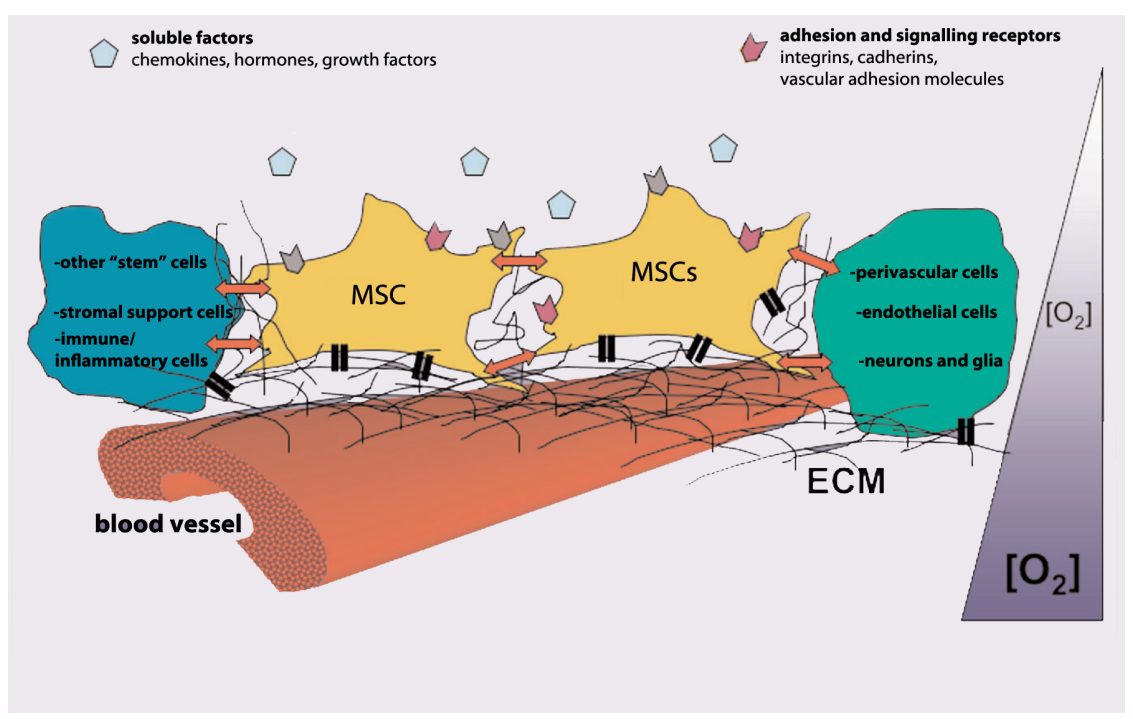

Figure 1.2: The mesenchymal stromal cell niche (adapted from [18]) MSCs experience a myriad of environmental factors in their respective niche. These factors include signalling molecules, growth factors, cytokines, interaction with neighbouring cells and interactions with proteins of the extracellular matrix.

called hypoxic culture, for MSCs has been used to increase the number of colony forming units (CFUs) of rat mesenchymal stromal cells [13], to alter the therapeutic potential of human MSCs [14], to reduce the level of senescence [15] and to alter MSC differentiation potential [16]. Expansion of MSC in low oxygen tension or hypoxia can advance the use of this cell source in cartilage tissue engineering.

\subsection{The role of low oxygen tension during chondrogenic differentiation}

Low levels of oxygen already occur naturally during early stages of embryonic development, leading to the coordinated development of organs and the blood system. During endochondral bone development the hypoxic mesenchymal growth plate undergoes an orchestrated plethora of steps to ultimately form bone. This indicates that strict oxygen regulation is important for cellular differentiation and tissue formation. During chondrogenesis of MSCs, as well as during re-differentiation of chondrocytes hypoxia can be employed to improve the level of glycosaminoglycan deposition as well as to limit the amount of ossification $[19,20]$. Additional to the inductive effect, hypoxia can have a protective effect, enabling differentiating MSCs to be less sensitive for increased catabolic processes in diseased joints [21]. 


\subsection{Aim and outline of this thesis}

This thesis focuses on the investigation of different culture techniques of MSCs and chondrocytes for cartilage tissue engineering and will thereby give indications to optimize cell culture conditions as well as the use of cell combinations for cartilage repair. Furthermore, the application of small molecules with a potential beneficial effect in cartilage tissue engineering is explored.

Chapter two and three give a general overview on the field of cartilage tissue engineering. Chapter three focuses more on the different cell types that can be used in cartilage tissue engineering. This chapter focuses as well on the beneficial combinations of chondrocytes with cells mediating trophic effects and thereby inducing improved chondrogenic performance [22].

Chapter four draws major attention to the use of MSCs in cartilage tissue engineering, describes their limited chondrogenic potential and gives insight in the identification of potential prognostic markers indicative for chondrogenic potential.

Chapter five and six focus on the use of hypoxic culture conditions to improve MSC performance. Whereas chapter five explores the impact of continuous MSC expansion under hypoxic conditions on their cellular performance, chapter six investigates the enhanced chondrogenic performance of MSCs cultured under hypoxia during the differentiation process. Special attention is drawn to the regulation of recently identified markers of articular cartilage homeostasis: GREM1, FRZB and DKK1[23]. The evaluation of $o$-Phenanthroline, a mimicking agent of the hypoxic response as well as an inhibitor of matrix metalloproteinase, plays a significant role in chapter seven. The potential of $o$-Phenanthroline to improve chondrogenesis as well as its potential to block IL1 $\beta / \mathrm{TNF} \alpha$-induced matrix degradation is explored.

Ultimately chapter eight and nine investigate the co-culture of MSCs and chondrocytes for improvement of chondrogenesis. In chapter eight, mass spectrometry analysis is introduced as a novel method to gain spatial information on lipid expression in different cellular combination as well as under different oxygen tensions. Chapter nine describes the application of the co-culture model in a biomaterial-assisted strategy contributing to the identification of alternative approaches to overcome the two-step surgical procedure of ACI. 


\section{References}

1. Steadman JR, Rodkey WG, Briggs KK, Rodrigo JJ. [The microfracture technic in the management of complete cartilage defects in the knee joint]. Orthopade 1999; 28: 26-32.

2. Beiser IH, Kanat IO. Subchondral bone drilling: a treatment for cartilage defects. The Journal of foot surgery 1990; 29: 595-601.

3. Brittberg M, Lindahl A, Nilsson A, Ohlsson C, Isaksson O, Peterson L. Treatment of deep cartilage defects in the knee with autologous chondrocyte transplantation. N Engl J Med 1994; 331: 889-895.

4. Gallay SH, Miura Y, Commisso CN, Fitzsimmons JS, O'Driscoll SW. Relationship of donor site to chondrogenic potential of periosteum in vitro. J Orthop Res 1994; 12: 515-525.

5. Tokalov SV, Gruner S, Schindler S, Wolf G, Baumann M, Abolmaali N. Age-related changes in the frequency of mesenchymal stem cells in the bone marrow of rats. Stem cells and development 2007; 16: 439-446.

6. Spradling A, Drummond-Barbosa D, Kai T. Stem cells find their niche. Nature 2001; 414: 98-104. 7. Cipolleschi MG, Dello Sbarba P, Olivotto M. The role of hypoxia in the maintenance of hematopoietic stem cells. Blood 1993; 82: 2031-2037.

8. Schofield R. The relationship between the spleen colony-forming cell and the haemopoietic stem cell. Blood cells 1978; 4: 7-25.

9. Busuttil RA, Rubio M, Dolle ME, Campisi J, Vijg J. Oxygen accelerates the accumulation of mutations during the senescence and immortalization of murine cells in culture. Aging Cell 2003; 2: 287-294.

10. Harrison JS, Rameshwar P, Chang V, Bandari P. Oxygen saturation in the bone marrow of healthy volunteers. Blood 2002; 99: 394.

11. Pasarica M, Sereda OR, Redman LM, Albarado DC, Hymel DT, Roan LE, et al. Reduced adipose tissue oxygenation in human obesity: evidence for rarefaction, macrophage chemotaxis, and inflammation without an angiogenic response. Diabetes 2009; 58: 718-725.

12. Kofoed H, Sjontoft E, Siemssen SO, Olesen HP. Bone marrow circulation after osteotomy. Blood flow, pO2, pCO2, and pressure studied in dogs. Acta orthopaedica Scandinavica 1985; 56: 400-403. 13. Lennon DP, Edmison JM, Caplan AI. Cultivation of rat marrow-derived mesenchymal stem cells in reduced oxygen tension: effects on in vitro and in vivo osteochondrogenesis. Journal of cellular physiology 2001; 187: 345-355.

14. Rosova I, Dao M, Capoccia B, Link D, Nolta JA. Hypoxic preconditioning results in increased motility and improved therapeutic potential of human mesenchymal stem cells. Stem Cells 2008; 26: 2173-2182.

15. Tsai CC, Chen YJ, Yew TL, Chen LL, Wang JY, Chiu CH, et al. Hypoxia inhibits senescence and maintains mesenchymal stem cell properties through down-regulation of E2A-p21 by HIF-TWIST. Blood 2011; 117: 459-469.

16. Adesida AB, Mulet-Sierra A, Jomha NM. Hypoxia mediated isolation and expansion enhances the chondrogenic capacity of bone marrow mesenchymal stromal cells. Stem Cell Res Ther 2012; 3: 9 .

17. Mohyeldin A, Garzon-Muvdi T, Quinones-Hinojosa A. Oxygen in stem cell biology: a critical component of the stem cell niche. Cell Stem Cell 2010; 7: 150-161.

18. Kolf CM, Cho E, Tuan RS. Mesenchymal stromal cells. Biology of adult mesenchymal stem cells: regulation of niche, self-renewal and differentiation. Arthritis research \& therapy 2007; 9: 204. 19. Gawlitta D, van Rijen MH, Schrijver EJ, Alblas J, Dhert WJ. Hypoxia Impedes Hypertrophic Chondrogenesis of Human Multipotent Stromal Cells. Tissue Eng Part A 2012.

20. Robins JC, Akeno N, Mukherjee A, Dalal RR, Aronow BJ, Koopman P, et al. Hypoxia induces chondrocyte-specific gene expression in mesenchymal cells in association with transcriptional activation of Sox9. Bone 2005; 37: 313-322.

21. Felka T, Schafer R, Schewe B, Benz K, Aicher WK. Hypoxia reduces the inhibitory effect of IL-1beta on chondrogenic differentiation of FCS-free expanded MSC. Osteoarthritis Cartilage 2009; 17: $1368-1376$.

22. Wu L, Leijten JC, Georgi N, Post JN, van Blitterswijk CA, Karperien M. Trophic effects of mesenchymal stem cells increase chondrocyte proliferation and matrix formation. Tissue Eng Part A 2011; 17: 1425-1436. 
23. Leijten JC, van Blitterwijk CA, Karperien M, Emons J, van Gool S, Wit JM, et al. GREM1, FRZB and DKK1 are key regulators of human articular cartilage homeostasis. Arthritis Rheum 2012. 


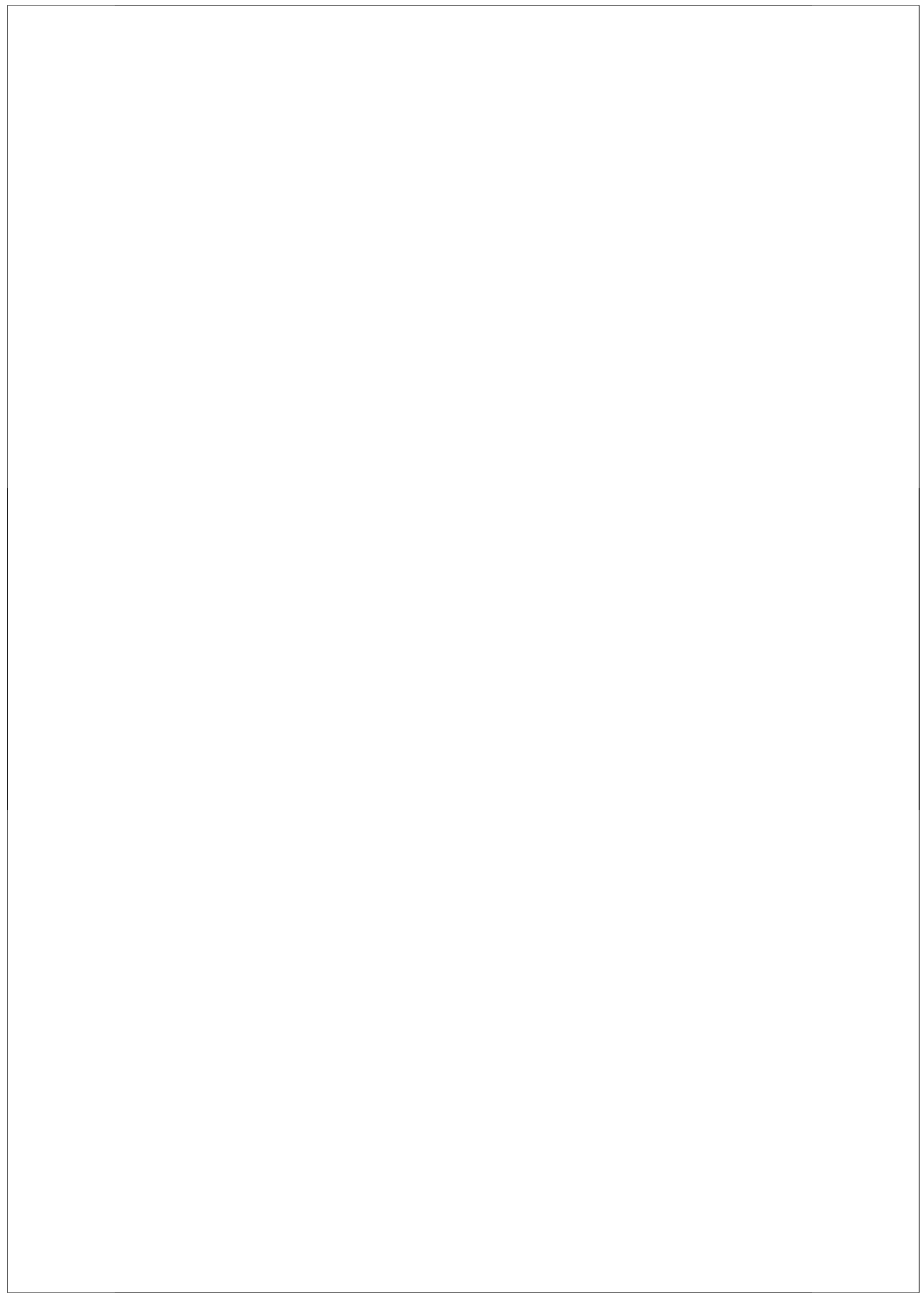




\section{Chapter 2}

\section{Cartilage tissue engineering}

Nicole Georgi*, Liliana Moreira Teixeira*, Jeroen Leijten*, Ling Wu, Marcel Karperien

* Shared first co-authorship

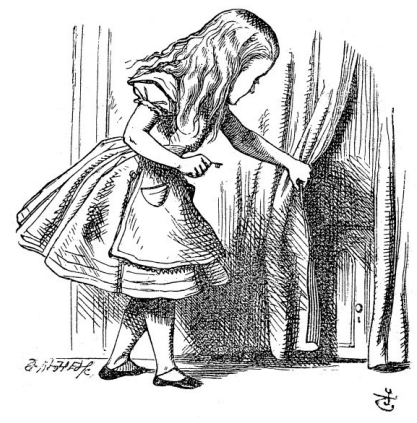




\begin{abstract}
Cartilage tissue engineering is the art aimed at repairing defects in the articular cartilage, which covers the bony ends in the joints. Since its introduction in the early 90 'ties of the past century, cartilage tissue engineering using autologous chondrocyte implantation (ACI) has been used in thousands of patients to repair articular cartilage defects. This review focuses on emerging strategies to improve cartilage repair by incorporating fundamental knowledge of developmental and cell biology in the design of optimized strategies for cell delivery at the defect site and to locally stimulate cartilage repair responses.
\end{abstract}




\section{$2.1 \quad$ Introduction}

Tissue engineering is the art of utilizing (biological) material to generate new tissue that will replace worn out or lost native tissue mimicking its original function. Mature joint cartilage is unable to repair itself sufficiently when damaged. This results in degeneration of the cartilage and inevitably to joint failure. The need to intervene in this progressive degeneration and to restore or replace the affected cartilage effectively has created the field of cartilage tissue engineering. The main aim of cartilage tissue engineering is to repair joint or articular cartilage. Like epiphyseal growth plate cartilage, articular cartilage is a hyaline cartilage of which the extracellular matrix is rich in glycosaminoglycans and collagen type 2 as the most abundant protein. Unlike for articular cartilage, there is no clear clinical need for epiphyseal cartilage tissue engineering. Thus if one speaks about cartilage tissue engineering, we are specifically talking about articular cartilage.

This review first discusses the development of cartilage focusing on the development of long bones, the growth plate and in particular articular cartilage. Many of the molecular mechanisms identified in the developing long bones can be applied in tissue engineering strategies. In addition to the biological knowledge, it is important to understand the history of clinical applications of articular cartilage repair and how this led to presently used tissue engineering strategies. Another essential element for the creation of an optimal and effective therapy is, in case cells are used, the cell source. For this, the focus will be on historically used cell sources, current trends and options for future therapy. The use of currently available commercial biomaterials and their use in cartilage tissue engineering, as well as emerging smart materials that are adapted to certain selected requirements are highlighted. Finally, this review gives a perspective on the future of cartilage tissue engineering.

\subsection{Development of cartilage}

\subsubsection{Joint formation}

The main purpose of tissue engineering is to generate new tissue that can mimic the original functions to replace worn out or lost native tissues. Fundamental knowledge on the tissue of interest, as well as its natural development, is therefore of paramount importance. Chondrogenesis is heralded from three different origins: the cranial neural crest that forms craniofacial cartilage, the somites leading to the axial skeleton and the lateral plate mesoderm resulting in the formation of limbs. From here on we will focus on the latter, since cartilage tissue engineering mostly focuses on the joints of the limbs [1].

Secretion of fibroblast growth factor (FGF)-7 from the lateral plate mesoderm initiates the formation of the limb organizing apical ectodermal ridge (AER). Subsequently a signalling loop between FGF-10 in the limb mesoderm and FGF-8 in the AER directs the proximal distal outgrowth of the limb buds. Cartilage formation starts with the mesenchymal condensations in these developing limb buds and is formed from a seemingly heterogeneous cell population. The up-regulation of TGF- 
$\beta$, a member of the bone morphogenetic protein (BMP) superfamily, leads to enhanced expression of numerous molecules including N-cadherin, N-CAM, fibronectin and Tenascin-C, which are all implicated in the condensation of the mesenchymal cells $[2]$.

Initiation of the expression of the cartilage master regulator SOX-9 instigates chondrogenesis and is associated with the expression of collagen type IIA and, at a later stage, its splice variant collagen type IIB. Under the influence of a growth factor cocktail, including amongst others insulin growth factor-1, FGF-2 and BMPs, the mesenchymal condensation develops into a cartilage anlage.

The determination of the location of the joint is dependent on a site called the interzone. Although the mechanism behind this phenomenon is largely unknown, the involvement of several molecules such as WNT-14, GDF-5 and Chordin has been implicated. Cells in the interzone start to produce lubricin, which is suggested to play a role in the cavitation and separation of the original cartilage anlage resulting in the formation of the joint itself [3]. When fully formed, the articulated ends of the joints are still lined with lubricin producing cells that will allow almost frictionless movement. In the mid-section of the remaining cartilage anlage, the primary centre starts to mineralize and is eventually replaced by bone in a process called endochondral ossification. Postnatally, a second centre of ossification appears in the primary growth plate that effectively separates the articular cartilage covering the distal ends of the long bone from the epiphyseal growth plate cartilage entrapped between the epiphysis and metaphysis. Unlike epiphyseal growth plate cartilage, which disappears at the end of puberty by growth plate fusion, healthy articular cartilage is resistant to endochondral ossification and does not disappear after puberty.

\subsubsection{Growth plate cartilage}

Being primarily responsible for longitudinal growth, the activity of the epiphyseal growth plate is tightly orchestrated by multiple autocrine, paracrine and endocrine factors. After the initial mesenchymal condensation and chondrogenic differentiation, the chondrocytes in the centre of the cartilage anlage start to undergo hypertrophic differentiation. This terminal differentiation allows for the formation of a mineralized matrix, in growth of blood vessels and eventually chondrocyte death, most likely via apoptosis. On the remaining cartilage anlage, osteoblasts start producing bone, forming the primary spongiosa. At the opposing end of the hypertrophic chondrocytes, chondrocyte proliferation continues in vertical columns further lengthening the long bones. These proliferating chondrocytes are recruited from the resting zone which covers the distal ends of the long bones. After the formation of the secondary ossification center, the resting zone is located directly adjacent to the epiphysis [4] and contains the growth plate stem cells. The continuous cycle of stem cell recruitment, proliferation, hypertrophic differentiation and chondrocyte death is tightly regulated by a plethora of signalling molecules. The feedback loop between Indian Hedgehog and Parathyroid Hormone-related Protein is demonstrated to be one of the key regulators of endochondral ossification. Additionally, many other factors have been shown to play (major) roles in endochondral ossification including paracrine factors 
like FGFs, BMPs, WNTs, and endocrine regulators such as thyroid hormone, growth hormones, insulin-like growth factor-1 (IGF-1), testosterone and estrogens [5]. Many of these factors are currently explored for application in tissue engineering strategies for cartilage repair.

\subsubsection{Articular cartilage}

As already indicated, the main focus of cartilage tissue engineering is on restoration of the articulated surface of the joint, the articular cartilage. In its healthy mature form the tissue has an extremely high matrix/cell ratio: only 2-3\% of its mass consists of chondrocytes, the only residing cells in articular cartilage. For the remaining it consists out of $65-80 \%$ of water, $12-21 \%$ of collagens being predominantly collagen type II, $6-10 \%$ of proteoglycans and approximately $2-3.5 \%$ other proteins. The arch-like orientation of collagen type II fibrils, being almost horizontal in the superficial zone and almost fully vertical in the deep zone, gives the articular cartilage its anisotropic nature and allows it to transduce mechanical forces throughout the entire tissue. Additionally, the different zones do not contain the same (ratio of) molecules, having different (levels of) glycosaminoglycans and collagens as well as other more characteristic features such as the calcification of the cartilage near the subchondral bone and the production of lubricin in the superficial zone [6]. An important characteristic of healthy articular cartilage is the resistance to endochondral ossification. In joint degenerative diseases such as osteoarthritis, this resistance disappears and it is described that the degeneration is, at least in part, caused by endochondral ossification [7]. Articular and epiphyseal chondrocytes have many features in common and it has been long believed that they have a common progenitor. In the past years however, preliminary proof has been provided that articular and epiphyseal growth plate chondrocytes arise from distinct cell populations. At present, the mechanisms by which articular chondrocytes are formed and by which they are able to resist hypertrophic differentiation and subsequent endochondral ossification remains unknown.

\subsection{History of clinical applications in cartilage repair}

The clinical and biological need to develop new cartilage repair strategies arises from the fact that cartilage has a low capacity of self repair. When damaged by either trauma or degenerative diseases it will progressively degrade and thereby destabilizing the joint. The majority of cartilage engineering strategies focusses on the repair of cartilage lesions induced by trauma, since progressively diseased cartilage, such as seen in osteoarthritis, needs different repair approach.

If left untreated, acute trauma will inevitably result in joint degeneration nescessitating unicompartmental or total joint replacement as the only possible solution to treat the degenerated joint. To avoid total joint replacement, the surgeon has a number of treatment options all with inherent drawbacks. The most popular clinical cartilage repair approaches of the last 20 years are osteochondral transplantation (OT), marrow stimulation techniques e.g. microfracture (MF) and autologous chondrocyte implantation (ACI). 
OT can be divided into autologous mosaicplasty and allograft osteochondral transplantation. In the more recently developed mosaicplasty, [8] cylindrical osteochondral grafts are harvested from a non-load bearing site of the donor and will then be press fitted in pre-drilled osteochondral holes of the defect area. During the healing process, space between the grafts will be filled with fibrocartilaginous tissue. This strategy carries the risk of bone collapse at the donor and recipient site, but shows acceptable results in long term follow up. Since mosaicplasty can only be applied to smaller lesions, allograft osteochondral transplantation with matching fresh or frozen cartilage pieces from organ donors is an alternative option.

During MF, the subchondral bone of the affected cartilage is perforated leading to blood clot formation at the defect site and, after the invasion of progenitor cells, to cartilage matrix formation. This cost saving and fast technique, based on the selfhealing capacity of invading bone marrow cells, was first introduced by Steadman et al [9] in the early 90s. The procedure of MF leads to satisfactory outcome, but has been reported to induce fibrous cartilage formation with poor mechanical properties in some cases, questioning the long term performance of the de novo formed tissue. Next to MF, ACI gained popularity after its introduction by Brittberg et al in 1994 . ACI is the first cell based therapeutic cartilage tissue engineering strategy [10]. This two step surgical procedure requires donor cartilage harvest from a non-load bearing site for chondrocyte isolation, followed by upto 6 weeks of cell expansion ex vivo and finally re-implantation of the expanded cells at the defect site. During re-implantation, the cartilage defect is first covered with a periosteal flap sealed with fibrin glue before injecting the cultured chondrocytes underneath the periosteal flap (Fig 2.1). This time consuming and costly technique has been shown to promote the formation of hyaline like cartilage with functional improvement in most patients, whereas other studies provide evidence for the abundance of substantial amounts of fibrous cartilage [11]. In the last decade, various studies compared microfracture to ACI with conflicting results. The findings indicate that ACI and MF lead to similar outcomes in the repair of small lesions, but the repair of large defects might have a superior outcome after ACI. In 2008, Saris et al [12] introduced characterised chondrocyte implantation (CCI) to overcome existing problems with the quality of the engineered cartilage obtained by ACI. The strategy of this CCI relies on the pre-assessment of chondrocyte populations with a greater potential to form hyaline cartilage. Compared with MF, this technique resulted in noticeably better clinical outcome after 36 months [13].

Although all these described cartilage repair strategies support enhanced joint function and pain relief for the patient, they do not succeed in restoring the natural cartilage structure with its associated biomechanical properties. Recent cartilage tissue engineering approaches include established methods in combination with the delivery of cells and/or bioactive molecules via a biomaterial scaffold. Bartlett et al described two variations of the traditional ACI. In the first variation, the periosteal flap is replaced with a porcine-derived type I/type III collagen (ACI-C) matrix. In the second variation, chondrocytes were first seeded in a collagen bilayer before implantation (matrix-induced ACI MACI). Both methods resulted in an improvement of ACI based on the Cincinnati knee score and International Cartilage Repair Society score, which provide both a measure for cartilage and joint quality. 


\subsection{Cell sources of cartilage engineering}

Presently, cartilage tissue engineering is primarily based on the use of two cell types: chondrocytes or mesenchymal stromal cells (MSCs). As the most intuitive cell source for cartilage regeneration, autologous chondrocytes, have been successfully used in many studies of cartilage repair with or without the use of a scaffold [10]. However, using chondrocytes in cartilage repair applications obviously has some disadvantages. One problem could be injury of healthy cartilage from which chondrocytes are harvested. Although donor cartilage is taken from low weight bearing sites of the joint, this procedure often results in morbidity at donor sites. Another problem of using autologous chondrocytes in cartilage engineering is that they can only be harvested from small biopsies of articular cartilage. To obtain sufficient chondrocytes for cartilage repair, in vitro expansion is necessary. Culture expansion of chondrocytes results in a gradual loss of the chondrocyte phenotype with increasing passage number, a process known as chondrocyte dedifferentiation.

After several passages of expansion in two-dimensional culture environment, chondrocytes lose their initial characteristics and become fibroblast-like cells [14]. Expanding chondrocytes on microcarriers instead of tissue culture plastic can omit subculture steps in flask, thus can prevent dedifferentiation of chondrocytes. It is also believed that dedifferentiated chondrocytes may regain the ability to produce cartilage matrix when cultured in a 3D environment (e.g., suspension in hydro-gel), or in chondrogenic differentiation medium containing transforming growth factor- $\beta$ (TFG- $\beta$ ). This growth factor plays an important role in cartilage formation during organogenesis in the embryo. However, the cartilage phenotypes obtained by these treatments are significantly inferior when compared to native cartilage [15]. Yet the complex molecular events occurring in the induction and maintenance of the chondrogenic phenotype should still be enlightened for further identification of the bioactive levels and kinetics of the key factors involved in cartilage repair. Moreover, integration of repair cartilage with the native tissue and reestablishment of the zonal organization of articular cartilage are still challenging and only partly resolved.

To improve the quantity of regenerated cartilage, mesenchymal stromal cells (MSC) are considered to be a promising alternative cell source. MSCs are adult stem cells isolated from somatic tissue. They have been found to be multipotent, showing the ability to differentiate into chondrocyte, osteoblast, adipocytes and endothelial cells. MSCs isolated from different origins like bone marrow, fat tissue, synovium and muscles all show potency of chondrogenic differentiation and may have possible applications in cartilage tissue engineering [16]. Most clinical studies use autologous MSCs, though allograft MSCs may be used in some cases. Traditionally, ex vivo chondrogenic differentiation of MSCs is induced by culturing high-density cell pellets in serum-free medium containing TGF- $\beta$. High-density pellets mimics the first step of cartilage formation in the embryo, namely the condensation of mesenchymal cells. For MSCs isolated from fat tissue BMP-6 is often added to the differentiation medium. In recent years, it has been reported that culturing MSCs in gel-like biomaterials made of collagen or fibrin increases chondrogenic differentiation of MSCs when compared with pellet culture [17]. When using MSCs for cartilage engineering, the greatest 
challenge is not the differentiation of the cells into chondrocytes per se but to prevent the chondrogenically differentiated MSCs from undergoing endochondral ossification. Substantial evidence indicates that the chondrogenically differentiated MSCs acquire an epiphyseal growth plate phenotype rather than an articular phenotype [18]. To direct differentiation of MSCs in the articular cartilage lineage instead of a growth plate lineage is an active area of research.

To reduce the number of chondrocytes needed for cartilage engineering, MSCs started to be co-cultured with chondrocytes. Interestingly, it was reported that cocultures of bone marrow MSCs with articular chondrocytes produced more matrix compared to chondrocytes alone [19]. This phenomenon of increased cartilage formation was not only observed in differentiation medium containing TGF- $\beta$, but also in medium without any growth factors. Enhancement of cartilage matrix formation was also found in co-culture of articular chondrocytes with other sources of MSCs [20]. This effect has been attributed to the chondrogenic differentiation of MSCs stimulated by the chondroctyes. In recent years, it has been suggested that lineage commitment of MSCs, however, cannot fully explain their benefits on tissue remodelling and repair. Many studies have suggested a role for MSCs in secreting trophic mediators that stimulate local tissue repair mechanisms. These factors promote tissue specific cells to restore the damaged or lost tissue. A combination of MSCs and autologous chondrocytes may be a promising strategy for cartilage engineering in which the trophic effects of MSCs support and facilitate the chondrocytes to repair cartilage defects. The strategy also reveals possibility of omitting in vitro expansion of chondrocytes in traditional ACI procedures. The mixture of chondrocyte and MSCs may lead to a single step surgery for cartilage treatment, in which chondrocytes are isolated, mixed with bone marrow cells from the same patient, loaded on a scaffold and directly re-implanted into the patient. Many aspects of ACI still need further optimization. For example, the integration of the neo tissue is still far from optimal. It can be hindered by cell loss, either by apoptosis or necrosis caused by, for example inflammatory cytokines or mechanical stress, or due to leakage of the cells. The relatively limited ECM production by the implanted cells, and the dissimilarities in structure and/or composition compared to native cartilage can also lead to integration failure. Thus, strategies that circumvent these complex molecular events, such as the delivery of anti-apoptotic or anti-dedifferentiating factors, combined with a structural orchestration of cells and soluble factors is thought to play an essential role in future therapies.

\subsection{Biomaterials for cartilage repair}

The commonly used strategy of tissue engineering is, in general terms, to seed cells in a scaffold that can be implanted into the damaged site, as illustrated in figure 2.1. Initially, the main purpose of the scaffold is to provide structural support and allow attachment, proliferation and differentiation of cells in a $3 \mathrm{D}$ environment. The mechanical support provided by the scaffold would lead to a decrease in the rehabilitation time for the patient. Nowadays, tissue engineered scaffolds may be developed 


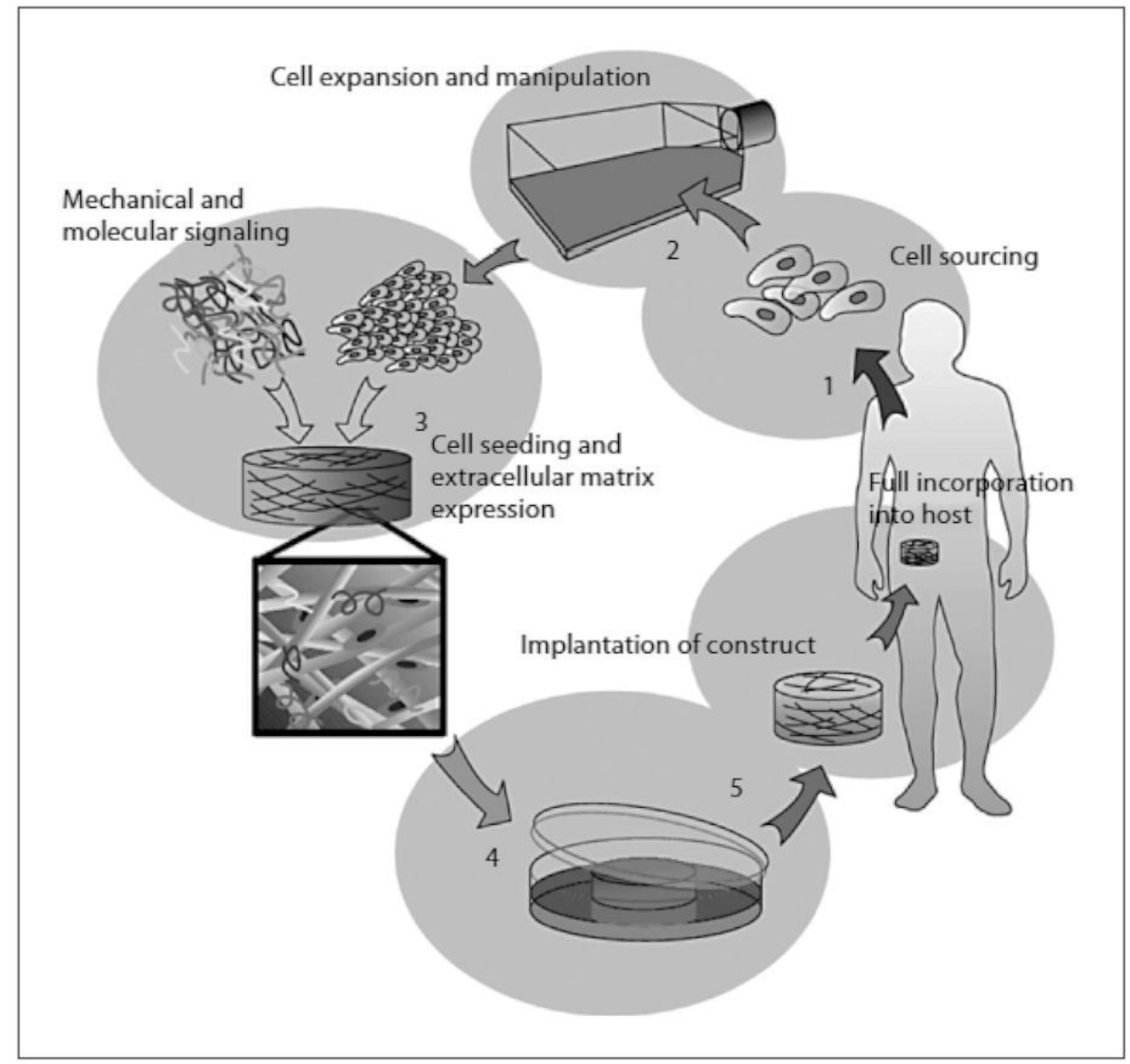

Figure 2.1: The tissue engineering approach

Adapted from: C.A. v Blitterswijk, Tissue Engineering. Academic Press Series in Biomedical Engineering [ Elsevier / Academic press, Amsterdam; London, 2008] pp. xvi, $740 \mathrm{p}$.

to trigger, interact and instruct cells by mimicry of key molecular features of the native extracellular matrix (ECM), conferred by both macromolecules (proteoglycans, collagens, fibronectin and laminins) and sequestered growth factors [21].

\subsubsection{Chondro-conducting scaffolds: natural and synthetic biomaterials}

A myriad of biomaterials has been used as scaffolds for 3D culture of chondrocytes in vitro and in vivo, as well as for medical applications. Scaffolds can vary depend- 


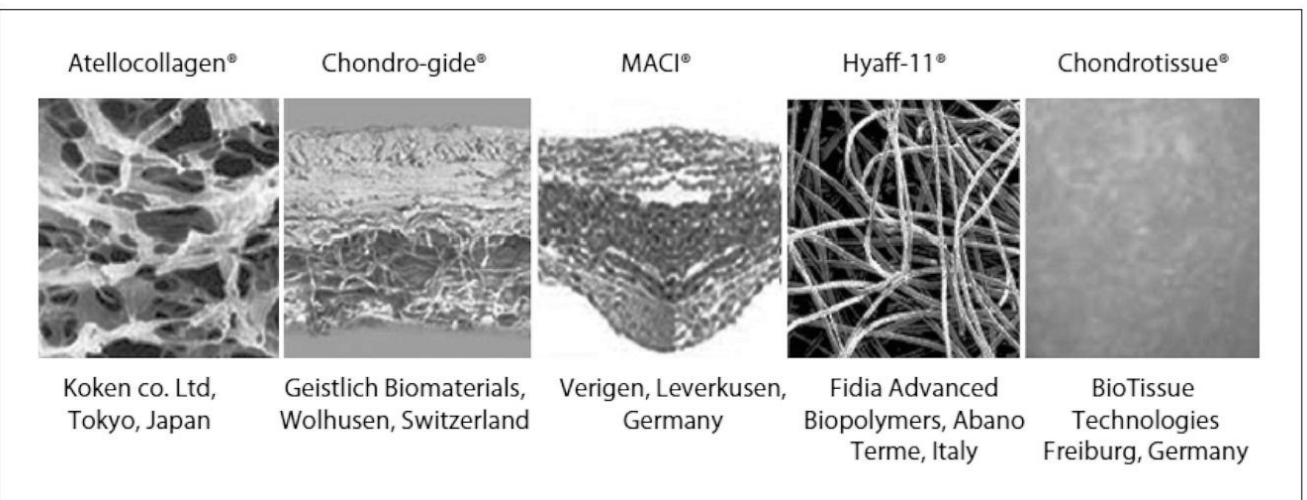

Figure 2.2: Protein-based membranes and gels already available for autologous chondrocyte implantation.

ing on material chemistry, 3D geometry, structure, mechanical properties and speed of degradation. The structure, mainly described in terms of pore distribution, orientation and connectivity, should maximize exchange of nutrients, metabolites and regulatory factors, as well as limit oxygen gradients and influence cell-cell interactions. The chemistry can play an instructional role and, overall, the scaffold should be biocompatible and biodegrade at a similar rate as ECM deposition, to ensure continuity and stability of the neo-tissue [22]. Additionally, the scaffolds' mechanical integrity and integration should not only be sufficient to support or match the native tissue, but also mediate mechanical stimulus to the cells during loading [23].

Scaffold materials for cartilage repair can be distinguished according to their source: natural or synthetic, as shown in table 2.1. Natural biomaterials can also be divided in of two types: protein- and polysaccharide-based. Many of these natural materials can be degraded by human enzymes, with non-toxic degradation products. Yet these materials have some drawbacks, mainly related to batch variation, processing and potential pathogen transfer. The main natural materials used for cartilage tissue engineering are collagen, hyaluronic acid, chitosan, agarose, alginate and fibrin glue [24]. These materials can be used either as temporary scaffolds and/or vehicles for cell and drug delivery or can be directly implanted or injected into the defect site.

Synthetic polymers are widely used in tissue engineering due to their flexibility in design and absence of the possibility of disease transmission; yet the disadvantages are related to their relatively poor biocompatibility for example of degradation products, which can lead to severe inflammatory responses. Synthetic materials, such as polylactide, polyglicolide and polyuretane, have been explored as suitable candidates for cartilage repair [24]. Figure 2.2 shows some protein-based membranes and gels which are currently explored in ACI procedures.

Scaffolds developed for cartilage tissue engineering can be either solid, like foams meshes or sponges, or gel-like, also termed as hydrogels. Hydrogels have been largely explored for cartilage repair strategies, because they consist of 3D hydrophilic net- 


\begin{tabular}{|c|c|c|}
\hline Material source & Examples & Advantages/disadvantages \\
\hline \multirow[t]{4}{*}{ Natural } & Collagen based & $\begin{array}{l}\text { Advantage: providers of molecular cues to the cells, } \\
\text { stimulating them to produce more collagen. } \\
\text { Disadvantage: poor mechanical properties and can } \\
\text { undergo contraction due to interactions with cells when } \\
\text { not combined with other materials. }\end{array}$ \\
\hline & Hyaluronic acid & $\begin{array}{l}\text { Advantage: bioactive properties, with the ability of } \\
\text { interacting with chondrocytes (via CD44). } \\
\text { Disadvantage: poor mechanical properties of the } \\
\text { unmodified hyaluronic acid; the combination or } \\
\text { engraftment with other materials, such as polyethylene } \\
\text { glycol or dextran, allowed optimization of the } \\
\text { biomechanical properties of the hyaluronic acid-based } \\
\text { scaffolds. }\end{array}$ \\
\hline & Fibrin glue & $\begin{array}{l}\text { Advantage: extensively used for wound healing and, } \\
\text { additionally for its use as fixative for scaffolds to native } \\
\text { tissue. It can also be used as a matrix. } \\
\text { Disadvantage: enhancement of cartilage repair is limited. }\end{array}$ \\
\hline & $\begin{array}{l}\text { Chitosan, agarose } \\
\text { and alginate }\end{array}$ & $\begin{array}{l}\text { Advantage: used as either hydrogels, sponges or pads. } \\
\text { Disadvantage: still not available for clinical applications. }\end{array}$ \\
\hline Synthetic & $\begin{array}{l}\text { Polylactide, } \\
\text { polyglycolide, } \\
\text { polyethylene glycol } \\
\text { and polyurethane }\end{array}$ & $\begin{array}{l}\text { Advantage: no batch variation. } \\
\text { Disadvantage: possible inflammatory response against } \\
\text { degradation products. }\end{array}$ \\
\hline
\end{tabular}

Table 2.1: Scaffold materials for cartilage repair.

works and their high water content mimics native cartilage, unlike solid-type materials. Additionally, due to high diffusion rates, hydrogels allow efficient transport of nutrients and waste products. Hydrogels can be composed of natural and/or synthetic polymers that form a gellified network by physical, ionic or covalent crosslinking. Some hydrogels can be thermo-reversible (liquid at approximately 25 degrees Celsius or below, only solidifying at body temperature, around 37 degrees Celsius), be chemically crosslinked (for example by enzymes), or by photo-polymerization (using visible or ultraviolet light). In situ forming hydrogels allow for replacement of open surgeries by a minimal invasive procedure that offers great advantages in integration with native tissue and limits the trauma caused by surgery. 


\subsubsection{Emerging "smart" biomaterials}

Novel scaffolds based on modification of natural polymers, such as dextran, silk, heparin and cellulose, or of synthetic polymers, such as polycaprolactone or co-polymers of polyether-esthers have been studied to support cartilage regeneration. Several of these studies have focused on the optimization of these materials and have shown that the combination of different materials may improve properties [24]. Hybrid materials can be designed to mimic ECM structure, for example by adding hyaluronic acid or chondroitin-6-sulfate, and, therefore, providing direct interaction with the chondrocytes by the enabling necessary signals to trigger tissue repair. The communication between the cells and ECM can also be mediated by integrins, surface-specific receptors that react with proteins, such as collagens, fibronectin and laminin, which affect cell survival, proliferation and differentiation. To facilitate these type of interactions, short synthetic peptides such as the Arg-Gly-Asp (RGD) sequence, can be incorporated into scaffolds to increase the interaction between biomaterials and cells. These recognition sequences have proven to be of great value in the case of synthetic materials that lack cell-attachment signals. Yet the involvement of the RGD sequence in inducing or supporting chondrogenic differentiation of MSCs is still controversial. In addition to these peptides, the controlled local delivery of growth and differentiation factors, including IGF-1, TGF- $\beta 1$ and TGF- $\beta 3$ or BMP-2 and BMP-6, have been successfully combined with scaffolds. These growth factors have been selected based on their proven role during cartilogenesis in the developing embryo. Hybrid scaffolds can either be designed to locally release the bioactive factors or produced in such a way that they mimic properties of the ECM. The release of growth factors by synthetic polymers is still highly dependent on the diffusion and degradation rates of the polymers.

Recently, surface-eroding scaffolds and materials of which the release occurs by cellular demand have been developed to allow a better and more effective control of the release profiles. By incorporation in the scaffold of peptide sequences which can be recognized by e.g. matrix metalloproteinases (MMPs), release of growth factors can be locally controlled [25]. This responsive feature of the scaffold can be of great interest as the release of the growth factor in these cases can be tailored to depend on the disease-activity. For example, MMP-13 is a factor that is significantly elevated in osteoarthritis and can be used as a trigger to release scaffold bound drugs [24].

Other strategies to improve scaffold design include the development of biphasic scaffolds. Such scaffolds can also be used in vitro for tissue formation prior to implantation, where the design prevents cell migration between regions of the scaffold [23]. Like the growth plate, articular cartilage has a zonal organization. Strategies have been developed that use predefined geometries (for example by using rapid prototyping technologies), or have incorporated physical and chemical gradients in the scaffold to recreate the zonal organization in tissue engineered constructs [26]. Using these strategies, the mimicry of the native cartilage-tissue anisotropy can be achieved. Gene therapy approaches can also be taken into account in scaffold design. In recent years promising results for cartilage repair strategies have been obtained by transfecting chondro-generative growth factor genes and/or chondro-protective cartilage catabolic 
inhibitor genes [23].

Starting from structural variations from nano to macroscale, the new generation of scaffolds often with a bioinspired design, aim at creating the optimal microenvironment for the formation of a de novo extracellular cartilaginous matrix by either chondrocytes, MSCs or a combination of both cell types.

\subsection{Future of cartilage tissue engineering}

Although a wide range of possible cartilage repair strategies have been described, none of them successfully restores the function and organisation of cartilage in long term studies. At the moment, numerous possible novel repair strategies arise. In general, the optimal approach will be determined by three major components: cells, biomaterials and bioactive compounds.

Cellular and molecular studies including improved cell culture, co-culture, cell tracking, gene therapy, gene arrays and proteomics will provide further cues for possible strategies in joint surface regeneration. The complex molecular events occurring in the induction and maintenance of the chondrogenic phenotype during embryogenesis may lead to the identification of novel mechanisms involved in cartilage formation. It seems promising to translate the findings from developmental biology into strategies for cartilage tissue formation. Beside optimised allogenic and autologous cartilage or cell transplants, progenitor cells, like autologous bone marrow derived stromal cells (MSCs), are likely to play an important role in future strategies for cartilage tissue repair being an alternative or supplementary cell source. Until now, however, the fate of these cells, the choice of cell fraction and optimal culture parameters are not determined and additional research is needed to clarify their applicability to articular cartilage engineering.

As indicated above, growth factors may play an important role in further optimization of cartilage tissue engineering. Presently, application of growth factors in cartilage tissue engineering is controversial and more robust studies are needed to demonstrate their applicability. The choice of the optimal combination of growth factor and method of delivery will very likely depend on the used cell type. For example different growth factors may be needed when MSCs or expanded primary chondrocytes are used for cartilage repair. Improvements in growth factor delivery should reflect an extended release profile, with protection of the proteins against fast degradation and must aim at targeting specific cell types. Multistep release, as a poly-therapy approach instead of single delivery systems, could be an additional improvement for cartilage repair strategies. The third pillar of cartilage tissue engineering is formed by biomaterials. At the moment evermore biomaterials are being developed that show better bioaffinity and manage to mimic the native environment of cartilage. An example of these new generations of biomaterials are in situ gelating hydrogels, which mimic the natural ECM and can perfectly fill up irregular defect sites. Importantly, in situ gelating hydrogels can be used in minimal invasive strategies, which will significantly reduce the burden for the individual patient.

"Smart" hydrogels sensitive to external stimuli such as temperature, $\mathrm{pH}$ or cer- 
tain biomolecules, that can trigger swelling or degradation, have been developed. Recently, dynamic hydrogels have been investigated, offering the ability to precisely control temporal and spatial behaviour of the cells, by creating a tissue-like hierarchical organization. This strategy can be combined with tailored delivery of bioactive signals that stimulate tissue repair. Translating fundamental knowledge in chondrogenesis and articular cartilage homeostasis into the design of novel smart materials is an active field of research, which undoubtedly will result in the development of improved strategies for cartilage repair in the near future. 


\section{References}

1. Olsen BR, Reginato AM, Wang W. Bone development. Annu Rev Cell Dev Biol 2000;16:191-220.

2. Chimal-Monroy J, Diaz de Leon L. Expression of N-cadherin, N-CAM, fibronectin and tenascin is stimulated by TGF-beta1, beta2, beta3 and beta5 during the formation of precartilage condensations. Int J Dev Biol 1999;43:59-67.

3. Pacifici M, Koyama E, Iwamoto M. Mechanisms of synovial joint and articular cartilage formation: recent advances, but many lingering mysteries. Birth Defects Res C Embryo Today 2005;75:237-48. 4. Zuscik MJ, Hilton MJ, Zhang X, Chen D, O'Keefe RJ. Regulation of chondrogenesis and chondrocyte differentiation by stress. J Clin Invest 2008;118:429-38.

5. Grumbach MM. Estrogen, bone, growth and sex: a sea change in conventional wisdom. J Pediatr Endocrinol Metab 2000;13 Suppl 6:1439-55.

6. Poole AR, Kojima T, Yasuda T, Mwale F, Kobayashi M, Laverty S. Composition and structure of articular cartilage: a template for tissue repair. Clin Orthop Relat Res 2001:S26-33.

7. Kawaguchi H. Regulation of osteoarthritis development by Wnt-beta-catenin signaling through the endochondral ossification process. J Bone Miner Res 2009;24:8-11.

8. Hangody L, Kish G, Karpati Z, Szerb I, Udvarhelyi I. Arthroscopic autogenous osteochondral mosaicplasty for the treatment of femoral condylar articular defects. A preliminary report. Knee Surg Sports Traumatol Arthrosc 1997;5:262-7.

9. Steadman JR, Rodkey WG, Briggs KK, Rodrigo JJ. [The microfracture technic in the management of complete cartilage defects in the knee joint]. Orthopade 1999;28:26-32.

10. Brittberg M, Lindahl A, Nilsson A, Ohlsson C, Isaksson O, Peterson L. Treatment of deep cartilage defects in the knee with autologous chondrocyte transplantation. N Engl J Med 1994;331:889-95. 11. McNickle AG, L'Heureux DR, Yanke AB, Cole BJ. Outcomes of autologous chondrocyte implantation in a diverse patient population. Am J Sports Med 2009;37:1344-50.

12. Saris DB, Vanlauwe J, Victor J, et al. Characterized chondrocyte implantation results in better structural repair when treating symptomatic cartilage defects of the knee in a randomized controlled trial versus microfracture. Am J Sports Med 2008;36:235-46.

13. Saris DB, Vanlauwe J, Victor J, et al. Treatment of symptomatic cartilage defects of the knee: characterized chondrocyte implantation results in better clinical outcome at 36 months in a randomized trial compared to microfracture. Am J Sports Med 2009;37 Suppl 1:10S-9S.

14. Schnabel M, Marlovits S, Eckhoff G, et al. Dedifferentiation-associated changes in morphology and gene expression in primary human articular chondrocytes in cell culture. Osteoarthritis Cartilage 2002;10:62-70.

15. Mukaida T, Urabe K, Naruse K, et al. Influence of three-dimensional culture in a type II collagen sponge on primary cultured and dedifferentiated chondrocytes. J Orthop Sci 2005;10:521-8.

16. Sakaguchi Y, Sekiya I, Yagishita K, Muneta T. Comparison of human stem cells derived from various mesenchymal tissues: superiority of synovium as a cell source. Arthritis Rheum 2005;52:2521-9. 17. Mueller MB, Tuan RS. Functional characterization of hypertrophy in chondrogenesis of human mesenchymal stem cells. Arthritis Rheum 2008;58:1377-88.

18. Tsuchiya K, Chen GP, Ushida T, Matsuno T, Tateishi T. The effect of coculture of chondrocytes with mesenchymal stem cells on their cartilaginous phenotype in vitro. Mat Sci Eng C-Bio S 2004;24:391-6.

19. Hildner F, Concaro S, Peterbauer A, et al. Human Adipose-Derived Stem Cells Contribute to Chondrogenesis in Coculture with Human Articular Chondrocytes. Tissue Eng Pt A 2009;15:3961-9. 20. Gnecchi M, He H, Liang OD, et al. Paracrine action accounts for marked protection of ischemic heart by Akt-modified mesenchymal stem cells. Nat Med 2005;11:367-8.

21. Place ES, Evans ND, Stevens MM. Complexity in biomaterials for tissue engineering. Nat Mater 2009;8:457-70.

22. Vunjak-Novakovic G. The fundamentals of tissue engineering: scaffolds and bioreactors. Novartis Found Symp 2003;249:34-46; discussion -51, 170-4, 239-41.

23. Woodfield TB, Bezemer JM, Pieper JS, van Blitterswijk CA, Riesle J. Scaffolds for tissue engineering of cartilage. Crit Rev Eukaryot Gene Expr 2002;12:209-36.

24. Stoop R. Smart biomaterials for tissue engineering of cartilage. Injury 2008;39 Suppl 1:S77-87. 25. Raeber GP, Lutolf MP, Hubbell JA. Mechanisms of 3-D migration and matrix remodeling of fibroblasts within artificial ECMs. Acta Biomater 2007;3:615-29. 
26. Klein TJ, Malda J, Sah RL, Hutmacher DW. Tissue engineering of articular cartilage with biomimetic zones. Tissue Eng Part B Rev 2009;15:143-57. 


\section{Chapter 3}

\section{Cell sources for articular cartilage repair strategies: shifting from mono-cultures to co-cultures}

Nicole Georgi*, Jeroen Leijten*, Ling Wu, Clemens van Blitterswijk, Marcel Karperien

* Shared first co-authorship

"I think I should understand that better," Alice said very politely, " if I had it written down: but I can't quite follow it as you say it." (Alice's Adventures in Wonderland, Chapter 9) 


\begin{abstract}
The repair of articular cartilage is challenging due to the sparse native cell population combined with the avascular and aneural nature of the tissue. In recent years cartilage tissue engineering has shown great promise. As with all tissue engineering strategies, the possible therapeutic outcome is intimately linked with the used combination of cells, growth factors and biomaterials. However, the optimal combination has remained a controversial topic and no consensus has been reached. In consequence, much effort has been dedicated to further design, investigate and optimize cartilage repair strategies. Specifically, various research groups have performed intensive investigations attempting to identify the single most optimal cell source for articular cartilage repair strategies. However, recent findings indicate that not the heavily investigated mono cell source, but the less studied combinations of cell sources in co-culture might be more attractive for cartilage repair strategies.

This review will give a comprehensive overview on the cell sources that have been investigated for articular cartilage repair strategies. In particular, the advantages and disadvantages of investigated cell sources are comprehensively discussed with emphasis on the potential of co-cultures in which benefits are combined while the disadvantages of single cell sources for cartilage repair are mitigated.
\end{abstract}




\subsection{Introduction}

Mature articular cartilage is composed of an abundant extracellular matrix that is sparsely populated by chondrocytes. Articular cartilage is avascular and aneural and the native chondrocytes are largely in cell cycle arrest. As a consequence, it is challenging for this tissue to suitably respond to traumatic injury. Cartilage damage inevitably results in altered biomechanics of the joint and joint instability, which shift joint homeostasis towards catabolism $[1,2]$. If left untreated, this may ultimately lead to joint failure. As a result, the recalcitrant capacity of articular cartilage to self-heal acquired injuries drives research focused on (novel) cartilage reparative and regenerative treatments.

Current treatments of traumatic cartilage defects include osteochondral grafting, bone marrow stimulation techniques and more recently cell based therapies [3-6]. Osteochondral autografting is particularly suitable for smaller lesions, but is associated with donor-site morbidity [7]. Osteochondral allografting can be considered for larger defects, but is associated with graft failure and immune reactions $[8,9]$. Bone marrow stimulation techniques such as micro-fracturing and micro-drilling are used for defects smaller than 2-4 $\mathrm{cm}^{2}$ with little or no bone loss and are associated with the formation of fibrocartilage [10]. The most common form of cell-based therapies is autologous chondrocyte implantation (ACI). This treatment is based on the implantation of expanded autologous chondrocytes, which were isolated from a biopsy that was obtained from a non-load bearing site of the same donor. Since ACI is dependent on the violation of intact cartilage as well as ex vivo chondrocyte expansion, it is associated with donor-site morbidity and loss of chondrogenicity of cultured chondrocytes known as dedifferentiation [4].

Consequently, a myriad of alternative cell sources other than culture expanded articular chondrocytes have been investigated to circumvent these side-effects and thereby to improve the therapeutic outcome of cartilage repair strategies. In addition to several types of chondrocytes derived from a number of hyaline cartilage subtypes, the use of multi-potent cells with chondrogenic potential derived from various tissue sources has been proposed. In addition to conventional mono-culture the approach of co-cultures has gained significant attention. Interestingly, co-cultures have been shown to be able to outperform their respective single cultures. Unfortunately, in depth understanding and clinical translation of this phenomenon has remained wanted.

This review will discuss the different cell sources dominating the field of cartilage tissue engineering and highlights recent advances of co-culture approaches.

\subsection{Autologous articular chondrocytes: cell number versus dedifferentiation}

Conventional cell-based cartilage repair therapies characteristically use autologous articular chondrocytes. These cells are harvested from biopsies of macroscopically intact cartilage derived from a non-weight bearing part of the joint [11]. Removal of a biopsy 
from healthy articular cartilage can potentially lead to secondary osteoarthritis. However, more thorough studies with a longer follow-up are required to understand the full extent of the consequences of harvesting biopsies [12]. To minimize the chance of developing secondary osteoarthritis the biopsy size is limited. In consequence, the biopsy yields insufficient amounts of chondrocytes to allow for direct filling of the defect. Therefore, chondrocytes are expanded in vitro before reimplantation. Unfortunately, expansion is associated with progressive loss of the chondrogenic phenotype and results in dedifferentiated fibroblast-like chondrocytes [13]. We recently demonstrated that articular chondrocyte dedifferentiation is a continuous, progressive and multi-signaling-pathway-based process. Moreover, the potential to redifferentiate is also gradually lost and might be in part caused by epigenetic mechanisms such as DNA methylation. The loss of the chondrocyte phenotype during monolayer expansion is suggested to be dependent on the matrix elasticity of the culture environment [14]. As this process can impede the therapeutic outcome, the prevention of dedifferentiation and/or the induction of redifferentiation have been intensively investigated. Investigated strategies include exposure to optimized environmental properties like reduced oxygen levels [15] and physiological tonicity of the culture medium [16], dynamic non-adherent culturing as aggregates [17], decreased seeding density [18], three dimensional expansion of cells using e.g. microcarriers [19], varying the elasticity of the growth surface to simulate cartilage stiffness [14] or pore-size of carrier material [20], culture on predeposited extracellular matrices of e.g. synovium-derived stem cells [21], the use of medium preconditioned by primary chondrocytes or MSCs [22-24] or supplementation of the expansion medium with exogenous recombinant growth factors, like FGF-2 [25]. In general, these strategies led to improved expression of chondrogenic markers and a (partial) reduction of dedifferentiation markers. However, as large, comprehensive and well controlled comparative studies are largely lacking, consensus on an optimal strategy remains wanted.

Dedifferentiation can also be limited or even prevented by reducing or omitting the expansion phase. This idea is based on implanting fewer chondrocytes that are less expanded and have therefore a superior chondrogenic performance [26-28]. Although this approach demonstrated to be able to regenerate cartilage, it results in mechanically weaker cartilage when compared to implantation of higher densities of chondrocytes expanded over prolonged culture times in the same defect size. By reducing or omitting the amount of dedicated cell culture time, it might be possible to improve the costs-effectiveness of chondrocyte-based cell therapy and reduce the time between taking the biopsy and implanting expanded cells in a second surgical procedure.

\subsection{Non-autologous articular chondrocytes: morbidity versus immune response}

Allogenic, or even xenogenic, articular chondrocytes can be considered as an alternative cell source of which the isolation does not inflict additional damage to the joint. Advantageously, a larger number of chondrocytes can be obtained by taking larger 
biopsies and/or pooling different, potentially younger, donors. This might limit or obsolete the expansion phase, leading to a better preservation of the chondrocyte phenotype, and could potentially reduce inter-patient variation of the therapeutic outcome. Naturally, serious consideration should be given to drawbacks such as disease transmission and immune rejection [29]. Indeed, chondrocytes constitutively express histocompatibility complex class I at their cell surface and demonstrate cytokine inducible expression of histocompatibility complex class II [30]. Moreover, it has been shown that chondrocytes can interact with immune cells [31]. Several reports have described serious immune responses after allogenic chondrocyte implantation in full thickness defects where the access to the bone marrow increases the risk for immunological reactions [32-34]. Consequently, the clinical feasibility of allogenic chondrocytes implantation is questionable. In contrast, osteochondral allograft demonstrated only minor immunogenic signs in human clinical trials [35, 36]. On the one hand the immunological responses might be caused by the osseous part of the graft with residing bone marrow [9], whereas on the other hand the protective environment of the native cartilage will limit immunological reactions. The avascular and highly dense nature of the extra cellular matrix might be able to limit or prevent the invasion of immune cells from the joint to interact with chondrocytes. Indeed, isolated chondrocytes appear to be protected from an immune response when encapsulated in biocompatible biomaterials or when allowed to form a new extracellular matrix in vitro $[37,38]$. Due to their more wide availability and the limited immunogenic risk when embedded in an extracellular matrix, non-autologous articular chondrocytes can be still considered as a potentially interesting cell source for matrix assisted chondrocyte transplantations.

\subsection{Non-articular chondrocytes: morbidity versus phenotype}

Next to articular chondrocytes, several alternative chondrocyte sources have been investigated to design cartilage repair strategies that do not impose additional damage to the articular cartilage. In adults, other sources of (non-articular) hyaline cartilage are located in the nose, ribs, larynx, trachea and bronchi. In particular, costal and nasoseptal chondrocytes have been extensively investigated [29, 39-41]. Both costal and nasoseptal cartilage biopsies, respectively harvested from the ribcage or from the septum of the nose, grant a higher cell yield of chondrocytes. The proliferation rate of these chondrocytes is increased compared to articular chondrocytes [42]. Although they both undergo dedifferentiation during expansion they appear more susceptible to redifferentiation [43,44]. Moreover, transplantation of costal chondrocytes in full thickness defects results in the production of neocartilage [45]. Unfortunately, both costal and nasoseptal chondrocytes are known for their ability to ossify when reimplanted [40, 46, 47]. The different anatomical location and function of costal and nasoseptal cartilage might underlie their limited potential to form articular cartilage. In particular, the mechanical loading in the articular cartilage is frequent and highly compressive, whereas costal and nasoseptal cartilage experiences at best low tensile loads. 
Auricular chondrocytes derived from elastocartilage of the ear are as well considered as a possibly interesting cell source for cartilage repair strategies. Native and freshly isolated auricular chondrocytes typically express elastin. Although, upon in vitro culture the expression of elastin is gradually lost [41, 48], it has been reported that the elastin expression can be regained when implanted in vivo [49]. Whether the expression of elastin will negatively influence the mechanical properties of neocartilage in an articular cartilage defect remains to be clarified. Like nasoseptal and costal cartilage, isolated auricular cartilage provides a higher cell yield per gram of biopsied tissue and have a higher proliferation rate compared to articular cartilage. Auricular chondrocytes are prone to dedifferentiation and are susceptible to redifferentiation $[42,50]$. Mild forms of ossification have been observed after reimplantation [40]. Even though auricular cartilage has a rather non-loaded, supportive function for the external ear, it has been found that auricular chondrocytes express lubricin, a mucinous glycoprotein essential for lubrication of the joint [41]. Therefore, auricular chondrocytes are a cell source of considerable interest, in particular for repair or reconstruction of the superficial zone of articular cartilage. Meniscal chondrocytes derived from the meniscal fibrocartilage also express lubricin and have been investigated in cartilage repair strategies $[41,51]$. However, meniscal chondrocytes scarcely express collagen II, and have limited potential to secrete glycosaminoglycans. Consequently they generate neocartilage with inferior mechanical properties as compared to articular cartilage or other chondrocyte cell sources [52]. Like ACI, the use of meniscal chondrocytes is based on cells isolated from a biopsy and may predispose to secondary OA, as it can induce joint instability [53]. Additionally, the meniscus is partially exposed to the same catabolic environment as the articular cartilage, which deteriorates the chondrogenic behavior of the meniscal chondrocyte [54]. As meniscal chondrocytes have similar disadvantage compared to articular chondrocytes and produce inferior neocartilage compared to these cells, they are an unlikely cell source for articular cartilage repair strategies.

Taking all available alternative chondrocyte populations into consideration, it is obvious that none of the alternative chondrocyte sources are exposed to a mechanical challenge, which is comparable to the stimuli present in the articular joint. Nevertheless, chondrocytes from alternative sources surpass articular chondrocytes in availability, cell yield and proliferation capacity and might be suitable for patient groups where the access to articular chondrocytes is limited.

\subsection{Non-chondrocyte cell sources: morbidity versus control of differentiation}

Recently much research has been dedicated to cell sources other than articular chondrocytes. This is mainly due to articular chondrocytes low availability and its limited expansion capability without loss of function. These alternative cell sources include amongst others synovial fibroblasts, periosteocytes and multipotent progenitor cells.

Synovial fibroblasts are a part of the natural repair response to articular defects, as these cells tend to fill up non-treated defects with a fibrous matrix [55]. Unfortunately, 
this matrix is, like the matrix produced by meniscal chondrocytes, mechanically weak and predominantly consists of collagen type 1 [56]. Periosteocytes, depending on their site of isolation, possess chondrogenic potential that allows the formation of neocartilage [57]. However, it has been suggested that this potential is inversely correlated with age. [58]. In general, synovial fibroblast and meniscal chondrocytes have shown less promise compared to pluripotent/multipotent progenitor cells as an non-chondrocyte cell source.

Pluripotent cells such as embryonic stem cells and induced-pluripotent stem cells are able to form de novo articular-like cartilage and can in theory be considered for cartilage repair strategies [59,60]. However, gaining absolute control on the prevention of teratoma formation is paramount when using these cells [61, 62]. Until such control is acquired, it is unlikely that these cell sources will be clinically approved for treatment of non-lethal diseases such as articular cartilage repair.

The best characterized progenitor cell sources for articular cartilage repair include mesenchymal stromal cells (MSCs) derived amongst others from bone marrow, periosteum, synovium, synovial fluid, adipose tissue, bucal fat pad, infrapatellar fat pad and osteoarthritic cartilage [63-67]. Many other MSCs sources have remained largely uninvestigated for cartilage repair strategies and include amongst others umbilical cord blood, menstrual blood, muscles, ligaments, wartons jelly, amnion, chorion, breast milk and tonsil [68-75]. Important factors deciding on which MSC source to use should not only be based on chondrogenic potential and phenotype, but also on cell yield, accessibility, availability, age-related function decline, donor-site morbidity and acquisition costs.

Large inter-donor variation is a general complication encountered in all multipotent cell sources [76, 77]. This is exacerbated by the influence of temporal culture conditions, methods of harvest and disputably donor age [57, 78-81]. It has been suggested that distinct gene expression profiles might reflect their (chondrogenic) differentiation potential [82]. However, the highly desired markers for chondrogenic differentiation potential of undifferentiated MSCs have so far remained undiscovered. Additionally, expansion of multipotent cells negatively affects chondrogenesis and might thereby possibly further confound therapeutic outcome [83, 84].

MSCs are a heterogeneous population of cells. In consequence, both the maintenance of multipotency and chondrogenic potential of MSCs are greatly influenced by selection criteria, culture conditions in the expansion phase and optionally the differentiation phase. Criteria for the selection of MSCs were defined by the Society for Cellular Therapy in 2006. These criteria require adherence to tissue culture plastic, the expression of a panel of cell surface markers $\left(\mathrm{CD} 90^{+}, \mathrm{CD} 105^{+}, \mathrm{CD}^{+} 3^{+}\right.$, HLA-DR $\left.{ }^{-}, \mathrm{CD}_{45}^{-}, \mathrm{CD}^{-}, \mathrm{CD}^{-} 1 \mathrm{~b}^{-}, \mathrm{CD}^{-} 9^{-}\right)$and the ability to differentiate into the adipogenic, osteogenic and chondrogenic lineage [85]. Since then several further potential selection possibilities were published, including additional surface markers and distinct populations of MSCs that are found within the isolate [86-88]. The classical view on optimizing the culture of mammalian cells is based on medium composition where much research has been focused on medium type and medium supplements [89-94]. Non-autologous medium supplements might hamper the clinical applicability of tissue engineering strategies. Presently much attention is paid towards optimizing 
physiological factors, which influence cell behavior and thus therapy outcome, such as mechanical stress, substrate stiffness, substrate coating or chemistry and incubator gas composition in particular oxygen levels [95-103]. Other physiological variables such as tonicity have remained largely uninvestigated.

Rather than using MSCs for chondrogenic differentiation and direct production of neocartilage, one can also take advantage of the immunomodulatory or trophic properties of MSCs [104]. It is suggested that after reimplantation differentiated MSCs continue to modulate the immune response [105]. This might be of high importance in allogeneic treatments [106]. However, whether this modulation proves to be sufficient in tissues that are scarce in cells and rich in matrix, such as articular cartilage, remains to be further studied. Nonetheless, using allogeneic strategies allow for a decrease in the therapeutic inter-donor variation via the use of pools of multiple donors or selection of well performing donors.

Intra-articular injection of MSCs in a degenerating joint improves joint function and retards the development of osteoarthritis compared to untreated controls [107]. However, tracking experiments have shown that only a fraction of the injected MSCs are integrated in or located near the affected cartilage [108]. In fact, most MSCs are located in the joint capsule or migrated from the joint to seemingly unrelated tissues such as thymus, tongue, stomach, duodenum, jejunum and colon [109]. Together this suggests that the MSCs at least partially act via an indirect mechanism, most likely via the secretion of trophic factors. Indeed, in vitro co-culture experiments demonstrated the anabolic effects of MSCs-derived trophic factors on chondrocytes [24]. However, whether the same trophic factors are responsible for the anabolic effects observed in vivo remains to be proven.

Although MSCs can be differentiated in many different cell types and might contribute to tissue repair via released factors, it remains to be noted that their differentiation process cannot be fully controlled in vivo. Spontaneous sarcoma formation has been observed in long term expanded murine MSCs and after injection in mice [110, 111]. Although this has not yet been reported in humans, the lack of full control over the behavioral phenotype of the MSCs remains a potential concern. For example, injections of MSCs in cancer therapy has both been described to restrict tumor growth by decreasing the division rate of benign cells as well as augment tumor growth by stimulating angiogenesis [112]. These types of contradictions are not uncommon and underline the lack of deep understanding of the in vivo behavior of MSCs. Absolute control of the selection and differentiation process of MSCs is essential if MSCs are to be used routinely for cell therapy such as articular cartilage repair. It can be conceived that more stringent selection criteria for the isolation of MSCs will result in a more homogenous and controllable cell source. However, this would also result a more prolonged expansion phase as many cells will be discarded, which might lead to (partial) loss of multipotency.

In vitro MSCs are differentiated into chondrocytes in serum free media supplemented with transferrin, insulin sodium selenite, Transforming Growth Factor beta 1 or 3 (TGF- $\beta 1$ or 3), dexamethasone [113] and in some studies with BMP-6. Since the optimal combination and concentration of growth factors remains unclear, chondrogenic differentiation of multipotent cells such as MSCs typically results in the 
formation of neocartilage that is dissimilar to mature articular cartilage. However, it bears a striking phenotypical resemblance to fetal cartilage $[114,115]$. Moreover, chondrogenic differentiation of MSCs results in a gene expression profile that better resembles growth plate chondrocytes, which can differentiate into hypertrophic cartilage, than articular chondrocytes [116]. Indeed, cartilage formed by differentiated MSCs displays typical signs of hypertrophic differentiation [117-119]. In line with this, standard differentiation protocols currently used for chondrogenic differentiation of MSCs /emphin vitro, are able to induce the expression of chondrogenic genes, like aggrecan and collagen 2 , but do not express the recently identified articular cartilage enriched genes, like DKK1, GREM1 and FRZB. These secreted antagonists were proven to function as inhibitors of hypertrophic differentiation [116]. Consequently, chondrogenically differentiated multipotent and pluripotent cells undergo endochondral ossification upon subcutaneous implantation [60, 120]. Although this phenomenon is of notable interest for bone repair strategies, it is highly undesirable for cartilage repair strategies. Moreover, it demonstrates that current differentiation protocols, at least in vitro, are insufficient to yield articular-like cartilage and require improvement for reproducible cartilage repair strategies. Finally, it is of importance to note that the formation of functional neocartilage has been witnessed in orthotopic repair in animal models. This suggests that the joint microenvironment contains instructive stimuli for the formation of permanent articular cartilage [121].

\subsection{Co-cultures: combinatorial advantages versus current knowledge}

Performance of cell sources in cartilage formation can be augmented by making use of co-culture strategies. Co-cultures of different cell sources are based on the idea that the multi-signal events in vivo cannot be perfectly mimicked by adding a limited variety of growth factors to a mono-culture of which the optimal cocktail remains largely elusive. This problem can be circumvented by the introduction of another cell source in the culture. In this way, cells are exposed to a wider variety of stimuli. Moreover, the stimuli are based on autologous non-recombinant (secreted soluble) factors. In consequence, they could be considered as a preferred way of stimulation, as it omitting the remaining issues regarding the use of non-autologous recombinant factors in clinical settings.

Three decades ago, the first co-culture experiments for cartilage tissue engineering were performed. First co-culture experiments mainly focused on revealing the pathological mechanisms of cartilage destruction by mixing chondrocytes with cell types that are potentially involved in cartilage catabolism [122, 123]. More recently, co-cultures that include chondrocytes have been investigated for their capacity to enhance neocartilage formation. In general three (partially overlapping) categories can be identified: i) co-cultures with unilateral beneficial effect of one cell type on neocartilage formation; ii) co-cultures with mutually beneficial effects on neocartilage formation; iii) co-cultures based on cell types with unique features that do not (directly) affect the behavior of the other cell type (Fig 3.1). 
Expansion of isolated autologous chondrocytes is commonly required to obtain sufficient amount of cells for reimplantation. This expansion induces dedifferentiation of the chondrocytes. Interestingly, co-culturing expanded dedifferentiated chondrocytes with (previously frozen) primary chondrocytes can (partially) reverse their loss of phenotype [24, 124, 125] (Fig 3.1A). This redifferentiation appears to induce a stable phenotype; withdrawal of the exposure to primary chondrocytes does not lead to reversal of the effect [126].

Alternatively, articular chondrocytes have been co-cultured with non-articular chondrocytes [127]. However, so far little attention has been focused on these types of chondrocyte-chondrocyte co-cultures. In consequence, many questions still linger before an in-depth understanding of their actual therapeutic value can be obtained.

Presently, the most common co-cultures experiments investigate the effect of coculture on the differentiation of the used cell types, as well as on improving the tissue formation in engineered constructs. In 1999 Jikko et al. showed that co-culturing growth plate chondrocytes with articular chondrocytes inhibited the terminal differentiation of growth plate chondrocytes [128]. In line with this, it has been demonstrated that addition of articular chondrocytes to MSCs inhibits hypertrophic differentiation of the latter. Although the mechanism behind this phenomenon remains largely unknown, some evidence suggests that this effect is mediated via parathyroid hormone-related protein [129]. However, alternative explanations such as articular cartilage derived factors inhibiting hypertrophic chondrocyte differentiation have remained uninvestigated [116].

The first studies in which MSCs were combined with other cell sources to provide a distinct effect included the vascularization of bone tissue engineered constructs [130, 131] and improvement of matrix deposition in degenerative discs [132]. In contrast, in cartilage repair strategies MSCs were initially used to reduce the amount of chondrocytes needed or to omit their use all together. Fascinatingly, chondro-induction was observed in these experiments; superior neocartilage was formed by the combination of two different cell-types as compared to either cell type alone (Fig 3.1B) [24, 133]. In this context, the co-culture of articular chondrocytes and MSCs is most commonly studied. It is claimed that this phenomenon can be explained by the induction of chondrogenic differentiation of MSCs by articular chondrocytes [65, 134-136]. Indeed, the addition of articular chondrocyte-conditioned medium is able to instigate chondrogenic differentiation of MSCs [137]. However, recent findings demonstrate that chondrocyte proliferation is enhanced by the presence of MSCs $[24,136]$. The MSCs accomplish this effect by acting as a trophic mediator. Moreover, while chondrogenic differentiation of MSCs can be triggered by chondrocytes, it also induces apoptosis in the MSCs [24]. Although the majority of MSCs will undergo apoptosis, the remaining fraction displays a strong chondrogenic phenotype $[24,136]$. This effect of MSCs is mediated by an as yet unidentified soluble secreted mediator. This results in a progressive disappearance of the MCSs from the original co-culture. Further investigation has to demonstrate if MSCs eventually completely vanish from the coculture. If indeed this holds true, it can be considered as a beneficial factor for the use of (pools of) allogeneic MSCs. Moreover, if MSCs indeed predominantly stimulate neocartilage formation indirectly by acting as a source of trophic factors, one might 


\section{A Unilateral beneficial co-cultures}

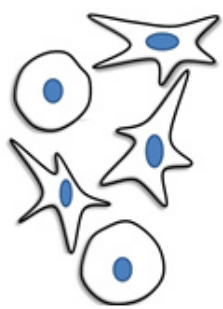

redifferentiation

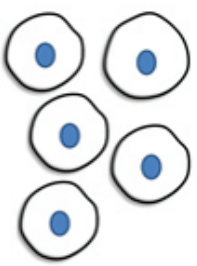

\section{B Mutually beneficial co-cultures}
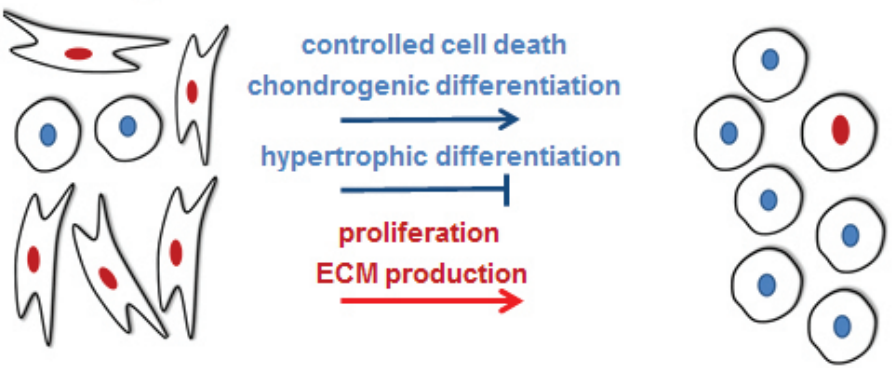

\section{Zonal co-cultures}
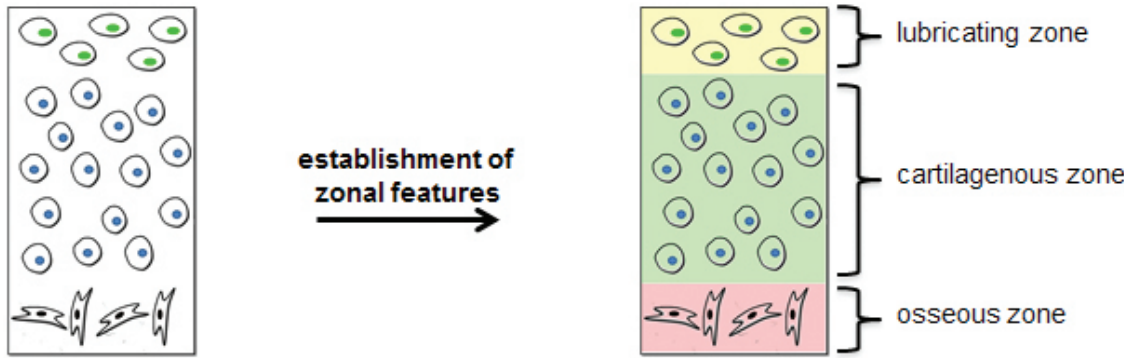

Figure 3.1: Different types of chondrocyte-based co-cultures

(A) The addition of freshly isolated chondrocytes promotes the redifferentiation of expanded dedifferentiated chondrocytes. (B) Co-culturing MSCs with chondrocytes result in the enhanced proliferation and matrix deposition of the chondrocytes via MSC-derived soluble factors. Additionally, chondrocytes induce controlled cell death of MSC, which results in a strong decline of MSCs in the co-culture. The remaining MSCs undergo chondrogenic differentiation, which is driven by chondrocyte-derived soluble factors. (C) Layered deposition of different cell types can be utilized to obtain a zonally structured construct, which display unique features in the distinct zones. For example, layering lubricin producing cells, chondrocytes, and bone-forming cells can be explored to form an osteochondral construct that mimics the native tissue. MSC, mesenchymal stromal cell. 
consider MSC implantation sites within the joint other than the cartilage defect as the secreted factors diffuse to the cartilage via the synovial fluid. Regardless, in light of these novel findings the direct contribution of the MSCs to cartilage matrix deposition is still unclear. In addition, the question whether /emphchondro-inductionn is induced due to exposure of factors normally produced by the opposite cell type or whether the co-culturing induces the expression of factors otherwise not expressed in either cell type remains to be answered.

Alternative strategies to improve neocartilage formation using co-cultures include the generation of articular cartilages zonal architecture (Fig 3.1C). In recent years novel cartilage repair strategies have been designed that aim at mimicking this anisotropic organization $[138,139]$. Co-cultures in combination with multilayer three-dimensional printing or layer-by-layer methodology using hydrogels that are able to covalently link by residual reactive residues e.g. dextran-tyramine gels [140-143] can further enhance these strategies. Calcifying cells, or their precursors, can be used for the deep zone, intensive extracellular matrix producing calcification resistant cells for the middle zone, and less intensive extracellular matrix producing and lubricin secreting cells for the superficial zone. Furthermore, for example, osteoblasts and chondrocytes can be cocultured in different regions of a construct to allow the formation of an osteochondral interface $[144,145]$. However, as only a scarce number of studies have been reported on such an approach, the feasibility remains to be determined.

\subsection{Conclusion}

The therapeutic outcome of cell-based therapies does not solely rely on the performance of the implanted cells. It also heavily relies on the expansion conditions and exogenous stimuli. In addition, functionalized biomaterials currently under development and which can be used as carriers for cell implantation are expected to provide a platform for controlling cellular phenotype in the near future. Subsequently, these factors can result in dissimilar responses in different cell sources. In short, much research remains to be performed in order to identify the combinations leading to optimal clinical results. The wide range of cell sources available to cartilage tissue engineers grants an optimal starting point for future improvement of cartilage repair strategies. Specifically, the combination of different cell sources currently holds great promise as it is able to grant combinatorial advantages by combining the benefits while mitigating the disadvantages of unique cell types. 


\section{References}

1. Roos, H., et al., Osteoarthritis of the knee after injury to the anterior cruciate ligament or meniscus: the influence of time and age. Osteoarthritis Cartilage, 1995. 3(4): p. 261-7.

2. Jacobsen, K., Osteoarthrosis following insufficiency of the cruciate ligaments in man. A clinical study. Acta Orthop Scand, 1977. 48(5): p. 520-6.

3. Beiser, I.H. and I.O. Kanat, Subchondral bone drilling: a treatment for cartilage defects. J Foot Surg, 1990. 29(6): p. 595-601.

4. Brittberg, M., et al., Treatment of deep cartilage defects in the knee with autologous chondrocyte transplantation. N Engl J Med, 1994. 331(14): p. 889-95.

5. Steadman, J.R., et al., [The microfracture technic in the management of complete cartilage defects in the knee joint]. Orthopade, 1999. 28(1): p. 26-32.

6. Hangody, L., et al., Autologous osteochondral grafting-technique and long-term results. Injury, 2008. 39 Suppl 1: p. S32-9.

7. Paul, J., et al., Donor-site morbidity after osteochondral autologous transplantation for lesions of the talus. J Bone Joint Surg Am, 2009. 91(7): p. 1683-8.

8. Williams, S.K., et al., Analysis of cartilage tissue on a cellular level in fresh osteochondral allograft retrievals. Am J Sports Med, 2007. 35(12): p. 2022-32.

9. Phipatanakul, W.P., et al., Immune response in patients receiving fresh osteochondral allografts. Am J Orthop (Belle Mead NJ), 2004. 33(7): p. 345-8.

10. Steinwachs, M.R., T. Guggi, and P.C. Kreuz, Marrow stimulation techniques. Injury, 2008. 39 Suppl 1: p. S26-31.

11. Jackson, D.W. and T.M. Simon, Chondrocyte transplantation. Arthroscopy, 1996. 12(6): p. $732-8$.

12. Matricali, G.A., G.P. Dereymaeker, and F.P. Luyten, Donor site morbidity after articular cartilage repair procedures: a review. Acta Orthop Belg, 2010. 76(5): p. 669-74.

13. Lin, Z., et al., Gene expression profiles of human chondrocytes during passaged monolayer cultivation. J Orthop Res, 2008. 26(9): p. 1230-7.

14. Schuh, E., et al., Effect of matrix elasticity on the maintenance of the chondrogenic phenotype. Tissue Eng Part A, 2010. 16(4): p. 1281-90.

15. Schrobback, K., et al., Effects of oxygen and culture system on in vitro propagation and redifferentiation of osteoarthritic human articular chondrocytes. Cell Tissue Res, 2011.

16. van der Windt, A.E., et al., Physiological tonicity improves human chondrogenic marker expression through nuclear factor of activated T-cells 5 in vitro. Arthritis Res Ther, 2010. 12(3): p. R100. 17. Lee, T.J., et al., Spinner-flask culture induces redifferentiation of de-differentiated chondrocytes. Biotechnol Lett, 2011. 33(4): p. 829-36.

18. Mandl, E.W., et al., Multiplication of human Chondrocytes with low seeding densities accelerates cell yield without losing redifferentiation capacity. Tissue Engineering, 2004. 10(1-2): p. 109-118.

19. Schrobback, K., et al., Adult human articular chondrocytes in a microcarrier-based culture system: expansion and redifferentiation. J Orthop Res, 2011. 29(4): p. 539-46.

20. Stenhamre, H., et al., Influence of pore size on the redifferentiation potential of human articular chondrocytes in poly(urethane urea) scaffolds. J Tissue Eng Regen Med, 2010.

21. Pei, M. and F. He, Extracellular matrix deposited by synovium-derived stem cells delays replicative senescent chondrocyte dedifferentiation and enhances redifferentiation. J Cell Physiol, 2011.

22. Ahmed, N., et al., Soluble signalling factors derived from differentiated cartilage tissue affect chondrogenic differentiation of rat adult marrow stromal cells. Cell Physiol Biochem, 2007. 20(5): p. 665-78.

23. Taylor, D.W., et al., Proteoglycan and collagen accumulation by passaged chondrocytes can be enhanced through side-by-side culture with primary chondrocytes. Tissue Eng Part A, 2010. 16(2): p. $643-51$.

24. Wu, L., et al., Trophic Effects of Mesenchymal Stem Cells Increase Chondrocyte Proliferation and Matrix Formation. Tissue Engineering Part A, 2011. 17(9-10): p. 1425-1436.

25. Mandl, E.W., et al., Serum-free medium supplemented with high-concentration FGF2 for cell expansion culture of human ear chondrocytes promotes redifferentiation capacity. Tissue Engineering, 2002. 8(4): p. 573-580.

26. Chaipinyo, K., B.W. Oakes, and M.P. Van Damme, The use of debrided human articular cartilage 
for autologous chondrocyte implantation: maintenance of chondrocyte differentiation and proliferation in type I collagen gels. J Orthop Res, 2004. 22(2): p. 446-55.

27. Jiang, C.C., et al., Repair of porcine articular cartilage defect with a biphasic osteochondral composite. J Orthop Res, 2007. 25(10): p. 1277-90.

28. Chiang, H., et al., Comparison of articular cartilage repair by autologous chondrocytes with and without in vitro cultivation. Tissue Eng Part C Methods, 2010. 16(2): p. 291-300.

29. Revell, C.M. and K.A. Athanasiou, Success rates and immunologic responses of autogenic, allogenic, and xenogenic treatments to repair articular cartilage defects. Tissue Eng Part B Rev, 2009. 15(1): p. $1-15$.

30. Jobanputra, P., et al., Cellular responses to human chondrocytes: absence of allogeneic responses in the presence of HLA-DR and ICAM-1. Clin Exp Immunol, 1992. 90(2): p. 336-44.

31. Kuhne, M., et al., HLA-B27-restricted antigen presentation by human chondrocytes to CD $8+\mathrm{T}$ cells: potential contribution to local immunopathologic processes in ankylosing spondylitis. Arthritis Rheum, 2009. 60(6): p. 1635-46.

32. Malejczyk, J., et al., Effect of immunosuppression on rejection of cartilage formed by transplanted allogeneic rib chondrocytes in mice. Clin Orthop Relat Res, 1991(269): p. 266-73.

33. Green, W.T., Jr., Articular cartilage repair. Behavior of rabbit chondrocytes during tissue culture and subsequent allografting. Clin Orthop Relat Res, 1977(124): p. 237-50.

34. Moskalewski, S., A. Hyc, and A. Osiecka-Iwan, Immune response by host after allogeneic chondrocyte transplant to the cartilage. Microsc Res Tech, 2002. 58(1): p. 3-13.

35. Gross, A.E., N. Shasha, and P. Aubin, Long-term followup of the use of fresh osteochondral allografts for posttraumatic knee defects. Clin Orthop Relat Res, 2005(435): p. 79-87.

36. Emmerson, B.C., et al., Fresh osteochondral allografting in the treatment of osteochondritis dissecans of the femoral condyle. Am J Sports Med, 2007. 35(6): p. 907-14.

37. Fujihara, Y., T. Takato, and K. Hoshi, Immunological response to tissue-engineered cartilage derived from auricular chondrocytes and a PLLA scaffold in transgenic mice. Biomaterials, 2010. 31(6): p. 1227-34.

38. Shangkai, C., et al., Transplantation of allogeneic chondrocytes cultured in fibroin sponge and stirring chamber to promote cartilage regeneration. Tissue Eng, 2007. 13(3): p. 483-92.

39. El Sayed, K., et al., Heterotopic autologous chondrocyte transplantation-a realistic approach to support articular cartilage repair? Tissue Eng Part B Rev, 2010. 16(6): p. 603-16.

40. Lohan, A., et al., In vitro and in vivo neo-cartilage formation by heterotopic chondrocytes seeded on PGA scaffolds. Histochem Cell Biol, 2011. 136(1): p. 57-69.

41. Zhang, L. and M. Spector, Comparison of three types of chondrocytes in collagen scaffolds for cartilage tissue engineering. Biomed Mater, 2009. 4(4): p. 045012.

42. Isogai, N., et al., Comparison of different chondrocytes for use in tissue engineering of cartilage model structures. Tissue Eng, 2006. 12(4): p. 691-703.

43. Lee, J., et al., Comparison of articular cartilage with costal cartilage in initial cell yield, degree of dedifferentiation during expansion and redifferentiation capacity. Biotechnol Appl Biochem, 2007. 48(Pt 3): p. 149-58.

44. Asawa, Y., et al., Aptitude of auricular and nasoseptal chondrocytes cultured under a monolayer or three-dimensional condition for cartilage tissue engineering. Tissue Eng Part A, 2009. 15(5): p. 1109-18.

45. Szeparowicz, P., et al., Comparison of cartilage self repairs and repairs with costal and articular chondrocyte transplantation in treatment of cartilage defects in rats. Rocz Akad Med Bialymst, 2004. 49 Suppl 1: p. 28-30.

46. Moskalewski, S. and J. Malejczyk, Bone formation following intrarenal transplantation of isolated murine chondrocytes: chondrocyte-bone cell transdifferentiation? Development, 1989. 107(3): p. $473-80$.

47. Landis, W.J., et al., Tissue engineering a model for the human ear: Assessment of size, shape, morphology, and gene expression following seeding of different chondrocytes. Wound Repair and Regeneration, 2009. 17(1): p. 136-146.

48. Ruszymah, B.H.I., et al., Pediatric auricular chondrocytes gene expression analysis in monolayer culture and engineered elastic cartilage. International Journal of Pediatric Otorhinolaryngology, 2007. 71(8): p. 1225-1234.

49. Ruszymah, B.H., et al., Pediatric auricular chondrocytes gene expression analysis in monolayer 
culture and engineered elastic cartilage. Int J Pediatr Otorhinolaryngol, 2007. 71(8): p. 1225-34. 50. Chung, C., et al., Effects of auricular chondrocyte expansion on neocartilage formation in photocrosslinked hyaluronic acid networks. Tissue Eng, 2006. 12(9): p. 2665-73.

51. Schumacher, B.L., et al., Proteoglycan 4 (PRG4) synthesis and immunolocalization in bovine meniscus. J Orthop Res, 2005. 23(3): p. 562-8.

52. Wilson, C.G., J.F. Nishimuta, and M.E. Levenston, Chondrocytes and meniscal fibrochondrocytes differentially process aggrecan during de cc extracellular matrix assembly. Tissue Eng Part A, 2009. 15(7): p. 1513-22.

53. Englund, M., The role of the meniscus in osteoarthritis genesis. Med Clin North Am, 2009. 93(1): p. $37-43$.

54. Sun, Y., et al., Calcium deposition in osteoarthritic meniscus and meniscal cell culture. Arthritis Res Ther, 2010. 12(2): p. R56.

55. Hjelle, K., et al., Articular cartilage defects in 1,000 knee arthroscopies. Arthroscopy, 2002. 18(7): p. $730-4$.

56. Hunziker, E.B. and L.C. Rosenberg, Repair of partial-thickness defects in articular cartilage: cell recruitment from the synovial membrane. J Bone Joint Surg Am, 1996. 78(5): p. 721-33.

57. Gallay, S.H., et al., Relationship of donor site to chondrogenic potential of periosteum in vitro. J Orthop Res, 1994. 12(4): p. 515-25.

58. Nakahara, H., V.M. Goldberg, and A.I. Caplan, Culture-expanded human periosteal-derived cells exhibit osteochondral potential in vivo. J Orthop Res, 1991. 9(4): p. 465-76.

59. Medvedev, S.P., et al., Human induced pluripotent stem cells derived from fetal neural stem cells successfully undergo directed differentiation into cartilage. Stem Cells Dev, 2011. 20(6): p. 1099-112.

60. Jukes, J.M., et al., Endochondral bone tissue engineering using embryonic stem cells. Proc Natl Acad Sci U S A, 2008. 105(19): p. 6840-5.

61. Yamashita, T., et al., Tumorigenic Development of Induced Pluripotent Stem Cells in Ischemic Mouse Brain. Cell Transplant, 2010.

62. Tang, C., et al., An antibody against SSEA-5 glycan on human pluripotent stem cells enables removal of teratoma-forming cells. Nat Biotechnol, 2011.

63. Koelling, S., et al., Migratory chondrogenic progenitor cells from repair tissue during the later stages of human osteoarthritis. Cell Stem Cell, 2009. 4(4): p. 324-35.

64. Pittenger, M.F., et al., Multilineage potential of adult human mesenchymal stem cells. Science, 1999. 284(5411): p. 143-7.

65. Lee, J.S. and G.I. Im, Influence of chondrocytes on the chondrogenic differentiation of adipose stem cells. Tissue Eng Part A, 2010. 16(12): p. 3569-77.

66. Jones, E.A., et al., Synovial fluid mesenchymal stem cells in health and early osteoarthritis: detection and functional evaluation at the single-cell level. Arthritis Rheum, 2008. 58(6): p. 1731-40. 67. Farre-Guasch, E., et al., Buccal fat pad, an oral access source of human adipose stem cells with potential for osteochondral tissue engineering: an in vitro study. Tissue Eng Part C Methods, 2010. 16(5): p. 1083-94.

68. Witkowska-Zimny, M. and E. Wrobel, Perinatal sources of mesenchymal stem cells: Wharton's jelly, amnion and chorion. Cell Mol Biol Lett, 2011. 16(3): p. 493-514.

69. Patki, S., et al., Human breast milk is a rich source of multipotent mesenchymal stem cells. Hum Cell, 2010. 23(2): p. 35-40.

70. Lee, O.K., et al., Isolation of multipotent mesenchymal stem cells from umbilical cord blood. Blood, 2004. 103(5): p. 1669-1675.

71. Allickson, J.G., et al., Recent Studies Assessing the Proliferative Capability of a Novel Adult Stem Cell Identified in Menstrual Blood. Open Stem Cell J, 2011. 3(2011): p. 4-10.

72. Hu, G., et al., Supernatant of bone marrow mesenchymal stromal cells induces peripheral blood mononuclear cells possessing mesenchymal features. Int J Biol Sci, 2011. 7(3): p. 364-75.

73. Wei, Y., et al., Human skeletal muscle-derived stem cells retain stem cell properties after expansion in myosphere culture. Exp Cell Res, 2011. 317(7): p. 1016-27.

74. Matsumoto, T., et al., Isolation and Characterization of Human Anterior Cruciate LigamentDerived Vascular Stem Cells. Stem Cells Dev, 2011.

75. Janjanin, S., et al., Human palatine tonsil: a new potential tissue source of multipotent mesenchymal progenitor cells. Arthritis Res Ther, 2008. 10(4): p. R83. 
76. Estes, B.T., et al., Isolation of adipose-derived stem cells and their induction to a chondrogenic phenotype. Nat Protoc, 2010. 5(7): p. 1294-311.

77. Siddappa, R., et al., Donor variation and loss of multipotency during in vitro expansion of human mesenchymal stem cells for bone tissue engineering. J Orthop Res, 2007. 25(8): p. 1029-41.

78. Phinney, D.G., et al., Donor variation in the growth properties and osteogenic potential of human marrow stromal cells. J Cell Biochem, 1999. 75(3): p. 424-36. 79. Tokalov, S.V., et al., A number of bone marrow mesenchymal stem cells but neither phenotype nor differentiation capacities changes with age of rats. Mol Cells, 2007. 24(2): p. 255-60.

80. Tokalov, S.V., et al., Age-related changes in the frequency of mesenchymal stem cells in the bone marrow of rats. Stem Cells Dev, 2007. 16(3): p. 439-46.

81. De Bari, C., F. Dell'Accio, and F.P. Luyten, Human periosteum-derived cells maintain phenotypic stability and chondrogenic potential throughout expansion regardless of donor age. Arthritis Rheum, 2001. 44(1): p. 85-95.

82. Jansen, B.J., et al., Functional differences between mesenchymal stem cell populations are reflected by their transcriptome. Stem Cells Dev, 2010. 19(4): p. 481-90.

83. Vacanti, V., et al., Phenotypic changes of adult porcine mesenchymal stem cells induced by prolonged passaging in culture. J Cell Physiol, 2005. 205(2): p. 194-201.

84. Tan, Q., P.P. Lui, and Y.F. Rui, Effect of In Vitro Passaging on the Stem Cell-Related Properties of Tendon-Derived Stem Cells-Implications in Tissue Engineering. Stem Cells Dev, 2011.

85. Dominici, M., et al., Minimal criteria for defining multipotent mesenchymal stromal cells. The International Society for Cellular Therapy position statement. Cytotherapy, 2006. 8(4): p. 315-7.

86. Buhring, H.J., et al., Novel markers for the prospective isolation of human MSC. Ann N Y Acad Sci, 2007. 1106: p. 262-71.

87. Ho, A.D., W. Wagner, and W. Franke, Heterogeneity of mesenchymal stromal cell preparations. Cytotherapy, 2008. 10(4): p. 320-30.

88. Tallone, T., et al., Adult Human Adipose Tissue Contains Several Types of Multipotent Cells. Journal of Cardiovascular Translational Research, 2011. 4(2): p. 200-210.

89. Chen, T., Y. Zhou, and W.S. Tan, Influence of lactic acid on the proliferation, metabolism, and differentiation of rabbit mesenchymal stem cells. Cell Biol Toxicol, 2009. 25(6): p. 573-86.

90. Goedecke, A., et al., Differential effect of platelet-rich plasma and fetal calf serum on bone marrow-derived human mesenchymal stromal cells expanded in vitro. J Tissue Eng Regen Med, 2011. 5(8): p. 648-54

91. Chase, L.G., et al., A novel serum-free medium for the expansion of human mesenchymal stem cells. Stem Cell Res Ther, 2010. 1(1): p. 8.

92. Perez-Ilzarbe, M., et al., Comparison of ex vivo expansion culture conditions of mesenchymal stem cells for human cell therapy. Transfusion, 2009. 49(9): p. 1901-10.

93. Fan, X., et al., Optimization of primary culture condition for mesenchymal stem cells derived from umbilical cord blood with factorial design. Biotechnol Prog, 2009. 25(2): p. 499-507.

94. Lund, P., et al., Effect of growth media and serum replacements on the proliferation and differentiation of adipose-derived stem cells. Cytotherapy, 2009. 11(2): p. 189-97.

95. Engler, A.J., et al., Matrix elasticity directs stem cell lineage specification. Cell, 2006. 126(4): p. 677-89.

96. Weijers, E.M., et al., The Influence of Hypoxia and Fibrinogen Variants on the Expansion and Differentiation of Adipose Tissue-Derived Mesenchymal Stem Cells. Tissue Eng Part A, 2011.

97. Muller, J., et al., Hypoxic conditions during expansion culture prime human mesenchymal stromal precursor cells for chondrogenic differentiation in three-dimensional cultures. Cell Transplant, 2011.

98. Karlsen, T.A., et al., Effect of three-dimensional culture and incubator gas concentration on phenotype and differentiation capability of human mesenchymal stem cells. J Cell Biochem, 2011. 112(2): p. 684-93.

99. Dos Santos, F., et al., Ex vivo expansion of human mesenchymal stem cells: a more effective cell proliferation kinetics and metabolism under hypoxia. J Cell Physiol, 2010. 223(1): p. 27-35.

100. Lozoya, O.A., et al., Regulation of hepatic stem/progenitor phenotype by microenvironment stiffness in hydrogel models of the human liver stem cell niche. Biomaterials, 2011. 32(30): p. 7389402 .

101. Winer, J.P., et al., Bone marrow-derived human mesenchymal stem cells become quiescent on 
soft substrates but remain responsive to chemical or mechanical stimuli. Tissue Eng Part A, 2009. 15(1): p. 147-54.

102. Kisiday, J.D., et al., Expansion of mesenchymal stem cells on fibrinogen-rich protein surfaces derived from blood plasma. J Tissue Eng Regen Med, 2011. 5(8): p. 600-11.

103. Curran, J.M., et al., The use of dynamic surface chemistries to control msc isolation and function. Biomaterials, 2011. 32(21): p. 4753-60.

104. Caplan, A.I. and J.E. Dennis, Mesenchymal stem cells as trophic mediators. Journal of Cellular Biochemistry, 2006. 98(5): p. 1076-1084.

105. Le Blanc, K., et al., HLA expression and immunologic properties of differentiated and undifferentiated mesenchymal stem cells. Exp Hematol, 2003. 31(10): p. 890-6.

106. Chen, X., M.A. Armstrong, and G. Li, Mesenchymal stem cells in immunoregulation. Immunol Cell Biol, 2006. 84(5): p. 413-21.

107. Lee, K.B., et al., Injectable mesenchymal stem cell therapy for large cartilage defects-a porcine model. Stem Cells, 2007. 25(11): p. 2964-71.

108. Murphy, J.M., et al., Stem cell therapy in a caprine model of osteoarthritis. Arthritis and Rheumatism, 2003. 48(12): p. 3464-3474.

109. Wood, J.A., et al., Periocular and Intra-Articular Injection of Canine Adipose-Derived Mesenchymal Stem Cells: An In Vivo Imaging and Migration Study. J Ocul Pharmacol Ther, 2011.

110. Helman, L.J. and P. Meltzer, Mechanisms of sarcoma development. Nat Rev Cancer, 2003. 3(9): p. 685-94.

111. Tolar, J., et al., Sarcoma derived from cultured mesenchymal stem cells. Stem Cells, 2007. 25(2): p. 371-9.

112. Suzuki, K., et al., Mesenchymal stromal cells promote tumor growth through the enhancement of neovascularization. Mol Med, 2011. 17(7-8): p. 579-87.

113. Johnstone, B., et al., In vitro chondrogenesis of bone marrow-derived mesenchymal progenitor cells. Exp Cell Res, 1998. 238(1): p. 265-72.

114. Zhai, L.J., et al., Mesenchymal stem cells display different gene expression profiles compared to hyaline and elastic chondrocytes. Int J Clin Exp Med, 2011. 4(1): p. 81-90.

115. Hillel, A.T., et al., Characterization of human mesenchymal stem cell-engineered cartilage: analysis of its ultrastructure, cell density and chondrocyte phenotype compared to native adult and fetal cartilage. Cells Tissues Organs, 2010. 191(1): p. 12-20.

116. Leijten, J.C.H., et al., Leijten, J.C., et al., Gremlin 1, frizzled-related protein, and Dkk-1 are key regulators of human articular cartilage homeostasis. Arthritis Rheum, 2012. 64(10): p. 3302-12. 117. Scotti, C., et al., Recapitulation of endochondral bone formation using human adult mesenchymal stem cells as a paradigm for developmental engineering. Proc Natl Acad Sci U S A, 2010. 107(16): p. 7251-6.

118. Mueller, M.B. and R.S. Tuan, Functional characterization of hypertrophy in chondrogenesis of human mesenchymal stem cells. Arthritis Rheum, 2008. 58(5): p. 1377-88.

119. Abrahamsson, C.K., et al., Chondrogenesis and mineralization during in vitro culture of human mesenchymal stem cells on three-dimensional woven scaffolds. Tissue Eng Part A, 2010. 16(12): p. 3709-18.

120. Pelttari, K., et al., Premature induction of hypertrophy during in vitro chondrogenesis of human mesenchymal stem cells correlates with calcification and vascular invasion after ectopic transplantation in SCID mice. Arthritis Rheum, 2006. 54(10): p. 3254-66.

121. Koga, H., et al., Synovial stem cells are regionally specified according to local microenvironments after implantation for cartilage regeneration. Stem Cells, 2007. 25(3): p. 689-96.

122. Huybrechts-Godin, G., P. Hauser, and G. Vaes, Macrophage-fibroblast interactions in collagenase production and cartilage degradation. Biochem J, 1979. 184(3): p. 643-50.

123. Goldring, S.R., J.M. Dayer, and S.M. Krane, Rheumatoid synovial cell hormone responses modulated by cell-cell interactions. Inflammation, 1984. 8(1): p. 107-21.

124. Ahmed, N., et al., Passaged human chondrocytes accumulate extracellular matrix when induced by bovine chondrocytes. J Tissue Eng Regen Med, 2010. 4(3): p. 233-41.

125. Gan, L. and R.A. Kandel, In vitro cartilage tissue formation by Co-culture of primary and passaged chondrocytes. Tissue Eng, 2007. 13(4): p. 831-42.

126. Ahmed, N., et al., Cartilage tissue formation using redifferentiated passaged chondrocytes in vitro. Tissue Eng Part A, 2009. 15(3): p. 665-73. 
127. Kuhne, M., et al., Characterization of auricular chondrocytes and auricular/articular chondrocyte co-cultures in terms of an application in articular cartilage repair. Int J Mol Med, 2010. 25(5): p. $701-8$.

128. Jikko, A., et al., Inhibition of chondrocyte terminal differentiation and matrix calcification by soluble factors released by articular chondrocytes. Calcif Tissue Int, 1999. 65(4): p. 276-9.

129. Fischer, J., et al., Human articular chondrocytes secrete parathyroid hormone-related protein and inhibit hypertrophy of mesenchymal stem cells in coculture during chondrogenesis. Arthritis Rheum, 2010. 62(9): p. 2696-706.

130. Villars, F., et al., Effect of human endothelial cells on human bone marrow stromal cell phenotype: role of VEGF? J Cell Biochem, 2000. 79(4): p. 672-85.

131. Hofmann, A., et al., The effect of human osteoblasts on proliferation and neo-vessel formation of human umbilical vein endothelial cells in a long-term 3D co-culture on polyurethane scaffolds. Biomaterials, 2008. 29(31): p. 4217-26.

132. Le Visage, C., et al., Interaction of human mesenchymal stem cells with disc cells: changes in extracellular matrix biosynthesis. Spine (Phila Pa 1976), 2006. 31(18): p. 2036-42.

133. Bian, L., et al., Coculture of human mesenchymal stem cells and articular chondrocytes reduces hypertrophy and enhances functional properties of engineered cartilage. Tissue Eng Part A, 2011. 17(7-8): p. $1137-45$.

134. Aung, A., et al., Osteoarthritic chondrocyte-secreted morphogens induce chondrogenic differentiation of human mesenchymal stem cells. Arthritis Rheum, 2011. 63(1): p. 148-58.

135. Bigdeli, N., et al., Coculture of human embryonic stem cells and human articular chondrocytes results in significantly altered phenotype and improved chondrogenic differentiation. Stem Cells, 2009. 27(8): p. 1812-21.

136. Acharya, C., et al., Enhanced chondrocyte proliferation and mesenchymal stromal cells chondrogenesis in coculture pellets mediate improved cartilage formation. J Cell Physiol, 2012. 227(1): p. 88-97.

137. Hwang, N.S., et al., Chondrogenic priming adipose-mesenchymal stem cells for cartilage tissue regeneration. Pharm Res, 2011. 28(6): p. 1395-405.

138. Klein, T.J., et al., Tissue engineering of articular cartilage with biomimetic zones. Tissue Eng Part B Rev, 2009. 15(2): p. 143-57.

139. Klein, T.J., et al., Strategies for zonal cartilage repair using hydrogels. Macromol Biosci, 2009. 9(11): p. 1049-58.

140. Jin, R., et al., Enzymatically crosslinked dextran-tyramine hydrogels as injectable scaffolds for cartilage tissue engineering. Tissue Eng Part A, 2010. 16(8): p. 2429-40.

141. Jin, R., et al., Chondrogenesis in injectable enzymatically crosslinked heparin/dextran hydrogels. J Control Release, 2011. 152(1): p. 186-95. 142. Jin, R., et al., Enzymatically-crosslinked injectable hydrogels based on biomimetic dextran-hyaluronic acid conjugates for cartilage tissue engineering. Biomaterials, 2010. 31(11): p. 3103-13.

143. Moreira Teixeira, L.S., et al., The effect of platelet lysate supplementation of a dextran-based hydrogel on cartilage formation. Biomaterials, 2012.

144. Jiang, J., S.B. Nicoll, and H.H. Lu, Co-culture of osteoblasts and chondrocytes modulates cellular differentiation in vitro. Biochem Biophys Res Commun, 2005. 338(2): p. 762-70.

145. Nakaoka, R., S.X. Hsiong, and D.J. Mooney, Regulation of chondrocyte differentiation level via co-culture with osteoblasts. Tissue Eng, 2006. 12(9): p. 2425-33. 


\section{Chapter 4}

\section{microRNA levels as prognostic markers for chondrogenesis of MSC donors}

Nicole Georgi, Hanna Taipaleenmaki, Christian Raiss, Andre van Wijnen, Nathalie Groen, Karolina Janaeczek-Portalska, Clemens van Blitterswijk, Jan de Boer and Marcel Karperien 


\begin{abstract}
The ability of mesenchymal stromal/stem cells (MSCs) to differentiate into chondrocytes makes them a promising cell source for the use in cartilage repair strategies. Nevertheless, MSCs chondrogenic potential differs between donors and therefore genetic markers for identifying donors with high chondrogenic potential are vastly desired. In this study, we want to introduce a novel way to separate donors with high chondrogenic potential from low chondogenic potential by the use of miRNA expression levels. Twenty human MSC donors were first tested for their chondrogenic differentiation potential on the basis of histological matrix formation, mRNA expression levels of chondrogenic marker genes, and quantitative glycosaminoglycan deposition. Three donors out of twenty were identified as donors with high chondrogenic potential, whereas nine showed moderate and eight low chondrogenic potential. Global mRNA expression profiles of the donors before the onset of chondrogenic differentiation revealed minor differences in gene expression between good and bad chondrogenic responders. In contrast, sharp delineation of good and bad responders could be made based on microRNA (miRNA) profiles using miRNAs involved in chondrogensis and cartilage homeostasis. Furthermore, we followed the changes in miRNA expression in a seven-day differentiation period and identified $m i R$-210 and $m i R-630$ as positive regulators of chondrogenesis. $m i R-181$ and $m i R$-34a, which are negative regulators of chondrogenesis, were up-regulated during differentiation in low performing donors. In conclusion, miRNA profiling of MSC donors may have prognostic value to select donors with high chondrogenic potential to improve MSC based strategies for cartilage regeneration.
\end{abstract}




\subsection{Introduction}

Mesenchymal stromal/stem cells (MSCs) are a multipotent cell source that can be easily harvested from various locations of the body, including bone marrow, periosteum, synovium, synovial fluid, adipose tissue, bucal fat pad, infrapatellar fat pad and osteoarthritic cartilage [1-6]. The MSCs potential to differentiate into chondrocytes as well as their potential as trophic mediators makes them an particular interesting cell source for cartilage tissue engineering [7]. Unfortunately, large inter-donor variation of chondrogenic differentiation potential is a general complication encountered when MSCs are used $[8,9]$. Donor age, method or location of harvest, culture conditions as well as culture time are known factors having impact on MSCs differentiation potential [10-14] $[15,16]$. Jansen et al. suggested that distinct gene expression profiles might result in varying differentiation potential [17]. However, markers indicative for chondrogenic differentiation potential of undifferentiated MSCs have so far remained undiscovered.

The differentiation potential of MSCs is regulated by genetic and epigenetic mechanisms. Recent research is identifying not only variation in mRNA expression as potential marker for MSCs differentiation potential but as well microRNA (miRNAs) levels [18-21]. miRNAs modulate cellular mechanisms by targeting both transcription factors and mRNA transcripts, regulating negatively the expression of their targets and are thereby involved in the determination of cellular fate. For MSCs miRNAs can be a tool to map the proliferation and differentiation potential.

In this study, we tested twenty bone marrow derived MSC donors for their potential to undergo chondrogenesis. From the donor panel we identified three donors with high chondrogenic potential (good responder) as well as three donors with low chondrogenic potential (bad responder) and link this potential with MSCs mRNA expression before the onset of differentiation. Similarly, the chondrogenic potential was linked with a panel of miRNAs previously identified to play a role in chondrogenesis or cartilage maintenance. miRNA evaluation was performed before the onset of differentiation and after the initiation of differentiation at seven days of pellet culture in chondrogenic culture conditions.

In contrast to the marginal differences between donors at the global mRNA level, screening of a panel of miRNAs previously implemented in cartilage formation demonstrated more clear segregation between good and bad responders. miRNA profiling of MSC donors may therefore have prognostic value to select MSC donors with respect of their chondrogenic differentiation potential.

\subsection{Materials and Methods}

\subsubsection{Cell expansion and differentiation}

The use of human bone marrow aspirates was approved by a local Medical Ethics Committee and written informed consent by the donors was given [22]. Aspirates were resuspended using a $20 \mathrm{G}$ needle and plated at a density of 0.5 million mononucleated cells $/ \mathrm{cm}^{2}$. MSCs were selected by adherence in proliferation media $(\alpha$-MEM, 
$10 \%$ fetal bovine serum (Lonza, Verviers, Belgium), $0.2 \mathrm{mM}$ ascorbicacid, $2 \mathrm{mM} \mathrm{L-}$ glutamine, $100 \mathrm{U} / \mathrm{mL}$ of penicillin, $100 \mathrm{U}$ penicillin $/ \mathrm{mL}, 100 \mathrm{mg} / \mathrm{mL}$ streptomycin, and $1 \mathrm{ng} / \mathrm{mL}$ of basic Fibroblast Growth Factor (Instruchemie, Delfzijl, The Netherlands). MSCs were expanded up to passage 2 and used in passage 3 to test the chondrogenic differentiation potential. Commonly used chemicals were purchased from Sigma-Aldrich.

\subsubsection{Chondrogenic differentiation}

To induce chondrogenic differentiation, 250000 MSCs were seeded in 96-round bottom 96 well plates [23]. Pellets were formed by centrifugation (500 rcf, $5 \mathrm{~min}$ ) and maintained in chondrogenic differentiation media (Dulbeccos modified Eagles medium supplemented with $40 \mathrm{mg} / \mathrm{mL}$ of proline, $50 \mathrm{mg} / \mathrm{mL}$ ITS-premix, $50 \mathrm{mg} / \mathrm{mL}$ of ascorbic acid, $100 \mathrm{mg} / \mathrm{mL}$ of sodium pyruvate, $100 \mathrm{U}$ penicillin $/ \mathrm{mL}$, and $100 \mathrm{mg} / \mathrm{mL}$ streptomycin, $10 \mathrm{ng} / \mathrm{mL}$ of transforming growth factor- $\beta, 10^{-7} \mathrm{M}$ of dexamethasone) for four weeks as previously described [23]. Media was changed twice a week.

\subsubsection{Alcian Blue staining}

Chondrogenic pellets were fixed with $10 \%$ buffered formalin for 15 min, dehydrated and embedded in paraffin using routine procedures. Sections of $5 \mu \mathrm{m}$ were cut and stained for sulfated glycosaminoglycans (GAGs) with Alcian Blue $\left(0.5 \%\right.$, in $\mathrm{H}_{2} \mathrm{O}$, $\mathrm{pH}=1$ adjusted with $\mathrm{HCl}, 30 \mathrm{~min}$ ) combined with counterstaining of Nuclear Fast Red $(0.1 \%$ in $5 \%$ aluminum sulfate, $5 \mathrm{~min})$. Staining was quantified using Adobe Photoshop with the select colour range tool (Cache 1, staining in pixels relative to pellet size). Scoring of histology was further done by three independent blinded observers according to intensity of Alcian Blue staining and morphology of the formed pellets

\subsubsection{RNA isolation and quantitative polymerase chain reaction}

Total RNA was isolated from pellet cultures with the Nucleospin RNA II kit (Bioke). Up to one microgram of total RNA was reverse-transcribed into cDNA using the iScript cDNA Synthesis kit (Bio-Rad). The primers for quantitative polymerase chain reaction (qPCR) are listed in table 4.1. mRNA expression levels were normalized with GAPDH and B2M as house keeping genes. All reagents were purchased from Invitrogen unless otherwise stated.

\subsubsection{Microarray processing}

To analyse the gene expression profile of MSCs, microarray analysis was used. RNA isolated at passage two before the initiation of the chondrogenic differentiation was hybridized to the Human Genome U133A 2.0 Array (Affymetrix) and scanned with a GeneChip G3000 scanner (Affymetrix). To normalize the measurements, we used a normalization method which removes hybridization, amplification and array location 


\begin{tabular}{|c|l|}
\hline micro-RNA & 'rimer sequence \\
\hline universal reverse primer & 5'-GACGAGGACTCGAGCTCAAGCT-3' \\
\hline oligodT-adaptor & 5'-GACGAGGACTCGAGCTCAAGCTTTTTTTTTTTTTTTT-3' \\
\hline U6 & 5'CGCAAGGATGACACGCAAATTC-3' \\
\hline miR-30b & 5'- TGTAAACATCCTACACTCAGCT -3' \\
\hline miR-221 & 5'- AGCTACATTGTCTGCTGGGTTTC -3' \\
\hline miR-34a & 5'- TGGCAGTGTCTTAGCTGGTTGT -3' \\
\hline miR-23b & 5'- TGGGTTCCTGGCATGCTGATTT -3' \\
\hline miR-26 & 5'- TTCAAGTAATCCAGGATAGGCT -3' \\
\hline miR-181 & 5'- AACATTCAACGCTGTCGGTGAG -3' \\
\hline miR-210 & 5'- CTGTGCGTGTGACAGCGGCTGA -3' \\
\hline miR-630 & 5'- AGTATTCTGTACCAGGGAAGGT -3' \\
\hline miR-140 & 5'- TACCACAGGGTAGAACCACGG -3' \\
\hline miR-145 & 5'- GTCCAGTTTTCCCAGGAATCCCT -3' \\
\hline Let-7e & 5'- TGAGGTAGGAGGTGTATAGTT -3' \\
\hline &
\end{tabular}

Table 4.1: primers used for quantitative PCR of genes involved in chondrogenesis

based technical effects. Further data analysis and statistical testing were performed using R and Bioconductor statistical software (http://www.bioconductor.org/). A linear modelling approach with empirical Bayesian methods, as implemented in Limma package [24], was used to determine differential gene expression. To analyse the donor variation in terms of chondrogenic differentiation ability, we scored the different donor-derived MSCs based on their histological appearance, glycosaminoglycan deposition and expression of markers of mRNA markers of chondrogenesis after 28 days of differentiation. Subsequently, a list of genes ranked on fold change between the highest and lowest chondrogenically differentiating donors was generated. The raw and normalized data are deposited in the Gene Expression Omnibus database (http://www.ncbi.nlm.nih.gov/geo/). Search Tool for the Retrieval of Interacting Genes/Proteins (STRING) was used to investigate the predicted gene-gene interaction network [25]. Clusters were formed using Markov clustering algorithms.

\subsection{6 miRNA isolation and quantitative analysis}

Total RNA and small RNAs were isolated from monolayer MSC cultures at passage 2 and from pellet cultures at day seven of chondrogenic differentiation with the AllPrep DNA/RNA/Protein Mini Kit in combination with the RNeasy ${ }^{\circledR}$ MinElute ${ }^{\circledR}$ Cleanup Kit according to the manufacturers protocol (Qiagen). The concentration of all nucleic acids was measured with the Nanodrop2000. The small RNA fraction cDNA was prepared using revertAid $\mathrm{H}$ minus first strand cDNA synthesis kit (Fermentas). SYBR (N,N-dimethyl-N-[4-[(E)-(3-methyl-1,3-benzothiazol-2-ylidene)methyl]1-phenylquinolin-1-ium-2-yl]-N-propylpropane-1,3-diamine) green mRNA Primer sequences are listed in Table 1. QuantimiR-RT kit (Systems Biosciences (SBI)) was used according to manufacturers instruction to convert small RNAs into cDNA. Expression levels were analyzed by qRT-PCR (SYBR Green supermix and iCycler IQ 


\begin{tabular}{|c|l|}
\hline micro-RNA & Primer sequence \\
\hline universal reverse primer & 5'-GACGAGGACTCGAGCTCAAGCT-3' \\
\hline oligodT-adaptor & 5'-GACGAGGACTCGAGCTCAAGCTTTTTTTTTTTTTTTT-3' \\
\hline U6 & 5'CGCAAGGATGACACGCAAATTC-3' \\
\hline miR-30b & 5'- TGTAAACATCCTACACTCAGCT -3' \\
\hline miR-221 & 5'- AGCTACATTGTCTGCTGGGTTTC -3' \\
\hline miR-34a & 5'- TGGCAGTGTCTTAGCTGGTTGT -3' \\
\hline miR-23b & 5'- TGGGTTCCTGGCATGCTGATTT -3' \\
\hline miR-26 & 5'- TTCAAGTAATCCAGGATAGGCT -3' \\
\hline miR-181 & 5'-AACATTCAACGCTGTCGGTGAG -3' \\
\hline miR-210 & 5'- CTGTGCGTGTGACAGCGGCTGA -3' \\
\hline miR-630 & 5'- AGTATTCTGTACCAGGGAAGGT -3' \\
\hline miR-140 & 5'- TACCACAGGGTAGAACCACGG -3' \\
\hline miR-145 & 5'- GTCCAGTTTTCCCAGGAATCCCT -3' \\
\hline Let-7e & 5'- TGAGGTAGGAGGTGTATAGTT -3' \\
\hline &
\end{tabular}

Table 4.2: primers used for quantitative PCR of miRNAs reported to be involved in chondrogenesis

detection system; Bio-Rad) using conventional protocols [26]. The relative expressions were calculated by $\Delta \mathrm{Ct}$ method normalized to $\mathrm{U} 6$ expression.

\subsubsection{Statistical analysis}

Statistics were performed using SPSS one-way ANOVA with Tukey as post-hoc test (different sized groups). Significances of $\mathrm{p} \leqq 0.05$ are indicated $(*)$.

\subsection{Results}

\subsubsection{Limited chondrogenic potential in MSCs donors}

The comparison of twenty MSC donors for their chondrogenic potential based on histological appearance, glycosaminoglycans (GAG) deposition and chondrogenic mRNA expression revealed, that only three donors show substantial chondrogenesis after 28 days of pellet culture. Another nine donors show moderate levels of chondrogenesis and eight donors have only a limited potential to undergo chondrogenesis (Fig S4.1). Alcian blue stain for GAG of two representative donors of each group revealed that intensity of staining is decreasing from donors with high chondrogenic potential to donors with low chondrogenic potential. Reduction in GAGs is going along with limited abundance of chondron formation, an increase in fibrous cartilage formation and a higher cell/matrix ratio (Fig 4.1A). Gene expression levels of the chondrogenic genes $A C A N$ and COL2A1 were significantly upregulated in donors with high chondrogenic potential. $S O X 9$, a transcription factor known to be regulated in chondrogenesis as well as $F R Z B$ a recently identified marker for articular cartilage were higher expressed in good performers. COL10A1, a marker for cartilage hypertrophy was as well significantly higher expressed in good donors. COL1A1, a de-differentiation marker was only limited regulated inbetween the different groups (Fig 4.1B). Donors with high 
A

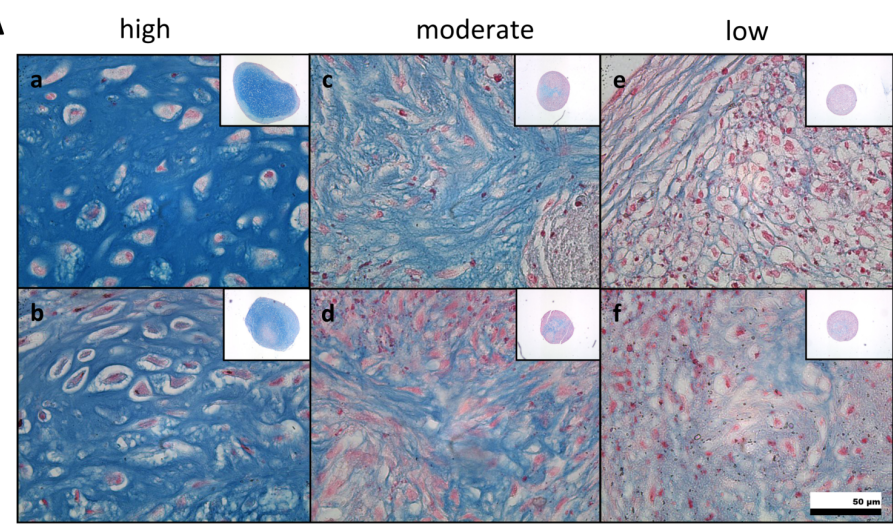

B
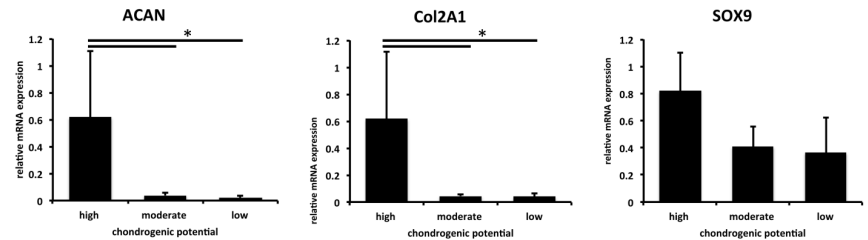

COL1A1
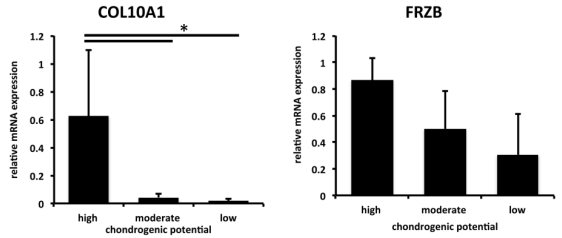

C
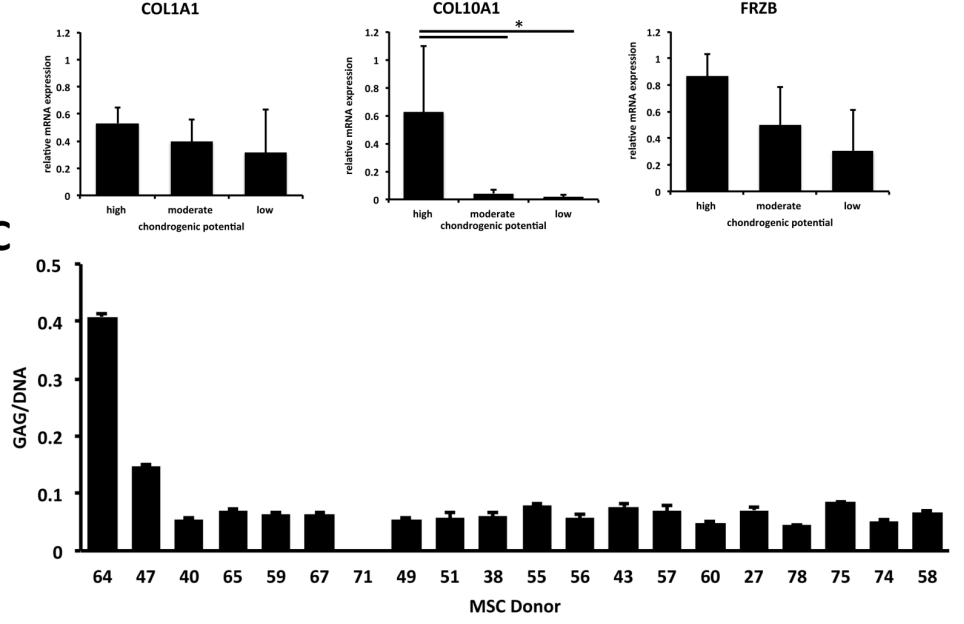

Figure 4.1: Comparison of twenty MSC donors for their chondrogenic potential after 28 days of differentiation

(A) Alcian Blue stain for GAG of two representative donors of each group: intensity of staining is decreasing from donors with high chondrogenic potential to donors with moderate and low chondrogenic potential (B) Gene expression levels of the chondrogenic genes ACAN, COL2A1 and COL10A1 were assessed using qPCR analysis in good and bad responders. Data represent the three donors in the performing performing group, nine donors in the moderate group and eight donors in the low performing group +/- SD. (C) GAG levels as overview for all twenty donors: donors with high chondrogenic potential demonstrate distinct quantitative GAG levels compared to moderate and low performers, quantitative GAG levels do not distinguish moderate from low performing donors . The average measure of three different pellets per donor $+/$ - SD is illustrated. 
chondrogenic potential show distinct quantitative GAG levels from moderate and low performers (Fig. 4.1C). Histologically assessed GAG levels did not distinguish moderate from low performing donors (Fig 4.1C).

\subsection{2 microarray mRNA analysis reveals limited seperation of different chondrogenic groups}

Overall differences in global gene expression levels between the 20 donors were small. For better seperation of the donor groups mRNA levels of donors with high chondrogenic potential $(n=3)$ and donors with the lowest chondrogenic potential $(n=3)$ were compared. The statistical evaluation revealed only marginal differences in global gene expression levels between the two groups (Figure S4.2). STRING network analysis of genes with a minimal 0.5 fold up-regulation in donors with high chondrogenic potential compared to poor performing donors demonstrated that networks are associated with transcriptional regulation and signal transduction. Members of the major network include a transcriptional factor modulating chondrogenesis: basic helix loop-helix family member E40 (BHLHE40) [27]. Furthermore, several proteins regulating transcriptional activity, such as activating transcription factor 3 (ATF3), nuclear receptor group 4A2 (NR4A2), MAFB transcription factor, FOSB and FOS were identified. All of these regulators are involved in signal transduction, cell proliferation and differntiation [28] (Fig 4.2A). On the contrary network analysis of genes with a minimal 0.5 fold up-regulation in donors with low chondrogenic potential compared to donors with high chondrogenic potential revealed that major networks are associated with transcripts of extracellular matrix proteins like ACAN, COL4A1, TIMP3, EFEMP1 and a network of signalling proteins (JAG1, dickkopf-related protein 1 (DKK1), and tumor-necrosis factor receptor superfamily member 11B (TNFRSFB11) as well known as osteoprotegerin (Fig 4.2B). By using the ingenuity pathway analysis software the top ten differentially regulated cellular functions between the 3 best and the three poorest performing donors were identified. The differentially expressed pathways were linked to cellular growth, proliferation, survival and development (Fig 4.2C). TGF $\beta 1$ was identified as a major upstream contributor to the differentially regulated genes between donors with high and low chondrogenic potential (Fig 4.2D).

\subsubsection{Differential expression of miRNAs between groups with distinct chondrogenic potential}

The expression of previously identified miRNAs known to be involved in chondrogenesis was evaluated before chondrogenesis and at day seven of chondrogenic pellet culture. miRNA levels of donors with high chondrogenic potential $(n=3)$ were compared with donors with low chondrogenic potential $(\mathrm{n}=3)$. miR-30b and -221, which are known to negatively influence osteoblast and chondrocyte differentiation display a higher expression in good donors before the onset of chondrogenesis (fold upregulation good donor/ low donor: miR-30b: 1,63, miR-221: 1,83). Both miRs were strongly down-regulated during chondrogenic differentiation (fold down-regulation day 0 / day 7: miR-30b: 4,10, miR-221: 7,86). In contrast lower or no down- 
A

higher levels in donors with high chondrogenic potential

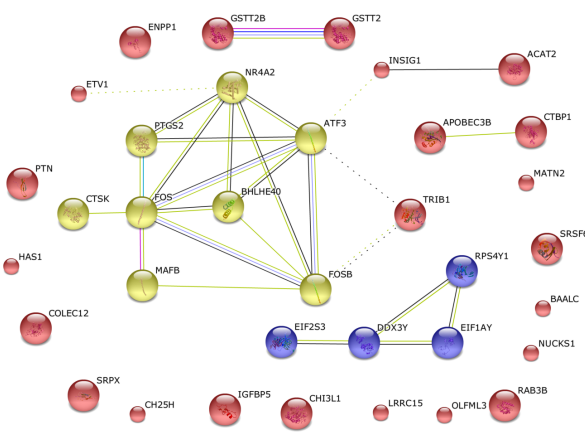

C

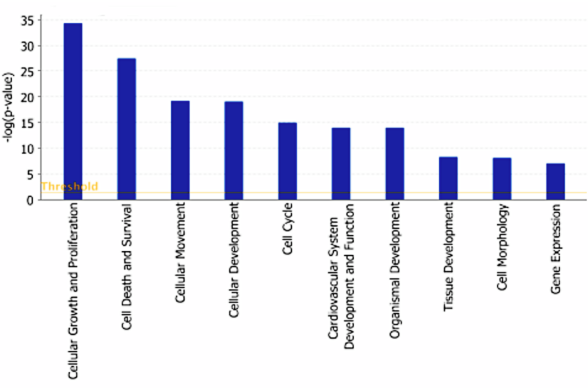

higher levels in donors with low chondrogenic potential

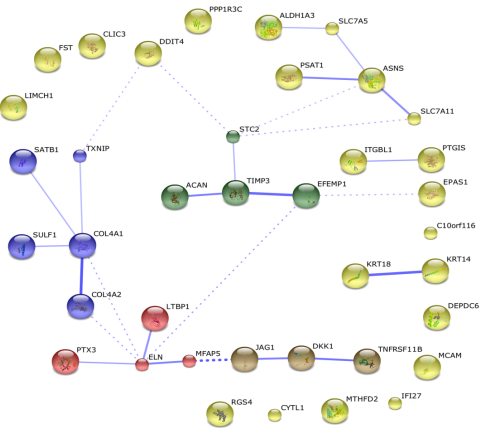

D

\begin{tabular}{|c|c|}
\hline Upstream Regulator & Molecule Type \\
\hline TGFB1 & growth factor \\
\hline TP53 & transcription regulator \\
\hline ERBB2 & kinase \\
\hline E2F4 & transcription regulator \\
\hline PGR & ligand-dependent nuclear receptor \\
\hline PDGF BB & complex \\
\hline TP63 & transcription regulator \\
\hline SMARCA4 & transcription regulator \\
\hline E2F1 & transcription regulator \\
\hline FSH & complex \\
\hline \multicolumn{2}{|c}{} \\
\hline
\end{tabular}

Figure 4.2: Microarray mRNA comparison of three good performers vs three bad performers

(A) STRING network analysis of genes with a minimal 0.5 fold up-regulation in donors with high chondrogenic potential compared to poor performing donors demonstrated that networks are associated with transcriptional regulation and signal transduction: basic helix loop-helix family member E40 (BHLHE40), activating transcription factor 3 (ATF3), nuclear receptor group 4A2 (NR4A2), MAFB transcription factor, FOSB, FOS. (B) STRING network analysis of genes with a minimal 0.5 fold up-regulation in donors with low chondrogenic potential compared to donors with good chondrogenic potential reveals that major networks are associated with transcripts of extracellular matrix proteins like: ACAN, COL4A1, TIMP3, EFEMP1 and a network of signalling proteins ( $J A G 1$, dickkopf-related protein 1 (DKK1), and tumor-necrosis factor receptor superfamily member 11B (TNFRSFB11/ osteoprotegerin). (C) Ingenuity pathway analysis software of the top ten differentially regulated cellular functions between the three best and the three poorest performing donors. (D) TGF $\beta 1$ was identified as a major upstream contributor to the differentially regulated genes between donors with high and low chondrogenic potential. 


\begin{tabular}{|c|c|c|c|}
\hline miRNA & reported function & References & observed regulation \\
\hline miR-30b & negative regulation of osteoblast differentiation & [29] & higher expressed in good responders at day 0 \\
\hline miR-221 & negative regulation of chondrocyte differentiation & {$[30,31]$} & $\begin{array}{l}\text { higher expressed in good responders at day } 0 \\
\text { down-regulated during differentiation in good responders } \\
\text { no regulation in bad responders }\end{array}$ \\
\hline miR-34a & regulates osteoarthritis pathogenesis & [32] & $\begin{array}{l}\text { higher expressed in good responders at day } 0 \\
\text { up-regulation in bad responders during chondrogenesis }\end{array}$ \\
\hline miR-23b & $\begin{array}{l}\text { potentially upregulated in OA; } \\
\text { negative regulation of TGF } \beta \text { and BMP signalling }\end{array}$ & {$[33,34]$} & $\begin{array}{l}\text { higher in good responders at day } 0 \\
\text { up-regulation in bad responders during chondrogenesis }\end{array}$ \\
\hline miR-26 & $\begin{array}{l}\text { mediates cholesterol metabolism; } \\
\text { hypoxic upregulation }\end{array}$ & {$[35,36]$} & $\begin{array}{l}\text { higher expressed in good responders at day } 0 \\
\text { up-regulation in bad responders during chondrogenesis }\end{array}$ \\
\hline miR-181 & $\begin{array}{l}\text { regulation of TGF } \beta \text { signalling in chondrocytes; } \\
\text { downregulation during chondrogenesis; } \\
\text { hypoxic upregulation }\end{array}$ & {$[36-38]$} & $\begin{array}{l}\text { higher expressed in good responders at day } 0, \\
\text { up-regulation in bad responders during chondrogenesis }\end{array}$ \\
\hline miR-210 & $\begin{array}{l}\text { upregulation during chondrogenesis } \\
\text { cell survival of MSCs } \\
\text { hypoxic upregulation }\end{array}$ & {$[20,31,36]$} & up-regulation in both donor groups during chondrogenesis \\
\hline miR-630 & activation of TGF $\beta$ signalling in chondrocytes & {$[37]$} & $\begin{array}{l}\text { up-regulation during differentiation } \\
\text { higher up-regulation in good responders }\end{array}$ \\
\hline $\mathrm{miR}-140$ & $\begin{array}{l}\text { positive regulation of chondrogenesis } \\
\text { negative regulation of } \mathrm{HDAC} 4 \text { (histone deacetylase) } \\
\text { regulation of } \mathrm{OA} \text { pathogenesis and endochondral bone formation }\end{array}$ & {$[39-41]$} & $\begin{array}{l}\text { higher expressed in good responders; decreased during } \\
\text { chondrogenesis }\end{array}$ \\
\hline miR-145 & $\begin{array}{l}\text { negatively regulates chondrogenesis by targeting SOX9 } \\
\text { downregulation during chondrogenesis }\end{array}$ & {$[31,38,42]$} & $\begin{array}{l}\text { higher expressed in good responders; decreased during } \\
\text { chondrogenesis }\end{array}$ \\
\hline
\end{tabular}

Table 4.3: microRNAs used in the miRNA profiling of good and bad responders

Each miRNA is reported with the assigned function as well as the regulation of its expression during a seven days differentiation period.

regulation was observed in low chondrogenic donors (fold down-regulation day 0 / day 7: $m i R$-30b: 0,94, miR-221: 2,72).

The miRNAs -34a, -23b, -26, -181 were higher expressed in donors with good chondrogenic potential before the onset of chondrogenesis (fold up-regulation good donor/ low donor : miR-34a: 2,46, miR-23b: 1,25, miR-26: 1,54, miR-181: 1,15). These miRNAs were downregulated during differentiation (fold down-regulation day 0 / day 7: miR-34a: 3,70, miR-23b: 1,67, miR-26: 1,20, miR-181: 1,10). Remarkably, while their expression in poor performing donors was lower compared to good performing donors before the onset of chondrogenic differentiation, their expression was upregulated during differentiation (fold up-regulation day $0 /$ day 7: miR-34a: 1,90, miR-23b: 1,30, miR-26: 1,60, miR-181: 1,39). miR-34a and -23b are known to negatively influence cartilage homeostasis and/or chondrogenic differentiation. $m i R$ 630 , a positive regulator of chondrogenesis, and $m i R$-210, a marker of the hypoxic cell response, are up-regulated during chondrogenesis (fold up-regulation day 0 / day 7: good donors miR-630: 1,99, miR-210: 14,14; low donors: miR-630: 3,52, miR-210: $21,93)$. The negative regulators of chondrogenesis ( $m i R-140,-145$ and let-7e) are downregulated during the differentiation process and display only minor differences between the different groups (Fig 4.3, Table 4.3). 


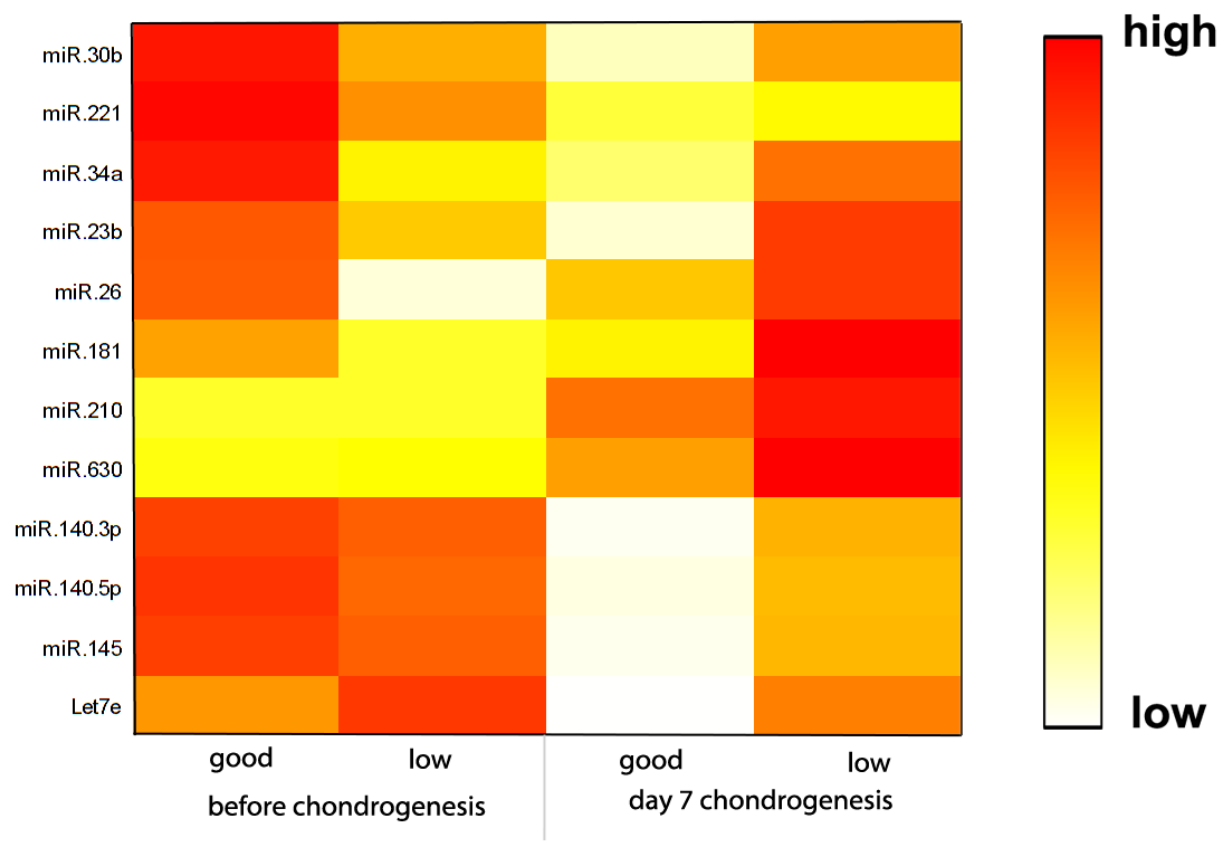

Figure 4.3: miRNA level regulation of good performing compared with low performing donors

Expression of miRNAs known to be involved in chondrogenesis was evaluated before chondrogenesis and at day seven of chondrogenic pellet culture. miRNA levels of donors with high chondrogenic potential $(\mathrm{n}=3)$ were compared with donors with low chondrogenic potential $(\mathrm{n}=3) \cdot m i R-30,-221,34 a,-236,-26$ and -181 display a higher expression in good donors before the onset of chondrogenesis and were strongly down-regulated during chondrogenic differentiation. miR-630 and miR-210 are upregulated during chondrogenesis. Negative regulators of chondrogenesis miR-140, -145 and let-7e are downregulated during the differentiation process in good and bad responders. Data represents the mean of three independent human MSC donors. 


\subsection{Discussion}

By comparison of the chondrogenic differentiation potential of twenty human MSC donors we are the first to show that only about $15 \%$ of MSC donors have the natural capability to undergo efficient chondrogenic differentiation ex vivo. Chondrogenic differentiation was mainly marked by increased GAG deposition, better histological cartilage formation including chondron formation and limited fibrogenous cartilage formation as well as the significantly higher mRNA expression of $A C A N$ and COL2A1. In previous studies, research groups mainly focused on the osteogenic differentiation of MSC donors, in which only differences in differentiation potential were noticed and no scoring was done. Differences in performances were shown to be independent of donor age, gender, and source of isolation [9, 44]. In this setup we tested if donors with high chondrogenic potential could be identified in a pool of donors based on their global gene expression profile determined by microarray mRNA before the onset of the differentiation experiment. Groups separated with a maximum 1.6-fold change in transcript expression levels (Fig S4.2). Donors with high chondrogenic potential showed increased expression of mRNAs involved in transcriptional processes although overall differences were small. Two examples of the major network generated with STRING are the basic helix loop-helix family member E40 (BHLHE4O) as a transcriptional factor modulating chondrogenesis [27] and the transcription factor FOS, which is involved in signal transduction, cell proliferation and differentiation [45] (Fig $4.2 \mathrm{~A})$. FOS belongs to a group of leucine zipper proteins that dimerize with the JUN family and thereby form the transcription complex AP-1. The activation of AP-1 has been described to be involved in the progress of terminal chondrocyte differentiation as well as in the homeostasis of MMP13 expression [46]. The tight regulation of this transcription factor can thereby have an impact on MSCs chondrogenic performance. On the contrary, donors with low chondrogenic potential mainly revealed higher expression of matrix associated proteins. Interestingly, the genes being differently regulated in-between donor with high and low chondrogenic potential lead to the identification of TGF $\beta 1$ as top upstream regulator. The TGF $\beta$-family is involved in embryonic development as well as in cartilaginous matrix formation [47]. This suggests that differences in TGF $\beta$-responsiveness of MSC donors might lead to distinct chondrogenic performance of MSCs. This is relevant since exogenous added TGF $\beta$ is the main driver of chondrogenic differentiation in MSC pellet cultures. Nevertheless, this study as well as previous studies demonstrate that the separation of MSC donors according to their chondrogenic differentiation potential on the basis of global mRNA expression levels is limited due to the marginal differences in gene expression levels [17].

In this study, we broadened our findings to epigenetic analysis by including expression levels of miRNAs known to be associated with chondrogenic differentiation. miRNA levels were evaluated before differentiation and at day seven of chondrogenic pellet culture. Selected miRNAs show distinct separation between good donors and bad responders before differentiation. We selected miR-210, miR-630 and miR-140 as positive regulators of chondrogenesis [37, 39-41]. We confirmed the positive regulation of $m i R$-210 and miR-630 after seven days of chondrogenesis with miR-630 
being slightly higher expressed in good donors. Bakhshandeh et al. were the first to describe $m i R-630$ as a miRNA with a clear chondrogenic signature [37]. TargetScan (http://genes.mit.edu/targetscan) was used to find putative targets of miR-630 and revealed ERBB signaling, gap junction communication, MAP-Kinase signaling and TGF $\beta$ signaling as regulated pathways. Both MAP-Kinase/Erk signaling as well as TGF $\beta$-signaling have been reported before to be strongly involved in the onset of chondrogenic differentiation $[48,49]$. The use of the TGF $\beta$ in the presented seven-day chondrogenic pellet culture model is assumed to have an influence on the up-regulation of these pathways. In contrast, $m i R-181$ and $m i R-34 a$ which are negative regulators of chondrogenesis, were up-regulated during differentiation in low performing donors. $m i R-181$ acts as a negative regulator of the TGF $\beta$ pathway [37], whereas $m i R-34 a$ has been described to disturb cartilage homeostasis by inducing apoptosis, cell cycle arrest and senescence while targeting for E2F3, cyclin E2, CDK6 and others [32, 50]. These findings indicate that both miR-181 and miR-34a can be further markers to separate good performing donors from low performing donors. MSCs. Interestingly, modulation of TGF $\beta$ responsiveness appears to be a common denominator in both the observed differences in mRNA expression profiles and the differences in miRNA expression between good and bad responders. Although more studies are warranted, these data suggests that the responsiveness of an MSC donor to TGF $\beta$ signaling may explain at least part of the observed differences in chondrogenic potential of MSC donors.

We prove that miRNA profiling of MSC donors offers a therapeutic chance to link MSC donors to their chondrogenic differentiation potential. A short pre-clinical differentiation period of seven days can give insight in miRNA regulation during chondrogenesis in comparison to the MSCs natural miRNA expression. Further identification of positive and negative miRNA regulators of chondrogenesis in different donor groups can offer the potential to employ miRNA levels as prognostic markers. Nevertheless, this study gives only implications for prognostic miRNA identification. Further evaluation of the predictive value of miRNA expression for chondrogenic potential of MSCs in a larger donor group as well as their for in vivo chondrogenic potential needs to be performed. 


\section{References}

1. Pittenger, M.F., et al., Multilineage potential of adult human mesenchymal stem cells. Science, 1999. 284(5411): p. 143-7.

2. Baksh, D., R. Yao, and R.S. Tuan, Comparison of proliferative and multilineage differentiation potential of human mesenchymal stem cells derived from umbilical cord and bone marrow. Stem Cells, 2007. 25(6): p. 1384-92.

3. Jones, E.A., et al., Synovial fluid mesenchymal stem cells in health and early osteoarthritis: detection and functional evaluation at the single-cell level. Arthritis Rheum, 2008. 58(6): p. 1731-40.

4. Koelling, S., et al., Migratory chondrogenic progenitor cells from repair tissue during the later stages of human osteoarthritis. Cell Stem Cell, 2009. 4(4): p. 324-35.

5. Farre-Guasch, E., et al., Buccal fat pad, an oral access source of human adipose stem cells with potential for osteochondral tissue engineering: an in vitro study. Tissue Eng Part C Methods, 2010. 16(5): p. 1083-94.

6. Tallone, T., et al., Adult human adipose tissue contains several types of multipotent cells. J Cardiovasc Transl Res, 2011. 4(2): p. 200-10.

7. Leijten, J.C., et al., Cell Sources for Articular Cartilage Repair Strategies: Shifting from Monocultures to Cocultures. Tissue Eng Part B Rev, 2012.

8. Estes, B.T., et al., Isolation of adipose-derived stem cells and their induction to a chondrogenic phenotype. Nat Protoc, 2010. 5(7): p. 1294-311.

9. Siddappa, R., et al., Donor variation and loss of multipotency during in vitro expansion of human mesenchymal stem cells for bone tissue engineering. J Orthop Res, 2007. 25(8): p. 1029-41.

10. Phinney, D.G., et al., Donor variation in the growth properties and osteogenic potential of human marrow stromal cells. J Cell Biochem, 1999. 75(3): p. 424-36. 11. Tokalov, S.V., et al., A number of bone marrow mesenchymal stem cells but neither phenotype nor differentiation capacities changes with age of rats. Mol Cells, 2007. 24(2): p. 255-60.

12. Tokalov, S.V., et al., Age-related changes in the frequency of mesenchymal stem cells in the bone marrow of rats. Stem Cells Dev, 2007. 16(3): p. 439-46.

13. Gallay, S.H., et al., Relationship of donor site to chondrogenic potential of periosteum in vitro. J Orthop Res, 1994. 12(4): p. 515-25.

14. De Bari, C., F. Dell'Accio, and F.P. Luyten, Human periosteum-derived cells maintain phenotypic stability and chondrogenic potential throughout expansion regardless of donor age. Arthritis Rheum, 2001. 44(1): p. 85-95.

15. Vacanti, V., et al., Phenotypic changes of adult porcine mesenchymal stem cells induced by prolonged passaging in culture. J Cell Physiol, 2005. 205(2): p. 194-201.

16. Tan, Q., P.P. Lui, and Y.F. Rui, Effect of In Vitro Passaging on the Stem Cell-Related Properties of Tendon-Derived Stem Cells-Implications in Tissue Engineering. Stem Cells Dev, 2011.

17. Jansen, B.J., et al., Functional differences between mesenchymal stem cell populations are reflected by their transcriptome. Stem Cells Dev, 2010. 19(4): p. 481-90.

18. Zou, Z., et al., More insight into mesenchymal stem cells and their effects inside the body. Expert Opin Biol Ther, 2010. 10(2): p. 215-30.

19. Tome, M., et al., miR-335 orchestrates cell proliferation, migration and differentiation in human mesenchymal stem cells. Cell Death Differ, 2011. 18(6): p. 985-995.

20. Nie, Y., et al., Identification of MicroRNAs involved in hypoxia- and serum deprivation-induced apoptosis in mesenchymal stem cells. Int J Biol Sci, 2011. 7(6): p. 762-8.

21. Laine, S.K., et al., MicroRNAs miR-96, miR-124, and miR-199a regulate gene expression in human bone marrow-derived mesenchymal stem cells. J Cell Biochem, 2012. 113(8): p. 2687-95.

22. Both, S.K., et al., A rapid and efficient method for expansion of human mesenchymal stem cells. Tissue Eng, 2007. 13(1): p. 3-9.

23. Wu, L., et al., Trophic effects of mesenchymal stem cells increase chondrocyte proliferation and matrix formation. Tissue Eng Part A, 2011. 17(9-10): p. 1425-36.

24. Wettenhall, J.M. and G.K. Smyth, limmaGUI: a graphical user interface for linear modeling of microarray data. Bioinformatics (Oxford, England), 2004. 20: p. 3705-6.

25. Szklarczyk, D., et al., The STRING database in 2011: functional interaction networks of proteins, globally integrated and scored. Nucleic Acids Res, 2011. 39(Database issue): p. D561-8.

26. Hassan, M.Q., et al., miR-218 Directs a Wnt Signaling Circuit to Promote Differentiation of 
Osteoblasts and Osteomimicry of Metastatic Cancer Cells. The Journal of biological chemistry, 2012. 287(50): p. 42084-92.

27. Shen, M., et al., Molecular characterization of the novel basic helix-loop-helix protein DEC1 expressed in differentiated human embryo chondrocytes. Biochemical and Biophysical Research Communications, 1997. 236(2): p. 294-8.

28. Muller, R. and E.F. Wagner, Differentiation of F9 teratocarcinoma stem cells after transfer of c-fos proto-oncogenes. Nature, 1984. 311(5985): p. 438-42.

29. Wu, T., et al., miR-30 family members negatively regulate osteoblast differentiation. J Biol Chem, 2012. 287(10): p. 7503-11.

30. Kim, D., J. Song, and E.J. Jin, MicroRNA-221 regulates chondrogenic differentiation through promoting proteosomal degradation of slug by targeting Mdm2. The Journal of biological chemistry, 2010. 285(35): p. 26900-7.

31. Karlsen, T.A., A. Shahdadfar, and J.E. Brinchmann, Human primary articular chondrocytes, chondroblasts-like cells, and dedifferentiated chondrocytes: differences in gene, microRNA, and protein expression and phenotype. Tissue engineering. Part C, Methods, 2011. 17(2): p. 219-27.

32. Abouheif, M.M., et al., Silencing microRNA-34a inhibits chondrocyte apoptosis in a rat osteoarthritis model in vitro. Rheumatology, 2010. 49(11): p. 2054-60.

33. Rogler, C.E., et al., MicroRNA-23b cluster microRNAs regulate transforming growth factorbeta/bone morphogenetic protein signaling and liver stem cell differentiation by targeting Smads. Hepatology, 2009. 50(2): p. 575-84.

34. Goldring, M.B. and K.B. Marcu, Epigenomic and microRNA-mediated regulation in cartilage development, homeostasis, and osteoarthritis. Trends Mol Med, 2012. 18(2): p. 109-18.

35. Sun, D., et al., MiR-26 controls LXR-dependent cholesterol efflux by targeting ABCA1 and ARL7. FEBS letters, 2012. 586(10): p. 1472-9.

36. Kulshreshtha, R., et al., A microRNA signature of hypoxia. Mol Cell Biol, 2007. 27(5): p. 1859-67.

37. Bakhshandeh, B., et al., A microRNA signature associated with chondrogenic lineage commitment. Journal of genetics, 2012. 91(2): p. 171-82.

38. Sorrentino, A., et al., Isolation and characterization of CD146+ multipotent mesenchymal stromal cells. Experimental hematology, 2008. 36(8): p. 1035-46.

39. Tuddenham, L., et al., The cartilage specific microRNA-140 targets histone deacetylase 4 in mouse cells. FEBS Lett, 2006. 580(17): p. 4214-7.

40. Nicolas, F.E., et al., mRNA expression profiling reveals conserved and non-conserved miR-140 targets. RNA Biol, 2011. 8(4): p. 607-15.

41. Tardif, G., et al., Regulation of the IGFBP-5 and MMP-13 genes by the microRNAs miR-140 and miR-27a in human osteoarthritic chondrocytes. BMC musculoskeletal disorders, 2009. 10: p. 148.

42. Yang, B., et al., MicroRNA-145 regulates chondrogenic differentiation of mesenchymal stem cells by targeting Sox9. PLoS One, 2011. 6(7): p. e21679.

43. Koh, W., et al., Analysis of deep sequencing microRNA expression pr ofile from human embryonic stem cells derived mesenchymal stem cells reveals possible role of let- 7 microRNA family in downstream targeting of hepatic nuclear factor 4 alpha. Bmc Genomics, 2010. 11 Suppl 1: p. S6. 44. Phinney, D.G., et al., Donor variation in the growth properties and osteogenic potential of human marrow stromal cells. Journal of cellular biochemistry, 1999. 75(3): p. 424-36.

45. Van Beveren, C., et al., Expression of the c-fos gene during differentiation. Advances in experimental medicine and biology, 1987. 213: p. 263-74.

46. Ijiri, K., et al., A novel role for GADD45beta as a mediator of MMP-13 gene expression during chondrocyte terminal differentiation. The Journal of biological chemistry, 2005. 280(46): p. 3854455 .

47. Loveridge, N., et al., The control of chondrocyte differentiation during endochondral bone growth in vivo: changes in TGF-beta and the proto-oncogene c-myc. Journal of cell science, 1993. 105 ( Pt 4): p. $949-56$

48. Jin, E.J., et al., Wnt-5a is involved in TGF-beta3-stimulated chondrogenic differentiation of chick wing bud mesenchymal cells. The international journal of biochemistry \& cell biology, 2006. 38(2): p. 183-95.

49. Papachristou, D.J., et al., JNK/ERK-AP-1/Runx2 induction "paves the way" to cartilage load- 
ignited chondroblastic differentiation. Histochemistry and cell biology, 2005. 124(3-4): p. 215-23.

50. He, L., et al., A microRNA component of the p53 tumour suppressor network. Nature, 2007. 447(7148): p. 1130-4. 


\section{Supplemental Figures}
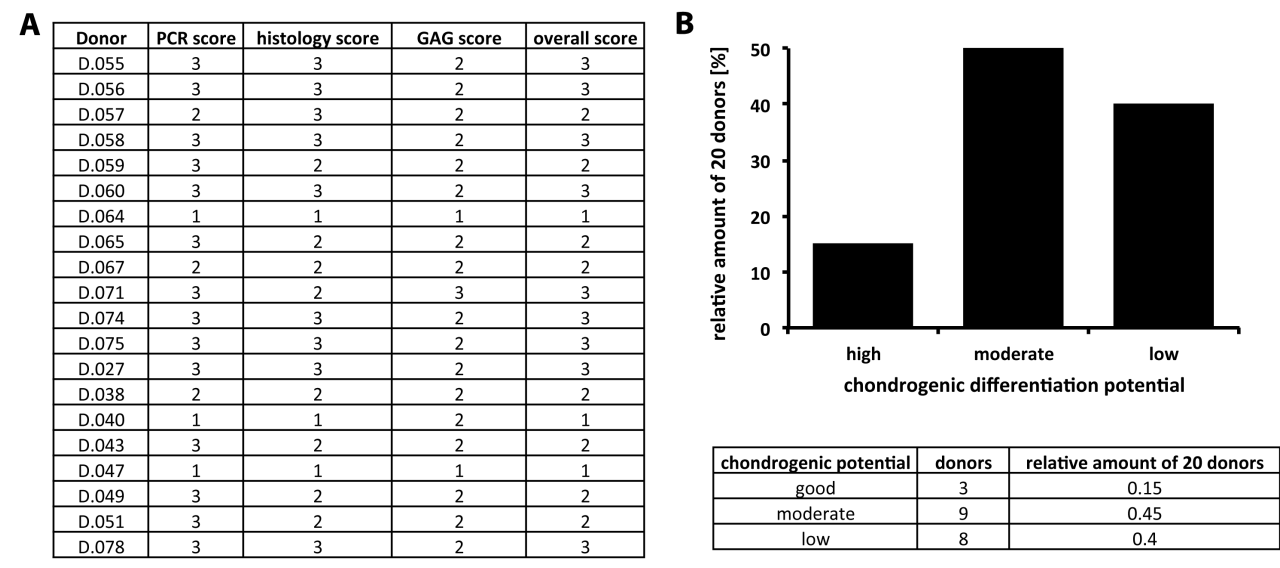

Figure S4.1: Scoring of twenty donors according to their chondrogenic potential

(A) Scoring was done using mRNA expression levels of chondrogenic marker genes (positive judgement for high expression of ACAN, COL2A1, FRZB and SOX9; low expression of COL10A1, COL1A1). Histological scoring was done by three independent individuals based on amount of positive Alcian Blue stain as well as histological appearance of the cartilage matrix. For GAG scoring, donors were separated into high levels, moderate levels and no level of GAG expression. (B) Based on the overall score the percentage of donors in each group was plotted, data for (B) was based on table in $(\mathrm{C})$. 


\begin{tabular}{|c|c|c|c|}
\hline Symbol & Entrez Gene Name & Log Ratio & p-value \\
\hline CHI3L1 & chitinase 3-like 1 (cartilage glycoprotein-39) & 1,654 & $4,81 \mathrm{E}-02$ \\
\hline RPS4Y1 & ribosomal protein $\mathrm{S} 4, \mathrm{Y}$-linked 1 & 1,390 & $2,16 \mathrm{E}-01$ \\
\hline TRIB1 & tribbles homolog 1 (Drosophila) & 1,024 & $4,31 \mathrm{E}-02$ \\
\hline GAS1 & growth arrest-specific 1 & 0,941 & $2,21 \mathrm{E}-02$ \\
\hline SRSF6 & serine/arginine-rich splicing factor 6 & 0,935 & $3,54 \mathrm{E}-03$ \\
\hline COLEC12 & collectin sub-family member 12 & 0,925 & $1,35 \mathrm{E}-01$ \\
\hline HES1 & hairy and enhancer of split 1, (Drosophila) & 0,915 & $3,55 \mathrm{E}-02$ \\
\hline PTGS2 & prostaglandin-endoperoxide synthase 2 & 0,879 & $7,52 \mathrm{E}-02$ \\
\hline LRRC15 & leucine rich repeat containing 15 & 0,850 & $1,58 \mathrm{E}-01$ \\
\hline CTSK & cathepsin K & 0,835 & $5,46 \mathrm{E}-02$ \\
\hline NR4A2 & nuclear receptor subfamily 4 , group $\mathrm{A}$, member 2 & 0,834 & $1,16 \mathrm{E}-01$ \\
\hline ENPP1 & ectonucleotide pyrophosphatase/phosphodiesterase 1 & 0,793 & $4,88 \mathrm{E}-02$ \\
\hline $\mathrm{CH} 25 \mathrm{H}$ & cholesterol 25-hydroxylase & 0,785 & $8,53 \mathrm{E}-02$ \\
\hline BAALC & brain and acute leukemia, cytoplasmic & 0,782 & $3,07 \mathrm{E}-02$ \\
\hline FOS & FBJ murine osteosarcoma viral oncogene homolog & 0,763 & $2,17 \mathrm{E}-01$ \\
\hline IGFBP5 & insulin-like growth factor binding protein 5 & 0,705 & $3,56 \mathrm{E}-03$ \\
\hline HAS1 & hyaluronan synthase 1 & 0,703 & $1,01 \mathrm{E}-01$ \\
\hline TNC & tenascin $\mathrm{C}$ & 0,696 & $3,37 \mathrm{E}-02$ \\
\hline SRPX & sushi-repeat containing protein, $\mathrm{X}$-linked & 0,660 & $8,02 \mathrm{E}-03$ \\
\hline CTBP1 & C-terminal binding protein 1 & 0,649 & $1,07 \mathrm{E}-01$ \\
\hline EIF1AY & eukaryotic translation initiation factor $1 \mathrm{~A}, \mathrm{Y}$-linked & 0,647 & $2,06 \mathrm{E}-01$ \\
\hline BHLHE40 & basic helix-loop-helix family, member e 40 & 0,637 & $8,87 \mathrm{E}-02$ \\
\hline RAB3B & RAB3B, member RAS oncogene family & 0,612 & $2,46 \mathrm{E}-02$ \\
\hline GSTT2/GSTT2B & glutathione $\mathrm{S}$-transferase theta 2 & 0,607 & $1,52 \mathrm{E}-03$ \\
\hline ETV1 & ets variant 1 & 0,584 & $2,30 \mathrm{E}-02$ \\
\hline FBN2 & fibrillin 2 & 0,583 & $2,25 \mathrm{E}-01$ \\
\hline MATN2 & matrilin 2 & 0,580 & $7,64 \mathrm{E}-03$ \\
\hline MAFB & v-maf musculoaponeurotic fibrosarcoma oncogene homolog B (avian) & 0,566 & $5,12 \mathrm{E}-02$ \\
\hline DDX3Y & DEAD (Asp-Glu-Ala-Asp) box polypeptide 3, Y-linked & 0,558 & $2,96 \mathrm{E}-01$ \\
\hline FOSB & FBJ murine osteosarcoma viral oncogene homolog B & 0,550 & $2,10 \mathrm{E}-01$ \\
\hline OLFML3 & olfactomedin-like 3 & 0,548 & $9,79 \mathrm{E}-02$ \\
\hline ATF3 & activating transcription factor 3 & 0,544 & $1,43 \mathrm{E}-01$ \\
\hline INSIG1 & insulin induced gene 1 & 0,536 & $1,82 \mathrm{E}-01$ \\
\hline PTN & pleiotrophin & 0,532 & $5,33 \mathrm{E}-03$ \\
\hline NUCKS1 & nuclear casein kinase and cyclin-dependent kinase substrate 1 & 0,527 & $2,96 \mathrm{E}-02$ \\
\hline APOBEC3B & apolipoprotein B mRNA editing enzyme, catalytic polypeptide-like 3B & 0,524 & $3,67 \mathrm{E}-03$ \\
\hline ACAT2 & acetyl-CoA acetyltransferase 2 & 0,524 & $3,96 \mathrm{E}-02$ \\
\hline EIF2S3 & eukaryotic translation initiation factor 2 , subunit 3 gamma, $52 \mathrm{kDa}$ & 0,513 & $8,23 \mathrm{E}-02$ \\
\hline PTX3 & pentraxin 3 , long & $-0,500$ & $4,03 \mathrm{E}-01$ \\
\hline CNN1 & calponin 1 , basic, smooth muscle & $-0,504$ & $1,78 \mathrm{E}-02$ \\
\hline ITGBL1 & integrin, beta-like 1 (with EGF-like repeat domains) & $-0,516$ & $7,01 \mathrm{E}-02$ \\
\hline TXNIP & thioredoxin interacting protein & $-0,517$ & $8,55 \mathrm{E}-02$ \\
\hline CYTL1 & cytokine-like 1 & $-0,517$ & $4,11 \mathrm{E}-01$ \\
\hline MCAM & melanoma cell adhesion molecule & $-0,519$ & $9,54 \mathrm{E}-02$ \\
\hline TIMP3 & TIMP metallopeptidase inhibitor 3 & $-0,520$ & $4,11 \mathrm{E}-02$ \\
\hline IFI27 & interferon, alpha-inducible protein 27 & $-0,521$ & $1,71 \mathrm{E}-01$ \\
\hline FST & follistatin & $-0,530$ & $2,23 \mathrm{E}-01$ \\
\hline MFAP5 & microfibrillar associated protein 5 & $-0,532$ & $1,21 \mathrm{E}-01$ \\
\hline FHL1 & four and a half LIM domains 1 & $-0,535$ & $6,07 \mathrm{E}-02$ \\
\hline JAG1 & jagged 1 & $-0,549$ & $2,32 \mathrm{E}-01$ \\
\hline ACAN & aggrecan & $-0,565$ & $8,00 \mathrm{E}-02$ \\
\hline KRT18 & keratin 18 & $-0,565$ & $4,25 \mathrm{E}-01$ \\
\hline LTBP1 & latent transforming growth factor beta binding protein 1 & $-0,567$ & $1,19 \mathrm{E}-02$ \\
\hline EPAS1 & endothelial PAS domain protein 1 & $-0,571$ & $4,00 \mathrm{E}-02$ \\
\hline SLC7A11 & solute carrier family, member 11 & $-0,573$ & $6,99 \mathrm{E}-02$ \\
\hline DDIT4 & DNA-damage-inducible transcript 4 & $-0,592$ & $1,80 \mathrm{E}-01$ \\
\hline ASNS & asparagine synthetase (glutamine-hydrolyzing) & $-0,600$ & $1,83 \mathrm{E}-01$ \\
\hline LIMCH1 & LIM and calponin homology domains 1 & $-0,600$ & $1,12 \mathrm{E}-01$ \\
\hline EFEMP1 & EGF containing fibulin-like extracellular matrix protein 1 & $-0,602$ & $3,69 \mathrm{E}-02$ \\
\hline MTHFD2 & $\begin{array}{l}\text { methylenetetrahydrofolate dehydrogenase (NADP+ dependent) } 2 \text {, } \\
\text { methenyltetrahydrofolate cyclohydrolase }\end{array}$ & $-0,607$ & $4,80 \mathrm{E}-02$ \\
\hline C10orf116 & chromosome 10 open reading frame 116 & $-0,617$ & $3,85 \mathrm{E}-02$ \\
\hline
\end{tabular}

Table S4.1: Microarray mRNA comparison of three good performers vs three bad performers at passage 2 of cell expansion without the use of chondrogenic induction media

Only genes with at least 0.5 -fold difference are listed. 


\section{Chapter 5}

\section{Epigenetic changes associate with improved performance of MSCs expanded in hypoxia}

Nicole Georgi, Hanna Taipaleenmaki, Jeroen Leijten, Clemens van Blitterswijk, Janine N. Post, Andre van Wijnen and Marcel Karperien

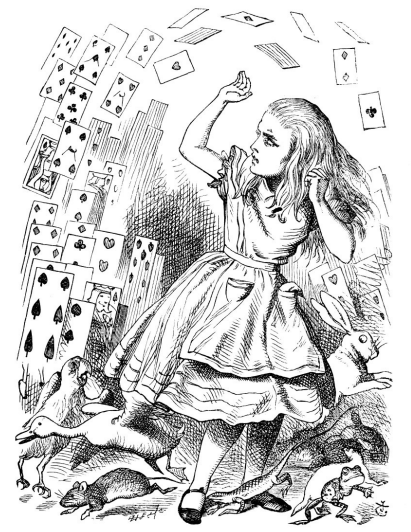




\begin{abstract}
Multipotent mesenchymal stromal/stem cells (MSCs) are a heterogeneous cell source that rapidly looses its self-renewal and differentiation potential during conventional ex vivo expansion. In this study we used hypoxic culture expansion $\left(2.5 \% \mathrm{O}_{2}\right)$ compared to normoxic cell culture expansion $\left(21 \% \mathrm{O}_{2}\right)$ to explore hypoxia as environmental factor to overcome limitations of MSC expansion. Next to the investigation of altered cellular performance, we focused on the identification of genetic changes induced by oxygen tensions at passage two and passage seven of cell culture. We identified hypoxic MSC expansion to improve cell proliferation, CD marker panel expression, differentiation potential and to delay cellular senescence. Microarray mRNA analysis revealed mainly changes in genes involving the cellular glucose metabolism and histone related genes. DNA methylation demonstrated major methylation changes introduced by cellular passaging as well as by the two different oxygen tensions when only passage seven cells were compared. Selected miRNA levels were mainly downregulated by cell passaging, but we were able to identify miR-210 and miR-125b as markers for hypoxic expanded MSCs and the senescence-associated miRNAs let- $7 f$ and miR-23 to be higher regulated in normoxic expanded cells. We are thereby the first to link altered performance of MSCs during cellular passaging to a range of genetic markers. Nevertheless, we identified cell passaging as an environmental factor with partially higher impact on cellular performance and genetic changes than reduced oxygen tension. Hypoxic cell expansion can thereby assist in overcoming passaging related limitations, but not eliminate associated changes.
\end{abstract}




\section{$5.1 \quad$ Introduction}

Mesenchymal stromal/stem cells (MSCs) are a multipotent cell source that can be easily harvested from various locations of the body, including amongst others bone marrow, periosteum, synovium, synovial fluid, adipose tissue, bucal fat pad, infrapatellar fat pad and osteoarthritic cartilage [1-6]. MSCs are a heterogeneous cell population, which rapidly lose self-renewal and differentiation potential upon culture expansion. In consequence, the maintenance of their multipotency is greatly influenced by selection criteria and culture conditions in the expansion and the differentiation phase. Criteria for the selection of MSCs are defined by the Society for Cellular Therapy. MSCs are adherent to culture plastic, are CD90 ${ }^{+}, \mathrm{CD}_{105^{+}}, \mathrm{CD} 3^{+}$ positive and HLA-DR ${ }^{-}, \mathrm{CD}_{4}{ }^{-}, \mathrm{CD}^{-} 4^{-}, \mathrm{CD} 11 \mathrm{~b}^{-}, \mathrm{CD}^{-}{ }^{-}$negative and have the ability to differentiate into the adipogenic, osteogenic and chondrogenic lineage [7]. Nevertheless, large inter-donor variation as well as loss of differentiation potential during cell expansion is the general complication encountered during MSCs culture [8]. This is further influenced by culture conditions, methods of harvest and possibly donor age and health [9-11]. It has been suggested that distinct gene expression profiles at the onset of MSC differentiation might reflect their differentiation potential [12]. However, the highly desired markers for differentiation potential of undifferentiated MSCs have so far remained undiscovered. To obtain sufficient cells for therapeutic applications, freshly isolated MSCs are first expanded for several passages. It has been shown that continuous expansion of MSCs has a strong impact on cellular senescence $[13,14]$. The senescence of these expanded MSCs impairs proliferation, multi lineage potency and differentiation potential.

Presently much attention is paid towards optimizing physiological factors to maintain MSCs growth rates as well as their multi-lineage potency during culture expansion. Variations that are currently under investigation include mechanical stress, tissue culture substrate stiffness, coating or chemical composition and tension of various gasses in particular oxygen during incubation [15-17]. In particular expansion or pre-treatment of MSCs under low oxygen tension has shown to improve the growth rate, differentiation potential as well as to delay senescence $[18,19]$. While various groups have shown the beneficial effects of culture expansion of MSCs in hypoxia, the molecular mechanism responsible for this beneficial effect has remained largely elusive. In this study we present a comprehensive side-by-side evaluation of three donors expanded from passage zero (P0) to passage seven (P7) in either hypoxic (2.5\% oxygen) or normoxic (21\% oxygen) culture conditions. Next to the evaluation of proliferation and differentiation potential, we particularly investigated global mRNA expression- and epigenetic changes that may explain the beneficial effect of culture expansion under hypoxic conditions. To our knowledge we are the first to provide such a comprehensive comparison of hypoxic and normoxia expanded MSCs. 


\subsection{Materials and Methods}

\subsubsection{Cell expansion and differentiation}

Local Medical Ethics Committees approved the use of human bone marrow aspirates. Bone marrow from the same donor was split in 2 aliquots and MSCs were selected by plastic adherence in proliferation media ( $\alpha$-MEM, $10 \%$ fetal bovine serum (Lonza, Verviers, Belgium), $0.2 \mathrm{mM}$ ascorbicacid, $2 \mathrm{mM}$ L-glutamine, $100 \mathrm{U} / \mathrm{mL}$ of penicillin, $100 \mathrm{U}$ penicillin $/ \mathrm{mL}, 100 \mathrm{mg} / \mathrm{mL}$ streptomycin, and $1 \mathrm{ng} / \mathrm{mL}$ of basic Fibroblast Growth Factor (Instruchemie, Delfzijl, The Netherlands) in high oxygen (21\%) or low oxygen $(2.5 \%)$ tension. MSCs were expanded for seven passages in respective conditions and counted during passaging. Cell doublings were calculated using the least square fitting method as published before [20]. All data were obtained of three MSC donors. All reagents were purchased from Invitrogen unless otherwise stated. Common chemicals were purchased from Sigma-Aldrich.

\subsubsection{Immunophenotyping of adherence selected MSCs}

To characterize the population of MSCs after selection by adherence in either hypoxia (2.5\% oxygen) or normoxia ( $21 \%$ oxygen), cell-surface marker expression was assessed. MSCs at P0 were harvested by trypsinisation and incubated for 30 min in block buffer (PBS with $5 \%$ BSA and $0.05 \% \mathrm{NaN}_{2}$ ), then incubated with primary antibodies or with isotype control antibodies (CD45, HLA-DR, CD19, CD90/Thy1, Endoglin/CD105, Integrin $\alpha \mathrm{M} / \mathrm{CD} 11 \mathrm{~b}$ from R\&D Systems, CD34 and CD73 from Abcam) diluted in wash buffer (PBS with 1\% BSA and $0.05 \%$ NaN2) for $1 \mathrm{hr}$. Cells were then washed three times with wash buffer and incubated with secondary antibody (anti-mouse IgM or anti-mouse IgG, conjugated with phycoerythrin from R\&D systems) for 30 min. Samples were then washed three times and resuspended in $250 \mu$ l of wash buffer. The percentage of cells expressing each marker and the respective overlays of the histograms (hypoxia vs normoxia) were obtained using FACSCalibur software (Becton Dickinson Immunocytometry Systems).

\subsubsection{Chondrogenic differentiation}

Pellets (250 000 cells) were formed by centrifugation ( $500 \mathrm{rcf}, 5 \mathrm{~min}$ ) in round bottom ultra low attachment 96-wells culture plates and maintained in 2001 chondrogenic differentiation media (Dulbeccos modified Eagles medium supplemented with $40 \mathrm{mg} / \mathrm{mL}$ of proline, $50 \mathrm{mg} / \mathrm{mL}$ ITS-premix, $50 \mathrm{mg} / \mathrm{mL}$ of ascorbic acid, $100 \mathrm{mg} / \mathrm{mL}$ of sodium pyruvate, $100 \mathrm{U}$ penicillin $/ \mathrm{mL}$, and $100 \mathrm{mg} / \mathrm{mL}$ streptomycin, $10 \mathrm{ng} / \mathrm{mL}$ of transforming growth factor- $\beta, 10^{-7} \mathrm{M}$ of dexamethasone) for 4 weeks. Media was changed twice a week.

\subsubsection{Adipogenic differentiation}

MSCs were seeded at a density of 10.000 cells per $\mathrm{cm}^{2}$ in 6 well plates and kept in adipogenic media (Dulbeccos modified Eagles medium supplemented with $10 \%$ FBS 
(Lonza, Verviers, Belgium), $100 \mathrm{U} / \mathrm{ml}$ penicillin, $100 \mathrm{mg} / \mathrm{ml}$ streptomycin (Gibco, 15140-122), $0.2 \mathrm{mM}$ Indomethacin, 0.5 mM IBMX, 10 ${ }^{-6} \mathrm{M}$ dexamethasone, $10 \mathrm{mg} / \mathrm{ml}$ human Insulin) for 21 days. Medium was changed twice a week

\subsubsection{Osteogenic differentiation}

MSCs were seeded at a density of 5.000 cells $/ \mathrm{cm}^{2}$ in 6 well and 96 well plates and kept in osteogenic media $\alpha$-MEM, $10 \%$ foetal bovine serum (Lonza), $2 \mathrm{mM}$ L-glutamin, $0.2 \mathrm{mM}$ ascorbic acid, $100 \mathrm{U} / \mathrm{ml}$ penicillin, $100 \mathrm{mg} / \mathrm{ml}$ streptomycin, $10^{-8} \mathrm{M}$ dexamethasone for 1 week for ALP measurement. To induce calcification, media was supplemented with $0.01 \mathrm{M} \beta$-glycerol phosphate for 28 days. Media was changed twice a week.

\subsubsection{Senescence-associated $\beta$-galactosidase expression (SA- $\beta$ gal)}

P7 hypoxia or normoxia expanded cells were seeded in T25 culture flasks (7.500 cells $/ \mathrm{cm}^{2}$ ) and cultured overnight in respective conditions. To induce lysosomal alkalinization, subconfluent cells were treated with $100 \mathrm{nM}$ bafilomycin A1 for one hour in fresh cell culture medium in respective conditions. Then $33 \mu \mathrm{M}$ di- $\beta$-Dgalactopyranoside $\left(\mathrm{C}_{12} \mathrm{FDG}\right)$ was added and cells were further incubated for 1-2 h. Cells were washed, harvested by trypsinization, resuspend in ice-cold PBS and analyzed with a FACSCalibur (Becton Dickinson Immunocytometry Systems). To estimate relative $\beta$-gal activity a two-parameter display of a green fluorescence histogram was set up where the $\mathrm{y}$-axis indicates cell number and the $\mathrm{x}$ axis indicates $\mathrm{C}_{12}$-fluorescein fluorescence intensity. Cells were compared to P0 of the same MSC donor.

\subsubsection{Staining}

\section{ALP}

To measure ALP activity, cells were washed twice with PBS (Life technologies) and lysed using $100 \mu \mathrm{l}$ of $0.2 \%$ Triton X-100 solution in $100 \mathrm{mM}$ PBS pH 7.8. The lysate was incubated in the dark at RT with CDP-Star substrate (Roche) and allowed to react for $30 \mathrm{~min}$. Luminescence was then measured using a VICTOR luminometer (Perkin Elmer).

\section{Oil Red O}

After 3 weeks of adipogenic differentiation, cells were rinsed with PBS, fixed with $10 \%$ buffered formalin for 10 minutes, washed with $60 \%$ isopropyl alcohol, and incubated for 5 minutes at room temperature in $0.35 \%(\mathrm{w} / \mathrm{v})$ Oil Red $\mathrm{O}$ reagent in $60 \%$ isopropanol solution. Hematoxilin was used as counterstain. Light microscopy pictures were taken with a Nikon Eclipse TE 300. Oil Red O stain was quantified by extraction with 4\% Igepal in isopropanol (1 ml per well) for 15 minutes by shaking at room temperature. Absorbance was measured at $540 \mathrm{~nm}$. Level of adipogenesis is expressed as fold induction in comparison to basic media treated wells. 


\begin{tabular}{|c|l|}
\hline micro-RNA & Primer sequence \\
\hline universal reverse primer & 5'-GACGAGGACTCGAGCTCAAGCT-3' \\
\hline oligodT-adaptor & 5'-GACGAGGACTCGAGCTCAAGCTTTTTTTTTTTTTTTT-3' \\
\hline U6 & 5'CGCAAGGATGACACGCAAATTC-3' \\
\hline miR-23a & 5'- ATCACATTGCCAGGGATTTCC -3' \\
\hline miR-30c & 5'- TGTAAACATCCTACACTCTCAGC -3' \\
\hline Let-7f & 5'- TGAGGTAGTAGATTGTATAGTT -3' \\
\hline miR-140 & 5'- TACCACAGGGTAGAACCACGG -3' \\
\hline miR-137 & 5'- TATTGCTTAAGAATACGCGTAG -3' \\
\hline mir-218 & 5'- TTGTGCTTGATCTAACCATGT -3' \\
\hline miR-210 & 5'- CTGTGCGTGTGACAGCGGCTGA -3' \\
\hline miR-125b & 5'- TCCCTGAGACCCTAACTTGTGA -3' \\
\hline miR-93 & 5'-CTTTGTGCTGTTCGTGCAGGTAG -3' \\
\hline miR-21 & 5'- TAGCTTATCAGACTGATGTTGA -3' \\
\hline miR-199a & 5'-CCCAGTGTTCAGACTACCTGTTC -3' \\
\hline miR-17 & 5'-CAAAGTGCTTACAGTGCAGGTAG -3' \\
\hline & \\
\hline
\end{tabular}

Table 5.1: Primers used in qRT-PCR analysis to identify changes in miRNA expression

\section{Von Kossa}

After washing with PBS cells were fixed with $10 \%$ formalin 10 min at RT. After rinsing with tap water, cells were stained with $5 \% \mathrm{AgNO}_{3}$ in demineralized water for about 15 seconds under mild UV exposure. All samples were exposed for the same time. $\mathrm{AgNO}_{3}$ solution was removed and light microscopy pictures were taken with a Nikon Eclipse TE 300.

\section{Alcian Blue}

Chondrogenic pellets were fixed with $10 \%$ buffered formalin for 15 min and embedded in paraffin using routine procedures. Sections of $5 \mathrm{~m}$ were cut and stained for sulfated glycosaminoglycans (GAGs) with alcian blue $\left(0.5 \%\right.$, in $\mathrm{H}_{2} \mathrm{O}, \mathrm{pH}=1$ adjusted with $\mathrm{HCl}, 30 \mathrm{~min})$ combined with counterstaining of nuclear fast red $(0.1 \%$ in $5 \%$ aluminum sulfate, 5 min). Staining was quantified using Adobe Photoshop with the select colour range tool.

\subsubsection{RNA, DNA, small RNA isolation and qRT-PCR}

Total RNA, DNA and small RNAs were isolated from monolayer culture of passage two (P2) and P7 cells with the AllPrep DNA/RNA/Protein Mini Kit in combination with the RNeasy ${ }^{\circledR}$ MinElute ${ }^{\circledR}$ Cleanup Kit according to the manufacturers protocol (Qiagen). Concentrations of all nucleic acids were measured with the Nanodrop2000. The small RNA fraction cDNA was prepared using revertAid $\mathrm{H}$ minus first strand cDNA synthesis kit (Fermentas). SYBR (N,N-dimethyl-N-[4-[(E)-(3-methyl1,3-benzothiazol-2-ylidene)methyl]-1-phenylquinolin-1-ium-2-yl]-N-propylpropane-1,3diamine) green mRNA qRT-PCR was performed using the primers listed in Table 1. Expression levels were analyzed by qRT-PCR (SYBR Green supermix and iCycler IQ detection system; Bio-Rad) using conventional protocols. 


\subsubsection{Microarray processing}

mRNA was processed and analysed as previously described [21]. In short, NuGEN Ovation PicoSL WTA System kit followed by the Encore BiotinIL module was used to generate biotinylated sscDNA starting from $50 \mathrm{ng}$ total RNA. $750 \mathrm{ng}$ of the obtained samples were hybridized onto the Illumina HumanHT-12 v4 Expression BeadChips. The samples were scanned using the Illumina iScan array scanner. Gene expression profiling was performed using lluminas Genomestudio v. 2010.3 software with the default settings advised by Illumina. The raw fluorescence intensity values were normalized applying quantile normalization. Differential gene expression was analysed using the commercial software package Genespring, version 11.5.1. (Agilent Technologies). Genes with at least 1.5-fold difference being significantly differentially expressed according to an oneway ANOVA with a Benjamini-Hochberg FDR correction and TukeyHSD post hoc test using a cut-off rate of $\mathrm{p}=0.05$ were selected. Changes of gene expression in annotated canonical pathways and bio-functions were visualized using ingenuity pathway analysis software (Ingenuity Systems). The raw and normalized data are deposited in the Gene Expression Omnibus database (http://www.ncbi.nlm.nih.gov/geo/). Search Tool for the Retrieval of Interacting Genes/Proteins (STRING) was used to investigate the predicted gene-gene interaction networks [22]. Clusters were formed using Markov clustering algorithms.

\subsubsection{Illumina ${ }^{\circledR}$ Methylation Array Infinium450k}

Methylated cytosines in $1.0 \mu \mathrm{g}$ DNA were converted by bisulfite treatment into uracil using the EZ DNA Methylation Kit (\#D5001 Zymo Research Corporation) according to the manufacturers instructions. DNA methylation analysis was performed on the HM-450K (Illumina) array platform. For each interrogated CpG two site-specific probes are present, one designed for the methylated and another for the unmethylated locus to which the chemically converted DNA is hybridized. Single-base extension of the hybridized probes incorporates a labeled ddNTP, which allows subsequent quantification of methylated and unmethylated loci. First analysis were undertaken using the Illumina ${ }^{\circledR}$ BeadStudio software. Furthermore $R$ with the packages IMA and minfi were used for methylation quality checks, SWAN normalization and MDS plot generation [23]. MethLab software was used to identify differently significantly changed methylated loci after FDR-correction [24].

\subsubsection{Statistical analysis}

Statistical analysis was performed using a One-Way-ANOVA followed by a post-hoc Tukey test. Significances of $\mathrm{p} \leqq 0.05$ are indicated $(*)$. For the analysis of the cell doublings over time a repeated measures test was performed. 
A

P 2

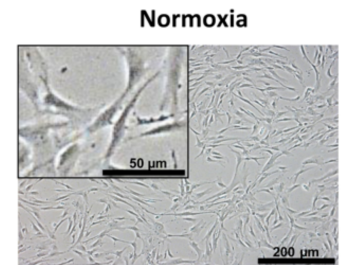

P 7

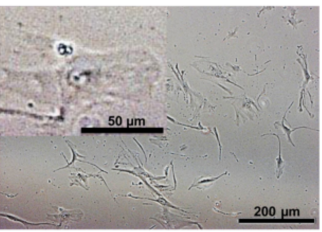

C
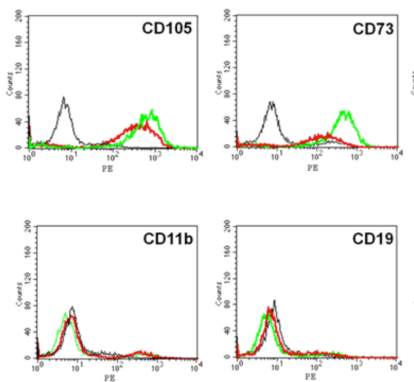

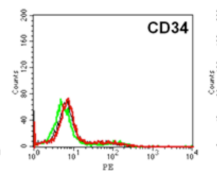

Hypoxia
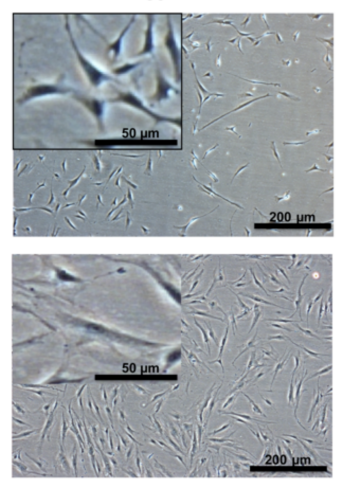

B

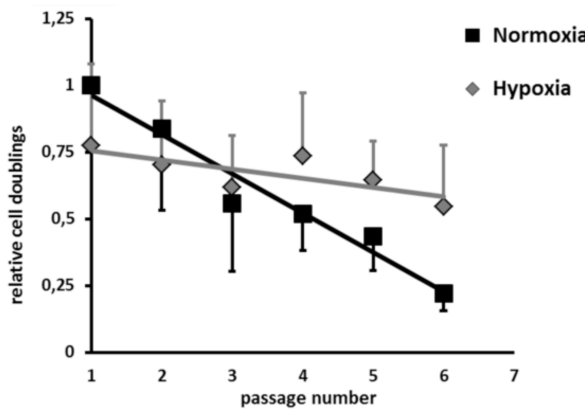

D

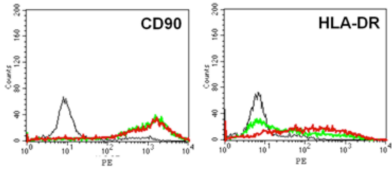

Figure 5.1: Phenotypical and immunophenotypical characterization of MSCs expanded in hypoxic $\left(2.5 \% \mathrm{O}_{2}\right)$ or normoxic $\left(21 \% \mathrm{O}_{2}\right)$ conditions

(A) Continuous expansion for seven passages leads in normoxia leads to a change in cell morphology, whereas hypoxic expanded MSCs better maintain their morphology (scale bar $200 \mu \mathrm{M}$ ). A representative picture is shown out of $3 \mathrm{MSC}$ donors. (B) Cell doubling numbers relative to the doubling speed of P1 normoxic expanded MSCs demonstrate a more pronounced decrease in cell doublings in normoxic conditions than in hypoxic cell expansion; multivariate testing shows significance for the passaging effect $\mathrm{p}=0.001$ and the effect of oxygen tension on the doubling numbers $\mathrm{p}=0.007$. (C) The surface markers CD90, CD105 and CD73 at passage 1 after adherent selection show a higher expression level in MSCs selected under hypoxic conditions than in MSCs selected in normoxia. Negative CD markers show minor differences in expression levels; FACS intensity plots are shown for one representative donor. The bar chart reflects the average of 3 independent donors. All data represent the mean +/$\mathrm{SD}$ of at least 3 independent experiments. ${ }^{*}=\mathrm{p} \leqq 0.05$. 
A
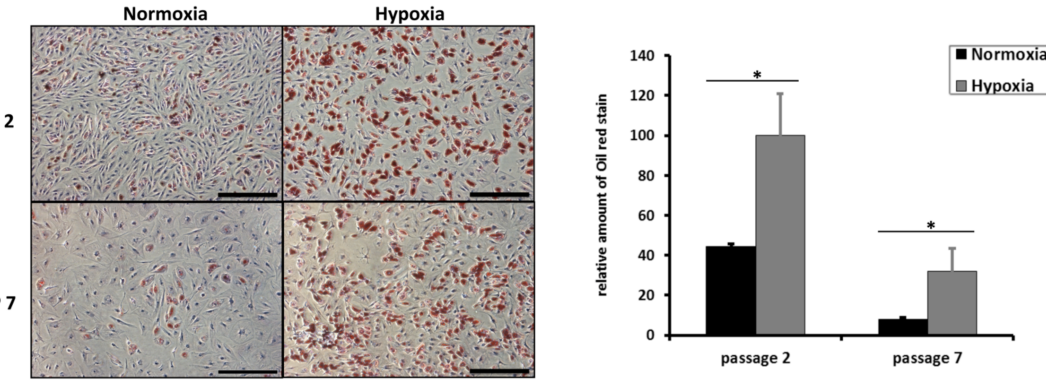

B
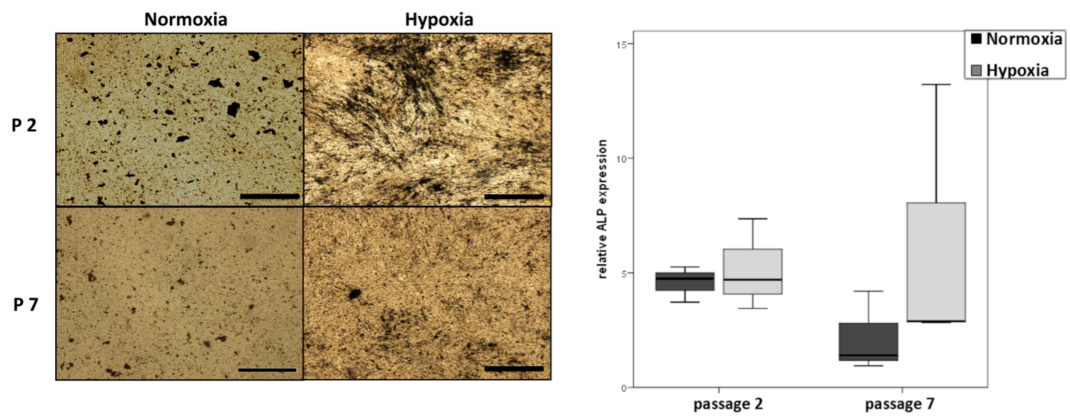

C
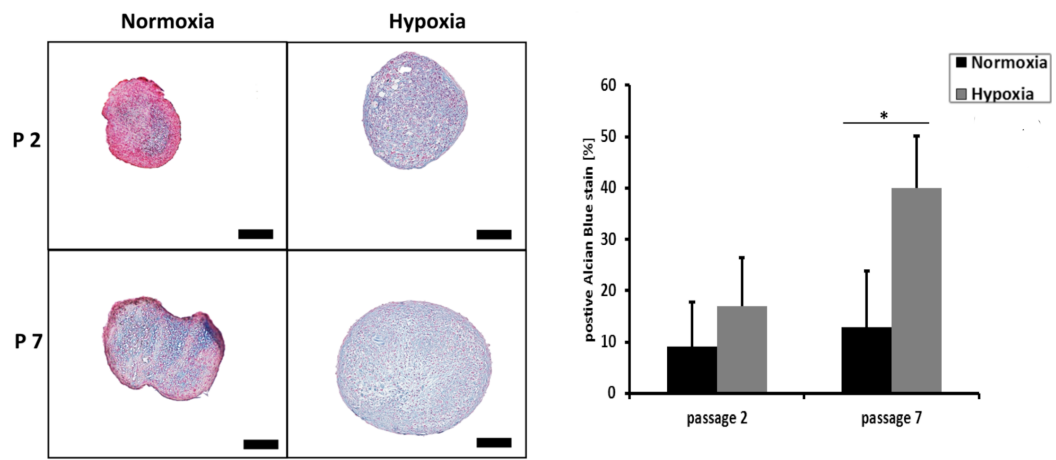

Figure 5.2: Differentiation potential of 3 MSC donors after continuous normoxic or hypoxic expansion

(Differentiation potential of $3 \mathrm{MSC}$ donors after continuous normoxic or hypoxic expansion (A) Adipogenic differentiation potential: Oil Red O stain of one representative donor demonstrating a generally higher adipogenic differentiation potential after hypoxic cell expansion. Bar chart shows the average oil-red o staining of 3 donors after lysis with $4 \%$ igepal indicating a significant better performance of hypoxic expanded MSCs (scalebar $200 \mu \mathrm{M}$ ). (B) Osteogenic differentiation potentential: von Kossa stain of the only donor showing calcification after four weeks of culture in osteogenic mineralization media. Box plot illustrates ALP expression of three donors after osteogenic expansion for one week. Error bars in the box plots demonstrates the huge inter donor variation in ALP expression, which reflected the differential potential of the donors to undergo osteogenesis (scalebar $200 \mu \mathrm{M}$ ). (C) Chondrogenic differentiation potential: Alcian Blue stain of one representive donor showing particular better staining in hypoxic expanded MSCs when compared to the same donor expanded in normoxia (scalebar $200 \mu \mathrm{M}$ ). Quantification of Alcian Blue staining revealed a significant better performance of P7 hypoxic expanded MSCs. Data represent the mean $+/-\mathrm{SD}$ of at least 3 independent experiments. ${ }^{*}=\mathrm{p} \leqq 0.05$. 

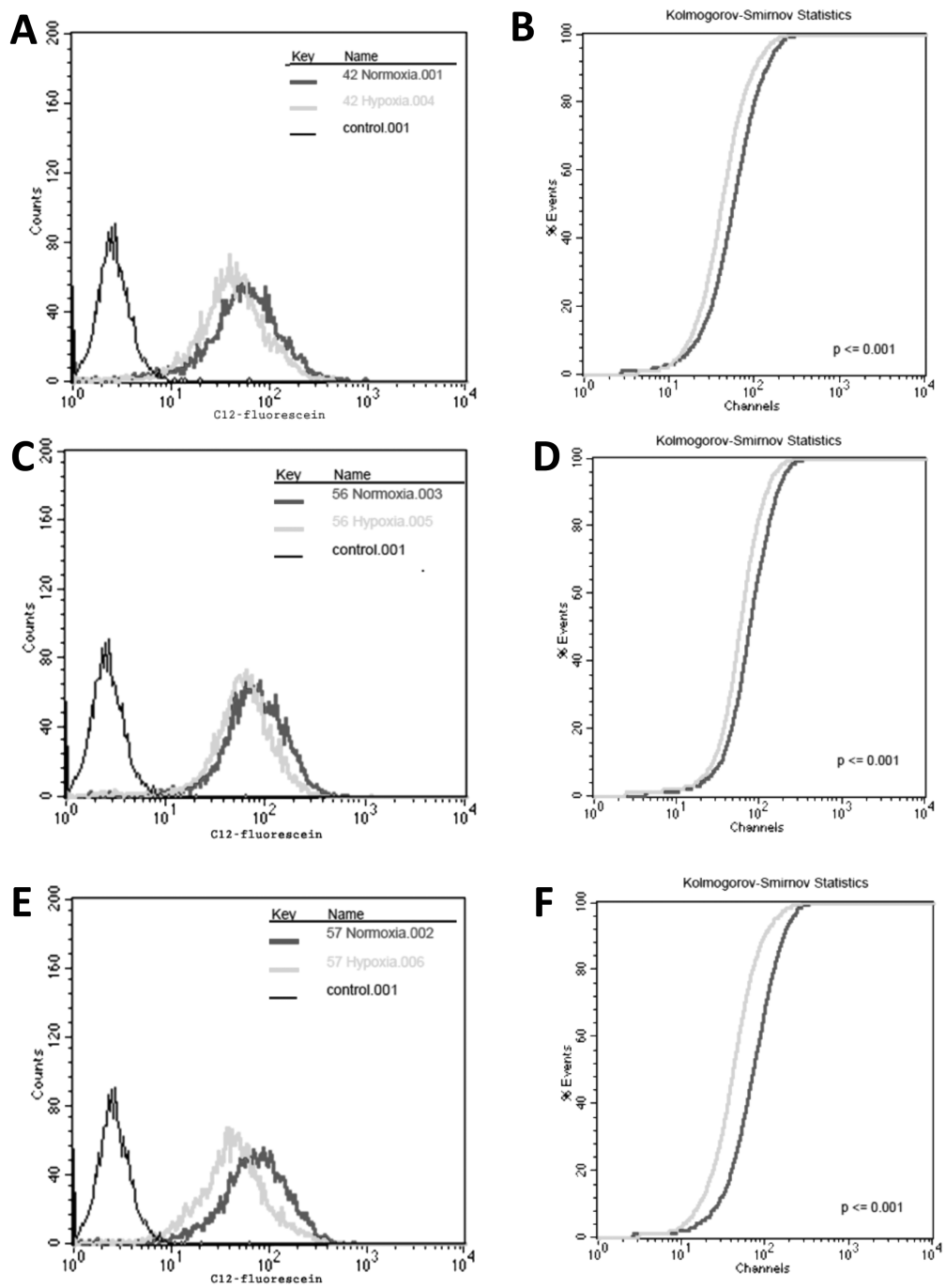

Figure 5.3: Senescence-associated $\beta$-galactosidase ( $\beta$-gal) expression in MSC donors expanded in hypoxia and normoxia for seven passages Senescence-associated $\beta$-galactosidase ( $\beta$-gal) expression in MSC donors expanded in hypoxia and normoxia for seven passages. P1 primary MSCs were used as control. $\beta$-gal staining, indicated by $\mathrm{C}_{12} \mathrm{FDG}$ fluorescence flow cytometry measurement, as well as the significance test is illustrated for each donor (A, B) donor 1, $(\mathrm{C}, \mathrm{D})$ donor 2 , (E, F) donor 3). All analysed donors display a significant lower $\beta$-gal expression after hypoxic cell expansion. 

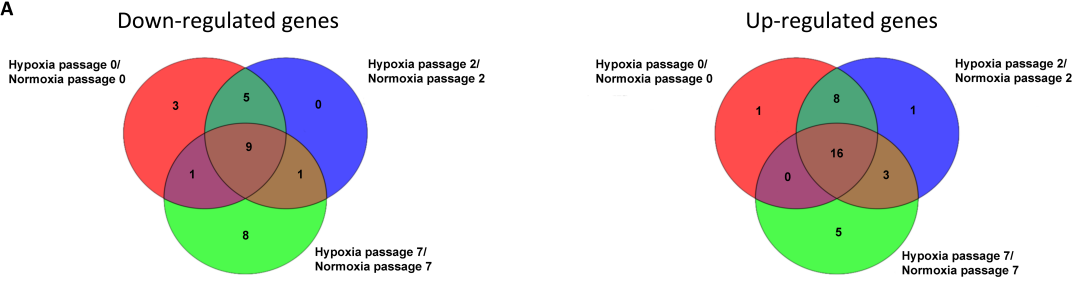

B

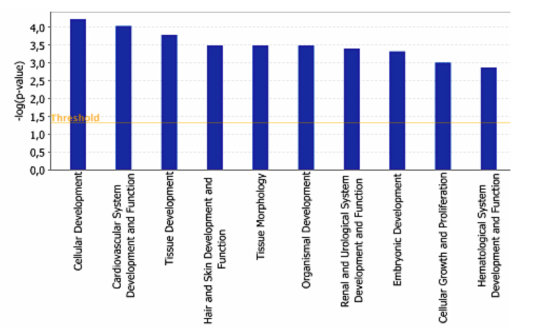

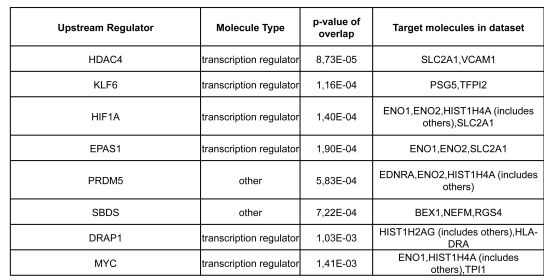

D

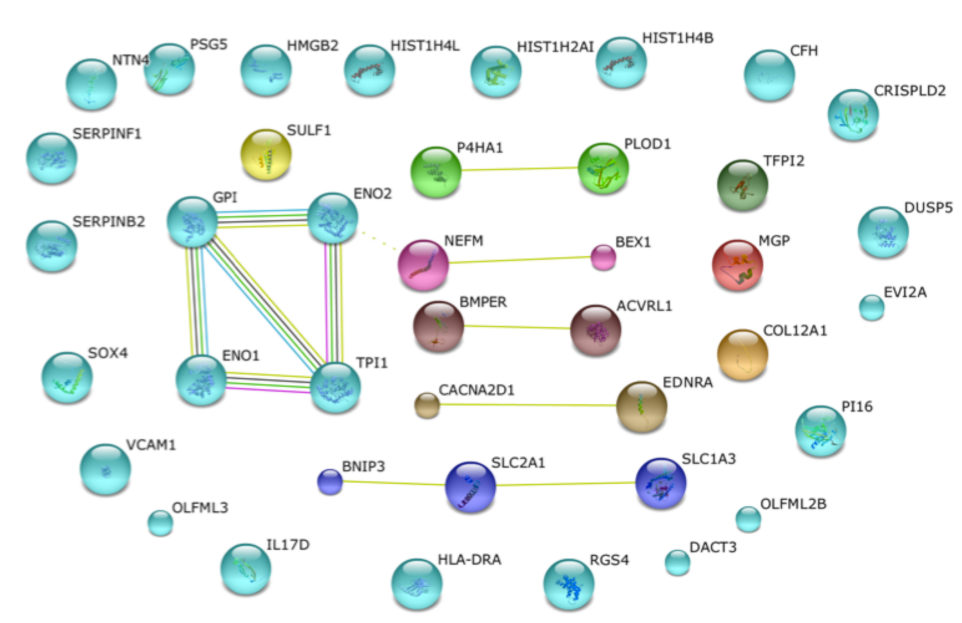

Figure 5.4: Microarray analysis of significantly changed genes with a fold change $\leqq 1.5$ - after hypoxic and normoxic MSCs expansion in passage 0 , 2 and 7

(A) Venn diagrams show that more genes are up-regulated than down-regulated during hypoxic cell expansion. With increasing passage number hypoxic and normoxic cultures become more divergent. (B) Top biological functions resulting from IPA analysis indicating a strong regulation of developmental as well as cellular processes. (C) Top upstream regulators of the differentially expressed genes indicate a strong involvement on gene transcription levels. (D) String analysis of the top regulated genes: The major light blue cluster contains mainly genes involved in glycolysis and hypoxic tolerance. Several histone and DNA regulating genes are listed as non-connected proteins (HMGB2, HIST1H2A1, HIST1H4B). Data represent the mean +/- SD of at least three independent experiments. ${ }^{*}=\mathrm{p} \leqq 0.05$. 


\section{$5.3 \quad$ Results}

\subsubsection{Hypoxic MSC expansion maintains cellular morphology and growth rate}

The continuous expansion of MSCs in normoxic $\left(21 \% \mathrm{O}_{2}\right)$ conditions leads to changes in cell morphology marked by a more round and flattened cell shape (Fig 5.1A). These changes coincided with a significant unremitting loss of proliferation capacity over time when standard lab conditions with normoxic oxygen conditions are used. On the contrary hypoxic expanded MSCs better maintain their morphology than normoxic expanded MSCs. If kept under hypoxia MSCs demonstrate a slower growth rate at the start of the culture up to passage three when compared to normoxic expanded MSCs. Remarkably the decrease in proliferation rate was decelerated when cells were cultured under hypoxia $(\mathrm{p}=0.007)$ (Fig 5.1B).

\subsubsection{Hypoxia slightly improves CD marker expression in culture expanded MSCs}

Flow cytometry analysis was performed to test the effect of oxygen tension during MSC isolation on CD marker panel expression. In all three tested donors CD90, CD105 and CD73 revealed higher expression in MSCs selected under hypoxic conditions. The difference in CD73 expression reached significance $\left(\mathrm{p}_{i} 0.05\right)$. Negative markers (CD45, HLA-DR, CD19, Integrin $\alpha \mathrm{M} / \mathrm{CD} 11 \mathrm{~b}, \mathrm{CD} 34)$ demonstrated only minor differences (Fig 5.1C, D). These differences disappeared with increasing passage number (results not shown).

\subsubsection{Expansion in hypoxia improves the differentiation potential of MSCs}

The decisive proof for the presence of MSCs is their test for differentiation into the osteogenic, adipogenic and chondrogenic lineage. Differentiation tests were performed at atmospheric, normoxic oxygen tension, irrespective of the oxygen tension during the expansion phase. A history of hypoxic expansion improved adipogenic, chondrogenic and osteogenic differentiation of MSCs (Fig 5.2). Hypoxic expansion increased adipogenic Oil Red O staining in three weeks differentiated MSCs at P2 and P7 (Fig $5.2 \mathrm{~A}$ ). Improvement of osteogenic differentiation potential was strongly dependent on the donor. One donor demonstrated a dramatic increase in matrix calcification at P2 when previously expanded under hypoxia, whereas other donors showed no improvement. ALP expression as an early marker for the onset of osteogenesis was used to characterize the osteogenic differentiation potential further. CDP-star based ALP measurement revealed as well a high donor-to-donor variation. At P7 ALP expression tended to be higher in MSCs expanded in hypoxia. This tendency did not reach significance $(\mathrm{p}=0.707)$ (Fig 5.2B). Hypoxic expansion of MSCs led to improved chondrogenic differentiation. Interestingly, P7 hypoxic expanded cells seem to outperform 
the cells of the same donor expanded up to P2 (Fig 5.2C). Senescence is delayed in hypoxic expanded MSCs.

Senescence is one of the key features associated with the loss of proliferation and loss of mulitipotency of MSC during culture expansion [13]. Senescence-associated $\beta$-galactosidase $(\beta$-gal) expression, as level of the enzymatic conversion of di- $\beta$-Dgalactopyranoside $\left(\mathrm{C}_{12} \mathrm{FDG}\right)$ was measured with flow cytometry. Both, P7 hypoxic and normoxic MSCs demonstrate higher levels of senescence than early passage MSCs. Interestingly, senescence was significantly delayed in all three hypoxic expanded MSC donors evidenced by lower amounts of $\mathrm{C}_{12} \mathrm{FDG}$ staining.

\subsubsection{Regulation of glycolytic and transcriptional genes in different oxygen tensions}

Genome wide mRNA expression profiles were obtained from MSCs at P2 and P7 expanded in normoxia or hypoxia. Significantly differentially expressed genes with a 1.5-fold difference between the conditions were selected for further analysis (Table S5.1). During hypoxic cell expansion more genes were up-regulated than downregulated. The most prominent differences in gene expression between hypoxic and normoxic expansion are observed at P7 (Fig 5.4A). IPA analysis showed that the top regulated biological functions are linked to regulation of developmental as well as cellular processes (Fig 5.4B). String analysis of the top regulated genes demonstrate the regulation of a cluster of glycolytic genes (ENO2, ENO1, GP1, TPI1) being involved in glucose transport and cellular glucose balance. Furthermore genes involved in the control of the hypoxic tolerance (SOX4, VCAM1, SERPINB2, SERPINF1) were differently regulated in MSCs expanded in hypoxia and normoxia. Interestingly, a number of genes that are involved in epigenetic modification such as $H M G B 2$, HIST1H2AI, HIST1H4B were differentially expressed between normoxic and hypoxic expanded cells (Fig 5.4C). Upstream regulators of the differentially expressed genes indicate a strong effect of hypoxia on gene transcription of glycolytic and histone genes. The displayed histone genes are S-Phase specific and identify thereby a difference in cellular proliferation and cell cycle kinetics.

\subsubsection{Hypoxia induces epigenetic changes in DNA methylation}

Since hypoxia significantly altered the expression of genes involved in epigenetic regulation of gene expression, we hypothesized that epigenetic mechanisms could be involved in the functional differences between MSCs expanded in hypoxia or in normoxia. To assess whether culture expansion induces epigenetic changes in DNA methylation, DNA was isolated of P2 and P7 MSCs expanded in hypoxia or normoxia and analysed with the 450k Illumina DNA methylation array. Hierarchical clustering using Illumina GenomeBeadStudio reveals that methylation patterns at P2 of MSCs either expanded in hypoxia or normoxia cluster together. Interestingly, in line with our hypothesis at P7 global methylation patterns in hypoxic and normoxic expanded MSCs are clearly distinct. Comparison of the global methylation patterns at P2 and P7 showed that passaging of cells has an dramatic impact on DNA methyla- 
tion and this process can be influenced by oxygen tension (Fig 5.5A). R package minfi generated multi dimensional scaling (MDS) plot of all samples underlined the outcome of the hierarchical clustering. Cells expanded up to P2 in normoxia and hypoxia mainly cluster on the positive side of the x-Axis, indicating that all donors have a comparable methylation pattern irrespective of oxygen tension. P7 hypoxic expanded donors are grouping on the very negative side of the $\mathrm{x}$-Axis indicating this condition has the largest impact on DNA methylation (Fig 5B). When the four experimental groups were compared using the MethLab software [24], the RhoGTPase activating protein GAP29 (ARHGAP29) was identified as most differently methylated gene $(\mathrm{FDR}=0.04)$. P7 cells in normoxia and hypoxia demonstrate lower methylation levels of ARHGAP29 than P2 cells (Fig 5.5C). Point spread functions of the methylation level display the most dissimilar methylation pattern when hypoxia P2 is compared with hypoxia P7 as well as when P7 of both oxygen tensions are compared. The same comparisons of groups were used to identify most differently methylated loci using the MethLAb software. The comparison of hypoxia P2 with P7 reveals neurexin 1 $(N R X N 1)$ as loci with lower methylation levels in $\mathrm{P} 7$. When both oxygen tensions at P7 were compared the transmembrane reporter solute carrier 25A18 (SLC25A18) and RPTOR demonstrated decreased methylation levels in hypoxia. Interestingly, hydroxyurea-sensitive-1 protein (HUS1) was identified with increased methylation in hypoxia. Even though P2 and P7 cells after normoxic expansion revealed less methylation difference, we were able to identify receptor-type tyrosine protein phosphatase N2 (PTPRN2) as a decreased methylated region at P7 (Fig 5.5D-F).

\subsubsection{Changes in miRNA expression are associated with cell passage and oxygen tension}

We next examined whether oxygen tension influences the expression of miRNAs involved in stem cell survival, proliferation, maintenance of the hypoxic response as well as differentiation potential (Table 5.2). The overall expression levels of the analysed miRNAs are down-regulated during cell expansion irrespective of oxygen tension. As expected microRNAs related to hypoxia such as miR-13\%, miR-218, miR-210 and miR-125b were up-regulated miRNA during hypoxic expansion at P2 and P7 compared to normoxic expanded cells. miR-23, miR-30c, let-7f and miR-140 are higher expressed in normoxic expanded MSCs at P2 and P7 but show a strong down-regulation during passaging (Fig 5.6, Table 5.2).

\subsection{Discussion}

The comparison of normoxic and hypoxic expanded MSCs revealed that hypoxic MSC expansion increases cell yield, improves adipogenic and chondrogenic differentiation potential and delays cellular senescence. The effect on osteoblast differentiation was less clear. These results are in line with previous observations [25]. Major efforts are directed to elucidate the molecular mechanism of improved MSC performance after hypoxic expansion. In our study we defined an oxygen tension of $21 \%$ as normoxic. However, cells in the human body are never exposed to an oxygen tension of $21 \%$. 


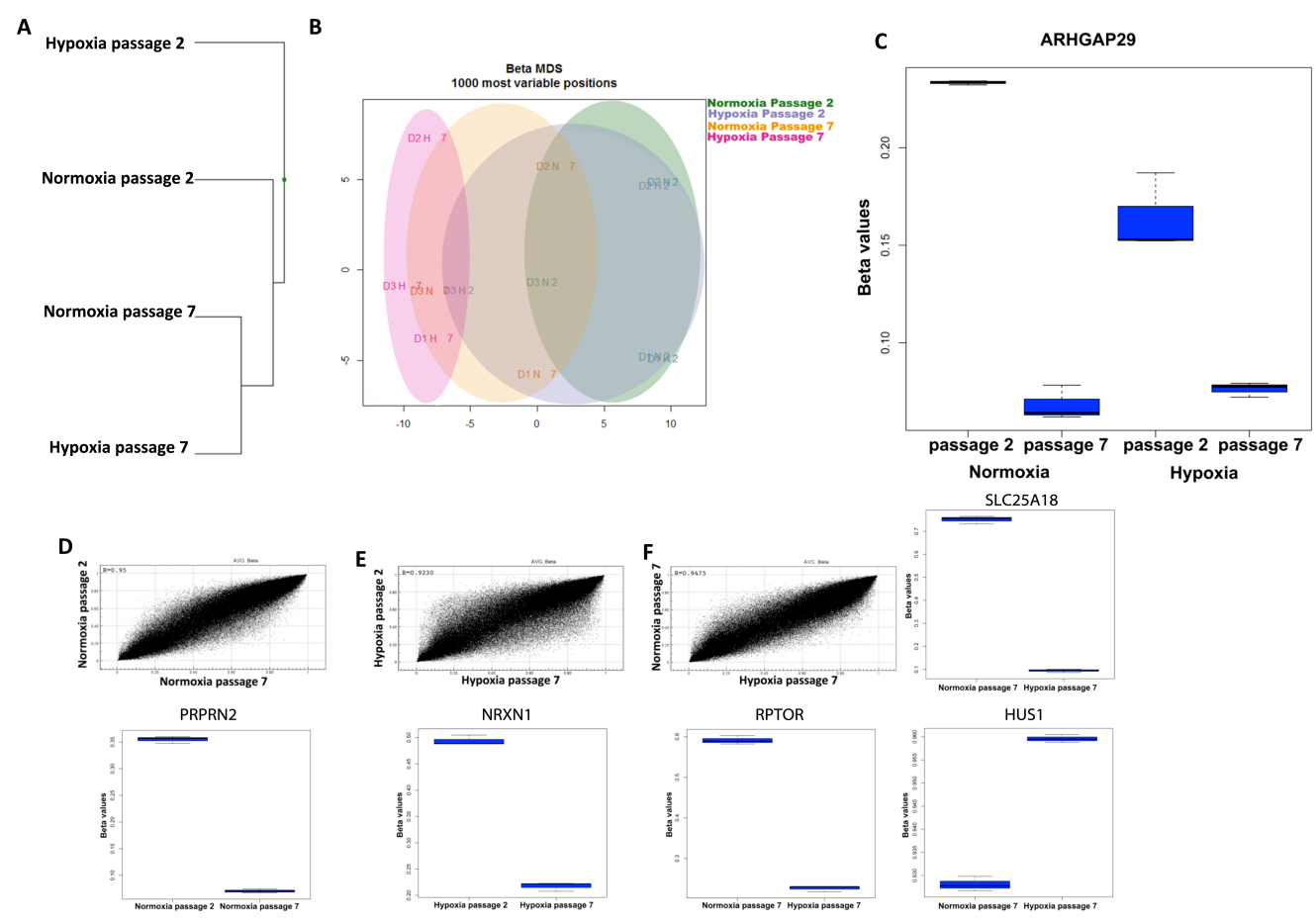

Figure 5.5: Global genomic methylation analysis of MSCs after continuous expansion in hypoxia and normoxia up to passage 2 and 7

(A) Hierarchical clustering reveals that early passage MSCs after hypoxic and normoxic expansion cluster in the same branch. P7 hypoxic and normoxic expanded MSCs cluster have become more divergent. (B) $\mathrm{R}$ package minfi generated multi dimensional scaling (MDS) plot of all samples included in the methylation array: The same conditions group among the $\mathrm{x}$-axis and underline the differences in methylation profile as seen in the hierarchical clustering. (C) Comparison of all 4 experimental groups revealed one methylated gene with significant regulation $(\mathrm{p}=0.04)$ : RhoGTP ase activating protein GAP29 (ARHGAP29). Passage seven cells in normoxia and hypoxia show lower methylation levels of ARHGAP29 than passage 2 cells. (D-F) Illumina GenomeBeadStudio point spread functions of the methylation level combined with the most differential methylated positions (MethLab software): Point spread functions indicate differences in methylation levels inbetween conditions. MSCs expanded till P7 in hypoxia or normoxia are more differently methylated than P2 MSCs in the respective condition. Data represent the mean at three independent experiments. 


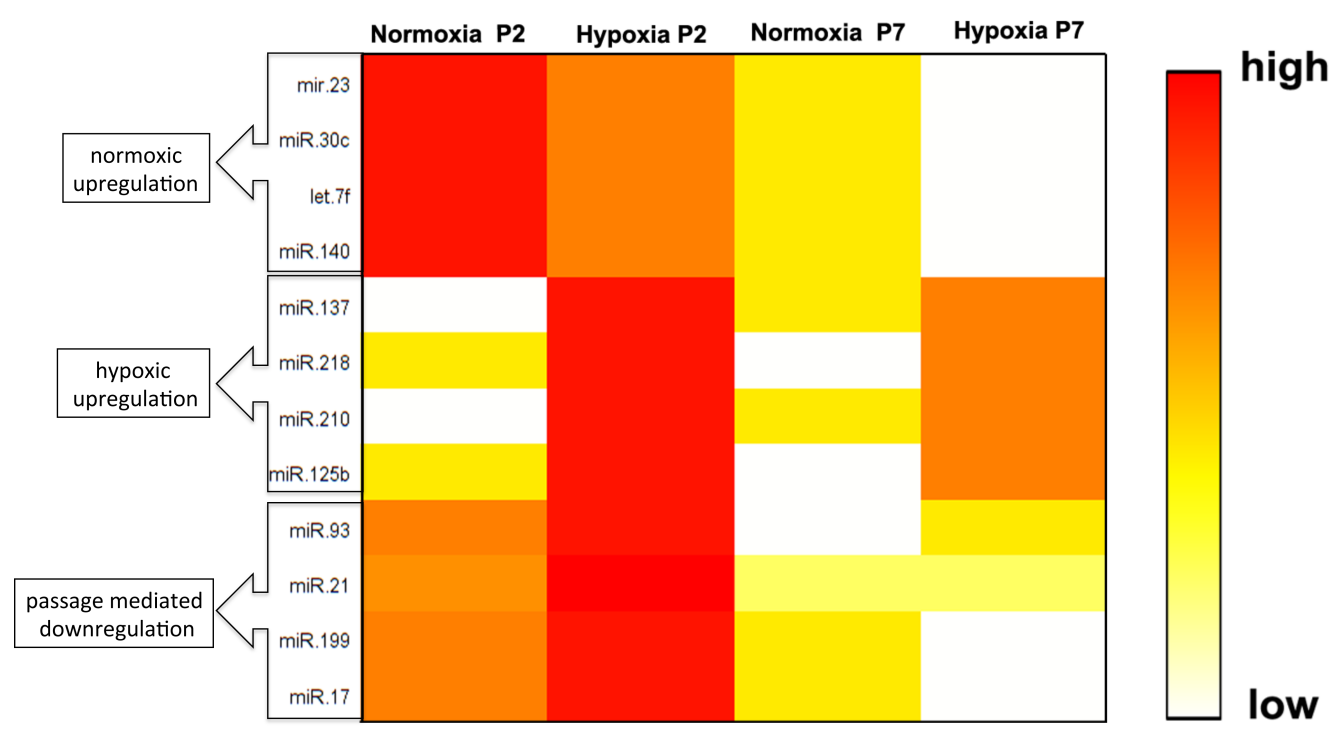

Figure 5.6: Regulation of miRNA expression during culture expansion. Heat plot of differentially regulated miRNAs sorted according their tendency of expression during different passages.

When blood reaches organs in the human body the $\mathrm{O}_{2}$ saturation has already dropped to $2-9 \%$ [26]. This oxygen concentration has recently been considered as physiologic normoxia [27]. Oxygen tension in organs and stem cell niches ranges from 1-6\% in the hematopoetic stem cell nice [28] to $2-8 \%$ in the mesenchymal stem cell niche [29]. Under physiologic normoxia cells exhibit the so-called hypoxic response, involving the stabilization of hypoxia inducible factor one alpha $(\mathrm{HIF} 1 \alpha)$. HIF $1 \alpha$ translocates to the nucleus, binds to HIF $1 \beta$ and activates transcription of target molecules. In contrast, most of the standard lab culture systems are kept under $21 \%$ atmospheric $\mathrm{O}_{2}$. Under atmospheric oxygen concentration, in this study normoxia, cells experience oxidative stress, which involves the generation of reactive oxygen species (ROS). ROS have been reported to accumulate DNA mutations as well as to drive cellular senescence in mouse fibroblasts [30]. It has been demonstrated that hypoxia can prevent the methylation of important promoter sequences involved in the expression regulation of genes involved in the maintenance of the endothelial cell lineage [31]. Therefore, we assumed that hypoxic expansion of MSCs might trigger a different methylation status of important sequences and thereby influence mRNA and miRNA expression. Genome-wide mRNA profiling using microarrays revealed differential regulation of gene expression dependent on oxygen tensions as well as on passage number (Fig 4A). The plotting in a string interaction network demonstrated glycolytic and histone related genes as major pools of regulated genes. It is well known that cells exposed to hypoxia $\left(2.5 \% \mathrm{O}_{2}\right)$ adapt by altering glucose metabolism [32]. ENO1 and ENO2 were described before to contain hypoxia responsive elements in their promoters and are thereby involved in 


\begin{tabular}{|c|c|c|c|}
\hline miRNA & reported function & References & observed regulation \\
\hline miR-23a & $\begin{array}{l}\text { hypoxia survival } \\
\text { upregulated during senescence } \\
\text { targets RUNX2 }\end{array}$ & {$[38-41]$} & $\begin{array}{l}\text { normoxic upregulation } \\
\text { passage downregulation }\end{array}$ \\
\hline miR-30c & negative regulation of osteoblast differentiation & {$[42]$} & normoxic upregulation \\
\hline Let-7f & $\begin{array}{l}\text { stem cell maintainence } \\
\text { marker of replicative senescence }\end{array}$ & {$[13,43]$} & normoxic upregulation \\
\hline $\mathrm{miR}-140$ & $\begin{array}{l}\text { positive regulation of chondrogenesis } \\
\text { negative regulation of HDAC4 }\end{array}$ & {$[44,45]$} & normoxic upregulation, \\
\hline miR-137 & targets specifically human RUNX2 & [46] & hypoxic upregulation \\
\hline mir-218 & $\begin{array}{l}\text { targets RUNX2 } \\
\text { osteogenic differentiation block }\end{array}$ & {$[46]$} & hypoxic upregulation \\
\hline $\operatorname{miR}-210$ & $\begin{array}{l}\text { hypoxic upregulation } \\
\text { cell survival } \\
\text { DNA damage repair }\end{array}$ & $\begin{array}{l}{[39,40,47,} \\
48]\end{array}$ & hypoxic upregulation \\
\hline $\operatorname{miR}-125 b$ & regulation of cell proliferation and differentiation & [49] & hypoxic upregulation \\
\hline miR-93 & $\begin{array}{l}\text { regulation of proliferation } \\
\text { upregulated by hypoxia }\end{array}$ & [39] & passage regulation \\
\hline miR-21 & $\begin{array}{l}\text { upregulated by TGFbeta } \\
\text { hypoxia survival }\end{array}$ & {$[40]$} & passage regulation \\
\hline miR-199a & $\begin{array}{l}\text { negative regulation of early chondrogenesis, } \\
\text { regulation of pluripotency }\end{array}$ & {$[50,51]$} & passage regulation \\
\hline miR-17 & HIF1 mediated cell differentiation & {$[52]$} & passage regulation \\
\hline
\end{tabular}

Table 5.2: microRNAs used in the miRNA profiling of hypoxic and normoxic expanded MSCs

Each miRNA is reported with the assigned function as well as the regulation of its expression in hypoxic and normoxic expanded MSCs.

this hypoxic response [33, 34]. The panel of differentially expressed genes leads to the identification of top upstream regulators, which indicates a strong regulation on the transcriptional level, and thereby draws attention to the altered genetic expression as well as transcriptional levels after hypoxic MSC expansion. The regulated histone mRNA levels are S-phase specific, leading to the regulation of cellular proliferation and cell cycle kinetics.

Nevertheless, we were interested if hypoxic cell expansion leaves as well a distinct epigenetic signature, indicated by different methylation levels. Global methylation analysis showed that MSCs expanded in hypoxia vs. normoxia reveal more distinct methylation at P7 when compared to P2 cells (Fig 5A,B). Nevertheless, the methylation differences between different passages are more prominent than differences between normoxia and hypoxia. The comparison of three donors at different passages revealed that RhoGTPase activating protein GAP29 (ARHGAP29) is the most differentially methylated position in-between the groups. RhoGTPases have been described 
to be up-regulated during senescence, which might explain their more passagingrelated methylation status [35]. The most interesting methylation loci (SLC25A18, RPTOR, HUS1) are detected when normoxic expanded MSCs P7 are compared with hypoxic expanded MSCs of the same passaging age. SLC25A18, a glutamate transmembrane transporter, reveals lower methylation levels after hypoxic cell expansion and has been described before to be regulated under hypoxia [36]. RPTOR exhibits lower methylation levels in $\mathrm{P} 7$ hypoxic expanded cells. RPTOR blocks the activation of the mammalian target of rapamycin ( $m T O R$ ) and is thereby involved in the regulation of cell growth and cell proliferation. Furthermore, $m T O R$ has been described to interact with HIF1 $\alpha$ and is thereby promoting its activity [37]. In response to DNA damage HUS1, with its higher methylation levels at $\mathrm{P} 7$ hypoxia, induces a cell cycle arrest and acts thereby as a selective element. Higher methylation levels of HUS1 in hypoxia indicate thereby lower amounts of DNA damage. The methylated genes can be linked to the regulation on mRNA levels, where cellular development and tissue development where major functions influenced, when hypoxic and normoxic expanded cells were compared.

To further check if changes in mRNA levels and epigenetic levels can be traced back as well on miRNA levels we analyzed a pool of miRNAs known to be involved in the hypoxic response, levels of chondrogenic or osteogenic differentiation or stem cell maintenance. All miRNA levels were down-regulated with increasing number of passages. We identified a group of miRNAs being higher expressed in normoxic expanded cells $(m i R-23 a,-30 c,-140$, let- $7 \mathrm{f})$ as well as a group of miRNAs higher expressed in hypoxic expanded cells (miR-137, -218, -210, -125b). In general, we identified the miRNA changes due to cellular passaging to be more prominent then seen by the influence of hypoxia or normoxia. These findings are in line with epigenetic methylation data as well as the $\beta$-gal senescence assay. In recent literature miR-23a and let-7f, both higher expressed at P2 in normoxia but down-regulated during passaging, are described as markers of replicative senescence [13, 38]. The down-regulation of both miRNAs further underlines that cells expanded in hypoxia undergo senescence, but in a limited extend when compared to normoxic expanded cells. Typical markers of the hypoxic response are miR-210 and miR-125b [39].

In conclusion we identified hypoxic MSC expansion to (1) reduce the oxidative stress by limiting the exposure to ROS leading to delayed cellular senescence, (2) alter the cellular glucose metabolism and (3) induce DNA methylation changes via altered mRNA and miRNA expression. Nevertheless we identified cell passaging as an environmental factor with partially higher impact on cellular performance and epigenetic changes. Hypoxic cell expansion can thereby assist in overcoming passaging related limitations, but not eliminate associated changes. 


\section{References}

1. Pittenger, M.F., et al., Multilineage potential of adult human mesenchymal stem cells. Science, 1999. 284(5411): p. 143-7.

2. Baksh, D., R. Yao, and R.S. Tuan, Comparison of proliferative and multilineage differentiation potential of human mesenchymal stem cells derived from umbilical cord and bone marrow. Stem Cells, 2007. 25(6): p. 1384-92.

3. Jones, E.A., et al., Synovial fluid mesenchymal stem cells in health and early osteoarthritis: detection and functional evaluation at the single-cell level. Arthritis Rheum, 2008. 58(6): p. 1731-40.

4. Koelling, S., et al., Migratory chondrogenic progenitor cells from repair tissue during the later stages of human osteoarthritis. Cell Stem Cell, 2009. 4(4): p. 324-35.

5. Farre-Guasch, E., et al., Buccal fat pad, an oral access source of human adipose stem cells with potential for osteochondral tissue engineering: an in vitro study. Tissue Eng Part C Methods, 2010. 16(5): p. 1083-94.

6. Tallone, T., et al., Adult human adipose tissue contains several types of multipotent cells. J Cardiovasc Transl Res, 2011. 4(2): p. 200-10.

7. Dominici, M., et al., Minimal criteria for defining multipotent mesenchymal stromal cells. The International Society for Cellular Therapy position statement. Cytotherapy, 2006. 8(4): p. 315-7.

8. Siddappa, R., et al., Donor variation and loss of multipotency during in vitro expansion of human mesenchymal stem cells for bone tissue engineering. J Orthop Res, 2007. 25(8): p. 1029-41.

9. Cicione, C., et al., Molecular profile and cellular characterization of human bone marrow mesenchymal stem cells: donor influence on chondrogenesis. Differentiation, 2010. 80(2-3): p. 155-65.

10. Ho, A.D., W. Wagner, and W. Franke, Heterogeneity of mesenchymal stromal cell preparations. Cytotherapy, 2008. 10(4): p. 320-30.

11. Tokalov, S.V., et al., Age-related changes in the frequency of mesenchymal stem cells in the bone marrow of rats. Stem cells and development, 2007. 16(3): p. 439-46.

12. Jansen, B.J., et al., Functional differences between mesenchymal stem cell populations are reflected by their transcriptome. Stem cells and development, 2010. 19(4): p. 481-90.]

13. Wagner, W., et al., Replicative senescence of mesenchymal stem cells: a continuous and organized process. PLoS One, 2008. 3(5): p. e2213.

14. Alves, H., et al., A link between the accumulation of DNA damage and loss of multi-potency of human mesenchymal stromal cells. Journal of cellular and molecular medicine, 2010. 14(12): p. 2729-38.

15. Engler, A.J., et al., Extracellular matrix elasticity directs stem cell differentiation. Journal of musculoskeletal \& neuronal interactions, 2007. 7(4): p. 335.

16. Rosova, I., et al., Hypoxic preconditioning results in increased motility and improved therapeutic potential of human mesenchymal stem cells. Stem Cells, 2008. 26(8): p. 2173-82.

17. Karlsen, T.A., et al., Effect of three-dimensional culture and incubator gas concentration on phenotype and differentiation capability of human mesenchymal stem cells. Journal of cellular biochemistry, 2011. 112(2): p. 684-93.

18. Basciano, L., et al., Long term culture of mesenchymal stem cells in hypoxia promotes a genetic program maintaining their undifferentiated and multipotent status. BMC Cell Biol, 2011. 12: p. 12. 19. Tsai, C.C., et al., Hypoxia inhibits senescence and maintains mesenchymal stem cell properties through down-regulation of E2A-p21 by HIF-TWIST. Blood, 2011. 117(2): p. 459-69.

20. Rabinovitch, P.S., Regulation of human fibroblast growth rate by both noncycling cell fraction transition probability is shown by growth in 5-bromodeoxyuridine followed by Hoechst 33258 flow cytometry. Proceedings of the National Academy of Sciences of the United States of America, 1983. 80(10): p. 2951-5.

21. Leijten, J.C., et al., GREM1, FRZB and DKK1 are key regulators of human articular cartilage homeostasis. Arthritis Rheum, 2012.

22. Szklarczyk, D., et al., The STRING database in 2011: functional interaction networks of proteins, globally integrated and scored. Nucleic Acids Res, 2011. 39(Database issue): p. D561-8.

23. Maksimovic, J., L. Gordon, and A. Oshlack, SWAN: Subset-quantile within array normalization for illumina infinium HumanMethylation450 BeadChips. Genome biology, 2012. 13(6): p. R44.

24. Kilaru, V., et al., MethLAB: a graphical user interface package for the analysis of array-based DNA methylation data. Epigenetics : official journal of the DNA Methylation Society, 2012. 7(3): 
p. 225-9.

25. Yang, D.C., et al., Hypoxia inhibits osteogenesis in human mesenchymal stem cells through direct regulation of RUNX2 by TWIST. PLoS One, 2011. 6(9): p. e23965.

26. Brahimi-Horn, M.C. and J. Pouyssegur, Oxygen, a source of life and stress. FEBS letters, 2007. 581(19): p. 3582-91.

27. Simon, M.C. and B. Keith, The role of oxygen availability in embryonic development and stem cell function. Nature reviews. Molecular cell biology, 2008. 9(4): p. 285-96.

28. Cipolleschi, M.G., P. Dello Sbarba, and M. Olivotto, The role of hypoxia in the maintenance of hematopoietic stem cells. Blood, 1993. 82(7): p. 2031-7.

29. Harrison, J.S., et al., Oxygen saturation in the bone marrow of healthy volunteers. Blood, 2002. 99(1): p. 394.

30. Busuttil, R.A., et al., Oxygen accelerates the accumulation of mutations during the senescence and immortalization of murine cells in culture. Aging Cell, 2003. 2(6): p. 287-94.

31. Ohtani, K., et al., Epigenetic regulation of endothelial lineage committed genes in pro-angiogenic hematopoietic and endothelial progenitor cells. Circulation research, 2011. 109(11): p. 1219-29.

32. Dos Santos, F., et al., Ex vivo expansion of human mesenchymal stem cells: a more effective cell proliferation kinetics and metabolism under hypoxia. Journal of cellular physiology, 2010. 223(1): p. 27-35.

33. Martin-Rendon, E., et al., Transcriptional profiling of human cord blood CD133+ and cultured bone marrow mesenchymal stem cells in response to hypoxia. Stem Cells, 2007. 25(4): p. 1003-12.

34. Semenza, G.L., et al., Hypoxia response elements in the aldolase A, enolase 1, and lactate dehydrogenase A gene promoters contain essential binding sites for hypoxia-inducible factor 1 . The Journal of biological chemistry, 1996. 271(51): p. 32529-37.

35. Alexander, K., H.S. Yang, and P.W. Hinds, Cellular senescence requires CDK5 repression of Rac1 activity. Molecular and cellular biology, 2004. 24(7): p. 2808-19.

36. Felfly, H., et al., Severe Hypoxia: Consequences to Neural Stem Cells and Neurons. Journal of Neurology Research, 2011. 1(5): p. 177-189.

37. Land, S.C. and A.R. Tee, Hypoxia-inducible factor 1alpha is regulated by the mammalian target of rapamycin (mTOR) via an mTOR signaling motif. The Journal of biological chemistry, 2007. 282(28): p. 20534-43.

38. Bonifacio, L.N. and M.B. Jarstfer, MiRNA profile associated with replicative senescence, extended cell culture, and ectopic telomerase expression in human foreskin fibroblasts. PLoS One, 2010. 5(9).

39. Kulshreshtha, R., et al., A microRNA signature of hypoxia. Mol Cell Biol, 2007. 27(5): p. $1859-67$.

40. Nie, Y., et al., Identification of MicroRNAs involved in hypoxia- and serum deprivation-induced apoptosis in mesenchymal stem cells. Int J Biol Sci, 2011. 7(6): p. 762-8.

41. Lee, S., et al., Histone deacetylase regulates high mobility group A2-targeting microRNAs in human cord blood-derived multipotent stem cell aging. Cell Mol Life Sci, 2011. 68(2): p. 325-36.

42. $\mathrm{Wu}, \mathrm{T}$., et al., miR-30 family members negatively regulate osteoblast differentiation. J Biol Chem, 2012. 287(10): p. 7503-11.

43. Peter, M.E., Let-7 and miR-200 microRNAs: guardians against pluripotency and cancer progression. Cell Cycle, 2009. 8(6): p. 843-52.

44. Tuddenham, L., et al., The cartilage specific microRNA-140 targets histone deacetylase 4 in mouse cells. FEBS Lett, 2006. 580(17): p. 4214-7.

45. Nicolas, F.E., et al., mRNA expression profiling reveals conserved and non-conserved miR-140 targets. RNA Biol, 2011. 8(4): p. 607-15.

46. Zhang, Y., et al., A program of microRNAs controls osteogenic lineage progression by targeting transcription factor Runx2. Proc Natl Acad Sci U S A, 2011. 108(24): p. 9863-8.

47. Crosby, M.E., et al., MicroRNA regulation of DNA repair gene expression in hypoxic stress. Cancer Res, 2009. 69(3): p. 1221-9.

48. Kim, H.W., et al., Ischemic preconditioning augments survival of stem cells via miR-210 expression by targeting caspase-8-associated protein 2. J Biol Chem, 2009. 284(48): p. 33161-8.

49. Mizuno, Y., et al., miR-125b inhibits osteoblastic differentiation by down-regulation of cell proliferation. Biochem Biophys Res Commun, 2008. 368(2): p. 267-72. 50. Lin, E.A., et al., miR-199a, a bone morphogenic protein 2-responsive MicroRNA, regulates chondrogenesis via direct targeting 
to Smad1. J Biol Chem, 2009. 284(17): p. 11326-35.

51. Laine, S.K., et al., MicroRNAs miR-96, miR-124, and miR-199a regulate gene expression in human bone marrow-derived mesenchymal stem cells. J Cell Biochem, 2012. 113(8): p. 2687-95. 52. He, M., et al., HIF-1alpha downregulates miR-17/20a directly targeting p21 and STAT3: a role in myeloid leukemic cell differentiation. Cell Death Differ, 2012. 


\section{Supplemental Figures}

\begin{tabular}{|c|c|c|}
\hline Symbol & Entrez Gene Name & Fold Change \\
\hline OLFML3 & olfactomedin-like 3 & 1,82 \\
\hline SULF1 & sulfatase 1 & 1,74 \\
\hline DACT3 & dapper, antagonist of beta-catenin, homolog 3 (Xenopus laevis) & 1,57 \\
\hline SLC2A1 & solute carrier family 2 (facilitated glucose transporter), member 1 & 1,52 \\
\hline HMGB2 & high mobility group box 2 & 1,50 \\
\hline P4HA1 & prolyl 4-hydroxylase, alpha polypeptide I & 1,46 \\
\hline BNIP3 & $\mathrm{BCL} 2 /$ adenovirus E1B 19kDa interacting protein 3 & 1,42 \\
\hline SERPINF1 & serpin peptidase inhibitor, clade F, member 1 & 1,31 \\
\hline ENO1 & enolase 1, (alpha) & 1,30 \\
\hline PLOD1 & procollagen-lysine, 2-oxoglutarate 5-dioxygenase 1 & 1,29 \\
\hline GPI & glucose-6-phosphate isomerase & 1,23 \\
\hline HIST1H2AG & histone cluster $1, \mathrm{H} 2 \mathrm{ag}$ & 1,22 \\
\hline TPI1 & triosephosphate isomerase 1 & 1,17 \\
\hline ENO2 & enolase 2 (gamma, neuronal) & 1,16 \\
\hline CRISPLD2 & cysteine-rich secretory protein LCCL domain containing 2 & 1,14 \\
\hline HIST1H4A & histone cluster $1, \mathrm{H} 4 \mathrm{a}$ & 1,11 \\
\hline SLC1A3 & solute carrier family 1 , member 3 & 1,01 \\
\hline PSG5 & pregnancy specific beta-1-glycoprotein 5 & 1,58 \\
\hline ACVRL1 & activin A receptor type II-like 1 & 1,54 \\
\hline COL12A1 & collagen, type XII, alpha 1 & 1,34 \\
\hline CACNA2D1 & calcium channel, voltage-dependent, alpha $2 /$ delta subunit 1 & $-2,18$ \\
\hline BEX1 & brain expressed, $\mathrm{X}$-linked 1 & $-2,38$ \\
\hline NEFM & neurofilament, medium polypeptide & $-4,31$ \\
\hline HLA-DRA & major histocompatibility complex, class II, DR alpha & $-1,04$ \\
\hline SOX4 & SRY (sex determining region Y)-box 4 & $-1,07$ \\
\hline EVI2A & ecotropic viral integration site $2 \mathrm{~A}$ & $-1,08$ \\
\hline TFPI2 & tissue factor pathway inhibitor 2 & $-1,11$ \\
\hline IL17D & interleukin 17D & $-1,52$ \\
\hline $\mathrm{CFH}$ & complement factor $\mathrm{H}$ & $-1,58$ \\
\hline DUSP5 & dual specificity phosphatase 5 & $-1,61$ \\
\hline BMPER & BMP binding endothelial regulator & $-1,61$ \\
\hline EDNRA & endothelin receptor type $\mathrm{A}$ & $-1,79$ \\
\hline VCAM1 & vascular cell adhesion molecule 1 & $-1,86$ \\
\hline SERPINB2 & serpin peptidase inhibitor, clade B (ovalbumin), member 2 & $-2,11$ \\
\hline NTN4 & netrin 4 & $-2,17$ \\
\hline RGS4 & regulator of G-protein signaling 4 & $-2,31$ \\
\hline MGP & matrix Gla protein & $-2,68$ \\
\hline
\end{tabular}

Table S5.1: Differentially regulated genes between hypoxia and normoxia at passage seven. 
Chapter 6

\section{Hypoxia steers chondrogenically differentiating human mesenchymal stromal cells towards an articular cartilage phenotype}

Nicole Georgi*, Jeroen Leijten*, Clemens van Blitterswijk and Marcel Karperien

* shared co-authorship

"Well! I've often seen a cat without a grin," thought Alice; " but a grin without a cat! It's the most curious thing I ever saw in my life!" (Alice's Adventures in Wonderland, Chapter 6) 


\begin{abstract}
In vitro chondrogenic differentiation of multipotent cells results in the formation of hypertrophic cartilage, that is prone to undergo endochondral ossification when implanted. In contrast to current in vitro differentiation protocols, embryonal hyaline cartilage formation occurs under hypoxic conditions while terminal hypertrophic differentiation is correlated with normoxic conditions. In the current study we investigated whether a hypoxic environment steers chondrogenic differentiation of MSCs towards a more articular cartilage phenotype. Human MSCs were chondrogenically differentiated under hypoxic $\left(2.5 \% \mathrm{O}_{2}\right)$ or normoxic $\left(21 \% \mathrm{O}_{2}\right)$ culture conditions up to five weeks. Hypoxia, in comparison to normoxia, increased the expression of both, hyaline cartilage markers such as COL2A1, ACAN and SOX9, and articular cartilage biomarkers such as GREM1, FRZB and DKK1. Furthermore, we demonstrated that the expression of GREM1, FRZB and DKK1 is under tight control of low oxygen tension after induction of chondrogenesis. Subcutaneous implantation of in vitro differentiated 3D alginate-MSC constructs in nude mice demonstrated calcification in normoxic, but not in hypoxic pre-cultured constructs. Taken together, our data suggested that hypoxic stimulation stirs chondrogenically differentiating MSCs into a more articular cartilage phenotype and inhibits endochondral ossification upon implantation. In consequence, oxygen tension is a critical factor to consider in chondrogenic MSC differentiation protocols and is an promising cue to augment articular cartilage repair therapies.
\end{abstract}




\subsection{Introduction}

The limited regenerative capacity of articular cartilage combined with its susceptibility to damage from high energy impacts, repetitive shear and torsional forces has led to a growing need for new therapeutic strategies. The use of multipotent cells, such as mesenchymal stromal/stem cells (MSCs), to form de novo hyaline cartilage remains a promising strategy [1]. Importantly, unlike articular chondrocytes, MSC can be isolated in high numbers from various sources [2, 3] without the creation of a secondary defect in the diseased joint. [2, 4]. Unfortunately, the hyaline cartilage produced by MSCs in repair strategies is unstable. It is characterized by expression of multiple biomarkers for hypertrophic differentiation and undergoes endochondral ossification when implanted [5-8]. Indeed, accumulating evidence suggests that the current chondrogenic differentiation protocols for MSCs result in hyaline cartilage that more closely resembles growth plate-like cartilage than articular cartilage [9, 10]. This is supported by the observation that standard chondrogenesis protocols do not induce the transcription of genes that are enriched in articular cartilage when compared to growth plate cartilage. Some of these factors were reported to inhibit hypertrophic differentiation including GREM1, FRZB and DKK1 [9, 10]. During embryonal development MSCs condensate, undergo chondrogenic differentiation giving rise to hyaline cartilage, which forms the anlage of a long bone. Upon birth the hyaline cartilage is physically separated in growth plate and articular cartilage by the formation of the secondary center of ossification [11]. In contrast to in vitro chondrogenic differentiation protocols, the differentiation of MSCs in the embryo occurs in a predominantly hypoxic environment [12]. Moreover, evidence suggests that alleviation of oxygen levels drives hypertrophic differentiation and endochondral ossification of hyaline (like) cartilage $[13,14]$. We hypothesized that oxygen levels play a determining role in differentiating MSCs towards its future hyaline cartilage subtype. In the present study, we studied the effect of normoxic or hypoxic MSC differentiation culture on the expression and secretion of markers for different hyaline cartilage subtypes. We provide new evidence that once MSCs have acquired a hyaline cartilage-like phenotype, hypoxia potently increases the expression of inhibitors of hypertrophic differentiation such as GREM1, FRZB and DKK1. Moreover, calcium mineralization, a crucial step during endochondral ossification, was strongly decreased by differentiating MSCs in a hypoxic environment.

\subsection{Materials and Methods}

\subsubsection{Patient material}

The use of patient material was approved by the local hospital ethical committees and for all samples informed written consent was obtained. Human mesenchymal stromal cells (MSCs) were isolated from fresh bone marrow samples as described previously [15]. In short, aspirates were resuspended using a 20-gauge needle, plated at 500,000 cells $/ \mathrm{cm}^{2}$ and cultured in MSC proliferation medium consisting of $\alpha$-MEM (Gibco), 10\% heat-inactivated fetal bovine serum (Biowhittaker), $0.2 \mathrm{mM}$ ascorbic 
acid (Sigma), $2 \mathrm{mM}$ L-glutamine (Gibco), $100 \mathrm{U} / \mathrm{ml}$ penicillin with $100 \mathrm{mg} / \mathrm{ml}$ streptomycin (Gibco) and $1 \mathrm{ng} / \mathrm{ml}$ basic fibroblast growth factor (Instruchemie, Delfzijl, The Netherlands). Chemicals were purchased from Sigma Aldrich.

\subsubsection{Chondrogenic differentiation of MSCs}

MSCs were seeded at $2.5 \times 10^{5}$ cells per well in Cell star U-shaped 96 well plates (Greiner Bio-one), centrifuged for three minutes at $800 \mathrm{rcf}$ and incubated at $37^{\circ} \mathrm{C}$ 's and $5 \% \mathrm{CO}_{2}$ to induce pellet formation. Chondrogenic differentiation of MSCs was chemically induced by exposing cell pellets to a chondrogenic medium composed of DMEM high glucose supplemented with $100 \mu \mathrm{g} / \mathrm{ml}$ sodium pyruvate (Sigma), $0.2 \mathrm{mM}$ ascorbic acid, $50 \mathrm{mg} / \mathrm{ml}$ insulin-transferrin-selenite (ITS+Premix, BD biosciences), $100 \mathrm{U} / \mathrm{ml}$ penicillin, $100 \mu \mathrm{g} / \mathrm{ml}$ streptomycin, $0.1 \mu \mathrm{M}$ dexamethasone and $10 \mathrm{ng} / \mathrm{ml}$ transforming growth factor $\beta 3$ (TGF $\beta 3, \mathrm{R} \& \mathrm{D}$ system). MSCs were cultured up to 35 days under normoxic condition $\left(21 \% \mathrm{O}_{2}\right)$ or hypoxic condition $\left(2.5 \% \mathrm{O}_{2}\right)$, receiving biweekly medium refreshments. On day 7, 21 and 35 four pellets were pooled for RNA isolation and two were fixed in $10 \%$ buffered formalin and subsequently embedded in paraffin.

\subsubsection{Total RNA extraction}

Total RNA isolation was performed by a method previously described [16]. MSCs were lysed using Trizol reagent (Invitrogen). Total RNA of all specimens was isolated and purified using the Nucleospin RNA II kit (Bioke) according to manufacturers instructions. Total RNA yields were measured using the Nanodrop2000 (ND-1000 Spectrophotometer, Isogen LifeScience). High Quality of the RNA was verified using the Agilent 2100 bioanalyzer (Agilent).

\subsubsection{Microarray processing and statistical analysis}

NuGEN Ovation PicoSL WTA System kit followed by Encore BiotinIL module was used to generate biotinylated sscDNA starting from $50 \mathrm{ng}$ total RNA. $750 \mathrm{ng}$ of the obtained samples was hybridized onto the Illumina HumanHT-12 v4 Expression BeadChips. The samples were scanned using the Illumina iScan array scanner. Gene expression profiling was performed using lluminas Genomestudio v. 2010.3 software with the default settings advised by Illumina. The raw fluorescence intensity values were normalized applying quantile normalization. Differential gene expression was analysed using the commercial software package Genespring, version 11.5.1. (Agilent Technologies). Genes with at least a twofold difference being significantly differentially expressed according to an oneway ANOVA with a Benjamini-Hochberg FDR correction and TukeyHSD post hoc test using a cut-off rate of $\mathrm{p}=0.05$ were selected. Changes of gene expression in annotated canonical pathways and bio-functions were visualized using ingenuity pathway analysis software (Ingenuity Systems). Search Tool for the Retrieval of Interacting Genes/Proteins (STRING) was used to inves- 
tigate the predicted gene-gene interaction network [17]. Clusters were formed using Markov clustering algorithms.

\subsubsection{Quantitative real-time reverse transcriptase-polymerase chain reaction ( $q R T-P C R)$}

One microgram of total RNA was reverse-transcribed using the iScript cDNA synthesis kit (BioRad) following manufacturers instructions. $20 \mathrm{ng}$ of cDNA was amplified using Sensimix (Bioline) and the MyIQ single color Real-time PCR detection system (BioRad). Analysis was performed on the iQ5 optical system software (Biorad). The qPCR amplifications were run under the following conditions: initial denaturation for 10 minutes at $95^{\circ} \mathrm{C}$, then cycled 45 times at $95^{\circ} \mathrm{C}$ for 15 seconds, $60^{\circ} \mathrm{C}$ for 15 seconds and $72^{\circ} \mathrm{C}$ for 15 seconds and was finally followed by a melting curve. Sequences of primers are available upon request. Data visualization was achieved using the program $\mathrm{R}$ with the heatmap script.

\subsubsection{Subcutaneous implantation}

MSCs were encapsulated in $100 \mu \mathrm{l}$ of $1.5 \%$ alginate at a concentration of ten million per ml. The constructs were allowed to chondrogenically differentiate in vitro for five weeks under either normoxic or hypoxic conditions. Then the cartilaginous constructs were surgically implanted subcutaneously in 8-weeks-old nude male mice (NMRINude, Harlan) for a period of five weeks. The operative procedure and the care of the mice were performed conform to the regulation of the Central Laboratory Animal Institute (GDL), Utrecht University (Netherlands). The study was approved by the local animal ethical committee.

\subsubsection{Histological analysis}

Paraffin embedded samples were cut into $5 \mu \mathrm{m}$ sections, deparaffinized in xylene and dehydrated using graded ethanol steps. Sections were stained either with Alcian Blue $\left(0.5 \%\right.$, in $\mathrm{H}_{2} \mathrm{O}, \mathrm{pH}=1$ adjusted with $\left.\mathrm{HCl}, 30 \mathrm{~min}\right)$ and counterstained with Nuclear fast red ( $0.1 \%$ in $5 \%$ aluminium sulfate, 5 min) or with Alizarin Red $\mathrm{S}\left(2 \%\right.$ in $\mathrm{H}_{2} \mathrm{O}$, $\mathrm{pH}=4.2$ adjusted with $\mathrm{NH}_{4} \mathrm{OH}, 2 \mathrm{~min}$ ) solutions according to standard procedures.

\subsubsection{Quantitative glycosaminoglycan and DNA assay}

Cell pellets $(n=4)$ were washed with phosphate-buffered saline and frozen overnight at $-80^{\circ} \mathrm{C}$. After thawing, the constructs were digested for 16 hours with proteinase $\mathrm{K}$ (Sigma) at $56^{\circ} \mathrm{C}$. Total DNA was quantified using the Cyquant dye kit (Molecular Probes) with a fluorescent plate reader (Perkin-Elmer). The amount of glycosaminoglycans (GAG) was measured spectrophotometrically after reaction with a DMMB dye (Sigma-Aldrich). The color intensity was quantified immediately in a microplate reader (Bio-TEK Instruments) by measuring the absorbance at $540 \mathrm{~nm}$. The amount of GAG was determined using a calibration curve based on chondroitin sulfate A 
A

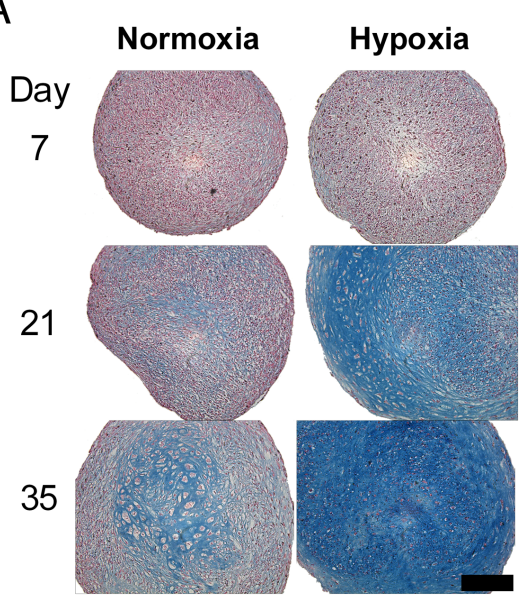

B

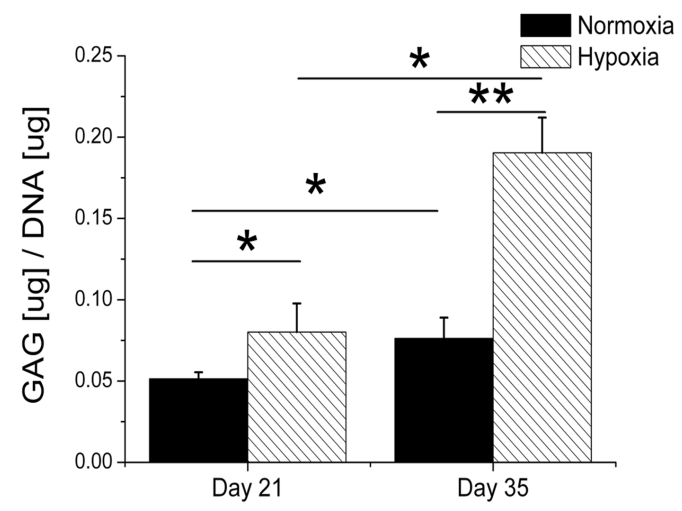

Figure 6.1: Hypoxia stimulates chondrogenic differentiation of MSCs (A) Micromasses of MSCs were cultured up to 35 days under either normoxic or hypoxic conditions. Histological analysis of midsagittal sections using Alcian Blue and Nuclear Fast Red was used to visualize chondrogenic differentiation. A representative example out of three donors is shown. (B) Biochemical analysis for GAGs was used to quantify chondrogenesis. Data represent the mean of 3 donors each measured in quadruplicate $+/-\mathrm{SD} .{ }^{*}=\mathrm{p} \leqq 0.05 ; * *=\mathrm{p} \leqq 0.01$. The black scale bar represents 100 $\mu \mathrm{m}$.

or B (Sigma-Aldrich). All values were normalized to their respective DNA amount (expressed as the GAG/DNA $[\mu \mathrm{g} / \mu \mathrm{g}]$ ratio).

\subsubsection{Quantification of GREM1, FRZB and DKK1 protein levels in conditioned media}

After 32 days of chondrogenic differentiation medium was conditioned for 3 days. GREM1 (USCN Life Science), FRZB (R\&D Systems) and DKK1 (R\&D Systems) protein levels in the culture supernatant were measured by enzyme-linked immunosorbent (following manufacturers instructions.

\subsubsection{Statistical analysis}

Statistical differences between two groups were analyzed using the Students t-test or One-way ANOVA. Statistical significance was set to a $\mathrm{p} \leqq 0.05$ and indicated with an asterisk or hash sign. Results are presented as mean +/- SD. 
A

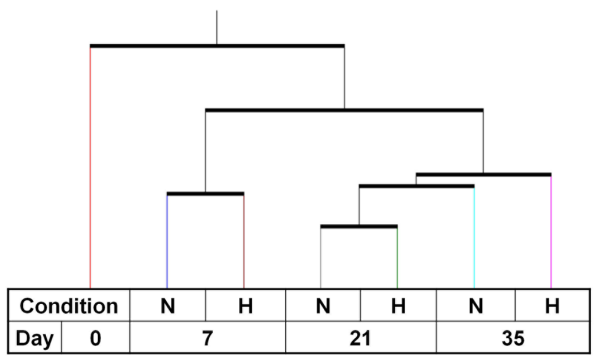

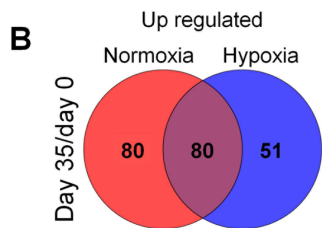

C

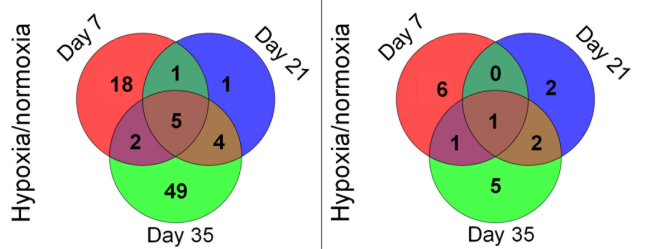

D

\begin{tabular}{|c|c|c|c|c|c|}
\hline \multicolumn{2}{|l|}{ Day 7} & \multicolumn{2}{|l|}{ Day 21} & \multicolumn{2}{|l|}{ Day 35} \\
\hline Biofunction & P-value & Biofunction & P-value & Biofunction & P-value \\
\hline Lipid Metabolism & $3.3 \mathrm{E}-05$ & Connective Tissue Development and Function & $3.7 \mathrm{E}-05$ & Skeletal System Development and Function & $1.3 \mathrm{E}-09$ \\
\hline Molecular Transport & 3.3E-05 & Skeletal System Development and Function & 3.7E-05 & Connective Tissue Development and Function & $3.5 \mathrm{E}-04$ \\
\hline Small Molecule Biochemistry & 3.3E-05 $>>>>>0$ & Tissue Morphology & 3.7E-05 & Tissue Development & 3.5E-04 $>2>>0$ \\
\hline Cellular Growth and Proliferation & $2.8 \mathrm{E}-04$ & Cell Morphology & 8.3E-04 & Cellular Assembly and Organization & 4.7E-04 \\
\hline Drug Metabolism & $5.4 E-04$ & Cellular Function and Maintenance & 8.3E-04 & Cellular Function and Maintenance & 4.7E-04 \\
\hline Cell Signaling & $6.1 \mathrm{E}-04$ & Cellular Development & 1.1E-03 & Tissue Morphology & $6.0 \mathrm{E}-04$ \\
\hline Nucleic Acid Metabolism & $6.1 \mathrm{E}-04$ & Cellular Growth and Proliferation & 1.1E-03 & Amino Acid Metabolism & 4.1E-03 \\
\hline Cell Death & $7.7 E-04$ & Cellular Movement & 1.1E-03 & Cellular Compromise & 4.1E-03 \\
\hline DNA Replication, Recombination, and Repair & $9.6 \mathrm{E}-04$ & Molecular Transport & 1.1E-03 & Cellular Development & 4.1E-03 \\
\hline Embryonic Development & $1.6 \mathrm{E}-03$ & Small Molecule Biochemistry & $1.1 \mathrm{E}-03$ & Cellular Growth and Proliferation & 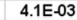 \\
\hline
\end{tabular}

Figure 6.2: Whole genome gene expression analysis of chondrogenically differentiated MSCs in either normoxic or hypoxic conditions

(A) Normalized microarray data was hierarchical clustered. (B) Venn diagrams of genes with at least a twofold difference that were significantly differentially expressed between day 35 and day 0 under normoxic or hypoxic culture conditions, or (C) between normoxic and hypoxic culture conditions at day 7, day 21 or day 35. (D) Significantly different biofunctions between normoxic and hypoxic culture conditions at day 7, day 21 and day 35. Each data point is based on the gene expression analysis of three donors.

\subsection{Results}

\subsubsection{Hypoxia stimulates chondrogenic differentiation of MSCs}

Micromasses of MSCs were differentiated into the chondrogenic lineage for up to 35 days in the presence of TGF $\beta 3$ in either normoxic or hypoxic conditions. Histological analysis demonstrated little to no positive GAG staining after seven days of culture in either normoxic or hypoxic conditions (Fig 6.1A). In contrast, at 21 days of chondrogenic differentiation intense GAG staining throughout the pellet was noted in pellets cultured in hypoxia compared to a modest GAG staining in pellets cultured in normoxia. After 35 days, GAG staining intensified in the pellets cultured in hypoxia. Interestingly, in pellets cultured in normoxia GAG staining remained lower and positive staining for GAGs was predominantly found in the center of the pellet, the area where the oxygen concentration is lowest. Biochemical quantification corroborated enhanced GAG deposition in hypoxia compared to normoxia at 21 and 35 days of differentiation (Fig 6.1B). 


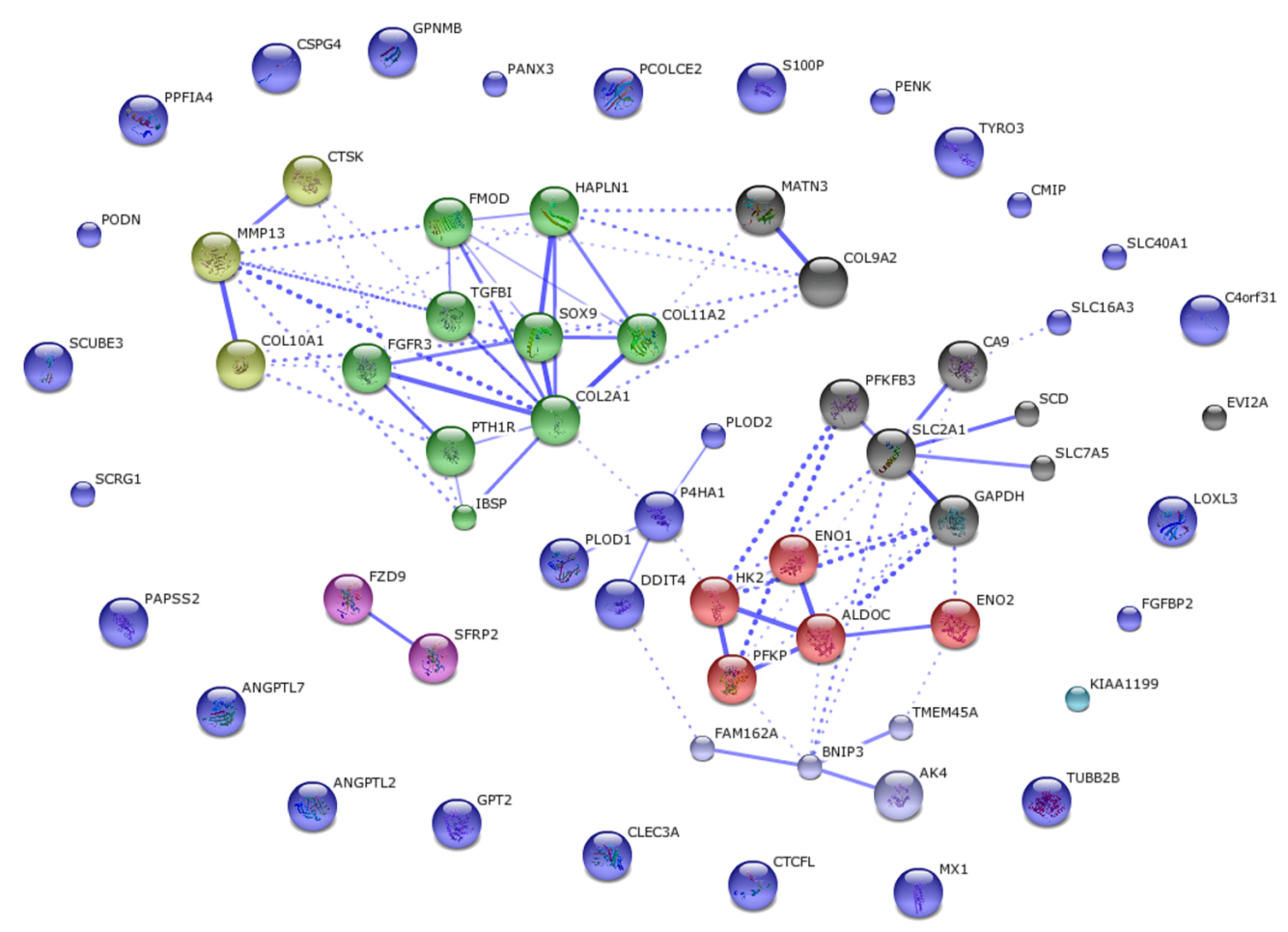

Figure 6.3: Network analysis of genes differentially expressed in MSCs after 35 days of chondrogenic differentiation in either normoxic or hypoxic conditions

Genes with at least a twofold significant difference were analyzed on known or predicted gene or protein interactions. The red cluster contains predominantly genes involved glycolysis and the green cluster contains predominantly genes with a cartilage signature. Both clusters are up-regulated in hypoxic conditions.

\subsubsection{Effect of oxygen on gene expression profile of chondrogenically differentiating MSCs}

Whole genome gene expression analysis was performed on MSCs that were chondrogenically differentiated for 7,21 or 35 days under either hypoxic or normoxic culture conditions. A total of 503 genes were significantly differentially expressed with a twofold change compared to undifferentiated cells in at least one of the conditions. Hierarchical clustering of these significantly differentially expressed genes revealed that up to day 21 of culture the experimental conditions grouped according to culture time and not to oxygen exposure. After 35 days, pellets cultured in normoxia demonstrated more resemblance with pellets cultured for 21 days than with pellets cultured for 35 days in hypoxia (Fig 6.2A). The comparison of undifferentiated MSCs pellets with chondrogenic differentiated pellets at day 35 revealed that 160 and 131 genes were up regulated more than twofold in hypoxic and normoxic culture conditions, respec- 

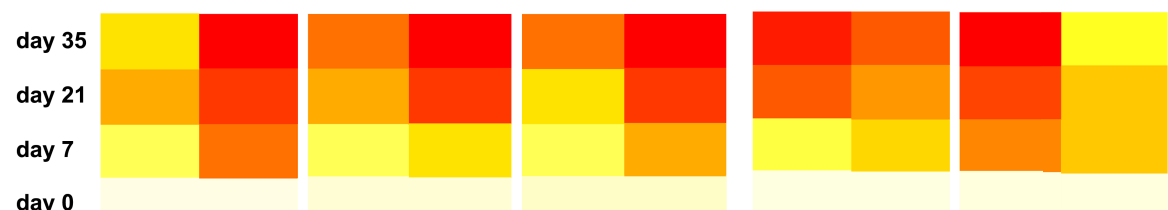

day 0
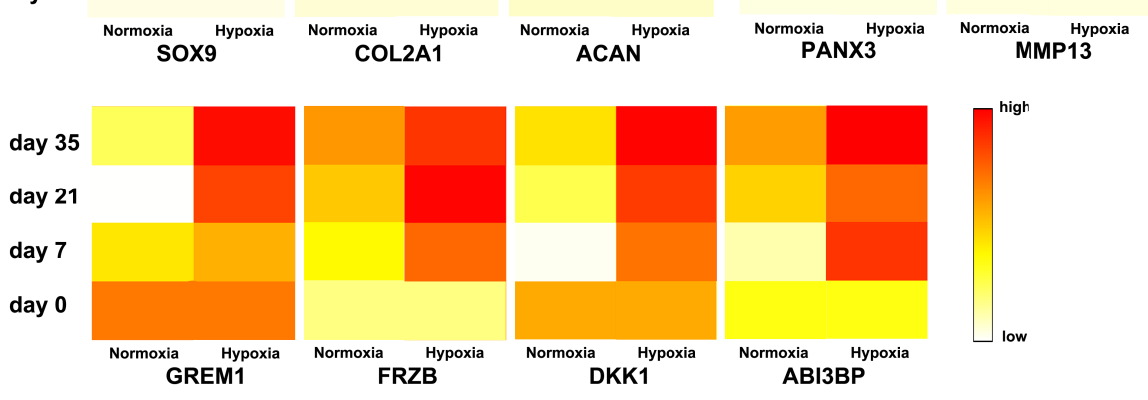

Figure 6.4: Hypoxia stimulated the expression of articular cartilageenriched gene transcripts

(A) Chondrogenically differentiating MSCs in either normoxic or hypoxic conditions were analyzed for gene expression of the cartilage markers SOX9, COL2A1 and $A C A N,(\mathrm{~B})$ the growth plate markers PANX3 and MMP13 (C) and the articular cartilage markers GREM1, FRZB, DKK1 and $A B I 3 B P$ by qPCR. Data is illustrated in a heatplot in which white represents the lowest gene expression and red represents the highest gene expression. Data represent the mean of three donors each measured in triplicate.
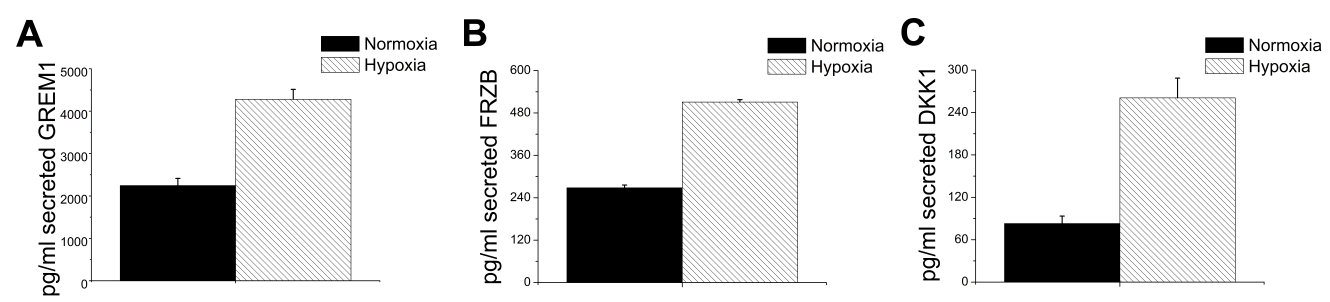

Figure 6.5: Protein quantification of MSCs chondrogenically differentiating in either hypoxia or normoxia

The articular cartilage enriched markers FRZB, GREM1 or DKK1 were analyzed using ELISA. Data represent the mean of 3 donors each measured in triplicate +/SD. ${ }^{*}=\mathrm{p} \leqq 0.05$ 


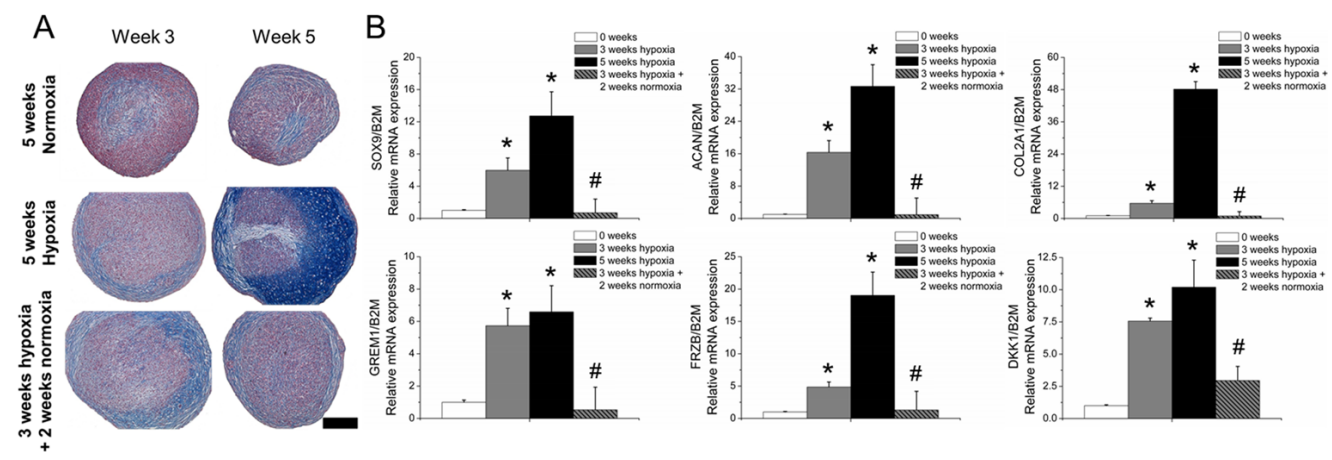

Figure 6.6: Chondrogenic differentiation of MSCs for five weeks in normoxia, five weeks in hypoxia or three weeks in hypoxia followed by two weeks of normoxia

(A) Histological analysis of GAGs using alcian blue and nuclear red on midsaggital sections of MSC micromasses, which were chondrogenically differentiated for 3 or 5 weeks. (B) Gene expression analysis of the articular cartilage markers SOX9, ACAN and COL2A1 and (C) the articular enriched markers GREM1, FRZB and DKK1. Data represent the mean of 3 donors each measured in triplicate $+/-\mathrm{SD} .{ }^{*}=\mathrm{p} \leqq 0.05$. The scale bar represents a $100 \mu \mathrm{m}$.

tively. 80 of these genes were present in both culture conditions. Correspondingly, 93 and 127 genes were down regulated after 35 days in hypoxic or normoxic culture conditions, respectively, of which 76 genes were down-regulated in both conditions (Fig 6.2B). Comparing overall differences in gene expression between hypoxia and normoxia demonstrated that 26, 11 and 60 genes were up regulated and 8,5 and 9 genes were down regulated more than twofold at day 7, 21 or 35 respectively (Fig $6.2 \mathrm{C})$. Pathway analysis revealed that the differences between hypoxia and normoxia at day 7 were dominated by metabolism and cell cycle related functions. On day 21 this shifted towards differentiation/development of connective tissue and skeletal function. This shift towards skeletal and muscular systems and function was even more prominent at day 35 as underlined by the strongly increased significance of this biofunction (P-values day 7: $1.73^{-2}$, day 21: $3.71^{-5}$, day 35: $1.34^{-9}$ ) (Fig 6.2D). Taken together, this data suggested that in the first week hypoxia leads to a strong change in the metabolism of the MSCs, but only robustly enhances chondrogenesis at later time points.

\subsubsection{Gene networks regulated by oxygen levels}

To reveal the gene networks underlying the differences in gene expression, the known and predicted gene/protein interactions were investigated for all genes twofold differentially expressed at day 35 between hypoxia and normoxia. Using Markov clustering algorithms two key nodes within the network were observed (Fig 6.3). Metabolism related genes, predominantly involving regulation of glycolysis, characterized the smaller cluster. The larger node consisted predominantly of cartilage related genes, such as 


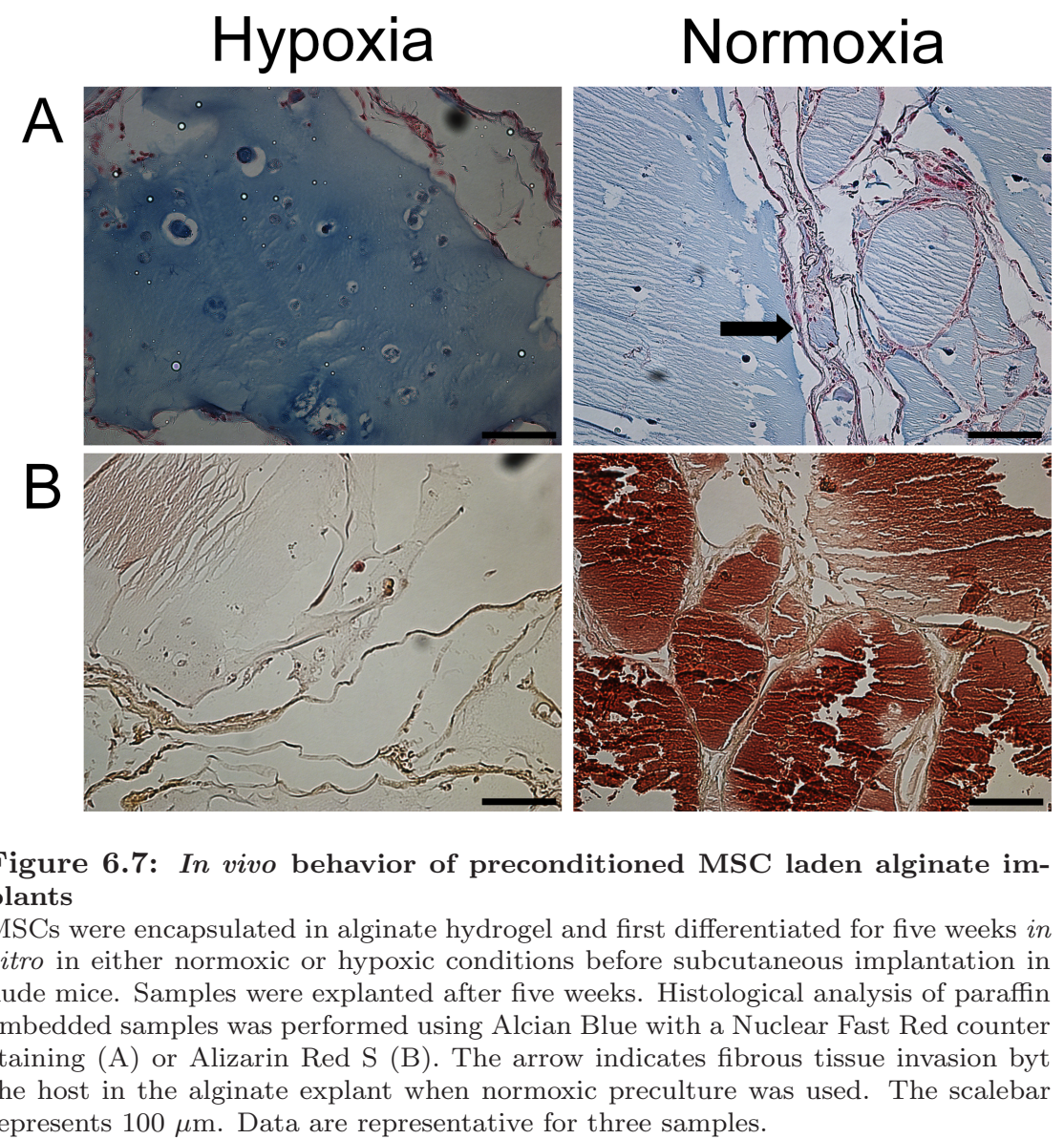

amongst others transforming growth factor beta 1 (TGFß1) and sex determining region Y-box 9 (SOX9), suggesting that these two genes might be key players in the observed enhanced cartilage formation in hypoxia.

\subsubsection{Hypoxia induces an articular cartilage-like profile in chondrogenically differentiated MSCs}

Using qPCR analysis we validated that hypoxia enhanced transcription of typical hyaline cartilage markers such as SOX9, COL2A1 and $A C A N$ (Fig 6.4A). Previously we identified a panel of markers which are enriched in either articular or growth plate cartilage [9]. The articular cartilage enriched gene transcripts of GREM1, FRZB, $D K K 1$ and $A B I 3 B P$ were robustly increased under hypoxic conditions, while under normoxic conditions these genes did not increase significantly (Fig 6.4C). The growth plate enriched gene transcripts of $P A N X 3$ and MMP13 mRNA levels were strongly 
upregulated under normoxic conditions compared to hypoxic conditions (Fig 6.4B). Moreover, GREM1, FRZB and DKK1 protein levels corroborated with the found trends on the mRNA level. The protein levels of all three secreted proteins were significantly higher after 35 days of chondrogenic differentiation under hypoxia compared to normoxia (Fig 6.5). Together, this suggests that continues exposure to hypoxia, during chondrogenesis of MSCs results in a biomarker profile that more resembles articular cartilage than growth plate cartilage.

\subsubsection{Continued hypoxia is needed to retain chondrogenic stimulus}

We next explored whether transient exposure to hypoxia was sufficient to steer MSCs chondrogenesis towards a more articular cartilage-like phenotype. MSCs were differentiated for five weeks in normoxia, five weeks in hypoxia or three weeks in hypoxia or normoxia followed by two weeks change in oxygen tension. Hypoxia progressively enhanced GAG deposition and increased SOX9, ACAN, COL2A1, GREM1, FRZB and DKK1 mRNA levels. However, when the hypoxic stress was alleviated after three weeks, it reversed the chondrogenic benefit generated by the initial exposure to hypoxia, as witnessed by decreased GAG deposition (Fig 6.6A). Moreover, when three weeks of hypoxic conditions were followed by two weeks of normoxic conditions, the increased mRNA levels of chondrogenic genes dropped to levels found in undifferentiated MSCs (Fig 6.6B). Inversely, mRNA expression levels of SOX9, ACAN, COL2A1, GREM1, FRZB and DKK1 were not significantly different between MSCs that were allowed to chondrogenically differentiate for two weeks in normoxia followed by three weeks in hypoxia and MSCs that underwent five weeks of continuous hypoxic differentiation (Fig S6.1). This suggested that oxygen level dependent stimulation is sufficient to drive MSCs undergoing chondrogenesis in either an articular cartilagelike or a growth plate-like phenotype. Moreover, this regulation of specific cartilage subtype formation appeared to be only effective after the initial differentiation period.

\subsubsection{Hypoxic chondrogenic differentiation of MSCs strongly reduces calcification upon implantation}

We next investigated whether the fate of tissue engineered constructs depended on the oxygen levels in the pre-culture period before implantation. For this, MSCs were encapsulated in alginate hydrogels and differentiated for five weeks in vitro in hypoxia or normoxia and implanted in nude mice subcutaneously. After five weeks in vivo, the specimen were explanted and histologically analyzed. Alcian Blue staining was positive in all samples, regardless of the oxygen levels during the preculture period (Fig $6.7 \mathrm{~A})$. It is noteworthy that normoxic preconditioned samples demonstrated striking invasion of non-cartilage forming cells that are presumably of the host (arrow Fig 6.7A). This phenomenon was not present in the specimens precultured in hypoxia. Alizarin Red S staining demonstrated intense mineralization in normoxic, but not in hypoxic, preconditioned implants. Together, this demonstrates that oxygen levels 
during the in vitro preculture period is an effective mechanism to prevent matrix mineralization after implantation in in vivo.

\subsection{Discussion}

Embryonal development of hyaline cartilage occurs under hypoxic conditions, while its terminal hypertrophic differentiation is associated with physiological normoxia. Mimicking this environmental factor in vitro has demonstrated similar effects. Specifically, chondrogenic differentiation under hypoxic conditions results in enhanced cartilage formation and suppresses hypertrophic differentiation [20,21]. In contrast chondrogenic differentiation under normoxic conditions yields less cartilage which has a clear hypertrophic signature $[8,18,19]$. Indeed, in our study we demonstrated that hypoxia augmented hyaline cartilage formation. More importantly, we provided novel evidence that the oxygen level is able to steer the chondrogenically differentiating MSCs towards either a more articular cartilage-like or hypertrophic/growth plate-like phenotype. Previously we identified the factors GREM1, DKK1 and FRZB being enriched in articular cartilage compared to other forms of hyaline cartilage, and able to inhibit hypertrophic differentiation. Chondrogenic differentiation of MSCs under standard culture conditions did not induce the expression of these genes. In fact, GREM1 and $D K K 1$ mRNA levels were down-regulated under normoxic culture conditions. Here, we demonstrated that hypoxic conditions were essential and sufficient to induce the expression of these vital biomarkers of articular cartilage. Varying environmental conditions like oxygen tension might be an efficient way to direct MSC differentiation into specific cartilage tissue subtypes. For example, by inducing cartilage formation under hypoxic conditions MSCs may generate a more articular cartilage-like tissue that could be used for treatment of articular cartilage defects. In contrast, by inducing cartilage formation in normoxia, cartilage with more growth plate like characteristics is formed which may be better suited for treatment of critical bone defects due to the propensity to undergo endochondral ossification [14]. However, although oxygen levels efficiently generate gene expression profiles similar to those found in articular cartilage or hypertrophic growth plate cartilage, it remains to be proven whether a change in oxygen level is sufficient to ensure or prevent hypertrophic differentiation and subsequent endochondral ossification of the formed hyaline cartilage in vivo. In our dataset we demonstrate, that subcutaneous implantations of hypoxic or normoxic conditioned 3D-MSCs constructs undergo limited chondrogenesis but reveal higher amount of calcification when pre-cultured in normoxia (Fig 6.7). These findings are in line with recent findings that hypoxic differentiation of MSCs reduces MSC hypertrophy [20]. Further studies at implantation sites of interest should now address the clinical applicability of these findings. Alternatively, hypoxic culture conditions can be utilized for expanding or preconditioning MSCs. MSCs in hypoxic low density cultures displayed superior expansion capabilities compared to traditional methods [21]. Moreover, hypoxia better maintained the multipotency of MSCs even in long term cultures [22]. This was emphasized by the increase in chondrogenic potential of MSC expanded under hypoxic conditions compared to those that were expanded 
under normoxic conditions [23]. Taken together, in the present study we demonstrated that reduction of oxygen tension boosted the chondrogenic differentiation of human bone-marrow derived MSCs in pellet cultures in the presence of TGF $\beta 3$. In addition, we showed that differentiation in hypoxia also steered the differentiation into a more articular cartilage-like tissue rather than a growth plate-like tissue. In conclusion variation of the oxygen tension might be a critical factor to consider in MSC differentiation protocols. 


\section{References}

1. Leijten, J.C., et al., Cell Sources for Articular Cartilage Repair Strategies: Shifting from Monocultures to Cocultures. Tissue Eng Part B Rev, 2012.

2. Pittenger, M.F., et al., Multilineage potential of adult human mesenchymal stem cells. Science, 1999. 284(5411): p. 143-7.

3. Hass, R., et al., Different populations and sources of human mesenchymal stem cells (MSC): A comparison of adult and neonatal tissue-derived MSC. Cell Commun Signal, 2011. 9: p. 12.

4. De Bari, C., et al., Multipotent mesenchymal stem cells from adult human synovial membrane. Arthritis Rheum, 2001. 44(8): p. 1928-42.

5. Jukes, J.M., et al., Endochondral bone tissue engineering using embryonic stem cells. Proc Natl Acad Sci U S A, 2008. 105(19): p. 6840-5.

6. Steck, E., et al., Mesenchymal stem cell differentiation in an experimental cartilage defect: restriction of hypertrophy to bone-close neocartilage. Stem Cells Dev, 2009. 18(7): p. 969-78.

7. Koga, H., et al., Synovial stem cells are regionally specified according to local microenvironments after implantation for cartilage regeneration. Stem Cells, 2007. 25(3): p. 689-96.

8. Pelttari, K., et al., Premature induction of hypertrophy during in vitro chondrogenesis of human mesenchymal stem cells correlates with calcification and vascular invasion after ectopic transplantation in SCID mice. Arthritis Rheum, 2006. 54(10): p. 3254-66.

9. Leijten, J.C., et al., Gremlin 1, frizzled-related protein, and Dkk-1 are key regulators of human articular cartilage homeostasis. Arthritis Rheum, 2012. 64(10): p. 3302-12.

10. van Gool, S.A., et al., Fetal Mesenchymal Stromal Cells Differentiating towards Chondrocytes Acquire a Gene Expression Profile Resembling Human Growth Plate Cartilage. PLoS One, 2012. 7(11): p. e44561.

11. Zuscik, M.J., et al., Regulation of chondrogenesis and chondrocyte differentiation by stress. J Clin Invest, 2008. 118(2): p. 429-38.

12. Provot, S., et al., Hif-1alpha regulates differentiation of limb bud mesenchyme and joint development. J Cell Biol, 2007. 177(3): p. 451-64.

13. Morita, K., et al., Reactive oxygen species induce chondrocyte hypertrophy in endochondral ossification. J Exp Med, 2007. 204(7): p. 1613-23.

14. Leijten, J.C., et al., Hypoxia inhibits hypertrophic differentiation and endochondral ossification in explanted tibiae. PLoS One, 2012. 7(11): p. e49896.

15. Both, S.K., et al., A rapid and efficient method for expansion of human mesenchymal stem cells. Tissue Eng, 2007. 13(1): p. 3-9.

16. Heinrichs, C., et al., Dexamethasone increases growth hormone receptor messenger ribonucleic acid levels in liver and growth plate. Endocrinology, 1994. 135(3): p. 1113-8.

17. Szklarczyk, D., et al., The STRING database in 2011: functional interaction networks of proteins, globally integrated and scored. Nucleic Acids Res, 2011. 39(Database issue): p. D561-8.

18. Khan, W.S., A.B. Adesida, and T.E. Hardingham, Hypoxic conditions increase hypoxia-inducible transcription factor 2alpha and enhance chondrogenesis in stem cells from the infrapatellar fat pad of osteoarthritis patients. Arthritis Res Ther, 2007. 9(3): p. R55. 19. Kanichai, M., et al., Hypoxia promotes chondrogenesis in rat mesenchymal stem cells: a role for AKT and hypoxia-inducible factor (HIF)-1alpha. J Cell Physiol, 2008. 216(3): p. 708-15. 20. Gawlitta, D., et al., Hypoxia Impedes Hypertrophic Chondrogenesis of Human Multipotent Stromal Cells. Tissue Eng Part A, 2012.

21. Tsai, C.C., et al., Hypoxia inhibits senescence and maintains mesenchymal stem cell properties through down-regulation of E2A-p21 by HIF-TWIST. Blood, 2011. 117(2): p. 459-69. 22. Basciano, L., et al., Long term culture of mesenchymal stem cells in hypoxia promotes a genetic program maintaining their undifferentiated and multipotent status. BMC Cell Biol, 2011. 12: p. 12.

23. Sheehy, E.J., C.T. Buckley, and D.J. Kelly, Oxygen tension regulates the osteogenic, chondrogenic and endochondral phenotype of bone marrow derived mesenchymal stem cells. Biochem Biophys Res Commun, 2011. 


\section{Supplemental Figures}
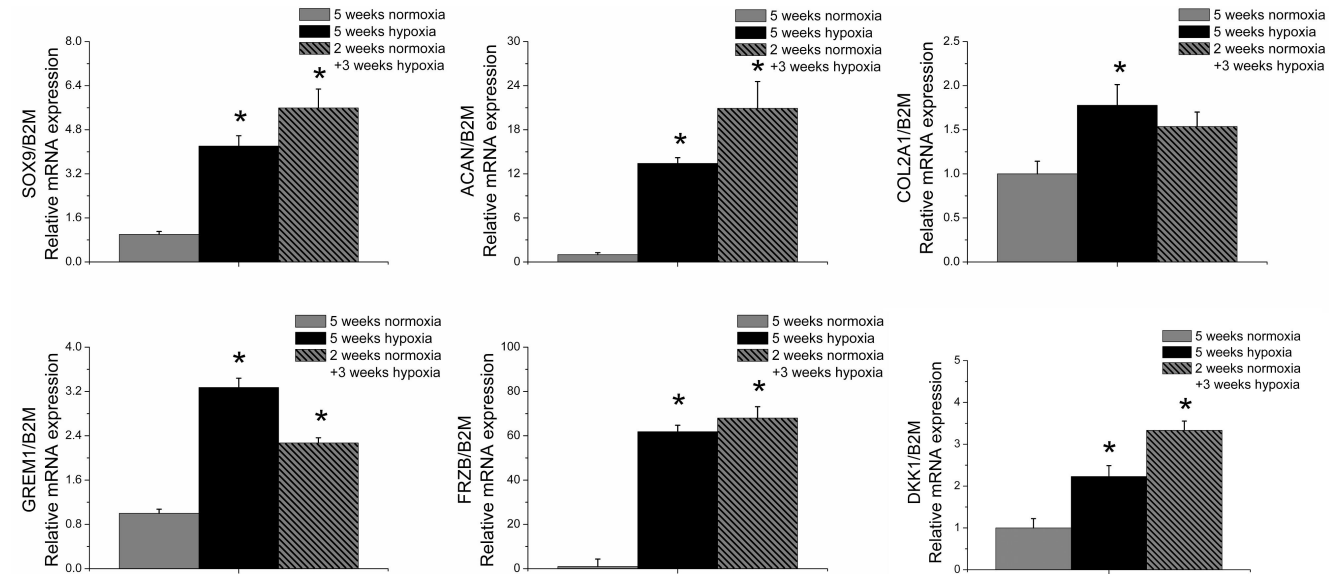

Figure S6.1: MSCs underwent chondrogenic differentiation for five weeks in normoxia, five in weeks hypoxia or two weeks in normoxia followed by three weeks in hypoxia.

(A) mRNA levels of articular cartilage matrix components SOX9, ACAN and COL2A1 and (B) the secreted antagonists GREM1, FRZB and DKK1 were investigated using qPCR. Data represent the mean of three donors each measured in triplicate $+/-\mathrm{SD} . *=\mathrm{P} \leqq 0.05$ 
Chapter 7

The effect of o-Phenanthroline as mediator of the hypoxic response in cartilage tissue engineering models

Nicole Georgi*, Ellie Landman*, Travis Klein, Clemens van Blitterswijk, Marcel Karperien

* shared co-authorship

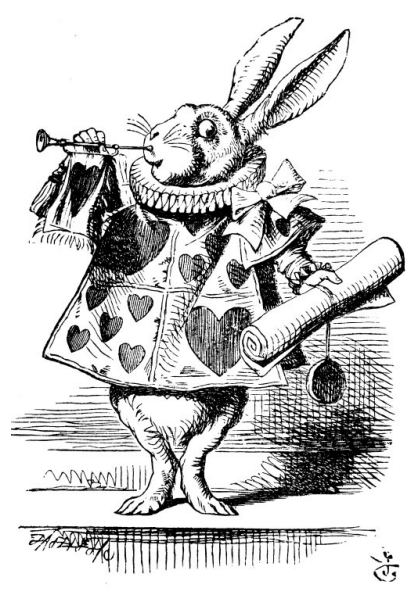




\begin{abstract}
Due to the avascular nature of articular cartilage, resident chondrocytes experience a hypoxic environment in vivo. Disturbance of this hypoxic environment, via cartilage degradation in osteoarthritis or in vitro culture in normoxic $\left(21 \% \mathrm{O}_{2}\right)$ conditions, may lead to a poor chondrocyte response and/or cartilage degradation. Hypoxic conditions in vitro have been shown to enhance the chondrogenic response of chondrocytes, but such cultures require specialized culture equipment. As an alternative, small hypoxia mimicking compounds are of interest to improve in vitro cartilage formation, and prevent cartilage degradation. O-Phenanthroline is a recently identified activator of the hypoxic response, as well as a known metalloproteinase (MMP) inhibitor. We tested o-Phenanthrolines potential to improve chondrogenesis of human chondrocytes $(\mathrm{hCh})$ in a pellet culture model, as well as its ability to inhibit cartilage catabolism in response to treatment with $\mathrm{TNF} \alpha$ and IL1 $\beta$ in an explant model. O-Phenanthroline reduced the expression of MMP3 and MMP13 mRNA levels in chondrogenic differentiation of $\mathrm{hCh}$ as well as in response to $\mathrm{TNF} \alpha / \mathrm{IL} 1 \beta$ exposure in the explant model. Interestingly, o-Phenanthroline significantly inhibited matrix degradation in a $\mathrm{TNF} \alpha / \mathrm{IL} 1 \beta$ dependent model of cartilage degeneration when compared to control and natural hypoxia $\left(2.5 \% \mathrm{O}_{2}\right)$. O-Phenanthroline had limited ability to improve the chondrogenic differentiation or matrix deposition in the pellet model of differentiation.

The data presented in this study indicate that o-Phenanthroline can be employed to inhibit MMP expression and activity, whereas it seems to have limited effect in improving chondrogenic differentiation.
\end{abstract}




\subsection{Introduction}

Since articular cartilage is an avascular tissue, the oxygen supply to chondrocytes is limited. Therefore, the oxygen tension within articular cartilage ranges from $6 \%$ at the joint surface to $0.5 \%$ in the deeper zones $[1,2]$. For chondrocytes to be able to survive in this hypoxic environment, they need an adaptive mechanism [3, 4]. Recently, the transcription factor Hypoxia Inducible Factor (HIF) $1 \alpha$ has been shown to play an important role in cartilage homeostasis by enabling the chondrocytes to survive in hypoxic conditions [5]. The gradient of oxygenation in cartilage is strongly linked to HIF1 $\alpha$ expression as well as to the level of chondrocytic growth arrest, cell size and the delay in hypertrophic differentiation [5]. Under normoxic conditions, HIF1 $\alpha$ is hydroxylated on specific proline residues by oxygen activated propyl-hydroxylase domain (PHD)-containing enzymes and subsequently targeted for ubiquitylation and degradation by the proteasome upon recognition by the von Hippel Lindau (VHL) protein. In hypoxia, PHD activity is reduced, resulting in stabilization of the HIF1 $\alpha$ protein, which subsequently forms a complex with the constitutively expressed HIF1 $\alpha$ subunit. This complex then translocates to the nucleus where it binds hypoxia responsive elements (HRE) present in the promoters of target genes, initiating the transcription of genes involved in metabolism, angiogenesis and apoptosis. HIF $1 \alpha$ stabilization and translocation can also be induced by hypoxia mimicking compounds, which exert their effect by targeting PHD activity [6]. In a similar manner, the activity of HIF $2 \alpha$, which is a homolog of HIF $1 \alpha$, is regulated via oxygen-dependent degradation [7].

It has been demonstrated that growth plate cartilage is hypoxic and that conditional inactivation of $\mathrm{HIF} 1 \alpha$ in cartilage causes cell death in both the proliferative and the hypertrophic zone of the cartilage [5]. This further indicates that HIF1 $\alpha$ is crucial for the survival of chondrocytes under hypoxic conditions. In addition, several indications have been found for the involvement of hypoxia in maintaining the chondrogenic phenotype as well as promoting the chondrogenic differentiation of progenitor cells [8-10]. The differentiated phenotype of chondrocytes can, for example, be disturbed by exposure to inflammatory factors such as Interleukin (IL) $1 \beta$ in the osteoarthritic joint. This process is marked by a change in the chondrocyte phenotype leading to a major reduction in the synthesis of extracellular matrix molecules, such as Collagen type II (COL2A1), ultimately resulting in cartilage matrix reduction and degradation [11]. Interestingly, an imbalance of HIF2 $\alpha$ expression was found in osteoarthritic cartilage, implying the involvement of this protein in the pathogenic mechanism of cartilage degeneration. The involvement of HIF $2 \alpha$ in cartilage degradation is supported by the findings that overexpression of HIF $2 \alpha$ elicits cartilage destruction, whereas genetic depletion of HIF2 $\alpha$ inhibits experimentally induced cartilage destruction [7].

Next to the involvement of hypoxia in maintaining the differentiated chondrocyte phenotype, indications have been found for a beneficial effect of hypoxia on chondrogenic differentiation. The chondrogenic differentiation of expanded human primary chondrocytes $(\mathrm{hCh})$ is normally hampered by their limited differentiation potential as well as by their preference to hypertrophic differentiation, which is associated with cartilage calcification. In hypoxic conditions, the chondrogenic potential of hCh as well as MSCs is enhanced in a HIF1 $\alpha$ dependent manner $[8,12]$. Transcriptional 
activation of SOX9 has been shown to have a major role in this beneficial effect [9]. Furthermore, hypertrophic differentiation is inhibited by hypoxic culture conditions $[13,14]$.

Since loss of the chondrocyte phenotype as well as hypertrophic differentiation are involved in osteoarthritis [15], the role of hypoxia in these processes might indicate that disturbance of hypoxic conditions is involved in cartilage degradation. The in vitro response of chondrocytes to IL1 $\beta$, which is one of the major cytokines implicated in cartilage degradation, appears to be greater in a hypoxic environment [16]. Interestingly, IL1 $\beta$ induced down-regulation of SOX9, ACAN and COL2A1 in chondrogenically differentiated human MSCs was partially alleviated by hypoxia. In contrast, the expression of cartilage-degrading matrix metalloproteinases $M M P 1$ and MMP3 was lowered. Therefore, parts of the beneficial effects of hypoxic culture conditions appear to be due to anti-catabolic effects on matrix degrading proteins and preservation of SOX9 expression [17].

Since hypoxia appears to be involved in both cartilage homeostasis and chondrogenic differentiation, modulating hypoxia-induced signaling might be beneficial in preventing cartilage degradation as well as inducing chondrogenic differentiation. Identication and use of compounds that have HIF $1 \alpha$ activation potential offer a strategy to improve cartilage matrix formation. In a screen of 1408 compounds o-Phenanthroline was identified as a potent HIF1 $\alpha$ inducing agent under normoxic conditions [18] and outperformed known hypoxia mimicking agents colbalt sulfate $\left(\mathrm{CoSO}_{4}\right)$ and cobalt chloride $\left(\mathrm{CoCl}_{2}\right)$. O-Phenanthroline is a strong chelator of metal ions and has been identified previously as an inhibitor of matrix metalloproteinases (MMP) by chelating $\mathrm{Zn}^{++}$ions which are required for MMP activity. Likewise, it is expected that o-Phenanthroline blocks the activity of dioxygenases, like PHDs, by chelating essential free ferrous ions and thereby activates the HIF pathway [6]. Both effects of $o$ Phenanthroline may be beneficial in cartilage homeostasis. In this study, we assessed the potential of o-Phenanthroline to improve chondrogenic differentiation in a hCh pellet culture model by mimicking hypoxia. Furthermore we tested $o$-Phenanthrolines efficiency to reduce matrix catabolism in an explant model for cartilage degradation.

\subsection{Materials and Methods}

\subsubsection{Human cell culture}

The use of human knee biopsies was approved by a local Medical Ethics Committee in Enschede and Almelo. Human primary chondrocytes (hCh) for HIF1 $\alpha$ staining were obtained from full-thickness cartilage dissected from knee biopsies of a patient undergoing total knee replacement, as published previously [19]. In short, the harvested cartilage was digested overnight in $0.15 \%$ collagenase type 2 solution. After digestion, hCh were washed and cultured up to passage one on tissue culture plastic in chondrocyte proliferation medium (Dulbeccos modified Eagles medium supplemented with $10 \%$ fetal bovine serum, $1 \%$ nonessential amino acids, $0.2 \mathrm{mM}$ ascorbic acid 2-phosphate, $0.4 \mathrm{mM}$ proline, $100 \mathrm{U}$ penicillin/mL, and $100 \mathrm{mg} / \mathrm{mL}$ streptomycin) 
at a density of 3000 cells $/ \mathrm{cm}^{2}$ under standard culture conditions $\left(21 \% \mathrm{O}_{2}, 5 \% \mathrm{CO}_{2}\right.$, $37^{\circ} \mathrm{C}$ ). Chemicals were purchased from Sigma-Aldrich.

\subsubsection{HIF $1 \alpha$ immunofluorescence staining}

hChs $\left(3000\right.$ cells $/ \mathrm{cm}^{2}$ ) were seeded on coverslips and cultured for 48 hours before adding respective compounds (o-Phenanthroline $10 \mu \mathrm{M}$, positive control: cobalt chloride $\left.\left(\mathrm{CoCl}_{2}\right) 25 \mu \mathrm{M}\right)$ or transfer of the cultures to a hypoxia incubator. Cells were exposed to the small molecules for 18 hours and 24 hours. In some experiments cells were cultured for 24 hours and 48 hours after an 18 hours compound exposure to follow cell growth after compound removal. Samples were washed and fixed (4\% paraformaldehyde (PFA), $15 \mathrm{~min}$ ) at indicated time points and stained for HIF1 $\alpha$. In short, cells were blocked (2\% BSA / 0.1\% Triton X-100 in PBS, 20 min) and the monoclonal mouse anti-HIF1 $\alpha$ antibody (1:100, Clone H1alpha67; Novus Biologicals, Littleton, USA) or mouse IgG isotype control antibody (Invitrogen) was incubated overnight. Cells were rinsed with PBS (5 min) before adding Alexa Fluor ${ }^{\circledR}$ 488labelled goat anti-mouse antibody (1:400, Invitrogen) and DAPI $(5 \mu \mathrm{g} / \mathrm{mL})$ in $2 \%$ BSA/PBS. Cells were rinsed with PBS (5 min) and covered with ProLong Gold. For total cell counts cell numbers were counted with Image J. In short, images were thresholded to only allow quantification of positive DAPI staining. Nuclei were then counted with the count particles-tool.

\subsubsection{Pellet culture}

For the differentiation study, micromass pellets of $0.25 \times 10^{6} \mathrm{hCh}$ were seeded in a round-bottom well plate and centrifuged ( $5 \mathrm{~min}, 500 \mathrm{rcf}$ ). Pellets were cultured for ten days in chondrogenic differentiation medium (DMEM, 1\% ITS, $0.2 \mathrm{mM}$ ascorbic acid, $100 \mathrm{U} / \mathrm{mL}$ penicillin, $100 \mathrm{mg} / \mathrm{mL}$ streptomycin, $100 \mathrm{mg} / \mathrm{ml}$ sodium pyruvate, 10 $\mathrm{ng} / \mathrm{ml}$ TGF $\beta 3,10^{-7} \mathrm{M}$ dexamethasone) before transferring pellets to hypoxia $(2.5 \%$ $\left.\mathrm{O}_{2}\right)$ or incubation with o-Phenanthroline $(5.0 \mu \mathrm{M})$ respectively for one week,.

\subsubsection{Mouse fetal metatarsals}

Animal experiments were approved by the ethical committee of the University Medical Centre Utrecht. Mouse fetal metatarsals were isolated from FVB mouse embryos (time-paired, Harlan) at day 17.5 of gestation [20, 21]. After isolation, metatarsals were individually cultured in 24-well plates in $200 \mu$ l per well of $\alpha$-MEM, supplemented with $10 \% \mathrm{FBS}, 100 \mathrm{U} / \mathrm{mL}$ penicillin, $100 \mathrm{mg} / \mathrm{mL}$ streptomycin and $1 \%$ Glutamax (Invitrogen) for 48 hours. After this equilibration period, metatarsals were cultured in hypoxia or in the presence of $5.0 \mu \mathrm{M}$ of $o$-Phenanthroline either alone or in combination with $10 \mathrm{ng} / \mathrm{mL} \mathrm{TNF} \alpha$ and IL1 $\beta$ (R\&D Systems) for four days for gene expression analysis or for seven days for histological analysis. 


\begin{tabular}{|c|c|c|c|c|}
\hline $\begin{array}{l}\text { Gene } \\
\text { Symbol } \\
\end{array}$ & & Sequence & $\begin{array}{l}\text { Annealing } \\
\text { temperature }\end{array}$ & Product size \\
\hline $\begin{array}{l}\text { Hum } \\
\text { COL2A1 }\end{array}$ & $\begin{array}{l}\text { For } \\
\text { Rev }\end{array}$ & $\begin{array}{l}\text { 5' CGTCCAGATGACCTTCCTACG 3' } \\
\text { 5' TGAGCAGGGCCTTCTTGAG 3' }\end{array}$ & $60^{\circ} \mathrm{C}$ & $122 \mathrm{bp}$ \\
\hline $\begin{array}{l}\text { Hum } \\
\text { SOX9 }\end{array}$ & $\begin{array}{l}\text { For } \\
\text { Rev }\end{array}$ & $\begin{array}{l}\text { 5' TGGGCAAGCTCTGGAGACTTC 3' } \\
\text { 5' ATCCGGGTGGTCCTTCTTGTG 3' }\end{array}$ & $60^{\circ} \mathrm{C}$ & $98 \mathrm{bp}$ \\
\hline $\begin{array}{l}\text { Hum } \\
M M P 9\end{array}$ & $\begin{array}{l}\text { For } \\
\text { Rev }\end{array}$ & $\begin{array}{l}\text { 5' GTGATTGACGACGCCTTTGC 3' } \\
\text { 5' CGCGACACCAAACTGGATGAC 3' }\end{array}$ & $60^{\circ} \mathrm{C}$ & $115 \mathrm{bp}$ \\
\hline $\begin{array}{l}\text { Hum } \\
M M P 13\end{array}$ & $\begin{array}{l}\text { For } \\
\text { Rev }\end{array}$ & $\begin{array}{l}\text { 5' AAGGAGCATGGCGACTTCT 3' } \\
\text { 5' TGGCCCAGGAGGAAAAGC 3' }\end{array}$ & $60^{\circ} \mathrm{C}$ & 72 bp \\
\hline $\begin{array}{l}\text { Hum } \\
B 2 M\end{array}$ & $\begin{array}{l}\text { For } \\
\text { Rev }\end{array}$ & $\begin{array}{l}\text { 5' GACTTGTCTTTCAGCAAGGA 3' } \\
\text { 5' ACAAAGTCACATGGTTCACA 3' }\end{array}$ & $60^{\circ} \mathrm{C}$ & $106 \mathrm{bp}$ \\
\hline $\begin{array}{l}\text { Mus } \\
\text { Acan }\end{array}$ & $\begin{array}{l}\text { For } \\
\text { Rev }\end{array}$ & $\begin{array}{l}\text { 5' AGGCAGCGTGATCCTTACC 3' } \\
\text { 5' GGCCTCTCCAGTCTCATTCTC 3' }\end{array}$ & $60^{\circ} \mathrm{C}$ & $136 \mathrm{bp}$ \\
\hline $\begin{array}{l}\text { Mus } \\
\text { Col2al }\end{array}$ & $\begin{array}{l}\text { For } \\
\text { Rev }\end{array}$ & $\begin{array}{l}\text { 5' CGTCCAGATGACCTTCCTACG 3' } \\
\text { 5' TGAGCAGGGCCTTCTTGAG 3' }\end{array}$ & $60^{\circ} \mathrm{C}$ & $122 \mathrm{bp}$ \\
\hline $\begin{array}{l}\text { Mus } \\
\text { Sox9 }\end{array}$ & $\begin{array}{l}\text { For } \\
\text { Rev }\end{array}$ & $\begin{array}{l}\text { 5' TGGGAGCGACAACTTTACCA 3' } \\
\text { 5' AACAGAGAACGAAACCGGGG 3' }\end{array}$ & $60^{\circ} \mathrm{C}$ & 88 bp \\
\hline $\begin{array}{l}\text { Mus } \\
\text { Mmp9 }\end{array}$ & $\begin{array}{l}\text { For } \\
\text { Rev }\end{array}$ & $\begin{array}{l}\text { 5' GGTGATTGACGACGCCTTTGC 3' } \\
\text { 5' CGCGACACCAAACTGGATGAC 3' }\end{array}$ & $60^{\circ} \mathrm{C}$ & $115 \mathrm{bp}$ \\
\hline $\begin{array}{l}\text { Mus } \\
\text { Mmp13 }\end{array}$ & $\begin{array}{l}\text { For } \\
\text { Rev }\end{array}$ & $\begin{array}{l}\text { 5' AAGGAGCATGGCGACTTCT 3' } \\
\text { 5' TGGCCCAGGAGGAAAAGC 3' }\end{array}$ & $60^{\circ} \mathrm{C}$ & 72 bp \\
\hline $\begin{array}{l}\text { Mus } \\
B 2 m\end{array}$ & $\begin{array}{l}\text { For } \\
\text { Rev }\end{array}$ & $\begin{array}{l}\text { 5' GACTTGTCTTTCAGCAAGGA 3' } \\
\text { 5' ACAAAGTCACATGGTTCACA 3' }\end{array}$ & $60^{\circ} \mathrm{C}$ & $106 \mathrm{bp}$ \\
\hline
\end{tabular}

Table 7.1: Primer sequences for qPCR analysis

\subsubsection{Histological analysis}

For histological examination, specimens were fixed in $10 \%$ buffered formalin and dehydrated in an ethanol series before embedding in paraffin. Five micrometer sections were cut using a rotary microtome (HM355S Microm International). Sections were stained for glycosaminoglycans using 0.5\% Alcian Blue in $\mathrm{H}_{2} \mathrm{O}$ ( $\mathrm{pH}$ set to 1 using $\mathrm{HCl}$ ) for 30 minutes and counterstained in 1\% Nuclear Fast Red in 5\% aluminum sulfate for 5 minutes.

\subsubsection{Gene expression analysis}

Metatarsals (five metatarsals per condition) and pellets (one pellet per condition) were lysed in Trizol (Invitrogen) for RNA isolation, using the Nucleospin RNA II kit (Bioke) according to manufacturers protocol. Subsequently, cDNA was synthesized using the iScript cDNA synthesis kit (Bio-Rad). Quantitative polymerase chain reaction (qPCR) was performed using iQ SYBR Green Supermix (Bio-Rad) on MyiQ2 TwoColor Real-Time PCR Detection System (Bio-Rad). Gene expression was normalized using species- specific B2M mRNA primers and expressed as fold induction compared to controls. Primer sequences are listed in Table 7.1. 


\subsubsection{Statistical analysis}

Statistical differences between two groups were analyzed using the Students t-test or One-way ANOVA. Statistical significance was set to a $\mathrm{p} \leqq 0.05$ and indicated with an asterisk or hash sign. Results are presented as mean +/- SD.

\subsection{Results}

\subsubsection{Dose-response effect of o-Phenanthroline on HIF $1 \alpha$ expression and cell count}

We first assessed the most effective concentration of o-Phenanthroline to induce HIF $1 \alpha$ expression in chondrocytes. Based on immunofluorescence staining of HIF $1 \alpha$, we found the highest upregulation of HIF $1 \alpha$ expression in cells treated with $2.5 \mu \mathrm{M}$ or $5.0 \mu \mathrm{M}$ o-Phenanthroline for 18 hours (Fig. 7.1A). At higher concentrations, oPhenanthroline became less effective. After 18 hours, o-Phenanthroline caused a slight increase in cell counts at concentrations up to $2.5 \mu \mathrm{M}$, whereas higher concentrations significantly reduced cell counts below the control level (Fig. 7.1B). Since $2.5 \mu \mathrm{M}$ and $5.0 \mu \mathrm{M}$ o-Phenanthroline effectively induced HIF $1 \alpha$ expression, a concentration of $5.0 \mu \mathrm{M}$ was used in subsequent experiments. This decision was mainly made based on the fact that we worked with 3D constructs and organ cultures in the following experiments. Previously we have shown that chondrocytes in a 3D environment are less sensitive than cells cultured in 2D [22].

\subsubsection{O-Phenanthroline induces HIF $1 \alpha$ expression less effectively than hypoxia or $\mathrm{CoCl}_{2}$}

Furthermore, cells exposed to $5.0 \mu \mathrm{M}$ o-Phenanthroline or hypoxia $\left(2.5 \% \mathrm{O}_{2}\right)$ were compared based on their effects on HIF $1 \alpha$ expression. For better evaluation of HIF $1 \alpha$ expression $25 \mu \mathrm{M} \mathrm{CoCl}_{2}$ was used as a reference. Compared to hypoxia and $\mathrm{CoCl}_{2}$, $o$-Phenanthroline was less effective in inducing HIF1 $\alpha$ expression in primary chondrocyte cultures. Low levels of HIF $1 \alpha$ expression were detected in hCh under normoxic culture, as reported before [23] (Fig. 7.2A). Exposure of hCh for 18 hours to hypoxia, defined as $2.5 \%$ oxygen, increased HIF $1 \alpha$ expression. HIF $1 \alpha$ expression was also increased by $25 \mu \mathrm{M} \mathrm{CoCl}_{2}$ and $5.0 \mu \mathrm{M}$ o-Phenanthroline. These hypoxia mimicking compounds were less effective than hypoxia.

Cell numbers significantly increased from 18 hours to 42 hours in control and in hypoxia (Fig. 7.2B). Interestingly, cell numbers increased more in cultures exposed to hypoxia, compared to control (Fig. 7.2B). In cultures exposed to o-Phenanthroline, proliferation was inhibited, while no increase in cell count was observed in cultures exposed to $\mathrm{CoCl}_{2}$ (Fig. 7.2B). Some cell nuclei showed a slight increase in size after o-Phenanthroline incubation. Treatment with o-Phenanthroline and $\mathrm{CoCl}_{2}$ both affected cell shape. In particular HIF $1 \alpha$ positive stained cells show a shortened more round cell shape or untypical spindle like extensions. We then examined the effect of the compounds on cell numbers after a pulse stimulation for 42 hours followed by 


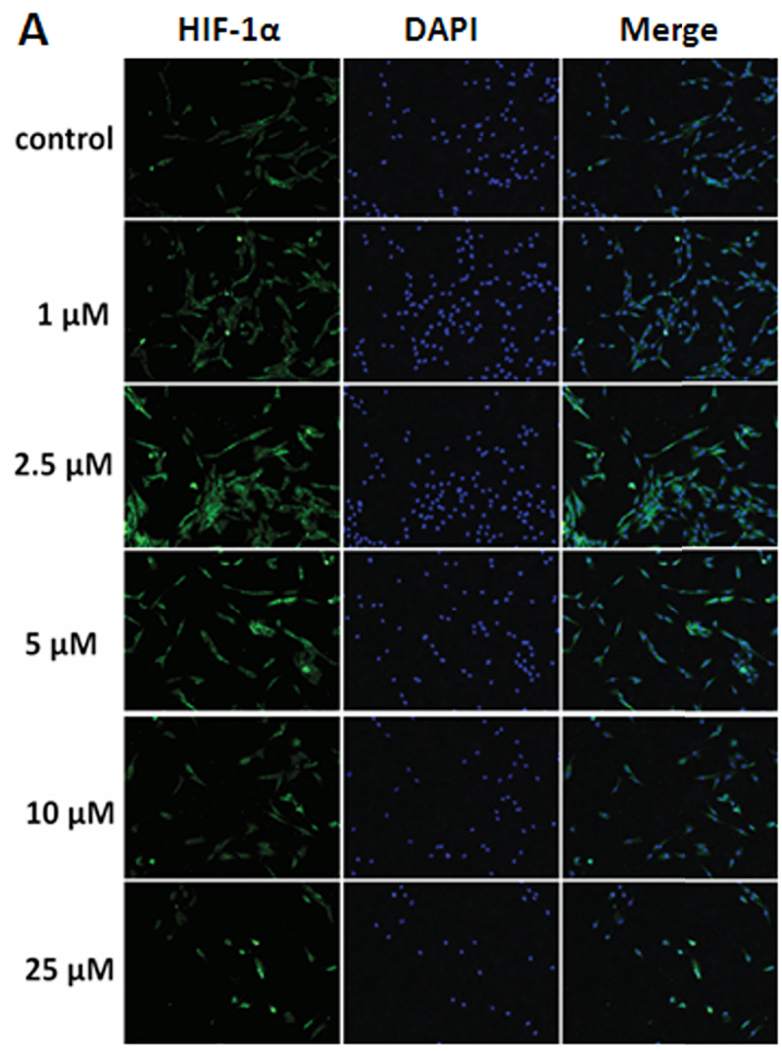

B

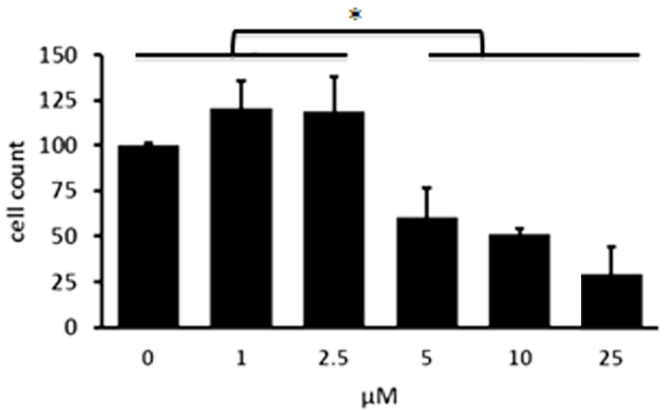

Figure 7.1: O-Phenanthroline dose-dependently affects HIF $\alpha$ expression and cell numbers

(A) hCh were exposed for 18 hours to concentrations of $1.0 \mu \mathrm{M}$ to $25 \mu \mathrm{M}$ of $o$ Phenanthroline and the effect on HIF1 $\alpha$ expression was studied using immunofluorescence. HIF $1 \alpha$ is illustrated in green (Alexa488) and nuclei are in blue (DAPI). A representative picture out of two experiments is shown; (B) hCh counts of cells exposed to different concentrations of o-Phenanthroline, indicating a toxic influence of the compound starting from $5 \mu \mathrm{M}$ onwards. Data represents the mean confidence intervals $(\alpha=0.05)$ counts in three different wells. 


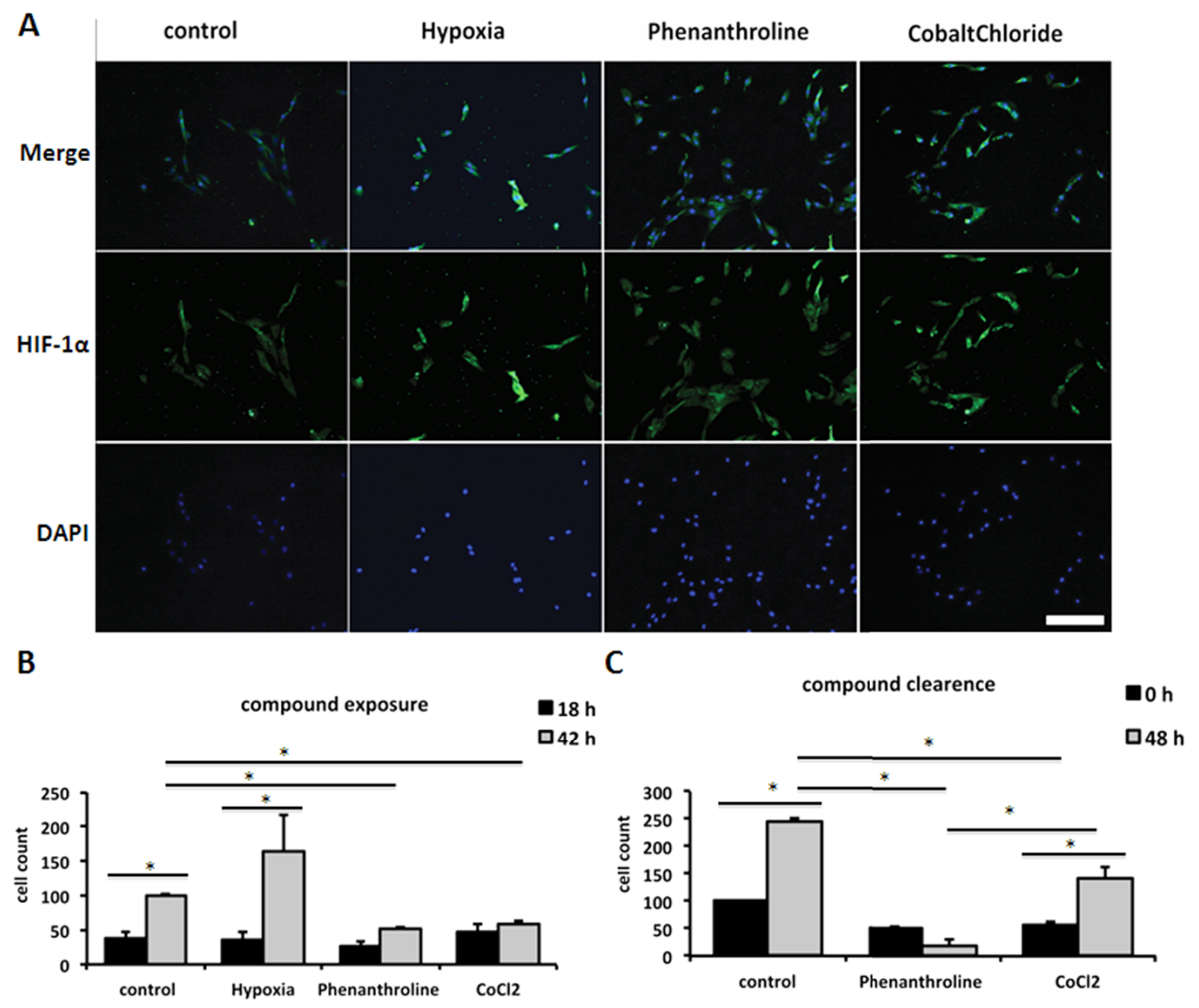

Figure 7.2: HIF1 $\alpha$ expression and cell counts after exposure to hypoxia and small molecule compounds

((A) hCh were exposed to hypoxia, o-Phenanthroline $(5.0 \mu \mathrm{M})$ and $\mathrm{CoCl}_{2}(25 \mu \mathrm{M})$ respectively. After 18 hours exposure, HIF1 $\alpha$ expression was visualized using immunofluorescence. The most intense HIF $1 \alpha$ stain was found after exposure to hypoxia followed by the known hypoxia mimicking substance $\mathrm{CoCl}_{2}$ and o-Phenanthroline. HIF $1 \alpha$ is shown in green (Alexa488) and nuclei are in blue (DAPI). Translocation of HIF $1 \alpha$ to the nucleus was not visible. A representative picture out of two replicates is shown. (B) hCh cell counts 18 hours and 42 hours after exposure to hypoxia or small molecule hypoxia mimics. Data represent the confidence intervals $(\alpha=0.05)$ of 3 counts in different wells. (C) hCh cell counts after compound removal indicating the irreversible influence of $o$-Phenanthroline on the proliferation potential, hCh exposed to $\mathrm{CoCl}_{2}$ start to proliferate again after compound removal. Data represents the mean confidence intervals $(\alpha=0.05)$ counts in three different wells. 


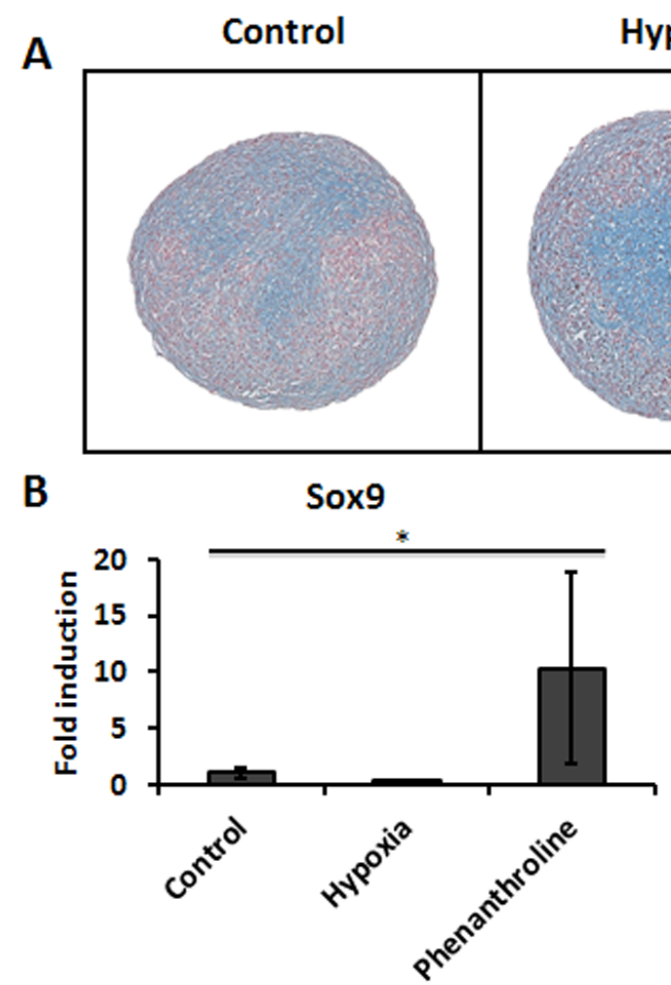

Hypoxia

Phenanthroline
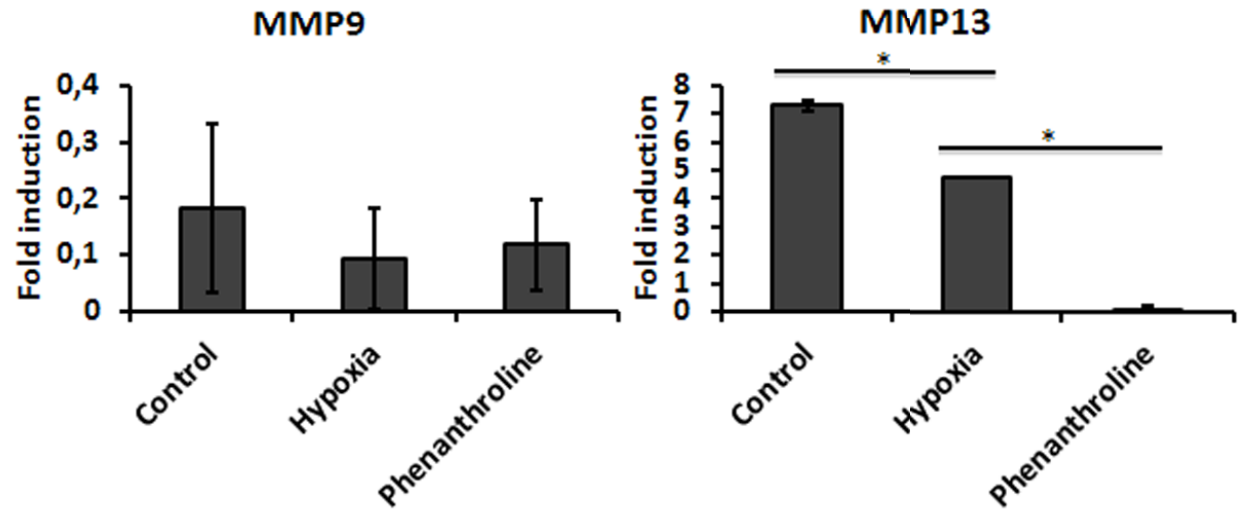

Figure 7.3: O-Phenanthroline does not induce cartilage matrix deposition, whereas hypoxia increases cartilage matrix

A) Alcian Blue staining for sulphated GAGs after seven days of exposure to 5.0 $\mu \mathrm{M}$ o-Phenanthroline or hypoxia after 10 days of chondrogenic re-differentiation of $\mathrm{hCh}$ in pellet culture, indicated no beneficial effect of Phenanthroline exposure on matrix formation. A representative picture out of three experiments is shown; (B) The mRNA expression of the chondrogenic marker SOX9 was significantly higher upregulated by o-Phenanthroline, compared to hypoxia, whereas COL2A1 expression was downregulated by $o$-Phenanthroline and $\mathrm{CoCl}_{2}$, in contrast to hypoxia. Hypoxia as well as o-Phenanthroline and $\mathrm{CoCl}_{2}$ downregulated mRNA expression of MMP9 and MMP13. Data represents the mean of three pellets +/- confidence intervals $(\alpha=0.05)$ 
a recovery period of 48 hours. As expected, cells cultured under control conditions continued to proliferate over time. The growth inhibitory effect of $\mathrm{CoCl}_{2}$ was alleviated. In contrast, cell numbers in cultures treated with o-Phenanthroline continued to decrease (Fig $7.2 \mathrm{C}$ ).

\subsubsection{O-Phenanthroline increased $S O X 9 \mathrm{mRNA}$ expression in chondrogenic pellets, without affecting cartilage matrix deposition}

The effect of o-Phenanthroline on chondrogenic differentiation of hCh cultured in micromass pellets was investigated. In line with previous observations, chondrogenic differentiation in hCh pellets was increased when cells were cultured in hypoxia as assessed using Alcian Blue staining (Fig. 7.3A). Similar Alcian Blue staining was observed in pellets treated with o-Phenanthroline compared to control (Fig 7.3A). Gene expression analysis showed an increase in mRNA expression of the cartilage transcription factor $S O X 9$ when cells were cultured in hypoxia or in the presence of $5.0 \mu \mathrm{M}$ o-Phenanthroline. COL2A1 mRNA expression was significantly upregulated by hypoxic culture conditions, whereas $o$-Phenanthroline did not significantly affect COL2A1 mRNA expression. The mRNA expression of the cartilage matrix degrading enzyme $M M P 9$ was not significantly affected by hypoxia or $o$-Phenanthroline, whereas MMP13 expression was significantly decreased by both hypoxia and $o$-Phenanthroline (Fig. 7.3B).

\subsubsection{O-Phenanthroline blocks IL1 $\beta / \mathrm{TNF} \alpha$ induced cartilage degradation}

As shown before, treatment with IL1 $\beta$ and TNF $\alpha$ for 7 days potently induces cartilage matrix degradation in mouse fetal metatarsals [24]. When cultured in hypoxic conditions, IL1 $\beta$ and TNF $\alpha$ induced cartilage degradation is reduced, as observed by light microscopy. In addition, Alcian Blue staining of mouse fetal metatarsals shows that glycosaminoglycan content of the extracellular matrix is to some extent, preserved in hypoxia. Interestingly $5 \mu \mathrm{M}$ o-Phenanthroline was even more effective in preserving the original shape of the metatarsals, as well as the glycosaminoglycan content of the extracellular matrix, when compared to hypoxia treatment (Fig. 7.4A).

Measurements of mouse metatarsals revealed a decrease in longitudinal length as well as length of the primary ossification center after treatment with IL1 $\beta$ and $\mathrm{TNF} \alpha$. o-Phenanthroline partially blocked the decrease in size of the metatarsals upon exposure to IL1 $\beta$ and $\mathrm{TNF} \alpha$, but led to a significant increase of the primary ossification center. In contrast the growth of the primary ossification center was decreased when metatarsals were cultured in hypoxia (Fig. 7.4B).

Gene expression analysis showed that o-Phenanthroline increased basal mRNA expression of Sox9, whereas basal mRNA expression of Acan and Col2a1 was decreased. Both hypoxia and o-Phenanthroline decreased expression of $\mathrm{Mmp}$ 9, without affecting Mmp13 expression (Fig. 7.4C). In line with previous studies, treatment of the mouse fetal metatarsals with IL1 $\beta$ and $\mathrm{TNF} \alpha$ had a deleterious effect on the expression of 
Acan and Col2a1, whereas this effect could be partially prevented when culturing the metatarsals in hypoxia and even more so in the presence of o-Phenanthroline (Fig. 7.4C). We found, in accordance with previous studies [24], that expression of matrix catabolic genes $M m p 13$ and $M m p 9$ was up-regulated by treatment of the metatarsals with IL1 $\beta$ and TNF $\alpha$. Hypoxic culture conditions and o-Phenanthroline down-regulated the expression of both catabolic genes, $M m p 9$ and expression $M m p 13$ (Fig. 7.4C).

\subsection{Discussion}

The data presented in this study indicates that o-Phenanthroline can be employed to reduce IL1 $\beta / \mathrm{TNF} \alpha$ mediated regulation of MMPs and matrix degradation in organ culture, whereas it seems to have limited capability to improve matrix deposition in chondrogenically differentiating hCh pellet cultures.

In previous research, o-Phenanthroline has been shown to induce the HIF $1 \alpha$-based hypoxic response as efficient as $1.0 \% \mathrm{O}_{2}$ or $\mathrm{CoCl}_{2}$ [18]. The strong iron chelator oPhenanthroline activates the cellular hypoxic response by depriving the HIF hydroxylases of their ferrous ion, whereas $\mathrm{CoCl}_{2}$ makes use of its cobaltous ions to compete with iron [25]. In immunological staining of chondrocytes for HIF1 $\alpha$ we demonstrate that o-Phenanthroline and $\mathrm{CoCl}_{2}$ induce HIF $1 \alpha$ stabilization. Both compounds could not outperform the natural hypoxic response based on HIF1 $\alpha$-staining. Furthermore, the exposure to o-Phenanthroline or $\mathrm{CoCl}_{2}$ leads to a growth arrest after 42 hours of exposure. It is likely that the strong chelating capacity of o-Phenanthroline for a variety of ions can explain side-effects not seen in hypoxic culture conditions. Similar mechanisms might apply for the competing activity for active ion binding sites of $\mathrm{CoCl}_{2}$ These findings are in line with the results of Felber et al, showing that o-Phenanthroline can block the activity of DNA polymerase in E.coli by the formation of $\mathrm{Zn}^{++}$complexes [26]. Inhibition of DNA polymerase may well explain o-Phenanthroline inhibitory effects on cell proliferation. Additionally, it has been shown that derivatives of $o$-Phenanthroline can be targeted to cancer cells to induce cell death [27] and that the formed complexes of o-Phenanthroline can have a proapoptotic effect [28].

In hCh pellet cultures, o-Phenanthroline was added after ten days of differentiation culture and removed after one week of exposure. o-Phenanthroline treated pellets showed the strongest activation of SOX9 mRNA expression, as well as down regulation of the mRNA encoding the catabolic genes MMP9 and MMP13. SOX9, a major transcription factor regulating chondrogenesis, was reported before to be strongly associated with HIF1 $\alpha$ and to be up-regulated after hypoxic exposure in hCh [9]. Our data indicates that the primary hypoxic response induced by o-Phenanthroline even outperforms the low oxygen $\left(2.5 \% \mathrm{O}_{2}\right)$ treatment with respect of $S O X 9 \mathrm{mRNA}$ expression. COL2A1, a regulated gene of chondrogenesis downstream of SOX9 displayed no up-regulation upon o-Phenanthroline exposure, but a positive response after hypoxic treatment. Furthermore, histological staining for glycosaminoglycans indicated a higher amount of matrix synthesis in hypoxic cultured pellets and thereby 


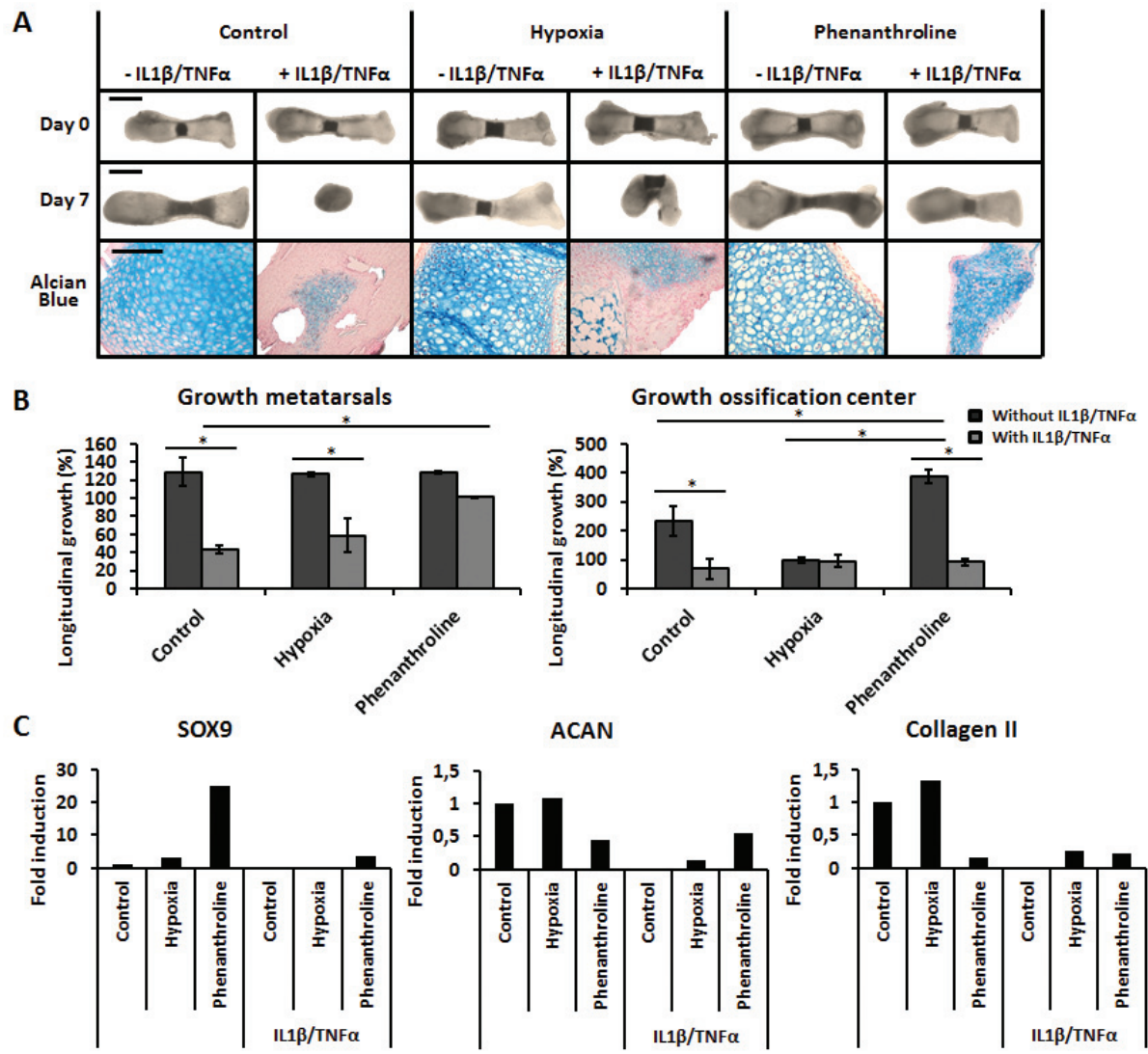

Figure 7.4: O-Phenanthroline blocks IL1 $\beta /$ TNF $\alpha$ induced cartilage matrix degradation in mouse fetal metatarsals

(A) Light microscopy as well as Alcian Blue staining show a protective effect of $o$-Phenanthroline against IL1 $\beta$ and $\mathrm{TNF} \alpha(10 \mathrm{ng} / \mathrm{ml}$ of both) induced cartilage matrix degradation. Representative pictures out of three experiments are shown. (B) The longitudinal growth of the metatarsals, as measured along the sagittal axis, was significantly decreased by the treatment with IL1 $\beta$ and TNF $\alpha$. o-Phenanthroline partially rescued the decrease in size of the metatarsals. The growth of the primary ossification center was decreased when metatarsals were cultured in hypoxia, whereas treatment with o-Phenanthroline significantly increased ossification. Treatment with IL1 $\beta$ and TNF $\alpha$ decreased the size of the ossification center in all conditions. Data represents the mean of three metatarsals per condition $+/$ - confidence intervals $(\alpha$ $=0.05)(\mathrm{C})$ Gene expression analysis shows that mRNA expression of the chondrogenic marker Sox9 is induced by o-Phenanthroline, whereas cartilage matrix genes Acan and Col2a1 are downregulated. Both o-Phenanthroline and hypoxic culture conditions partially block IL1 $\beta$ / TNF $\alpha$ induced downregulation of these genes. Hypoxia and o-Phenanthroline both downregulate Mmp9 and Mmp13 mRNA expression, whether or not IL1 $\beta$ and $\mathrm{TNF} \alpha$ are added. Data represents mRNA analysis of five pooled metatarsals. 
underlines the mRNA findings. The downregulation of MMP9 and MMP13 under hypoxia and o-Phenanthroline points to a potential anti-catabolic effect. We were able to confirm that $o$-Phenanthroline can act as potential inhibitor of MMP mRNA expression and reduce their activity in explant cultures [6].

The use of ex vivo organ cultures in the investigation of the effect of small molecule compounds can give information about their effect on various cells, tissues and ultimately on tissue growth. Miclea et al. showed that metatarsals can be employed to study the onset as well as possible interventions of cartilage degradation [29]. It has been shown that osteoarthritic cartilage destruction is marked by an overexpression of HIF2 $\alpha$, leading to up-regulation of a pool of MMPs and other catabolic mediators [7]. o-Phenanthroline is both known as an MMP inhibitor [26] as well as an inhibitor of PHD-mediated HIF1 $\alpha$ degradation [6]. Consequently, it might provide an active compound to overcome an imbalance in cartilage anabolism and catabolism as present in response to pro-inflammatory cytokines. Exposure to IL1 $\beta$ and TNF $\alpha$ induces total degradation of ex vivo cultured metatarsals, whereas hypoxia and $o$ Phenanthroline reduce matrix degradation and even maintain the elongated shape of the metatarsals as shown by Alcian Blue staining and measurements of longitudinal bone length. Furthermore, the growth of the primary ossification center was decreased when metatarsals were cultured in hypoxia but was increased when exposed to o-Phenanthroline (Fig. 7.4B). These findings suggest an effect on endochondral ossification, which is likely to be independent of the hypoxic response when o-Phenanthroline is used [13]. This regulation might be linked to the proposed role of HIF $2 \alpha$ in this process and to the downregulation of matrix degrading proteins, like MMPs [7]. The opposite effects of o-Phenanthroline and hypoxic culture conditions on the primary ossification center in cartilage explant cultures suggests that both treatments have common as well as distinct cellular effects [30].

Ultimately we conclude that small molecule hypoxia mimicking compounds, like $o$ Phenanthroline or $\mathrm{CoCl}_{2}$ can provide a platform to induce part of a hypoxic response. Off target effects are likely due to competition with metal ions for active positions in proteins which is not limited to the hypoxic pathway but can affect a myriad of cellular responses leading to genetic modifications, cell arrest and apoptosis. These effects are highly undesired for medical therapy and allow at this moment only for a limited ex vivo applicability of these small compounds. For - emphin vivo applications in osteoarthritic therapy intense dose-effect studies would have to be performed or more specific small compounds have to be developed to limit negative side effects. 


\section{References}

1. 1. Lund-Olesen K. Oxygen tension in synovial fluids. Arthritis Rheum 1970; 13: 769-776.

2. Brighton CT, Heppenstall RB. Oxygen tension in zones of the epiphyseal plate, the metaphysis and diaphysis. An in vitro and in vivo study in rats and rabbits. J Bone Joint Surg Am 1971; 53: 719-728.

3. Pfander D, Gelse K. Hypoxia and osteoarthritis: how chondrocytes survive hypoxic environments. Curr Opin Rheumatol 2007; 19: 457-462.

4. Murphy CL, Thoms BL, Vaghjiani RJ, Lafont JE. Hypoxia. HIF-mediated articular chondrocyte function: prospects for cartilage repair. Arthritis Res Ther 2009; 11: 213.

5. Schipani E, Ryan HE, Didrickson S, Kobayashi T, Knight M, Johnson RS. Hypoxia in cartilage: HIF-1alpha is essential for chondrocyte growth arrest and survival. Genes Dev 2001; 15: 2865-2876 6. Maxwell P, Salnikow K. HIF-1: an oxygen and metal responsive transcription factor. Cancer biology \& therapy 2004; 3: 29-35.

7. Yang S, Kim J, Ryu JH, Oh H, Chun CH, Kim BJ, et al. Hypoxia-inducible factor-2alpha is a catabolic regulator of osteoarthritic cartilage destruction. Nat Med 2010; 16: 687-693.

8. Muller J, Benz K, Ahlers M, Gaissmaier C, Mollenhauer J. Hypoxic conditions during expansion culture prime human mesenchymal stromal precursor cells for chondrogenic differentiation in threedimensional cultures. Cell Transplant 2011.

9. Robins JC, Akeno N, Mukherjee A, Dalal RR, Aronow BJ, Koopman P, et al. Hypoxia induces chondrocyte-specific gene expression in mesenchymal cells in association with transcriptional activation of Sox9. Bone 2005; 37: 313-322.

10. Lafont JE, Talma S, Hopfgarten C, Murphy CL. Hypoxia promotes the differentiated human articular chondrocyte phenotype through SOX9-dependent and -independent pathways. J Biol Chem 2008; 283: 4778-4786.

11. Hwang SG, Yu SS, Poo H, Chun JS. c-Jun/activator protein-1 mediates interleukin-1beta-induced dedifferentiation but not cyclooxygenase-2 expression in articular chondrocytes. J Biol Chem 2005; 280: 29780-29787.

12. Kanichai M, Ferguson D, Prendergast PJ, Campbell VA. Hypoxia promotes chondrogenesis in rat mesenchymal stem cells: a role for AKT and hypoxia-inducible factor (HIF)-1alpha. J Cell Physiol 2008; 216: 708-715.

13. J.C.H. Leijten LSMT, E.B.M. Landman, C.A. van Blitterswijk and M. Karperien. Hypoxia inhibits hypertrophic differentiation and endochondral ossification in explanted tibias. Submitted 2012 .

14. Gawlitta D, van Rijen MH, Schrijver EJ, Alblas J, Dhert WJ. Hypoxia Impedes Hypertrophic Chondrogenesis of Human Multipotent Stromal Cells. Tissue Eng Part A 2012.

15. Pfander D, Gelse K. Hypoxia and osteoarthritis: how chondrocytes survive hypoxic environments. Current Opinion in Rheumatology 2007; 19: 457-462.

16. Martin G, Andriamanalijaona R, Grassel S, Dreier R, Mathy-Hartert M, Bogdanowicz P, et al. Effect of hypoxia and reoxygenation on gene expression and response to interleukin-1 in cultured articular chondrocytes. Arthritis Rheum 2004; 50: 3549-3560.

17. Felka T, Schafer R, Schewe B, Benz K, Aicher WK. Hypoxia reduces the inhibitory effect of IL-1beta on chondrogenic differentiation of FCS-free expanded MSC. Osteoarthritis Cartilage 2009; 17: $1368-1376$.

18. Xia M, Huang R, Sun Y, Semenza GL, Aldred SF, Witt KL, et al. Identification of chemical compounds that induce HIF-1alpha activity. Toxicol Sci 2009; 112: 153-163.

19. Bogie JF, Stinissen P, Hellings N, Hendriks JJ. Myelin-phagocytosing macrophages modulate autoreactive T cell proliferation. J Neuroinflammation 2011; 8: 85 .

20. van Beek E, Oostendorp-van de Ruit M, van der Wee-Pals L, Bloys H, van de Bent C, Papapoulos $\mathrm{S}$, et al. Effects of experimental conditions on the release of 45 calcium from prelabeled fetal mouse long bones. Bone 1995; 17: 63-69.

21. Haaijman A, Karperien M, Lanske B, Hendriks J, Lowik CW, Bronckers AL, et al. Inhibition of terminal chondrocyte differentiation by bone morphogenetic protein 7 (OP-1) in vitro depends on the periarticular region but is independent of parathyroid hormone-related peptide. Bone 1999; 25: 397-404.

22. Miclea RL, Siebelt M, Finos L, Goeman JJ, Lowik CW, Oostdijk W, et al. Inhibition of Gsk3beta 
in cartilage induces osteoarthritic features through activation of the canonical Wnt signaling pathway. Osteoarthritis Cartilage 2011; 19: 1363-1372.

23. Coimbra IB, Jimenez SA, Hawkins DF, Piera-Velazquez S, Stokes DG. Hypoxia inducible factor1 alpha expression in human normal and osteoarthritic chondrocytes. Osteoarthritis Cartilage 2004; 12: $336-345$.

24. E.B.M. Landman RLM, C.A. van Blitterswijk, M. Karperien. Small molecule inhibitors of WNT $/ \beta$-catenin signaling block IL1 $\beta / \mathrm{TNF} \alpha$ induced cartilage degradation. Submitted 2012.25. Banerji B, Conejo-Garcia A, McNeill LA, McDonough MA, Buck MR, Hewitson KS, et al. The inhibition of factor inhibiting hypoxia-inducible factor (FIH) by beta-oxocarboxylic acids. Chem Commun (Camb) 2005: 5438-5440.

26. Felber JP, Coombs TL, Vallee BL. The mechanism of inhibition of carboxypeptidase A by 1,10phenanthroline. Biochemistry 1962; 1: 231-238.

27. Sergeeva NN, Donnier-Marechal M, Vaz GM, Davies AM, Senge MO. Simple but powerful: phenanthroline-based small molecules for cellular imaging and cancer screening. Bioorg Med Chem Lett $2011 ; 21: 4385-4388$.

28. Zhou H, Zheng C, Zou G, Tao D, Gong J. G(1)-phase specific apoptosis in liver carcinoma cell line induced by copper-1,10-phenanthroline. Int J Biochem Cell Biol 2002; 34: 678-684.

29. Miclea RL, Siebelt M, Finos L, Goeman JJ, Lowik CWGM, Oostdijk W, et al. Inhibition of Gsk3 beta in cartilage induces osteoarthritic features through activation of the canonical Wnt signaling pathway. Osteoarthritis and Cartilage 2011; 19: 1363-1372.

30. Hirao M, Tamai N, Tsumaki N, Yoshikawa H, Myoui A. Oxygen tension regulates chondrocyte differentiation and function during endochondral ossification. The Journal of biological chemistry 2006; 281: 31079-31092 
Chapter 8

Cholesterol and phosphocholine as regulators of the chondrogenic response in co-cultures of MSCs and primary chondrocytes

Nicole Georgi, Berta Cillero Pastor, Gert Eijkel, Andras Kiss, Clemens van Blitterswijk, Ron Heeren and Marcel Karperien 


\begin{abstract}
Previously we have shown that cartilage matrix formation is improved in pellet cocultures of mesenchymal stromal/stem cells (MSCs) and primary chondrocytes. Until now it is not known which factors mediate this phenomenon. In this study we have used time-of-flight secondary ion mass spectrometry (TOF-SIMS) and matrix-assisted laser desorption/ionization (MALDI) imaging mass spectrometry (IMS) to identify and locate possible small molecule mediators involved in the communication between MSCs and primary chondrocytes. Using IMS, we studied the lipid composition of the tissue arrays containing mono- and co-cultures of MSCs and chondrocytes cultured under oxygen tension of $21 \% \mathrm{O}_{2}$ and $2.5 \% \mathrm{O}_{2}$. Low oxygen tension did not reveal the same quantitative improvement of chondrogenesis in co-culture as seen previously. Therefore TOF-SIMS as well as MALDI-IMS was employed to investigate the differences in lipid and small molecules between both, different oxygen tensions as well as different cell types. Normoxic conditions $\left(21 \% \mathrm{O}_{2}\right)$ revealed a general higher lipid level than hypoxic conditons $\left(2.5 \% \mathrm{O}_{2}\right)$. We detected phosphocholine $(\mathrm{m} / z$ 184.1) being specific for chondrocytes and diacylglycerol $(\mathrm{m} / z$ 577), being more abundant in normoxic cultured MSCs. Most interestingly, cholesterol masses $m / z 369.3[\mathrm{M}+\mathrm{H}-$ $\mathrm{H} 2 \mathrm{O}]^{+}, 385.3[\mathrm{M}-\mathrm{H}]^{+}$and $970[2 \mathrm{M}+\mathrm{Au}]^{+}$were mainly separating normoxic culture conditions from hypoxic ones, indicating higher cholesterol content in normoxia. We prove that TOF-SIMS and MALDI-IMS can be employed to investigate and map lipid levels in different cellular combinations as well as different oxygen tensions. The technique is thereby powerful to detect small mediators for improved cartilage formation.
\end{abstract}




\subsection{Introduction}

Since cartilage is a tissue with low self-repair capability it is important to advance and improve potential therapy strategies. The current standard for repair of large size cartilage defects is autologous chondrocyte implantation (ACI) [1]. Nonetheless, for sufficient cell harvest ACI creates donor site injury as well as the need for further expansion of retrieved chondrocytes. Chondrocyte expansion is associated with dedifferentiation as well as loss of chondrogenic potential. It has been postulated that partial replacement of chondrocytes with mesenchymal stromal/stem cells (MSCs) can circumvent the problem of expansion and associated loss of function. Hendriks et al. demonstrated that cartilage matrix formation can be improved by the co-culture of chondrocytes with MSCs [2]. Further studies proved that this phenomenon is mediated by an increase of chondrocyte proliferation mediated by MSC secreted trophic factors [3]. So far, the identity of these soluble or cellular trophic factors remained unclear.

It has been hypothesized that the phenomenon of improved cartilage formation in co-cultures is dependent soluble factors, including small molecules, lipids or proteins. Lipids, like phospholipids, cholesterol and diacylglycerols (DAGs), play a significant role in cellular signalling, membrane integrity and metabolism [4]. In the past various techniques have been employed to study small molecules or lipids in biological tissues. For example, histochemical staining with Oil Red $\mathrm{O}$ allows for the non-specific allocation of lipid droplets and can be used to get insight in overall lipid content in biological samples. Chromatographic techniques, like high performance liquid chromatography (HPLC) allow for a more specific and quantitative analysis of lipids [5, 6]. Chromatographic methods do not provide information of the distribution of lipids in the tissue and are therefore limited for pure quantitative measures. In contrast, imaging mass spectrometry (IMS) can be employed for the visualisation of the spatial distribution of proteins, peptides, small compounds and lipids in tissue sections according to their mass/charge $(\mathrm{m} / z)$ ratio. In particular, with time-of-flight secondary ion mass spectrometry (TOF-SIMS) the label-free spatial measurement of specific molecules without the incorporation of labels or dyes is achievable. The low primary beam causes soft discharge of secondary ions from the samples surface, which can be separated specifically to their mass [7]. Furthermore, with surface metallization, like gold coatings [8], the detection of specific compounds by TOF-SIMS can be increased, due to better ionisation of molecules. Previous studies successfully identified key membrane molecules such as phosphocholine and choline as well as cofactors of biological processes, such as sodium and potassium [9, 10]. Recently the TOF-SIMS approach has been successfully employed for the first time in the field of cartilage research to investigate differences in the molecular composition and lipid distribution between healthy and osteoarthritic cartilage. This study revealed a major difference in cholesterol deposition in osteoarthritic and healthy chondrocytes [11]. Another approach to get insight in spatial tissue composition is matrix-assisted laser desorption/ionization (MALDI)-IMS. In MALDI, the matrix is of paramount importance. The applied matrix solution forms matrix-analyte crystals and thereby separates analytes from small molecules, like ions. An UV laser irradiates the section and releases 
of the matrix-crystals into the vacuum [12]. Multiple single mass spectra are acquired across the tissue section at a predefined spot size determining the spatial resolution. The different mass spectra are combined in order to obtain a ion density maps representing the spatial distribution of different analytes. Traditionally, MALDI-IMS is used to analyse oligonucleotides, proteins, peptides and synthetic polymers, but can as well be employed for the study of smaller molecules [13]. For the success of analysis the choice of the matrix for MALDI is of major importance. For example, 9-Aminoacridine (9-AA) is a basic matrix that readily accepts protons leading to the formation of $[\mathrm{M}-\mathrm{H}]$-species and reveals spectra with fewer background matrix peaks [14]. However some studies show its capability of also detecting lipids in the positive mode. It has been published that 9-AA can be efficiantly employed for lipid imaging $[15,16]$. We thus believe, that TOF-SIMS and MALDI-IMS will deliver additional insight in potential mediators of the improved cartilage formation in the pellet co-cultures of MSCs and chondrocytes.

We studied the co-culture of MSCs and chondrocytes under normoxic $\left(21 \% \mathrm{O}_{2}\right)$ and hypoxic conditions $\left(2.5 \% \mathrm{O}_{2}\right)$ and were able to demonstrate that co-culture has no beneficial effect on cartilage formation under lower oxygen tension. We subsequently used TOF-SIMS and MALDI-IMS for a side-by-side comparison between normoxic and hypoxic expanded pellet mono-cultures and co-cultures of primary MSCs and chondrocytes to identify differentially expressed lipids between these conditions.

\subsection{Materials and Methods}

\subsubsection{Cell culture}

Human chondrocytes $(\mathrm{hCh})$ were isolated from full-thickness cartilage knee biopsies of patients undergoing total knee replacement. Cartilage was cut and digested as previously described [17]. Mesenchymal stromal/stem cells (MSCs) were selected by adherence from bone marrow of patients undergoing total hip replacement. For the described experiments three different MSC donors with known differentiation potential were selected. High-density micromass cell pellets were formed by seeding 250.000 cells per well in a round-bottom 96-wells plate in chondrocyte proliferation medium (Dulbeccos modified Eagles medium supplemented with $10 \%$ fetal bovine serum, 1x nonessential amino acids, $0.2 \mathrm{mM}$ ascorbic acid 2-phosphate, $0.4 \mathrm{mM}$ proline, 100 $\mathrm{U}$ penicillin, and $100 \mathrm{mg} / \mathrm{mL}$ streptomycin) and centrifuged for $5 \mathrm{~min}$ at $500 \mathrm{rcf}$. Cultures were either kept under normoxic conditions $\left(21 \% \mathrm{O}_{2}\right)$ or hypoxic conditions $\left(2.5 \% \mathrm{O}_{2}\right)$. Medium was refreshed twice a week. hMSCs and hch were used in following combinations in both conditions: $100 \%$ MSCs, $80 \%$ MSCs $/ 20 \%$ hchs and $100 \%$ hch [3].

\subsubsection{Alcian Blue staining}

Pellets were fixed with $10 \%$ buffered formalin for $15 \mathrm{~min}$, dehydrated and embedded in paraffin using routine procedures. Sections of $5 \mu \mathrm{m}$ were cut and stained for sulfated glycosaminoglycans (GAGs) with alcian blue $\left(0.5 \%\right.$, in $\mathrm{H}_{2} \mathrm{O}, \mathrm{pH}=1$ adjusted 
with $\mathrm{HCl}, 30 \mathrm{~min})$ combined with counterstaining of nuclear fast red $(0.1 \%$ in $5 \%$ aluminum sulfate, 5 min).

\subsubsection{Sample preparation}

High density micromass cultures of three MSC donors were embedded in two tissue arrays containing pellets cultured in normoxia and hypoxia (Figure S8.1). 10\% gelatine $\left(30^{\circ} \mathrm{C}\right.$ embedding, $4 \mathrm{~h}$ at $4^{\circ} \mathrm{C}$, frozen at $\left.-20^{\circ} \mathrm{C}\right)$ was used for embedding. 20 $\mu \mathrm{m}$ tissue cryosections of both tissue arrays were mounted side-by-side on one indium tin oxide (ITO) coated conductive glass slide and washed with $100 \%$ Ethanol (30 s) and $70 \%$ Ethanol (2 min). This allowed for sampling of 18 sections of pellet cultures on one slide and thereby reduced intra-measurement variations. Samples were desicator dried before depositing $2 \mathrm{~nm}$ of gold (SC7640 sputter coater, FT707 quartz crystal microbalance stage) for TOF-SIMS measurements or 9-Aminoacridine $\left(7 \mathrm{mg} / \mathrm{ml} \mathrm{EtOH}: \mathrm{H}_{2} \mathrm{O}, 50: 50\right)$ with a vibrational sprayer system (ImagePrep; Bruker DaltonikGmbH; Bremen; Germany) for MALDI-IMS measurements.

\subsubsection{TOF-SIMS experiments}

TOF-SIMS experiments were performed in positive mode on a Physical Electronics (Eden Prairie, MN) TRIFTII secondary ion mass spectrometer with and $\mathrm{Au}^{1+}$ primary ion beam. For experiments a primary ion beam of $7.2 \mathrm{nA}$, a primary ion pulse length of $19 \mathrm{~ns}$ and a dose of $2.14 \times 10^{11}$ ions $/ \mathrm{cm}^{2}$ and $2.14 \times 10^{12}$ ions $/ \mathrm{cm}^{2}$ were used for low and high resolution images respectively. Whole pellet sections were analysed in a mosaic mode with an acquisition time of $3 \mathrm{~s} /$ tile for low resolution images and $30 \mathrm{~s} /$ tile for higher resolution images (256x256 pixels/tile). The raster size was set at $100-110 \mu \mathrm{m}$ and the lateral resolution was $390-426 \mathrm{~nm}$. WinCadence software was used for data acquisition.

\subsubsection{MALDI-IMS experiments}

Digital optical scans of all tissue sections were obtained prior to MALDIIMS experiments using a 2400 dpi desktop scanner. The resulting digital images were imported into the MALDI Imaging Pattern Creator software (Waters Corporation, Manchester, UK). Instrument calibration was performed using a standard calibration mixture of polyethylene glycol with a $\mathrm{Mw}$ of 100-3000 (Sigma-Aldrich). A MALDI SYNAPTHDMS system (Waters Corporation) operating with a $200 \mathrm{~Hz}$ Nd:YAG laser was congured to acquire data in the positive V-reflectron mode. Data were acquired using a raster size of $150 \mu \mathrm{m}$. Masslynx software (Waters) was used for data acquisition.

\subsubsection{Data interpretation}

Raw data was converted to MatLab format. Spatial binning, spectral binning and peak picking were performed prior to selection of the 500 mass channels with the 


\begin{tabular}{|l|l|l|}
\hline Mass & lipid & abundance \\
\hline 184 & phosphocholine & chondrocytes (hypoxia, normoxia) \\
\hline 369 & cholesterol & $\begin{array}{l}\text { generally higher in normoxia } \\
\text { more abundant in 100\% MSC and 80\% MSCs/ 20\% hch }\end{array}$ \\
\hline 385 & cholesterol & $\begin{array}{l}\text { generally higher in normoxia } \\
\text { more abundant in 100\% MSC and 80\% MSCs/ 20\% hch }\end{array}$ \\
\hline 577 & diacylglycerols & MSCs (hypoxia and normoxia) \\
\hline 599 & diacylglycerols & MSCs (hypoxia and normoxia) \\
\hline 603 & diacylglycerols & MSCs (hypoxia and normoxia) \\
\hline
\end{tabular}

Table 8.1: Summary of assigned lipids masses and their prevalence

highest variance. Results of the whole study were treated with principal component analysis in supervised and unsupervised approaches. For TOF-SIMS measurements sections of the pellets were selected as regions of interest (ROI) and a total of 13198 spectra were used for analysis. Using in-house build software ChemomeTricks principal component analysis (PCA) was performed to reveal spectral differences between samples. Category numbers were assigned to each donor and condition to facilitate the analysis. The same category numbers were used for technical replicates. Discriminant analysis was performed to identify the masses with highest differences (a) in a global analysis of all hypoxic and all normoxic cultured conditions, (b) in an inter-group analysis of different conditions in hypoxia as well as normoxia and (c) comparison of specific conditions cultured in hypoxia and normoxia. The scores for the different discriminant functions (DFs) of comparison (b) were adjusted to Gaussian curves following a normal distribution. The distribution and the overlap describes the sample identity and can be used to identify differences between conditions. After data analysis $m / z$ of interest were selected and assigned to previously classified lipid- $m / z$ identifications using the database on lipidmaps.org (http://www.lipidmaps.org/) and according literature [18]. For MALDI-IMS analysis BioMap software was used for data visualisation [19].

\subsubsection{Lipid staining}

Cryosections of samples were hydrated in distilled water for $5 \mathrm{~min}$, dipped in $60 \%$ isopropanol and then stained with $0.03 \%$ Oil Red solution (60\% isopropanol) for $20 \mathrm{~min}$. After rinsing in water slides were counterstained in haematoxilin (5 min, Sigma-Aldrich), washed, dehydrated and mounted. Images were acquired with the MIRAX imaging system (Carl Zeiss). Lipid droplet accumulation was quantified with the colour range tool in Adobe Photoshop as described before [20] and tested for significance (Students T-test). Significance of $\mathrm{p} \leqq 0.05$ is indicated $\left(^{*}\right)$. 


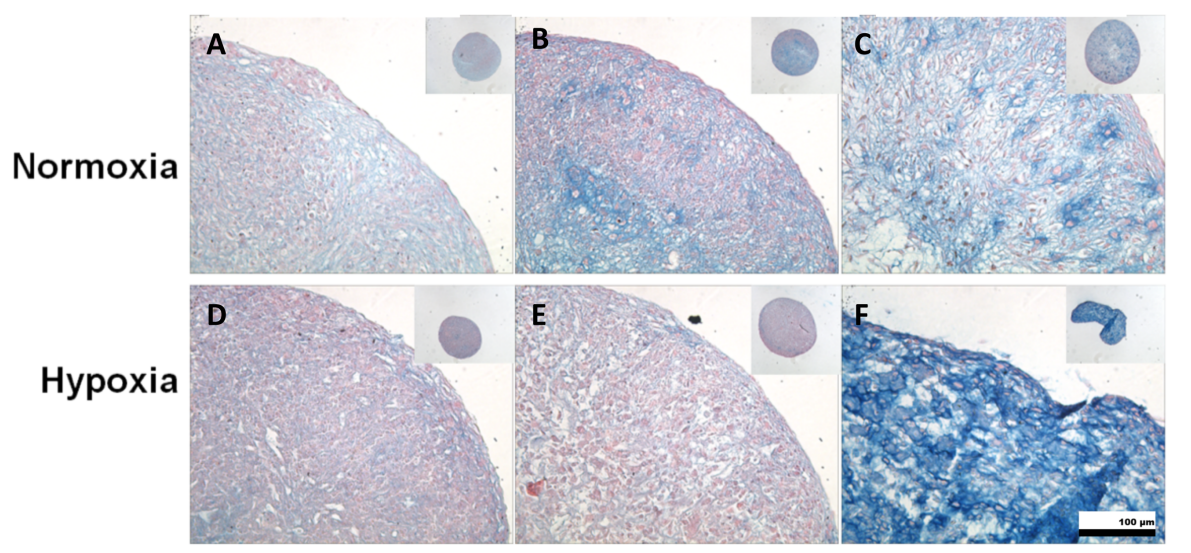

Figure 8.1: Alcian Blue stain of micromass pellet cultures expanded in normoxia $\left(21 \% \mathrm{O}_{2}\right)$ and hypoxia $\left(2.5 \% \mathrm{O}_{2}\right)$

(A, B, C) Pellets expanded in normoxia. (E, F, G) Pellets expanded in hypoxia. Coculture of MSCs and chondrocytes were in normoxia (B) reveal an improved chondrogenesis marked by more intense Alcian Blue stain as well chondron formation in the middle of the pellets. Co-culture in hypoxia (E) results in a negative outcome of Alcian Blue staining. 100\% chondrocyte pellets cultured in normoxia (C) exhibit significant less Alcian blue staining as well as fibrous cartilage formation when compared to chondrocytes in cultured in hypoxia $(\mathrm{F})$.

\subsection{Results}

\subsubsection{Co-culture leads to improved chondrogenesis under normoxia $\left(21 \% \mathrm{O}_{2}\right)$}

Pellets of MSCs and chondrocytes cultured in hypoxia and normoxia were histologically evaluated for their amount and the morphology of chondrogenic matrix formation. In line with previous observations [3], normoxic co-cultures of MSCs and chondrocytes improved chondrogenesis as noted by more intense Alcian Blue stain as well as the abundant occurence of chondrons (Fig 8.1). In accordance with literature [21], cartilage formation in hypoxic cultured $100 \%$ chondrocytes pellets was improved compared with pellet culture in normoxia (compare Fig 8.1C and Fig 8.1F). In marked contrast with pellet co-cultures differentiated in normoxia, hypoxic co-culture pellets did not reveal evidence for improved cartilage formation (compare Fig 8.1B and Fig 8.1E). 
A

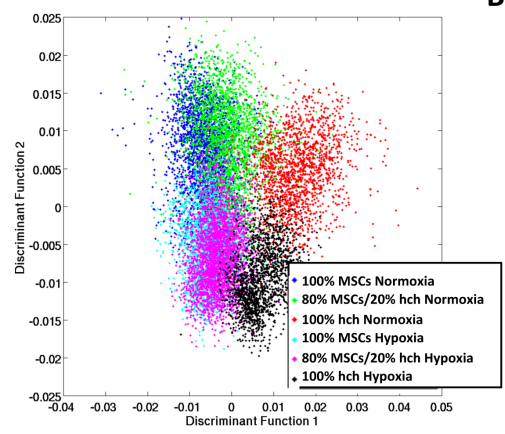

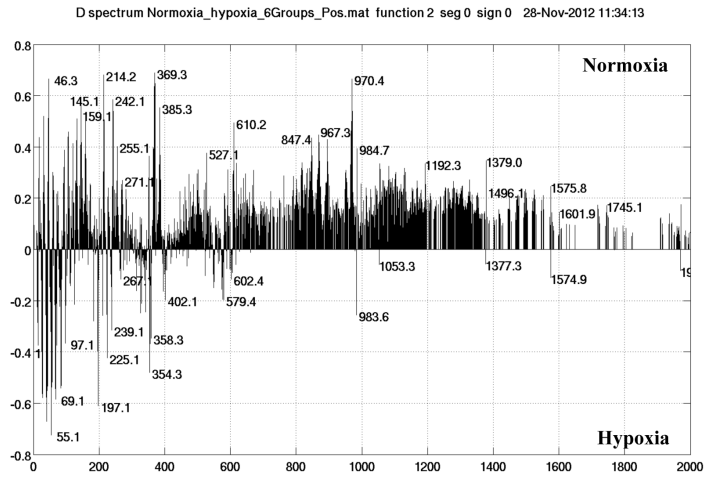

C
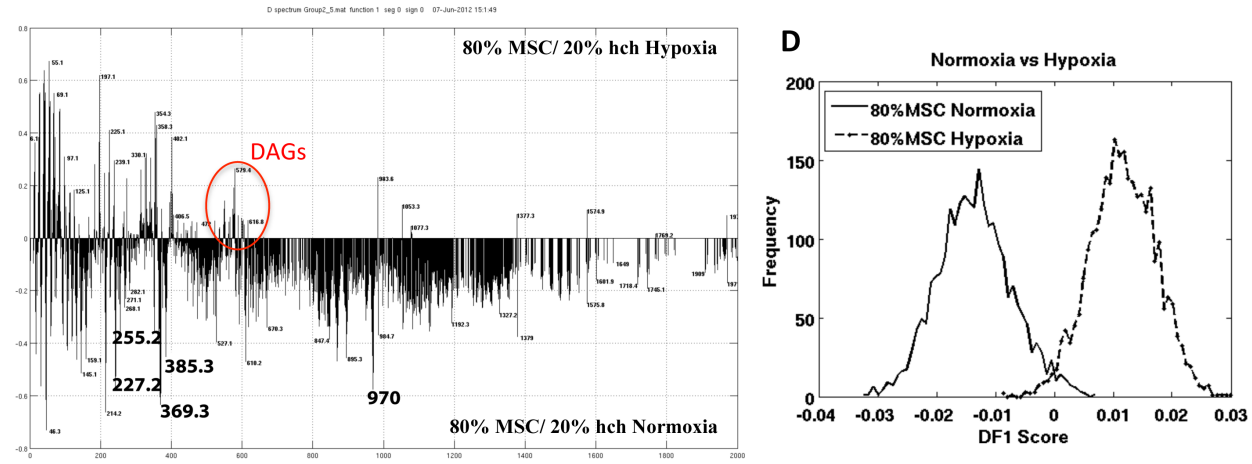

Figure 8.2: Discriminant analysis of hypoxic and normoxic cultured condition

(A) Tissue arrays of pellet cultures in normoxia and hypoxia were mounted on the same slide and analysed using TOF-SIMS Spectra of all pellets were obtained and analysed using PCA. 50 PCAs (20\% of the variance) were used for the discriminant function (DF) analysis: hypoxic and normoxic conditions separate among the second DF (normoxia $\leqq 0$, hypoxia $\geqq 0$ ); as visible in the distribution of the functions normoxia is spreading more among the first DF indicating that different conditions are less alike than in hypoxia. (B) The according discriminant loading spectra for (A) with separation of specific masses according to positive and negative second DF showing specific cholesterol masses $\left(\mathrm{m} / z 369.3[\mathrm{M}+\mathrm{H}-\mathrm{H} 2 \mathrm{O}]^{+}, \mathrm{m} / z 385.3[\mathrm{M}-\mathrm{H}]^{+}\right.$and $m / z 970[2 \mathrm{M}+\mathrm{Au}]^{+}$) for the normoxic cultured conditions. The higher frequency of mass peaks in normoxia indicates a higher lipid content in these conditions. (C) Comparing only co-culture conditions of both oxygen tensions reveal cholesterol still as most separating masses between hypoxia and normoxia. The red circle indicates a fraction of likely degraded diacylglycerols (DAGs) being abundant in hypoxic conditions. (D) Frequency plots of the hypoxia and normoxia cultured co-culture show a clear separation of both conditions indicating a different molecular pattern for each of the conditions. 
A
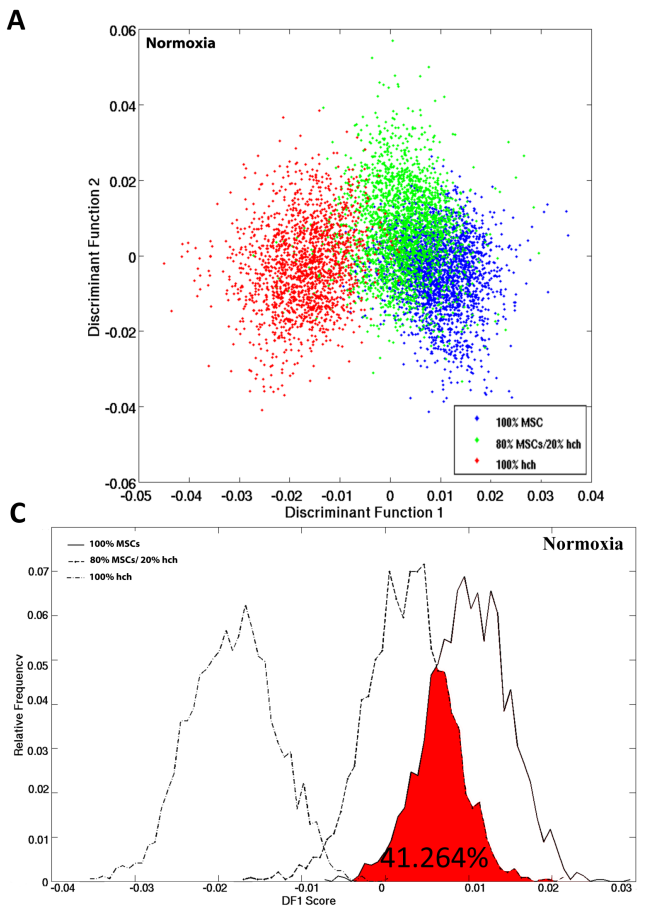

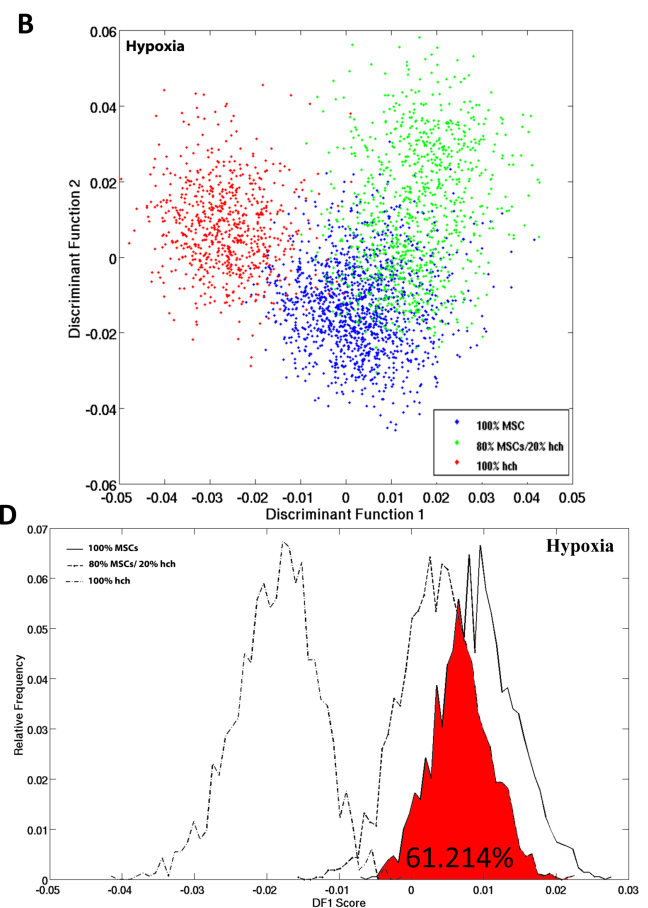

Figure 8.3: Distinct lipid profiles in hypoxia and normoxia

(A, B) Discriminant function analysis of the co-cultured and mono-cultured cell pellets in normoxic and hypoxic culture. (A) In normoxia 100\% MSCs and the co-culture of $80 \%$ MSCs and $20 \%$ chondrocytes partially separate among the first DF, whereas there is less separation between these conditions in hypoxia in the first discriminant function (B). (C, D) Respective frequency plots of the DF1 shown in (A and B) underlining the better separation of the co-culture from pure MSC pellets in normoxia (C).

\subsubsection{Molecular profile of normoxic pellet cultures separates clearly from hypoxic pellet cultures}

We next measured the spectra of each condition in a tissue array format using TOFSIMS. After performing the experiments, all conditions were analysed by principal component analysis (PCA) and 50 PCAs (20\% of the variance) were used for the discriminant function (DF) analysis. As illustrated in the scatterplot in figure $2 \mathrm{~A}$, the first DF separates the chondrocyte from MSC containing mono-culture and coculture pellets irrespective of the oxygen tension $(100 \%$ chondrocytes $\leqq 0,100 \%$ MSCs, $80 \%$ MSCs $/ 20 \%$ chondrocytes $\geqq 0$ ). The second DF can be used to distinguish pellets cultured in normoxia from pellets culture in hypoxia (normoxia $\leqq 0$, hypoxia $\geqq 0$ ) (Fig 8.2A). This indicates that the molecular panel in the pellets is dependent on the pellets cellular composition and employed oxygen tensions. Furthermore we demonstrate that spectra of pellets cultured in normoxia are spreading more among 
A

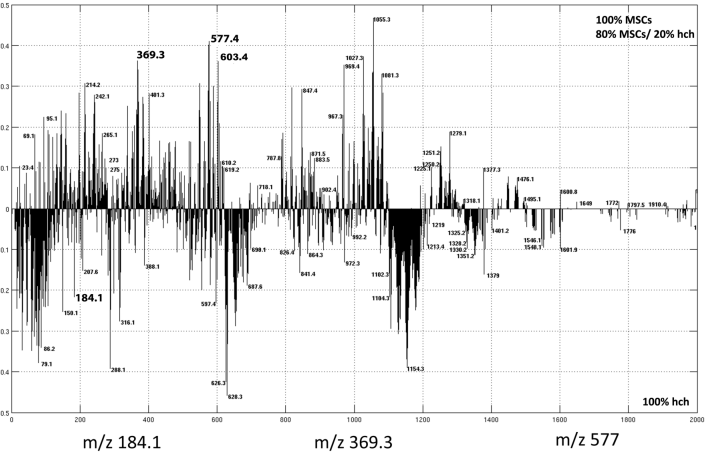

B
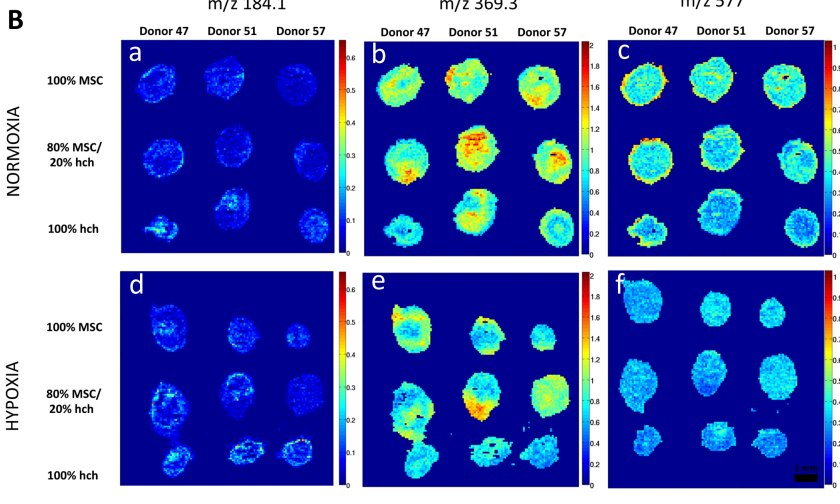

C

$\mathrm{m} / \mathrm{z} 184.1$

$\mathrm{m} / 2369.3$
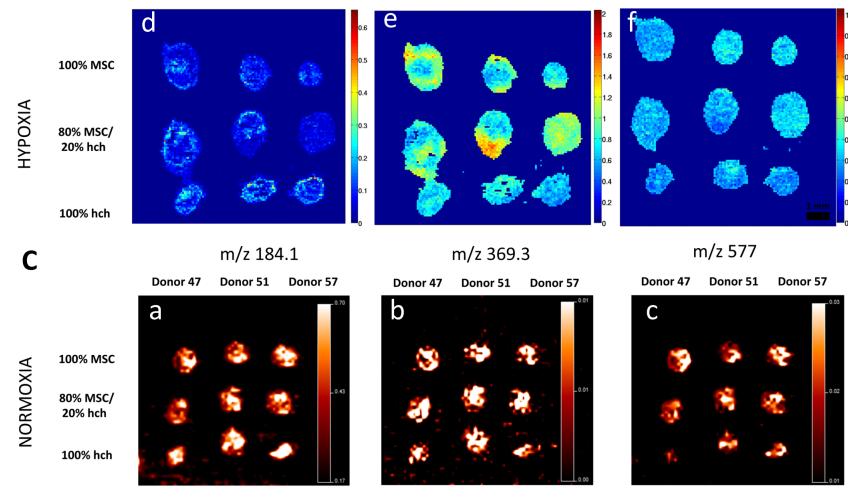

$\mathrm{m} / \mathrm{z} 577$
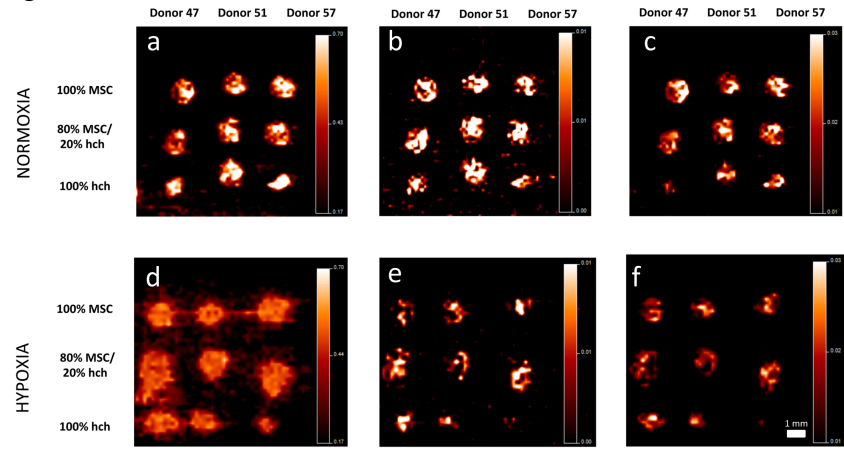

Figure 8.4: Spatial mapping of specific masses in cell pellets

(A) Based on the DF1 of Figure 8.3A, a discriminant loading spectra was generated for the identification of masses specific for cell types. For chondrocytes phosphocholine $(\mathrm{m} / z$ 184.1) was assigned, whereas for MSC containing conditions DAG $(\mathrm{m} / z$ 577) and the described cholesterol $(m / z$ 369.3) were used to visualize MSCs. (B, C) For the identified masses the spatial distribution is illustrated in normoxia and hypoxia using TOF-SIMS (B) and MALDI-IMS (C). $m / z 184.1$ is mainly abundant in normoxia $(\mathrm{C}$ a, $\mathrm{d}), \mathrm{m} / z 369.3$ is more prominent in normoxic conditions with a particular high expression in the middle of co-culture pellets ( $\mathrm{B}, \mathrm{D}: \mathrm{b}, \mathrm{e}) . \mathrm{m} / z 5^{77}$ is primarily expressed in normoxia with a higher expression in MSC containing conditions (B: c, f) 
the first DF than hypoxic pellets, indicating that different conditions are less alike in normoxia than in hypoxia (Fig 8.2A). The discriminant loading spectra for figure $8.2 \mathrm{~A}$ displays the separation of specific masses according to positive and negative second DF (Fig 8.2B). The positive fraction of masses indicates the specific molecular profile expressed under hypoxic culture, whereas the negative side indicates normoxic specific peaks. On the negative normoxic side of the plot we can observe specific cholesterol masses $\left(m / z 369.3[\mathrm{M}+\mathrm{H}-\mathrm{H} 2 \mathrm{O}]^{+}, m / z 385.3[\mathrm{M}-\mathrm{H}]^{+}\right.$and $\left.m / z 970[2 \mathrm{M}+\mathrm{Au}]^{+}\right)$, which were identified as major discriminating masses from the positive hypoxic fraction. Furthermore, the higher abundance of mass peaks in normoxia indicates a higher lipid content in these conditions (Fig 8.2B). The comparison of spectra from coculture pellets of MSCs and chondrocytes at both oxygen tensions reveals cholesterol as most separating mass between hypoxic and normoxic culture. Other differentially expressed peaks could be assigned to diacylglycerols (DAGs). A fraction of likely degraded DAGs was observed more pronounced in the hypoxic culture irrespective of cell pellet composition (Fig $8.2 \mathrm{C}$, red circle). DAGs can arise as products of the hydrolysis of the membrane phospholipid phosphatidylinositol 4,5-bisphosphate. This hydrolysis results in a cluster of masses ranging from $\mathrm{m} / z 519$ to $\mathrm{m} / z 603$ [18]. Frequency plots of hypoxia and normoxia cultured co-culture pellets were clearly distinct. This is suggestive for an oxygen dependent pattern of small molecules for each of the conditions [30] (Fig 8.2D).

\subsubsection{Co-culture lipid profiles are more different from MSC mono-culture in normoxia profiles than in hypoxia}

The supervised discriminant analysis of the two different oxygen concentrations can provide insight on the differences between cellular combinations in hypoxia and normoxia. In normoxia pellets of $100 \%$ MSCs and the co-cultured pellets of $80 \%$ MSCs and $20 \%$ chondrocytes partially separated in the first DF. Remarkably, there was less between these conditions in hypoxia (Fig 8.3A, B). Normoxic co-cultures display a $41.264 \%$ mass identity with $100 \%$ MSC cultures, whereas hypoxic co-cultures show a $61.214 \%$ overlap with $100 \%$ MSC cultures (Fig 8.3C, D). Previously, we have demonstrated that MSCs disappear over time by apoptosis in a normoxic pellet culture system [3]. The higher identity of co-cultures with pure MSC pellet cultures in hypoxia indicates that the previously identified selective co-culture mechanism is delayed or not abundant in hypoxic culture systems.

\subsubsection{Spatial mapping of specific masses reveals location and difference in expression between conditions}

TOF-SIMS has the advantage to combine the mass/charge information with the spatial location of specific masses in the examined tissues. In the discriminant analysis of all conditions cholesterol was detected as a lipid highly enriched in normoxia. Resulting from the separated supervised discriminant analysis of normoxic conditions (Fig 8.3A) a discriminant loading spectra was generated (Fig 8.4A). Based on the separation among the first DF, the identification of masses specific for cell types was possible. 
In chondrocytes phosphocholine $\left(\mathrm{m} / \mathrm{z} 184.1[\mathrm{M}+\mathrm{H}]^{+}\right)$was increased whereas in MSC containing conditions DAG $\left(m / z 577[\mathrm{M}+\mathrm{H}-\mathrm{OH}]^{+}, m / z 603.4[\mathrm{M}+\mathrm{H}-\mathrm{OH}]^{+}\right)$and the described cholesterol $\left(\mathrm{m} / z\right.$ 369.3 $\left.[\mathrm{M}+\mathrm{H}-\mathrm{H} 2 \mathrm{O}]^{+}\right)$were detected $(\mathrm{Fig} 8.4 \mathrm{~A})$. These known masses were further used to identify their spatial distribution in normoxia and hypoxia using TOF-SIMS as well as MALDI-IMS. These techniques demonstrated very similar results for the here represented data set and can therefore both be used to map identified masses to their location in the analysed pellet. The experimental tissue array set-up allowed for very stable imaging conditions as well as good opportunities for spatial comparison of different conditions. Phosphocoline, $\mathrm{m} / z$ 184.1 separated chondrocyte pellets from MSC and co-culture pellets in discriminant analysis. The spatial distribution of $\mathrm{m} / \mathrm{z} 184.1$ reveals abundance in chondrocyte- as well as MSC containing pellets with its presence limited to the rim of the pellet in TOF-SIMS experiments (Fig 8.4B (a, d)). In particular, MALDI-IMS experiments revealed that $\mathrm{m} / z 184.1$ is more abundant in normoxic pellets (Fig 8.4C (a,d)). For cholesterol mapping mass $m / z 369.3$ was used. Cholesterol is more prominent in normoxic conditions with a particular high expression in the middle of co-culture pellets (Fig 8.4B, $\mathrm{C}(\mathrm{b}, \mathrm{e}))$. The DAG indicated by $\mathrm{m} / z 577$ is primarily expressed in normoxia with a higher expression in MSC containing conditions (Fig 8.4B (c, f)) when TOF-SIMS or MALDI imaging was used. The abundance of further masses linked to the already described lipids was gained from all different discriminant comparisons of conditions and can be retrieved from table 8.1 .

\subsubsection{Higher lipid deposition in normoxic cultured conditions}

Oil Red O stain revealed a generally significantly higher abundance of lipid droplets in normoxic conditions (Fig 8.5A). In particular chondrocyte pellets contained the highest lipid accumulation, quantified with the colour range tool in Adobe Photoshop ${ }^{\circledR}$ CS5.1 as described before [20]. Quantification of Oil Red O stain furthermore disclosed that normoxic conditions contained the highest concentration of lipids in chondrocyte pellets followed by the co-culture pellets. In contrast, lipid concentration in hypoxia was still highest in the chondrocyte pellets but lowest in the co-culture pellets (Fig 8.5B).

\subsection{Discussion}

Employing TOF-SIMS and MALDI-IMS for the analysis of released lipids or small compounds allowed us to label-free identify different cell sources during the co-culture of MSCs and chondrocytes as well as in the culture of pure MSC and chondrocyte pellets. We demonstrate that mass spectrometry molecular profiling can be used to distinguish cell pellets cultured in normoxia and hypoxia. Not only was the overall lipid content higher in normoxia but also specific masses were detected as normoxiaenriched $(\mathrm{m} / \mathrm{z}$ 184.1, $\mathrm{m} / \mathrm{z}$ 369.3, $\mathrm{m} / \mathrm{z} 5 \mathrm{rr}, \mathrm{m} / z$ 603) (Fig 8.4). Additionally the identification differences between co-culture of MSCs and chondrocytes and monoculture of MSCs or chondrocytes cultured in either normoxia or hypoxia was achieved (Fig 8.3). We thereby revealed that co-cultures of MSCs and chondrocytes cultured 
A

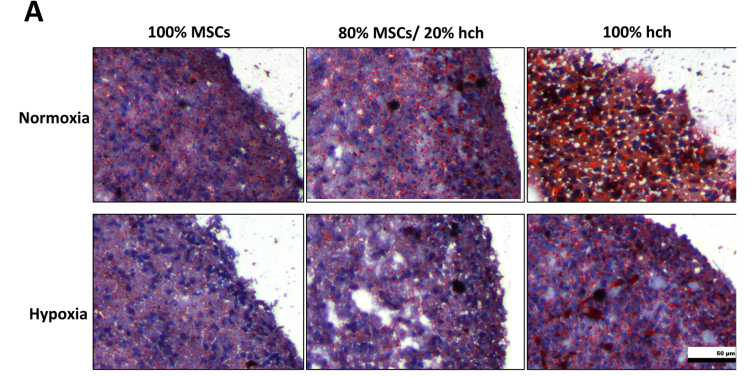

B

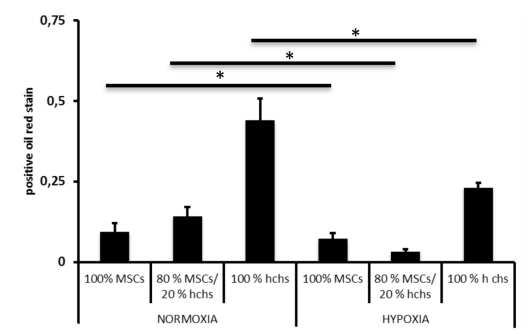

Figure 8.5: Oil Red $O$ stain for lipid depostion of pellets cultured in hypoxic and normoxic conditions

(A) Oil Red O stain revealed a higher staining in normoxic conditions, in particular chondrocyte pellets showed the highest lipid accumulation. (B) Quantification of Oil Red $\mathrm{O}$ stain revealed that normoxic pellets had a higher lipid content with highest concentration in chondrocyte pellets followed by the co-culture pellets. In hypoxia lipid concentration was still highest in the chondrocyte pellets but lowest in the coculture pellets.

under normoxia rather diverge from pure MSC cultures than the same condition in hypoxia. These results are overlapping with the reduced level of glycosaminoglycan deposition shown in Figure 8.1E. Furthermore, we managed to map three specifically detected lipids (phosphocholine: $\mathrm{m} / z$ 184.1, DAG: $\mathrm{m} / z$ 577, $\mathrm{m} / z 603$ cholesterol: $\mathrm{m} / z$ 369.3) to their location in the differently cultured pellets. In particular, specifically cholesterol mapped to the center of the co-culture pellet (Fig 8.4B b). Previously we described self-organisation of MSCs and chondrocytes in co-cultured pellets under normoxic conditions. Whereas chondrocytes reside in the rim of the pellet, MSCs seem to cluster in the center [3]. In the here shown experiments cholesterol is mainly present in the center of the pellet. Therefore, MSCs are the likely origin of the prominent cholesterol peak. Furthermore, we prove the more MSC specific expression of cholesterol by discriminant separation of pure chondrocytes pellets from MSC containing pellets (Fig 8.4A). The here illustrated measurements only reveal absolute measures of cholesterol but dont allow for conclusions if MSCs cultured under normoxia have an increased cholesterol metabolism or if hypoxia induces cholesterol degradation. Therefore biological real-time measurements are needed. Cholesterol has a major impact on membrane integrity as well as cellular signalling and metabolism. Thus, cholesterol levels in the cell might be crucial for mediating cellular responses, including differentiation, proliferation and ultimately the mediation of improved chondrogenesis in co-culture [4].

The regulation of cholesterol levels occurs via sterol-regulatory element binding protein (SREBP-2). Cholesterol uptake and synthesis is induced after SREBP-2 activation of cholesterogenic target genes, like low-density lipoprotein receptor (LDLR) and 3-hydroxy-3-methylglutaryl coenzyme A reductase (HMG-CoA-R). HMG-CoA-R regulates the reduction of HMG-CoA to mevalonate, a precursor of the cholesterol biosynthesis. To prove the abundance of higher cholesterol accumulation or biosyn- 
thesis in normoxic cell cultures the modulation of cholesterol metabolism is wanted. Negative regulators of HMG-CoA-R, as well as the measurement of LDLR activity as an indication of cholesterol uptake are two major strategies to get further insight in cholesterol metabolism and regulation in the cell. A sufficient block of cholesterol metabolism has been already described in the 70 s by Phillips et al. [22]. 3 beta- $(2-$ diethylaminoethoxy) androst-5-en-17-one hydrochloride, now named U18666A (Upjohn company), was described to inhibit cholesterol synthesis via HMG-CoA-R [23]. LDLR activity can be measured as level of the uptake of Dil-labeled low-density lipoprotein [24]. Additionally to the described methods mRNA levels of SREBP-2, HMG-Co-R as well as LDLR can be monitored to investigate their potential downregulation under hypoxic culture conditions. Interestingly it has been described before that hypoxia stimulates the degradation of HMG-CoA-R [25]. The cholesterol biosynthesis process, starting from the precursor lanosterol to cholesterol, requires the removal of three methyl groups, which consumes nine molecules of dioxygen. Thereby, this process is less efficient in lower oxygen levels, decelerating the process of demethylation. This leads to the accumulation of precursor molecules, which may even further inhibit HMG-CoA-R in a negative feedback-loop mechanism [25].

Besides prominent cholesterol peaks in spectra of normoxic cultured cells, we found increased levels of phosphocholine in chondrocytes as well as increased levels of DAG in normoxic MSCs. Furthermore, hypoxic expanded pellets revealed a cluster of DAGs ranging from mass 500-600 with low intensity. DAGs are basic components of cell membranes, an intermediate in lipid metabolism and involved in lipid mediated signalling [26]. Additional reports indicate a role of DAG in cell-cell communication, like neuronal signalling or receptor presentation $[27,28]$. This indicates that DAG can be potentially involved in MSC-chondrocyte communication as well as in the mediation of chondro-inductive signals. Interestingly, in a hypoxic environment diacylglycerol kinase (DAGK) leads to regulation of DAG and phosphatic acid (PA) levels. PA can be generated by the phosphorylation of DAG. These processes lead to stabilisation of the major mediator of the hypoxic response, hypoxia inducible factor 1 alpha (Hif1- $\alpha$ ) [29]. The fraction of DAGs observed in hypoxic cultured pellets might result from the tight regulation of DAGs under hypoxia.

With TOF-SIMS, the mapping of lipid profiles to different experimental conditions as well as different cellular types is achievable. Thereby, TOF-SIMS is a powerful technique for the identification of small mediators of chondrogenesis. 


\section{References}

1. Brittberg, M., et al., Treatment of deep cartilage defects in the knee with autologous chondrocyte transplantation. N Engl J Med, 1994. 331(14): p. 889-95.

2. Hendriks, J., et al., Primary chondrocytes enhance cartilage tissue formation upon co-culture with a range of cell types. Soft Matter, 2010. 6: p. 5080-5088.

3. Wu, L., et al., Trophic effects of mesenchymal stem cells increase chondrocyte proliferation and matrix formation. Tissue Eng Part A, 2011. 17(9-10): p. 1425-36.

4. Brown, A.J., Cholesterol, statins and cancer. Clinical and experimental pharmacology \& physiology, 2007. 34(3): p. 135-41.

5. Stevens, A.L., et al., A sodium dodecyl sulfate-polyacrylamide gel electrophoresis-liquid chromatography tandem mass spectrometry analysis of bovine cartilage tissue response to mechanical compression injury and the inflammatory cytokines tumor necrosis factor alpha and interleukin1beta. Arthritis Rheum, 2008. 58(2): p. 489-500.

6. Sullivan, R. and M. Klagsbrun, Purification of cartilage-derived growth factor by heparin affinity chromatography. The Journal of biological chemistry, 1985. 260(4): p. 2399-403.

7. Chughtai, K. and R.M. Heeren, Mass spectrometric imaging for biomedical tissue analysis. Chemical reviews, 2010. 110(5): p. 3237-77.

8. Altelaar, A.F., et al., Gold-enhanced biomolecular surface imaging of cells and tissue by SIMS and MALDI mass spectrometry. Analytical chemistry, 2006. 78(3): p. 734-42.

9. Fletcher, J.S., Cellular imaging with secondary ion mass spectrometry. The Analyst, 2009. 134(11): p. 2204-15.

10. Amstalden van Hove, E.R., et al., Multimodal mass spectrometric imaging of small molecules reveals distinct spatio-molecular signatures in differentially metastatic breast tumor models. Cancer research, 2010. 70(22): p. 9012-21.

11. Cillero-Pastor, B., et al., Time-of-Flight Secondary Ion Mass Spectrometry-Based Molecular Distribution Distinguishing Healthy and Osteoarthritic Human Cartilage. Analytical chemistry, 2012. 84(21): p. 8909-16.

12. McDonnell, L.A. and R.M. Heeren, Imaging mass spectrometry. Mass spectrometry reviews, 2007. 26(4): p. 606-43.

13. Nicola, A.J., A.I. Gusev, and D.M. Hercules, Direct Quantitative Analysis from Thin-Layer Chromatography Plates Using Matrix-Assisted Laser Desorption/Ionization Mass Spectrometry. Appl. Spectrosc., 1996. 50(12): p. 1479-1482.

14. Guo, Z. and L. He, A binary matrix for background suppression in MALDI-MS of small molecules. Analytical and bioanalytical chemistry, 2007. 387(5): p. 1939-44.

15. Vermillion-Salsbury, R.L. and D.M. Hercules, 9-Aminoacridine as a matrix for negative mode matrix-assisted laser desorption/ionization. Rapid Communications in Mass Spectrometry, 2002. 16(16): p. 1575-1581.

16. Sun, G., et al., Matrix-assisted laser desorption/ionization time-of-flight mass spectrometric analysis of cellular glycerophospholipids enabled by multiplexed solvent dependent analyte-matrix interactions. Analytical chemistry, 2008. 80(19): p. 7576-85.

17. Hendriks, J., J. Riesle, and C.A. Vanblitterswijk, Effect of stratified culture compared to confluent culture in monolayer on proliferation and differentiation of human articular chondrocytes. Tissue Eng, 2006. 12(9): p. 2397-405.

18. Passarelli, M.K. and N. Winograd, Lipid imaging with time-of-flight secondary ion mass spectrometry (ToF-SIMS). Biochim Biophys Acta, 2011. 1811(11): p. 976-90.

19. Stoeckli, M., et al., Imaging mass spectrometry: a new technology for the analysis of protein expression in mammalian tissues. Nature medicine, 2001. 7(4): p. 493-6.

20. Tolivia, J., et al., Application of Photoshop and Scion Image analysis to quantification of signals in histochemistry, immunocytochemistry and hybridocytochemistry. Analytical and quantitative cytology and histology / the International Academy of Cytology [and] American Society of Cytology, 2006. 28(1): p. 43-53. 21. Lawyer, T.J., M.A. Tucci, and H.A. Benghuzzi, Evaluation of chondrocyte growth and function subjected to $21 \%$ and $6 \%$ oxygen levels. Biomed Sci Instrum, 2012. 48: p. 246-53.

22. Phillips, W.A. and J. Avigan, Inhibition of cholesterol biosynthesis in the rat by 3 beta-(2diethylaminoethoxy) androst5-en-17-one hydrochloride. Proceedings of the Society for Experimental 
Biology and Medicine. Society for Experimental Biology and Medicine, 1963. 112: p. 233-6.

23. Panini, S.R., et al., Regulation of 3-hydroxy-3-methylglutaryl coenzyme A reductase activity and cholesterol biosynthesis by oxylanosterols. Journal of lipid research, 1986. 27(11): p. 1190-204. 24. Martinez-Botas, J., et al., Impact of different low-density lipoprotein (LDL) receptor mutations on the ability of LDL to support lymphocyte proliferation. Metabolism: clinical and experimental, 1999. 48(7): p. 834-9.

25. Nguyen, A.D., et al., Hypoxia stimulates degradation of 3-hydroxy-3-methylglutaryl-coenzyme A reductase through accumulation of lanosterol and hypoxia-inducible factor-mediated induction of insigs. The Journal of biological chemistry, 2007. 282(37): p. 27436-46.

26. Carrasco, S. and I. Merida, Diacylglycerol, when simplicity becomes complex. Trends in biochemical sciences, 2007. 32(1): p. 27-36.

27. Alonso, R., et al., Diacylglycerol kinase alpha regulates the secretion of lethal exosomes bearing Fas ligand during activation-induced cell death of T lymphocytes. The Journal of biological chemistry, 2005. 280(31): p. 28439-50.

28. Kim, K., J. Yang, and E. Kim, Diacylglycerol kinases in the regulation of dendritic spines. Journal of neurochemistry, 2010. 112(3): p. 577-87.

29. Aragones, J., et al., Evidence for the involvement of diacylglycerol kinase in the activation of hypoxia-inducible transcription factor 1 by low oxygen tension. The Journal of biological chemistry, 2001. 276(13): p. 10548-55.

30. Chughtai, K., et al., Mass Spectrometry Images Acylcarnitines, Phosphatidylcholines and Sphingomyelin in MDA-MB-231 Breast Tumor Models. Journal of lipid research, 2012. 


\section{Supplemental Figures}

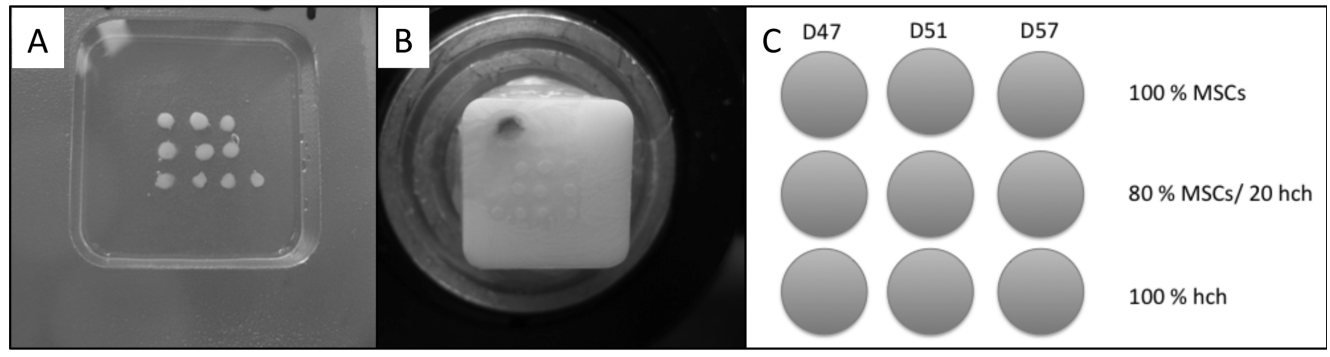

Figure S8.1: Procedure for gelatin sample embedding and processing.

(A) Samples are placed in a plastic mould. $10 \%$ gelatin is used to cast the samples. (B) The frozen gelatin array is mounted on a sample holder before cutting. A Ponceau Red fiducial marker is used to ensure the right orientation of the sample during MALDI measurements. (C) Outline of sample orientation in one array. Equal outlines were achieved for hypoxic and normoxic expanded samples and placed on the same slide. 


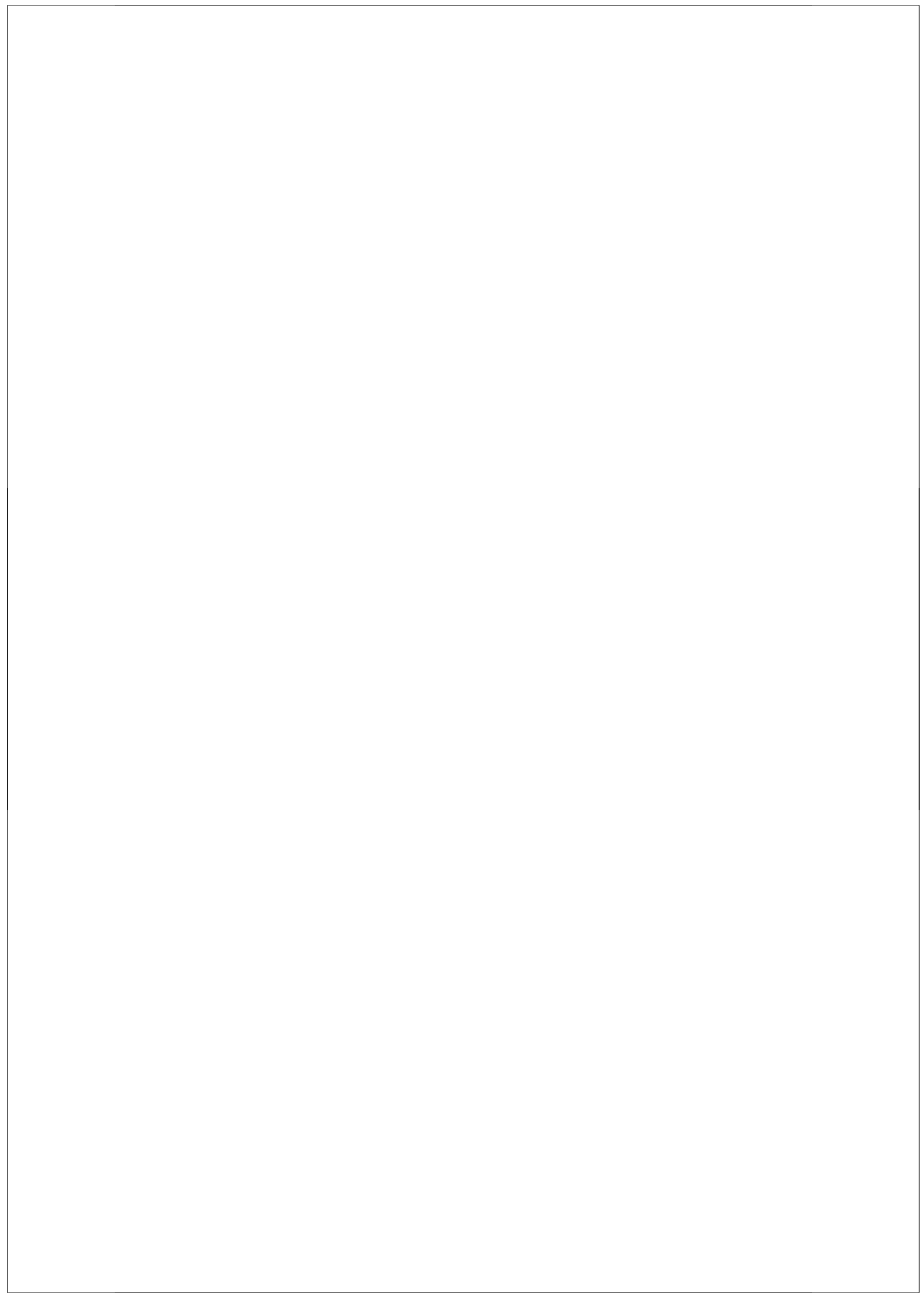


Chapter 9

MSC or chondrocyte seeded microcarriers as building blocks for cartilage tissue engineering

Nicole Georgi, Clemens van Blitterswijk and Marcel Karperien

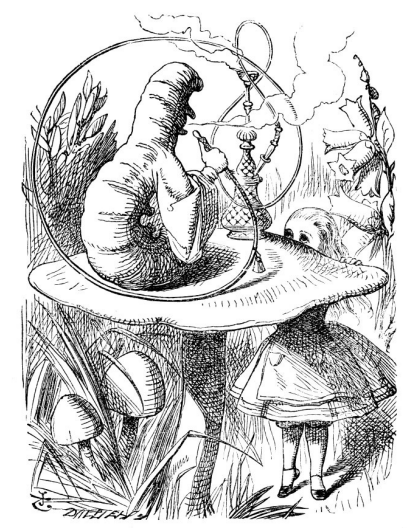




\begin{abstract}
The aim of this study is to test the use of mesenchymal stromal cell (MSC)- or human chondrocyte (hch) laden microcarriers as building blocks for cartilage tissue in comparison to tissue formation in single cell seeded constructs. Building blocks of MSCs and hch expanded on microcarriers were used in chondrogenic co-culture and compared with culture of MSCs or hch alone. The use of cell-laden microcarriers as building blocks for cartilage led to a compact tissue formation with significant volume increase compared to the biomaterial free approach. After 28 days of differentiation culture, formation of cartilaginous matrix in co-culture and chondrocyte approaches was observed. Co-culture resulted in beneficial glycosaminoglycan deposition compared to mono-culture of MSCs or chondrocytes attached to microcarriers. Furthermore, the microcarrier adhered co-culture showed increased levels of the differentiation marker $A C A N$ and reduced levels of de-differentiation marker $C O L 1 A 1$. To our knowledge, this is the first paper which successfully combines an innovative combination of cell expansion on microcarriers and the direct use of MSCs or hch cell laden microcarriers as building blocks in cartilage tissue engineering.
\end{abstract}




\subsection{Introduction}

In 1743, William Hunter described for the first time the avascular structure of cartilage, as well as its limited capacity for self-repair [1]. Until today, cartilage repair and regeneration after damage is only possible to a limited extent. Tissue engineering (TE) therefore offers possibilities for optimization of cartilage repair by combining different cell types, biomaterials and growth factors for the support of cartilage regeneration. For cellular approaches, two of the best described cell sources for cartilage repair are chondrocytes and mesenchymal stromal cells (MSCs). Human chondrocytes (hch) for autologous chondrocyte implantation (ACI) are mainly obtained from biopsies of the non-weight bearing parts of the joint. After harvesting, they need to be expanded to achieve sufficient cell numbers to fill and regenerate critical size defects. Traditionally monolayer chondrocyte cell expansion is associated with the loss of phenotype along with a decreased capacity to secrete extracellular matrix over increasing passage numbers. Therefore, scientists look into alternative expansion and culture strategies to overcome the described limitations.

In 1996, Frondonza et al. introduced a new culture method for chondrocytes; the expansion on commercially available microcarriers. This improved the yield, as well as the conservation of chondrogenic phenotype. Until now, microcarriers have been successfully used in several approaches to expand, redifferentiate and differentiate chondrocytes [2-5]. It was shown, that gelatin or dextran based microcarriers with highly porous structures especially support the round chondrocyte phenotype. Nevertheless, microcarriers are as well used to culture other cell sources, including liver cells $[6,7]$, embryonic stem cells [8] and most relevant for cartilage tissue engineering MSCs [9]. Notably, expansion of MSCs on microcarriers improved proliferation and differentiation and can be used to guide and improve differentiation [9-11].

Performance of the cell types in cartilage tissue engineering can be as well augmented by exploiting co-culture strategies. Co-cultures of different cell sources are based on the idea, that multi-signal events in vivo cannot be perfectly mimicked by adding a limited variety of growth factors to a mono-culture. In this way, cells are exposed to a wider variety of stimuli, mimicking in vivo conditions. In cartilage tissue engineering, MSCs were initially used to reduce the amount of chondrocytes needed or to omit their use all together. Interestingly, chondro-induction was observed in co-cultures of chondrocytes and MSCs; superior neocartilage was formed by the combination of the two different cell-types as compared to either cell type alone $[12,13]$. This phenomenon can only to a limited extend be explained by the induction of chondrogenic differentiation of MSCs by articular chondrocytes [14, 15]. However, in pellet cultures of MSCs and hch the MSC population shows a higher rate of apoptotic cell death leading to a major reduction of MSCs contributing to the final cell population. Furthermore it was shown that MSCs act as trophic mediators and enhance chondrocyte proliferation and differentiation $[12,15,16]$. The mechanism behind this phenomenon remains to a high extend unknown. This co-culture strategy also reveals the possibility of omitting in vitro expansion of chondrocytes in traditional ACI procedures. Combining freshly harvested chondrocytes with MSCs may lead to a single step surgery for cartilage treatment, in which chondrocytes are 
isolated during the surgery, mixed with bone marrow cells or expanded MSCs from the same patient, loaded on a scaffold and directly re-implanted into the patient.

Nevertheless, the applicability of using only cells for filling middle sized to large cartilage defects is limited. For improved clinical practice it is important to transfer cellular models to advanced tissue engineering strategies by including assisting biomaterials. Main purpose of the scaffold is the provision of structural support by optimal filling the entire defect and allowing attachment, proliferation and differentiation of cells in a 3-D environment. The mechanical support provided by the scaffold can lead to a decrease in the rehabilitation time for the patient. Nowadays, tissue engineered scaffolds are as well employed to mimic the natural cellular environment by employing natural materials (proteoglycans, collagens, fibronectin and laminins) to create a favorable microstructure for cellular homing. The porous gelatin microcarriers used in this paper provide supporting structures for cellular attachment and homing [17] and have been described as optimal expansion strategy for MSCs and chondrocytes [18].

Combining innovative co-culture approaches and the favorable characteristics of cellular expansion of cells on microcarriers, we show for the first time, how small units of chondrocyte or MSCs laden gelatin microcarriers can directly serve as building blocks for tissue culture constructs. Further we demonstrate, how these building blocks serve as an easy and time saving option for the transfer of co-culture approaches from cellular level to a complete tissue engineering strategy.

\subsection{Materials and Methods}

\subsubsection{Cell culture}

The use of human bone marrow aspirates and human knee biopsies was approved by the local Medical Ethics Committee. Hch were obtained from full-thickness cartilage dissected from knee biopsies of a patient undergoing total knee replacement as published previously [19]. In short, the harvested cartilage was digested overnight in $0.15 \%$ collagenase type II solution. After digestion, hch were washed and cultured up to passage 1 on tissue culture plastic in chondrocyte proliferation medium (Dulbeccos modified Eagle medium supplemented with 10\% fetal bovine serum, $1 \%$ nonessential amino acids, $0.2 \mathrm{mM}$ ascorbic acid 2-phosphate, $0.4 \mathrm{mM}$ proline, $100 \mathrm{U}$ penicillin/mL, and $100 \mathrm{mg} / \mathrm{mL}$ streptomycin). MSCs were isolated from aspirates as described previously [20]. MSCs were selected by adherence in proliferation media ( $\alpha$-MEM, 10\% fetal bovine serum (Lonza, Verviers, Belgium), $0.2 \mathrm{mM}$ ascorbic acid , $2 \mathrm{mM}$ L-glutamine, $100 \mathrm{U} / \mathrm{mL}$ of penicillin, $100 \mathrm{U}$ penicillin/mL, $100 \mathrm{mg} / \mathrm{mL}$ streptomycin, and $1 \mathrm{ng} / \mathrm{mL}$ of basic Fibroblast Growth Factor (Instruchemie, Delfzijl, The Netherlands).

After one passage of 2D expansion, MSCs or hchs were seeded on Cultisphere G microcarriers (Percell, Sweden) and were cultured for ten days in proliferation medium in stirrer flasks $(500 \mathrm{ml})$. In short, for $1 \times 10^{6}$ cells $0.1 \mathrm{~g}$ of Cultisphere-G were rehydrated in PBS, autoclaved and then transferred to $100 \mathrm{ml}$ of cell suspension in proliferation media. For the first $48 \mathrm{~h}$ the cells were cultured at $25 \mathrm{rpm}$ for $30 \mathrm{~s}$ and 30 


\begin{tabular}{|l|l|l|}
\hline condition & MSCs & chondrocytes \\
\hline $100 \%$ MSC mc & attached to microcarrier & none \\
\hline $80 \%$ MSC mc/ $20 \%$ hch & attached to microcarrier & $3 D$ expanded single cell solution \\
\hline $100 \%$ hch mc & none & attached to microcarrier \\
\hline $100 \%$ MSC 2D & monolayer expanded & none \\
\hline $80 \%$ MSC 2D/ $20 \%$ hch & monolayer expanded & 3D expanded single cell solution \\
\hline $100 \% \mathrm{CH}$ & none & 3D expanded single cell solution \\
\hline
\end{tabular}

Table 9.1: culture scheme for the comparison of microcarrier-cell combinations and single cell seeded constructs.

min pause. After $48 \mathrm{~h} 100 \mathrm{ml}$ proliferation media was added and stirring was changed to continuous mode at $50 \mathrm{rpm}$. For the reference culture without microcarriers MSCs were as well cultured in monolayer at a density of 2500 cells $/ \mathrm{cm}^{2}$. All data are averages of three MSC donors in combination with the same hch donor.

\subsubsection{Microcarrier construct culture}

At day ten of culture aliquots of the chondrocytes and MSCs attached to microcarriers were trypsinised and counted to determine the cell number per milliliter of microcarrier solution. Culture conditions with $1 \times 10^{6}$ cells per construct were prepared according to table 1 . Tissue culture constructs were formed by seeding microcarrierfree cell suspensions and cell-laden microcarrier suspensions in hanging well inserts (Millipore, $6 \mathrm{~mm}$ ) as described previously [21]. Cultures were maintained in chondrogenic differentiation media (Dulbeccos modified Eagle medium supplemented with $40 \mathrm{mg} / \mathrm{mL}$ of proline, $50 \mathrm{mg} / \mathrm{mL}$ ITS-premix, $50 \mathrm{mg} / \mathrm{mL}$ of ascorbic acid, $100 \mathrm{mg} / \mathrm{mL}$ of sodium pyruvate, $100 \mathrm{U}$ penicillin $/ \mathrm{mL}$, and $100 \mathrm{mg} / \mathrm{mL}$ streptomycin, $10 \mathrm{ng} / \mathrm{mL}$ of transforming growth factor-b, $10^{-7} \mathrm{M}$ of dexamethasone) for 4 weeks.

\subsubsection{Live dead staining}

Microcarriers after ten days of expansion culture or constructs after 28 days of culture were washed in $\mathrm{PBS}$ and stained for $30 \mathrm{~min}, 37^{\circ} \mathrm{C}$ in $6 \mu \mathrm{M}$ ethidium homodimer $/ 1 \mu \mathrm{M}$ calcein. Images of 3D constructs were taken by confocal microscopy (LEICA LSM510) whereas images of the single microcarrier constructs were taken with a Nikon (E600) upright fluorescence microscope.

\subsubsection{Scanning electron microscopy}

Samples were dehydrated in increasing series of ethanol, critical point dried, mounted on a sample holder and gold sputtered. Samples were broken in half after snap freezing 
in liquid nitrogen during the dehydration procedure. Imaging acquisition was done with Philips XL 30 ESEM-FEG scanning electron microscope (10 V).

\subsubsection{Rheology}

Rheological experiments were carried out with an MCR 301 rheometer (Anton Paar) using parallel plates $\left(25 \mathrm{~mm}\right.$ diameter) configuration at $37^{\circ} \mathrm{C}$ in the oscillatory mode. The plate distance was set to $2 \mathrm{~mm}$ and samples were measured at increasing frequency (1-10 Hz) and increasing strain (1-10\%). During measurements the measuring chamber was sealed and filled with oil to avoid drying of the sample.

\subsubsection{Histology}

Cell constructs were fixed with $10 \%$ buffered formalin for 15 min and embedded in paraffin using routine procedures. Sections of $5 \mathrm{~m}$ were cut and stained for sulfated glycosaminoglycans (GAGs) with Alcian Blue $\left(0.5 \%\right.$, in $\mathrm{H}_{2} \mathrm{O}, \mathrm{pH}=1$ adjusted with $\mathrm{HCl}, 30 \mathrm{~min})$ combined with counterstaining of nuclear fast red $(0.1 \%$ in $5 \%$ aluminum sulfate, $5 \mathrm{~min})$.

\subsubsection{Wet weight, dry weight and quantitative GAG, DNA assay}

Constructs were washed with phosphate-buffered saline and shortly dipped on filter paper to remove excess liquid before weighing. Samples were freeze dried overnight and weighed again to determine their dry weight. Subsequently, they were digested with $1 \mathrm{mg} / \mathrm{mL}$ proteinase K (Sigma) in Tris/EDTA buffer (pH 7.6) containing 185 $\mathrm{mg} / \mathrm{mL}$ iodoacetamide and $1 \mathrm{mg} / \mathrm{mL}$ pepstatin A (Sigma-Aldrich) for $16 \mathrm{~h}$ at $56^{\circ} \mathrm{C}$. GAG content was spectrophotometrically determined with 9-dimethylmethylene blue chloride (DMMB; $3.04 \mathrm{~g} / \mathrm{l}$ Glycine, $2.37 \mathrm{~g} / 1 \mathrm{NaCl} \mathrm{pH}=3$ ) (Sigma-Aldrich) staining with a microplate reader (Bio-Tek instruments, Richmond, VA) at an absorbance of $520 \mathrm{~nm}$. Cell number was determined via quantification of total DNA with CyQuant DNA kit according to the manufacturers description and fluorescent plate reader (Perkin Elmer, Boston, MA).

\subsubsection{RNA isolation, and quantitative polymerase chain reaction}

Total RNA was isolated from pellet culture with the Nucleospin RNA II kit (Bioke). Up to one microgram of total RNA was reverse-transcribed into cDNA using the iScript cDNA Synthesis kit (Bio-Rad). The primers for quantitative polymerase chain reaction (qPCR) are listed in table 9.2 All reagents were purchased from Invitrogen unless otherwise stated. Common chemicals were purchased from Sigma-Aldrich.

\subsubsection{Statistical analysis}

Statistical analysis was performed using a One-Way-ANOVA followed by a post-hoc Tukey test. Significances of $\mathrm{p} \leqq 0.05$ are indicated $(*)$. 


\begin{tabular}{|l|l|l|}
\hline Gene Symbol & Primer sequence & Length of amplicon \\
\hline HUM ACAN & 5' AGGCAGCGTGATCCTTACC 3' & $136 \mathrm{bp}$ \\
& 5' GGCCTCTCCAGTCTCATTCTC 3' & \\
\hline HUM COL1A1 & 5' GTCACCCACCGACCAAGAAACC 3' & $121 \mathrm{bp}$ \\
& 5' AAGTCCAGGCTGTCCAGGGATG 3' & \\
\hline HUM COL2A1 & 5' CGTCCAGATGACCTTCCTACG 3' & $122 \mathrm{bp}$ \\
& 5' TGAGCAGGGCCTTCTTGAG 3' & \\
\hline HUM COL10A1 & 5' GCAACTAAGGGCCTCAATGG 3' & $129 \mathrm{bp}$ \\
& 5' CTCAGGCATGACTGCTTGAC 3' & \\
\hline HUM SOX9 & 5' TGGGCAAGCTCTGGAGACTTC 3' & $98 \mathrm{bp}$ \\
& 5' ATCCGGGTGGTCCTTCTTGTG 3' & \\
\hline HUM GAPDH & 5' CGCTCTCTGCTCCTCCTGTT 3' & $101 \mathrm{bp}$ \\
& 5' CCATGGTGTCTGAGCGATGT 3' & \\
\hline HUM B2M & 5' GACTTGTCTTTCAGCAAGGA 3' & $106 \mathrm{bp}$ \\
& 5' ACAAAGTCACATGGTTCACA 3' & \\
\hline
\end{tabular}

Table 9.2: Human Primers used for qPCR analysis
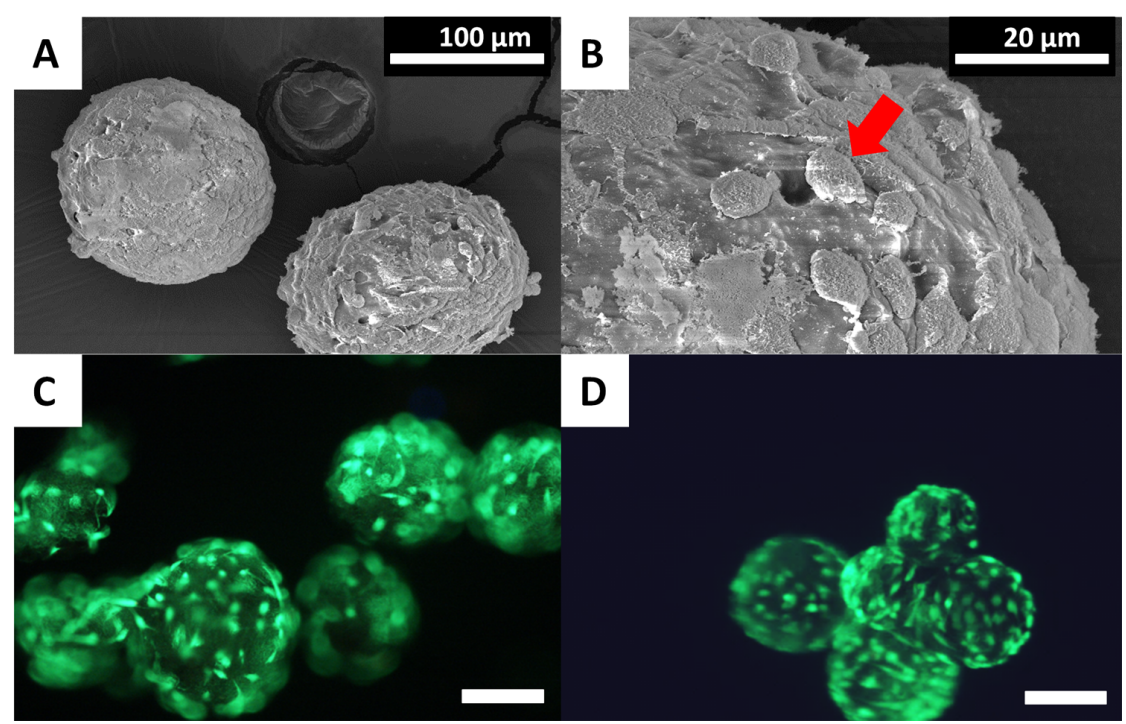

Figure 9.1: Expansion of chondrocytes and MSCs on microcarriers

(A) Scanning electron microscopy picture of a microcarrier laden with hch. (B) Higher magnification of $(\mathrm{A})$ showing that hch maintained their round phenotype (red arrow). (C) MSCs and (D) hch showing high viability after expansion on microcarriers as demonstrated by a life-dead staining, in which living cells fluoresce green and dead cells fluoresce red after 28 days of expansion culture. 
A
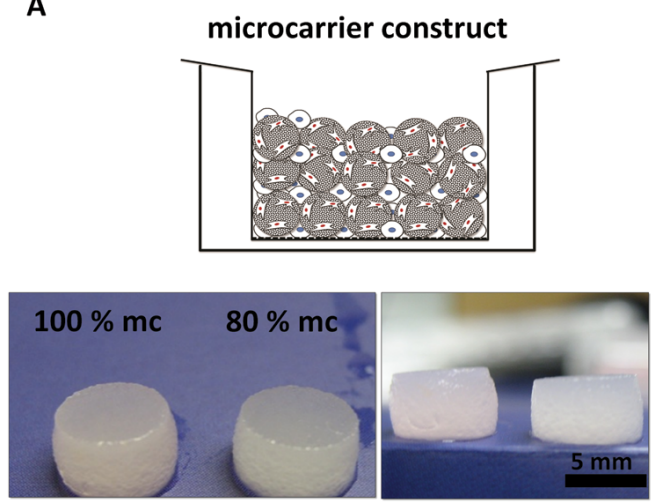

B

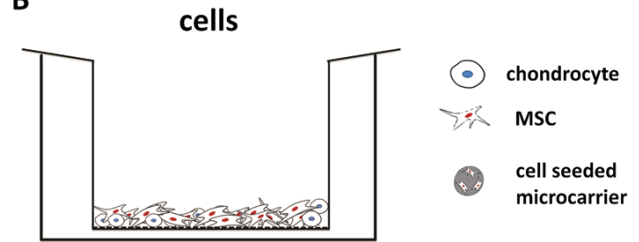

Figure 9.2: Efficient macrotissue formation using cell laden microcarriers as building blocks

(A) Cell laden microcarriers were cultured in hanging inserts alone or were mixed with single cell suspension of 3D-expanded hch and cultured in hanging inserts for 28 days in differentiation medium as shown in the top. $4 \mathrm{~mm}$ thick tissue constructs were obtained in each of the two conditions as shown at the bottom. (B) 3D-expanded MSCs were seeded in hanging inserts and cultured in differentiation medium as shown in the top. After 28 days of culture thin discs of tissue were obtained as shown in the bottom.

\subsection{Results}

\subsubsection{Cells expanded on microcarriers can be used as building units for cartilage TE-constructs}

Previous publications have shown that MSCs and chondrocytes can be expanded on microcarriers with the same or even improved efficiency. [5, 10, 22]. Here we show that chondrocytes retained their round morphology when expanded on microcarriers (Fig 9.1A, B). During expansion, both cell types maintained full viability as shown by calcein/ ethidiumhomodimer staining (Fig 9.1C, D).

We next explored whether chondrocyte or MSC laden microcarriers or combinations there off could be directly used in tissue engineering of cartilage tissue. For this, cell-laden microcarrier constructs were cultured in hanging well inserts. Cartilage tissue formation was compared with single cell seeded wells. Single cell suspensions of hch were derived after trypsinization of cells expanded on microcarriers. In an additional condition the MSC seeded microcarriers were mixed with single cell suspensions of chondrocytes in a cell:cell ratio of 4:1 to translate the culture model into a co-culture strategy. Identical cell numbers were used in each culture condition. Our strategy is depicted in figure $9.2 \mathrm{~A}$.

After 28 days of culture, small discs of microtissues with an average height of $\leq$ $1 \mathrm{~mm}$ were produced in hanging wells seeded with single cell suspensions (Fig 9.2B bottom). In contrast, stable microtissues with an average height of $4 \mathrm{~mm}$ were produced in hanging well inserts seeded with MSC laden microcarriers (MSC mc) only 
A
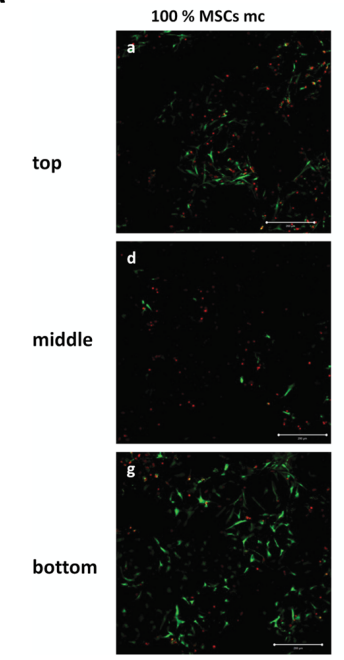

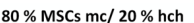
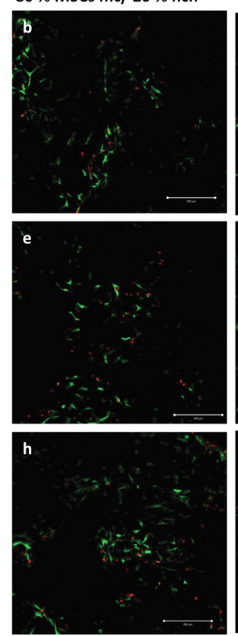

$100 \%$ hch mc
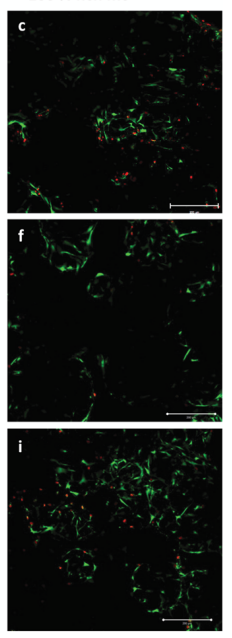

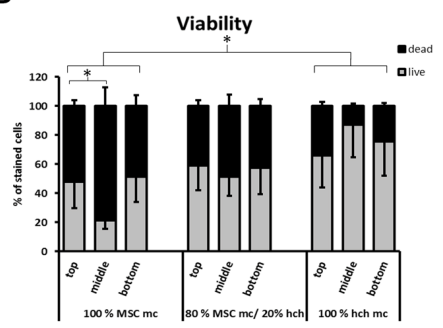

C

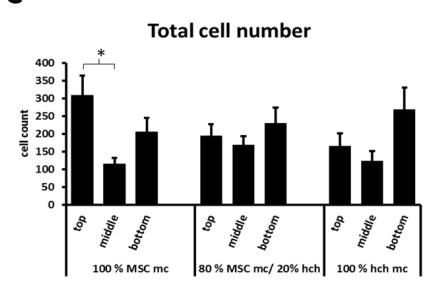

Figure 9.3: Cell viability in the microcarrier tissue constructs

(A) Tissue constructs of cell laden microcarriers (100\% MSCs mc (left), $80 \%$ MSCs mc mixed with $20 \%$ 3D expanded single hch (middle) or 100\% hch mc (right) were obtained after 28 days of culture in differentiation medium in hanging inserts. A live (FDA-green) dead (PI-red) staining of cross-sections was performed. The top row is a representative picture out of 3 repeats of the top zone of the construct (a-c). The middle row is representative for the middle section of the construct (d-f) and the bottom row is representative for living and dead cells in the bottom zone of the tissue construct (g-i). (B) Quantification of living and dead cells in the top, middle and bottom zone of the tissue constructs in (A). Data represent the mean +/- SD of three experiments. (C) Quantification of total cell numbers present in each zone of the tissue constructs. Data represent the mean +/- SD of at least three independent experiments. ${ }^{*}=\mathrm{p} \leqq 0.05$
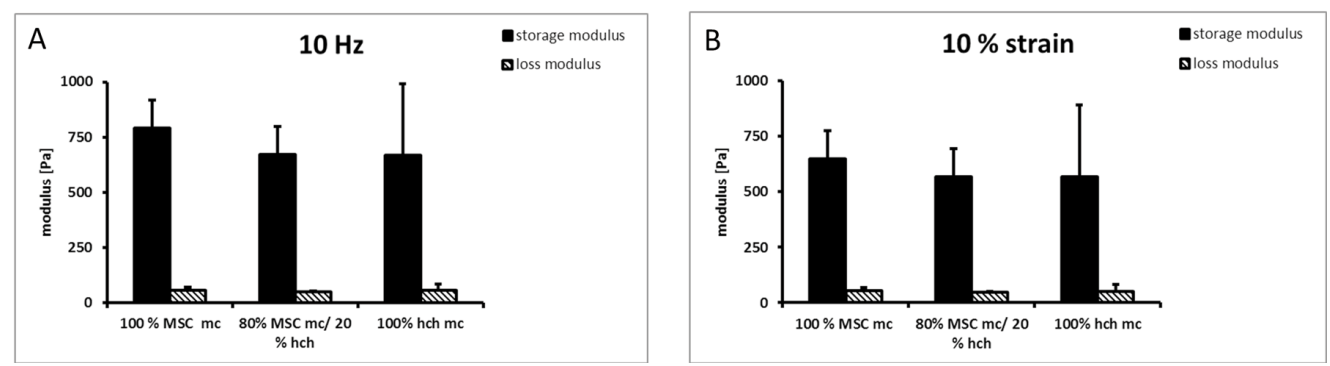

Figure 9.4: Rheological analysis of the microcarrier based tissue constructs

(Storage and loss modulus of cell laden microcarrier based tissues (various cell combinations) were determined at a stress of $10 \mathrm{~Hz}$ (A) or a strain of $10 \%$ (B). Data represent the mean of 3 independent experiments +/- SD. 

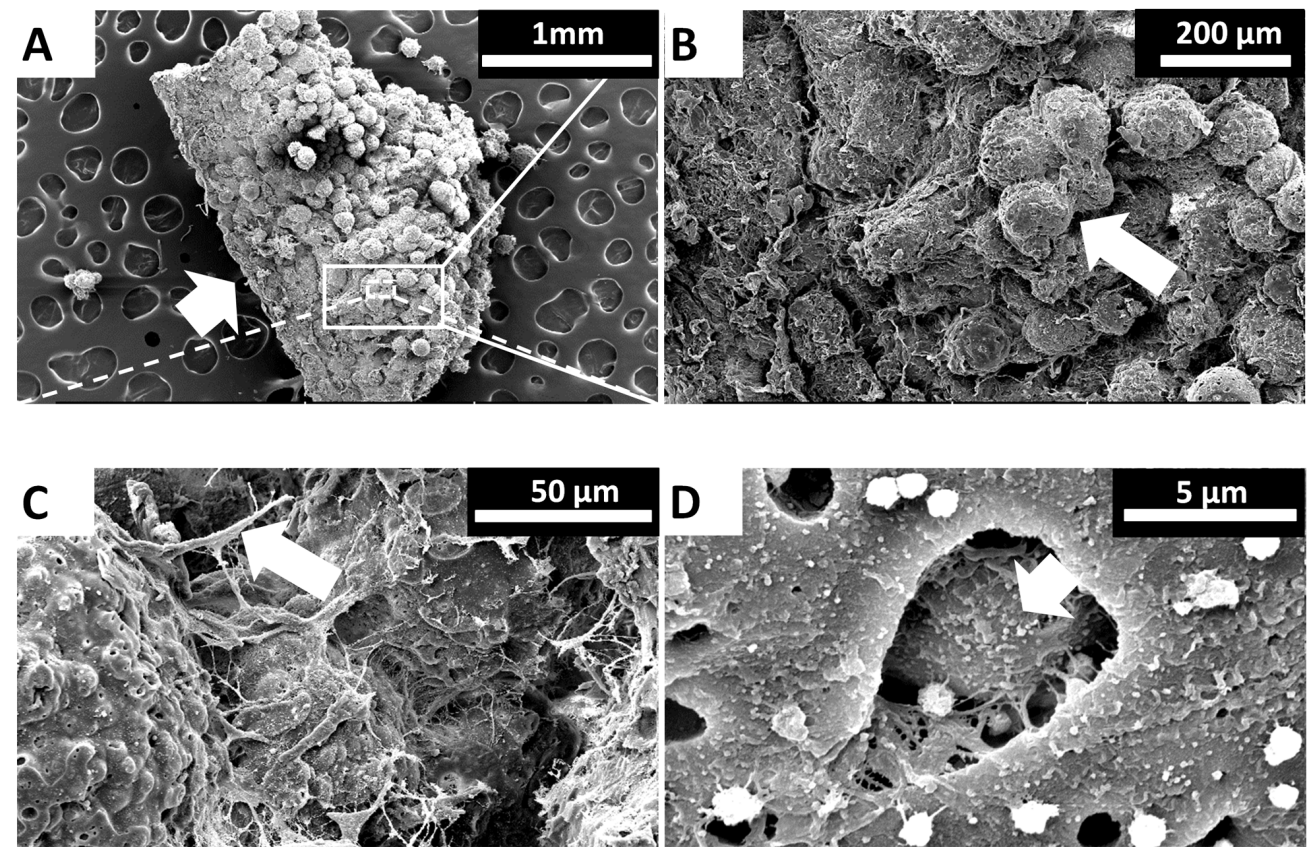

Figure 9.5: Scanning electron microscopy of the microcarrier tissue constructs after 4 weeks of culture

(A) Scanning electron microsopy showed compact tissue formation at the lower part of the construct (arrow) and more loose tissue with visible single microcarriers in the upper part. (B) Higher magnification of the boxed region in A showing individual microcarriers interconnected by cells and matrix. The arrow points to 4 microcarriers visible connected by protein fibers $(\mathrm{C})$ Further magnification of (B) showing the round outline of microcarriers (arrow) which are visibly connected by matrix (D) whereas it is difficult to distinguish individual cells on microcarriers SEM clearly provided evidence for the presence of cellular niches at the surface of the microcarrier which might be favorable for growth and differentiation. The arrow points at a cell homing in a microcarrier, whereas the light dots around the cells likely represent protein aggregates secreted by cells homing to the microcarriers (asterisk). Representative picture out of 3 independent experiments is shown. 


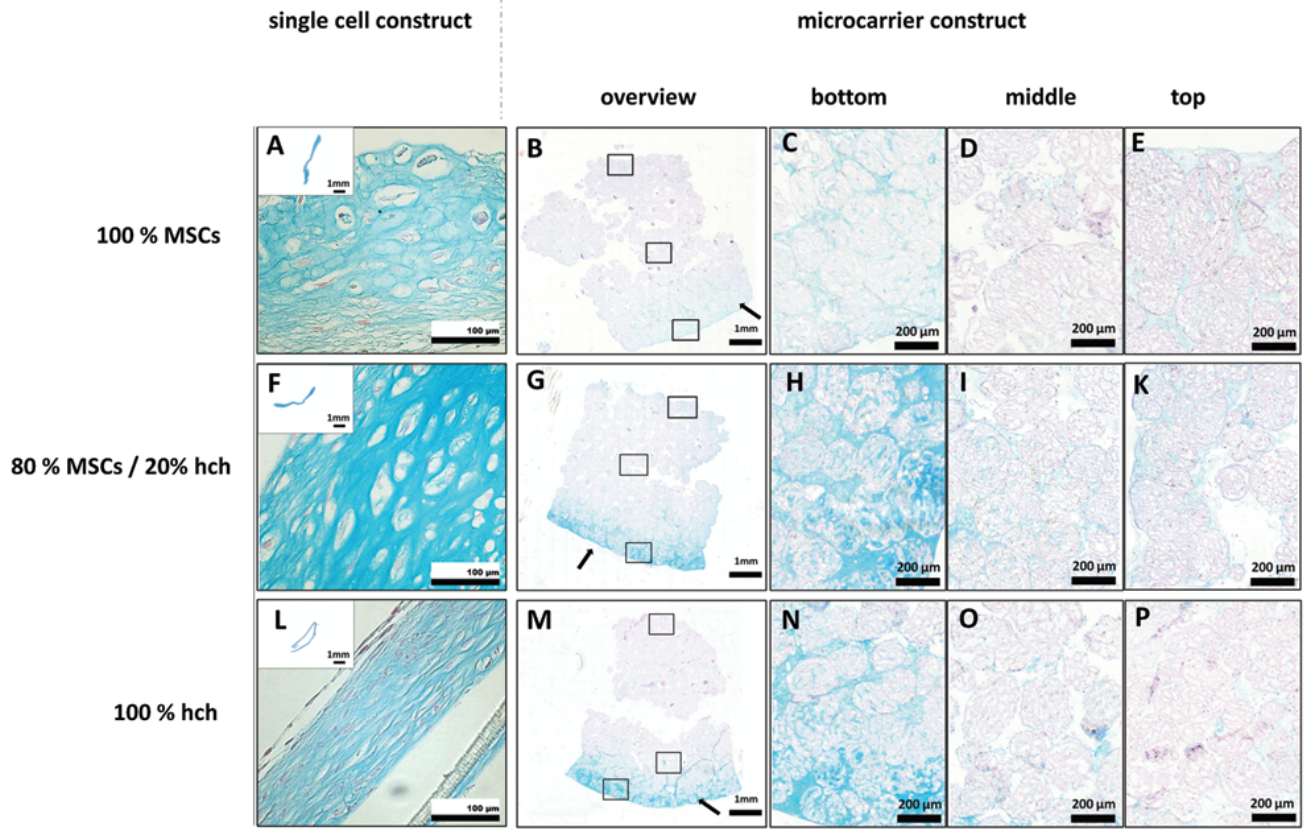

Figure 9.6: Alcian blue stain of GAG deposition in the microcarrier construct compared with the cellular constructs

(A, F, L) Histological sections show that single cell seeded constructs result in thin layers of tissue with Alcian Blue stain in all conditions; high magnifications show more fibrous cartilage formation in the hch tissue (L) whereas MSCs and co-culture led to round chondron-like cellular morphology inside the matrix (A, F); (B, G, M) microcarrier constructs show cartilaginous matrix formation at the bottom of the construct and lowest abundance of staining in the middle of the constructs (C-P), matrix formation inside the microcarriers is visible in the co culture of $80 \%$ hch and $20 \%$ MSCs as well as the $100 \%$ hch culture( H, N); the co-cultured constructs show a more intense Alcian Blue stain in single cell cultures as well as cell laden microcarrier cultures (F-K). Representative pictures out of 3 independent experiments are shown.

or with MSC mc in combination with a single cell suspension of chondrocytes in a cell:cell ratio of 4:1 (Fig 9.2A bottom). Macroscopically there was no obvious morphological difference between the latter two conditions. We next examined the effect of using cell-laden microcarriers to build 3D constructs for cartilage tissue engineering on cell viability. After 28 days of differentiation the 3-dimensional constructs were stained for living and dead cells, cross sectioned and confocal pictures of the bottom, middle and top part were taken. Viable cells were present in each compartment of the tissue construct, with variation between the different zones (Fig 9.3A and 9.3B). Cell numbers in different areas of the construct were evenly distributed in constructs containing chondrocytes whereas constructs consisting of pure MSC laden microcarriers contained significantly lower amount of cells in the middle part of the construct (Fig 9.3C). In each of the three seeding regimes, considerable cell death, in particular in the middle of the construct, was noted after 28 days of culture (Fig 9.3B). Cell 
death was most pronounced in constructs build of MSC laden microcarriers. Mixing the MSC laden micorcarriers with a single cell suspension of chondrocytes slightly improved cell viability particularly in the middle compartment of the construct. Highest cell survival was observed in constructs build of chondrocyte-laden microcarriers. Remarkably, while cell death was most pronounced in the middle compartment of constructs containing MSC laden microcarriers, most dead cells were found in the top and bottom compartment of the constructs build of chondrocyte laden microcarriers (Fig 9.3B).

We next measured the viscoelastic behavior of the hydrogel-like microcarrier constructs by determining the storage and loss modulus which represent values for the elastic portion and the viscous portion of a construct. Rheological analysis revealed minor differences between the different constructs with a storage modulus of about $750 \mathrm{~Pa}$ and an about 10-fold lower loss-modulus when $10 \mathrm{~Hz}$ of stress or $10 \%$ strain were applied. (Fig 9.4A and B, respectively). Similar results have been obtained for gelatin gels before [23].

\subsubsection{Microcarrier based tissue constructs show cartilaginous tissue formation}

The tissue engineered constructs using cell laden microcarriers as building blocks were then subjected to scanning electron microscopy (SEM). SEM analysis showed compact tissue formation at the lower part of the construct and more loose tissue in the upper part (Fig 5A, error indicating bottom of the construct). At higher magnifications the round and compact structure of the microcarriers could still be recognized easily (Fig 9.5B). The cell laden microcarriers were surrounded and connected by extracellular matrix (Fig 9.5B, C (arrow)). The microcarriers provided cellular niches for (in)growth and differentiation of the cells in the construct (Fig 9.5D).

Staining for glycosaminoglycan deposition demonstrated cartilaginous matrix formation. In the single cell seeded constructs, a thin layer of packed cells surrounded by Alcian Blue positive glycosaminoglycans was observed (Fig 9.6A, F, L). In all three conditions cartilage formation was observed. The chondrocyte based constructs had a rather fibrous morphology (Fig 9.6L). As expected, staining appeared more intense in the co-culture of MSCs and PCs in line with previous observations [12].

In contrast to the single cell seeded constructs, the microcarrier constructs showed heterogeneous extracellular matrix deposition. Constructs solely consisting of MSC laden microcarriers hardly stained positive for Alcian Blue, while intense staining was found at the bottom of the construct of MSC laden microcarriers mixed with chondrocytes or chondrocytes laden microcarriers (Fig 9.6B, G, M (arrows); C, H, $\mathrm{N})$. This staining gradually decreased when moving from bottom to top with a slight increase in staining at the top layer (Fig 9.6E, K, P). At higher magnifications, matrix formation inside the hollow structures of the microcarriers was observed, indicating first signs of microcarrier degradation as well as cellular ingrowth in the microcarriers (Fig 9.6 black arrows). The amount of matrix formation was lower in the MSC-only culture, whereas staining in co-cultures of MSC laden microcarriers and hch tended to be higher than in chondrocyte mono-culture. The cell density in the microcarrier 
based constructs was lower than in the according single cell constructs, resembling a more cartilage like phenotype

For validation of histological data, biochemical quantitative analysis was performed. In agreement with their bigger size, the wet weight of microcarrier seeded constructs was about twenty- fold higher compared to single cell seeded constructs. Also the dry weight of the microcarrier containing constructs was higher (Fig 9.7A, B). Quantitative DMMB-based glycosaminoglycan measurements of 3 different donors confirmed the lowest cartilage formation in MSC microcarrier cultures, and revealed a trend to increased glycosaminoglycan formation in the co-culture approach although this did not reach significance. Single cell seeded constructs showed the highest GAGdeposition in the MSC cultures whereas co-cultures and chondrocyte cultures showed comparable cartilaginous tissue formation after correction for DNA (Fig 9.7C). DNA content of cultures could give an indication about proliferation or cell death in the cell culture approach. Although seeding same total cell numbers in the beginning, the DNA content of single cell seeded constructs was always lower than of microcarrier seeded constructs. This suggested that the microcarrier environment better supported cell proliferation and/or cell survival than single cell seeded constructs. The DNA levels were more stable in microcarrier based constructs than in pure cell-based constructs.

\subsubsection{Reduced markers of de-differentiation and hypertrophy in microcarrier seeded constructs}

Subsequently we analyzed gene expression levels in single cell and microcarrier seeded constructs by quantitative (q) PCR. Comparison of single cell constructs and microcarrier constructs showed higher mRNA expression of the marker $S O X 9$ (significant) and COL2A1 in single cell seeded constructs (Fig 8A, C). ACAN was expressed to the same amount in co-culture of both culture approaches (Fig 9.8B). COL1A1, a marker of de-differentiation was expressed significantly higher in all cellular conditions (Fig $8 \mathrm{D})$, compared to microcarrier based constructs. The ratio between COL2A1 and COL1A1 was not different. COL10A1 mRNA was considerably lower in MSC laden microcarrier based constructs compared to pure cell based constructs. No COL10A1 mRNA expression was detected in constructs based on hch.

\subsection{Discussion}

In this paper, we demonstrate that microcarriers seeded with MSCs or chondrocytes can directly serve as building blocks for tissue engineered cartilage constructs. In contrast to constructs seeded with equal numbers of single cells, relatively thick, up to $4 \mathrm{~mm}$, cartilaginous tissue constructs can be obtained. To the best of our knowledge, we are the first to use cell seeded microcarriers as building blocks for cartilage tissue engineering. Our approach might be applicable for cartilage defects but also for other traumas in which relatively large defects need to be filled. A similar approach has previously been used before in bone tissue engineering. Instead of gelatin based microspheres, cell laden calcium phosphate particles were used to fill up critical 
A

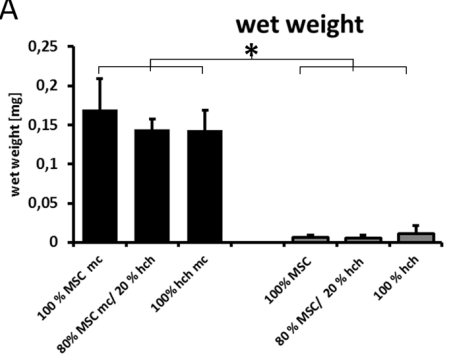

C

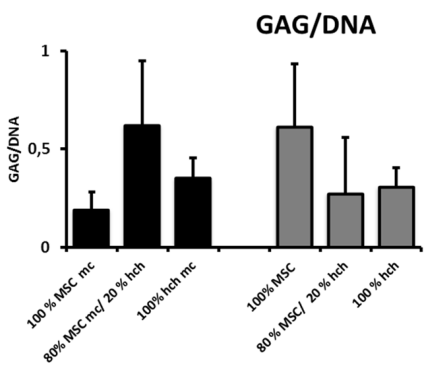

B

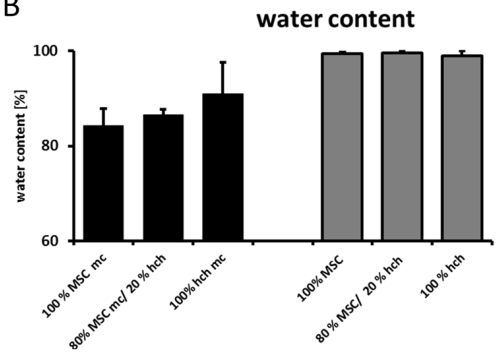

D

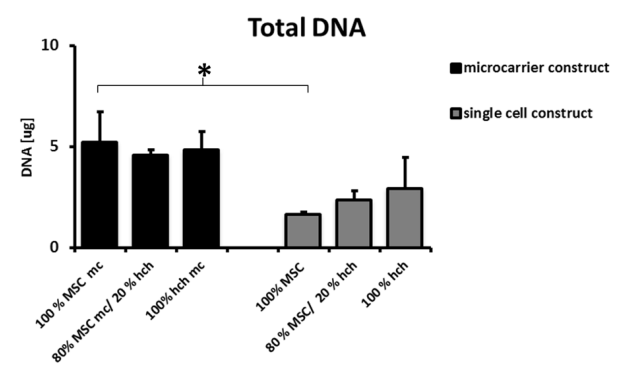

Figure 9.7: Biochemical analysis of the microcarrier based culture in comparison with the cellular construct

(A) wet weight of the microcarrier tissues is significantly higher than in the cellular tissues resembling the bigger volume of the tissues. (B) Microcarrier tissues contain less water than cellular constructs when normalized with construct weight. (C) The co-culture approach results in higher relative glycosaminoglican deposition in the microccarrier culture, whereas in the cellular approach MSCs seem to deposit more GAGs (not significant), Total DNA content is in general higher in the microcarrier containing constructs with significant difference in the MSC containing samples Data represent the mean $+/-\mathrm{SD}$ of at least 3 independent experiments. ${ }^{*}=\mathrm{p} \leqq 0.05$.

bone size defects [24]. Thus by selecting the appropriate material for microsphere generation, best fitting with characteristics of the desired tissue, this approach could be amenable for the tissue engineering of a wide-variety of tissues [25, 26].

The comparison of microcarrier based constructs with the single cell constructs showed significant volume increase and offers thereby the opportunity to efficiently fill critical size cartilage defects in vivo. Most importantly, we present a method which offers the possibility to be applied in cell based single-step cartilage repair strategies in clinical practice. For the improvement of current ACI, it is favorable to omit the step of chondrocyte expansion and assist the limited amount of fresh isolated primary chondrocytes with a second cell type. Co-cultures of MSCs and chondrocytes have been shown to improve chondrogenesis in cartilage tissue engineering strategies [12, 27 ] and might be a suitable strategy to overcome the low availability of chondrocytes 
A
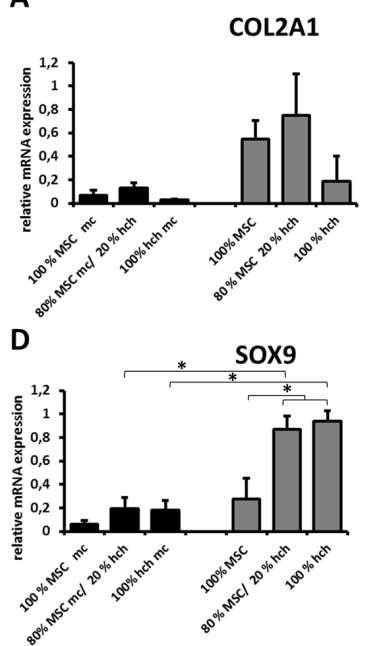

B
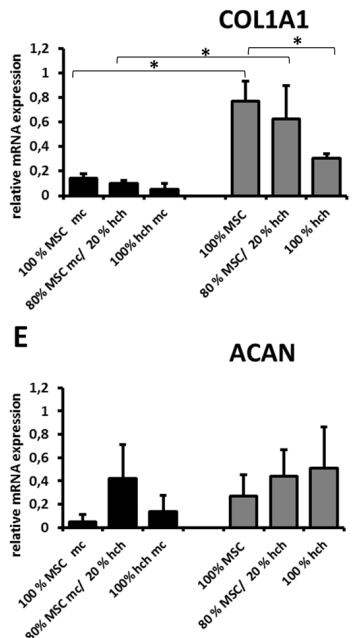

C

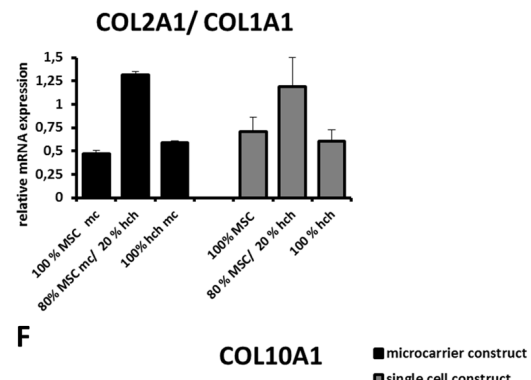

Figure 9.8: Relative mRNA expression in microcarrier and single cell based constructs

(A, D) chondrogenesis markers COL2A1 and SOX9 are higher in cellular constructs in all experimental conditions; whereas ACAN is expressed to the same amount in the co-culture approach of both culture approaches $(B),(B, C)$ despite the fact that COL1A1 is significantly higher expressed in single cell cultures, no difference between microcarrier and cellular constructs was observed when the ratio of COL2A1/ COL1A1 (ratio of differentiation vs de-differentiation is formed), COL1OA1 is only expressed in the co-culture and the MSC samples. Data represent the mean +/- SD of at least thre independent experiments. ${ }^{*}=\mathrm{p} \leqq 0.05$.

for repair. The here described expansion of MSCs on hollow microcarriers has been shown to improve MSC proliferation [10] and seems to provide microenvironments for homing of MSCs (Fig 9.5D). For microcarrier assisted co-cultures, autologous MSCs can be taken from iliac crest, expanded on microcarriers and used in the surgery with freshly isolated chondrocytes.

The tissue obtained by cell-laden microcarriers has a hydrogel like appearance (Fig 9.2A) which results mainly from the ability of the gelatin microcarrier to swell in water. Healthy cartilage consists of $75-85 \%$ of water and thereby it is desirable to engineer cartilage with biomaterials that offer similar physical composition [28]. The here newly engineered tissue consist of $80-90 \%$ of water and has thereby a desirable feature of engineered cartilage (Fig 9.7B). These characteristics are as well underlined by the rheological measurements which are in the range of gelatin hydrogels described in the literature [23].

An often observed problem in the use of collagen based hydrogels is contraction of the whole construct depending on the forces the cells develop as well as the degradation process of the biomaterial. Gelatin microcarriers are known to have a highly 
crosslinked structure which degrades very slowly. In histological stainings we observed cartilaginous matrix formation inside the microcarriers, which appeared more hollow and might have undergone first degradation by enzymes secreted by the ingrowing cells (Fig 9.6H, N). Even though degradation could be seen in histological stainings, the microcarriers mainly exhibited their round morphology, in particular in the top part of the construct, as was seen by scanning electron micrographs (Fig 9.5A). This indicated that the highly crosslinked structure of the gelatin based Cultisphere-G microcarriers likely enables long lasting support and will thereby allow further stabilization of the defect meanwhile facilitating tissue formation. In different tissue engineering approaches using the same type of microcarriers degradation took about 8 weeks [3]. For the proof of principle, these microcarriers provided sufficient support in the cartilage tissue engineering construct. Nevertheless, an optimization of degradation time might lead to even faster matrix deposition and improved chondrogenesis. The production of gelatin microcarriers with different degrees of crosslinking has been shown to have an influence on cell proliferation, survival and differentiation of mouse fibroblasts [29]. Evidence suggests that microspheres with longer degradation times has a positive effect on these parameters.

In the here described microcarrier constructs viability was lower in middle of the constructs when MSCs were used as major cell source. Constructs consisting of pure chondrocyte had a higher viability in all areas of the construct. In 3D cultures, microcarriers can be used as a porogen for better nutrient supply, which enables the formation of thicker tissue constructs. This key feature of microcarriers enables cells to survive in all parts of the constructs, whereas chondrocytes seem to have an optimized range of adaptation for reduced nutrient supply. Malda et al. described that nutrient deprivation can activate chondrogenesis [30]. This might indicate that chondrocytes with their limited nutrient supply in mature cartilage are more adopted to survival in 3D constructs than MSCs with limited nutrient supply and waste product exchange in the center of the constructs. By additional comparison of DNA content of the microcarrier assisted culture with single cell culture construct, it was clear that cell numbers in microcarrier constructs after 28 days of differentiation culture was higher. Higher cell numbers were likely the result from better proliferation conditions, offered by the presence of the microcarriers $[10,22]$. The increased surface area minimizes competition between cells for limited cell attachment places. With the here described culture set-up, we enable the transfer of co-culture of MSCs and chondrocytes to a full cartilage tissue engineering strategy.

The co-culture approach has been described to enable beneficial cartilage formation, namely chondro-induction, marked by increased GAG depositon, decreased cell de-differentiation, as measured by COL1A1 gene expression and decreased hypertrophic cell differentiation leading to less calcification/endochondral bone formation in vivo $[12,27,31]$. Co-culture of MSCs attached to microcarriers and 3D expanded chondrocytes led to improved GAG deposition, as well as a decrease in COL1A1 expression. We were able to confirm the down-regulation of COL10A1 in this culture model; whereas a decreased level of calcification would have to be tested in an in vivo model. Even though the microcarrier based culture model showed lower expression values for COL2A1 and SOX9 it was proven by DNA levels that more cells were 
abundant in the construct expressing the analyzed genes in a higher total amount.

In conclusion in this paper we show that cell-laden microcarriers used for the expansion of either MSCs or hch can be directly used as building blocks for tissue engineered constructs. They may have potential for direct application in cartilage repair strategies without the need of trypsinisation and isolation of microcarrier expanded single cells. 


\section{References}

1. Hunter, W., Of the Structure and Disease of Articulating Cartilages. Clin Orthop Relat Res, 1995. 317: p. 3-6.

2. Frondoza, C., A. Sohrabi, and D. Hungerford, Human chondrocytes proliferate and produce matrix components in microcarrier suspension culture. Biomaterials, 1996. 17(9): p. 879-88.

3. Pettersson, S., et al., Human articular chondrocytes on macroporous gelatin microcarriers form structurally stable constructs with blood-derived biological glues in vitro. J Tissue Eng Regen Med, 2009. 3(6): p. 450-60.

4. Schrobback, K., et al., Effects of oxygen and culture system on in vitro propagation and redifferentiation of osteoarthritic human articular chondrocytes. Cell Tissue Res, 2012. 347(3): p. 649-63.

5. Schrobback, K., et al., Adult human articular chondrocytes in a microcarrier-based culture system: expansion and redifferentiation. J Orthop Res, 2011. 29(4): p. 539-46.

6. Bosman, D.K., et al., Metabolic activity of microcarrier attached liver cells after intraperitoneal transplantation during severe liver insufficiency in the rat. J Hepatol, 1989. 9(1): p. 49-58.

7. Demetriou, A.A., et al., Survival, organization, and function of microcarrier-attached hepatocytes transplanted in rats. Proc Natl Acad Sci U S A, 1986. 83(19): p. 7475-9.

8. Fernandes, A.M., et al., Mouse embryonic stem cell expansion in a microcarrier-based stirred culture system. J Biotechnol, 2007. 132(2): p. 227-36.

9. Frauenschuh, S., et al., A microcarrier-based cultivation system for expansion of primary mesenchymal stem cells. Biotechnol Prog, 2007. 23(1): p. 187-93.

10. Schop, D., et al., Expansion of mesenchymal stem cells using a microcarrier-based cultivation system: growth and metabolism. J Tissue Eng Regen Med, 2008. 2(2-3): p. 126-35.

11. Sart, S., et al., Modulation of mesenchymal stem cell actin organization on conventional microcarriers for proliferation and differentiation in stirred bioreactors. J Tissue Eng Regen Med, 2012.

12. Wu, L., et al., Trophic effects of mesenchymal stem cells increase chondrocyte proliferation and matrix formation. Tissue Eng Part A, 2011. 17(9-10): p. 1425-36.

13. Bian, L., et al., Coculture of human mesenchymal stem cells and articular chondrocytes reduces hypertrophy and enhances functional properties of engineered cartilage. Tissue Eng Part A, 2011. 17(7-8): p. $1137-45$.

14. Aung, A., et al., Osteoarthritic chondrocyte-secreted morphogens induce chondrogenic differentiation of human mesenchymal stem cells. Arthritis Rheum, 2011. 63(1): p. 148-58. 15. Acharya, C., et al., Enhanced chondrocyte proliferation and mesenchymal stromal cells chondrogenesis in coculture pellets mediate improved cartilage formation. J Cell Physiol, 2012. 227(1): p. 88-97.

16. Caplan, A.I. and J.E. Dennis, Mesenchymal stem cells as trophic mediators. J Cell Biochem, 2006. 98(5): p. 1076-84.

17. Ng, Y.C., J.M. Berry, and M. Butler, Optimization of physical parameters for cell attachment and growth on macroporous microcarriers. Biotechnol Bioeng, 1996. 50(6): p. 627-35.

18. Malda, J. and C.G. Frondoza, Microcarriers in the engineering of cartilage and bone. Trends Biotechnol, 2006. 24(7): p. 299-304.

19. Bogie, J.F., et al., Myelin-phagocytosing macrophages modulate autoreactive T cell proliferation. J Neuroinflammation, 2011. 8: p. 85.

20. de Souza, T.O., et al., Phototherapy with low-level laser affects the remodeling of types I and III collagen in skeletal muscle repair. Lasers Med Sci, 2011. 26(6): p. 803-14.

21. Murdoch, A.D., et al., Chondrogenic differentiation of human bone marrow stem cells in transwell cultures: generation of scaffold-free cartilage. Stem Cells, 2007. 25(11): p. 2786-96.

22. Pettersson, S., et al., Cell expansion of human articular chondrocytes on macroporous gelatine scaffolds-impact of microcarrier selection on cell proliferation. Biomed Mater, 2011. 6(6): p. 065001. 23. Kalyanam, S., R.D. Yapp, and M.F. Insana, Poro-viscoelastic behavior of gelatin hydrogels under compression-implications for bioelasticity imaging. J Biomech Eng, 2009. 131(8): p. 081005.

24. Blokhuis, T.J., et al., Resorbable calcium phosphate particles as a carrier material for bone marrow in an ovine segmental defect. J Biomed Mater Res, 2000. 51(3): p. 369-75.

25. Tuin, A., et al., Recombinant gelatin microspheres: novel formulations for tissue repair? Tissue Eng Part A, 2010. 16(6): p. 1811-21.

26. Shen, H., et al., An injectable scaffold: rhBMP-2-loaded poly(lactide-co-glycolide)/hydroxyapatite composite microspheres. Acta Biomater, 2010. 6(2): p. 455-65. 
27. Mo, X.T., et al., Variations in the ratios of co-cultured mesenchymal stem cells and chondrocytes regulate the expression of cartilaginous and osseous phenotype in alginate constructs. Bone, 2009. $45(1):$ p. $42-51$.

28. Klein, T.J., et al., Strategies for zonal cartilage repair using hydrogels. Macromol Biosci, 2009. 9(11): p. 1049-58.

29. Tajima, S. and Y. Tabata, Preparation and functional evaluation of cell aggregates incorporating gelatin microspheres with different degradabilities. J Tissue Eng Regen Med, 2012.

30. Malda, J., et al., The effect of PEGT/PBT scaffold architecture on oxygen gradients in tissue engineered cartilaginous constructs. Biomaterials, 2004. 25(26): p. 5773-80.

31. Elder, S.H., et al., Production of hyaline-like cartilage by bone marrow mesenchymal stem cells in a self-assembly model. Tissue Eng Part A, 2009. 15(10): p. 3025-36. 


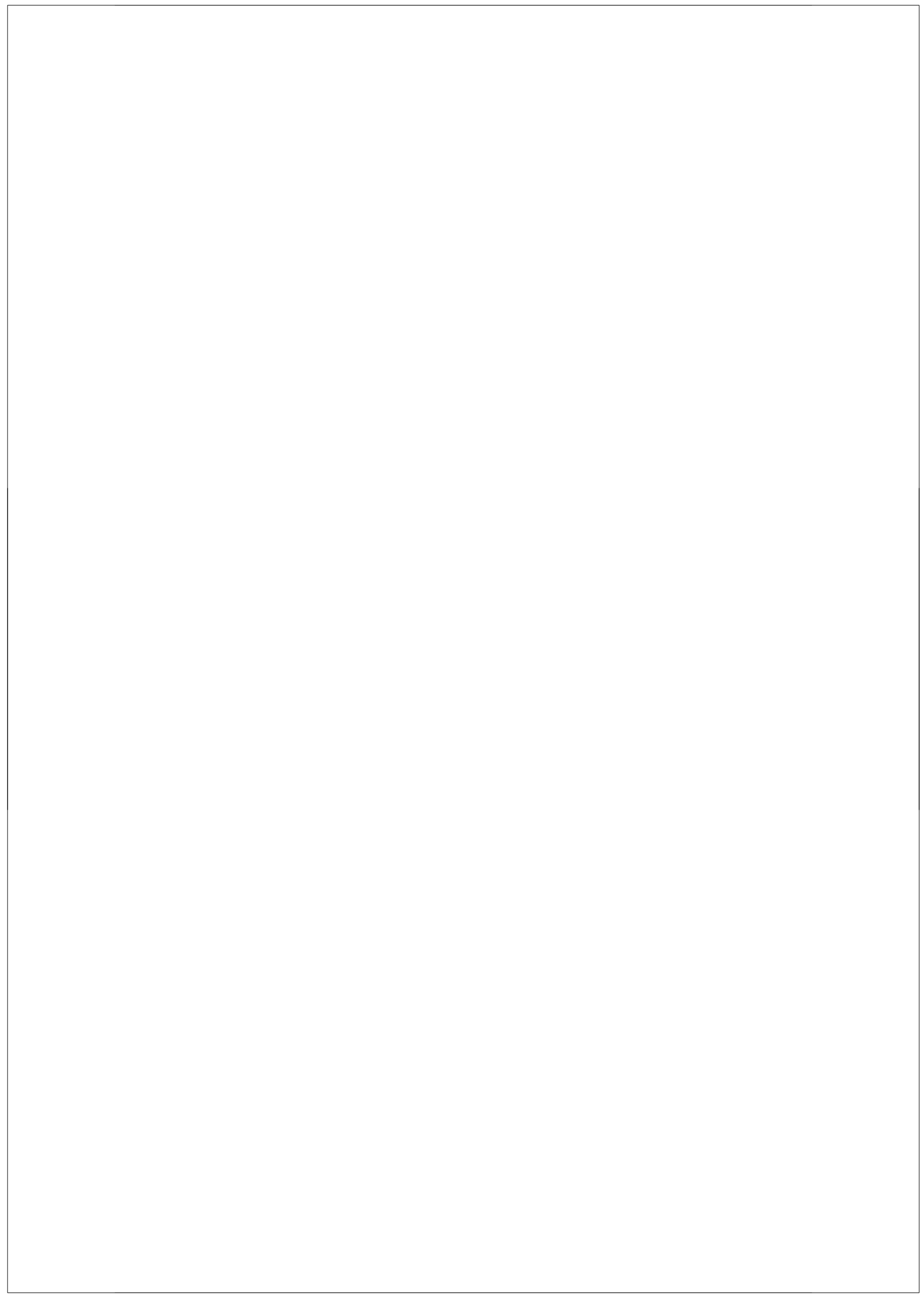


Chapter 10

\section{Conclusion and Outlook}




\subsection{Abstract}

Like all tissue engineering fields, cartilage tissue engineering relies on the wise decision for the optimal combination of the three pillars of tissue engineering. These three pillars include environmental factors, like the choice of support structure, the cellular factor as well as the growth factor (Fig 10.1). This thesis focuses on optimisation of two of these major pillars: (a) cells and (b) growth factors or bioactive molecules. Chapter four till six mainly focus on the optimisation of the use of mesenchymal stromal or stem cells (MSCs) for (cartilage) tissue engineering. Chapter seven up to nine introduces bioactive molecules to improve chondrogenesis of MSCs or chondrocytes. 


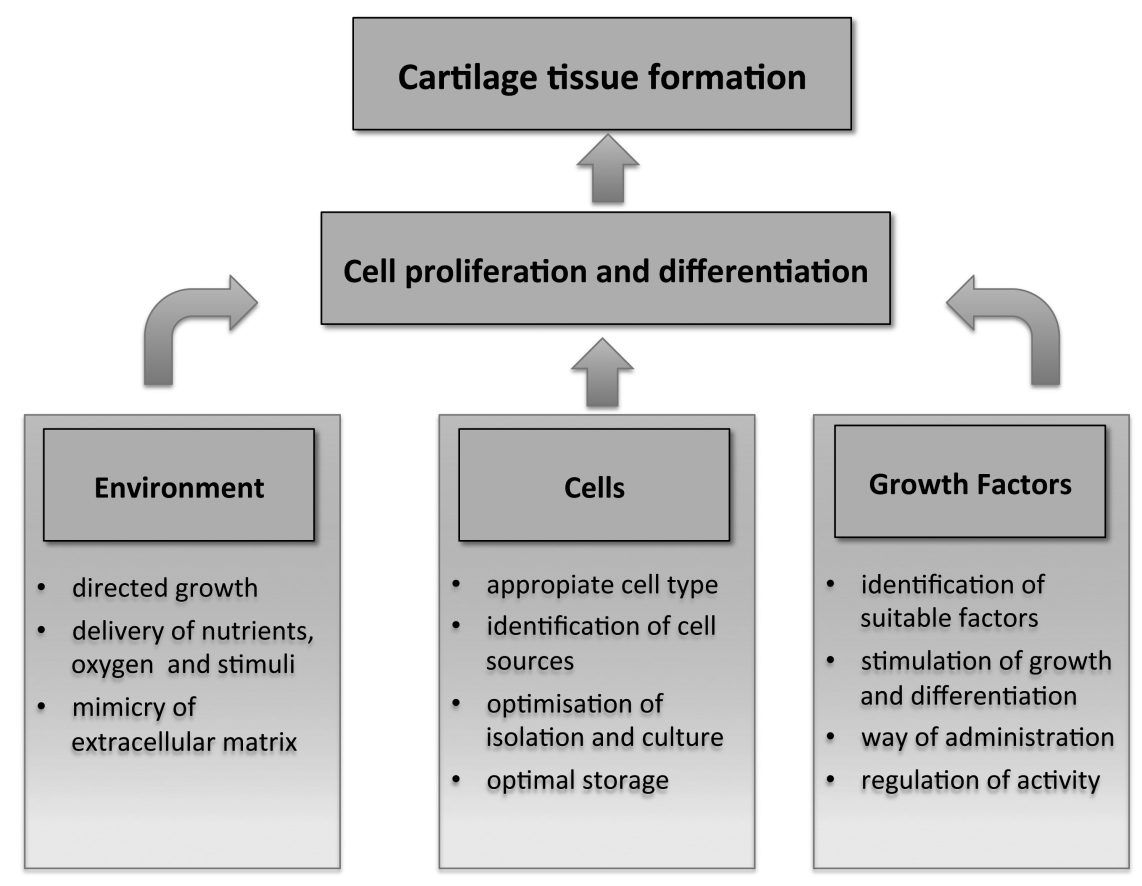

Figure 10.1: The three major pillars leading to an ultimate cartilage tissue engineering strategy

\subsection{Mesenchymal stromal cells and their position in the field in cartilage tissue engineering}

The application of bone-marrow-derived stromal cells in tissue engineering was first described in 1966 [1]. Mesenchymal stromal/stem cells (MSCs), derived from various harvest sites, are a valuable cell source in most fields of regenerative medicine. MSCs characteristics lie in their differentiation potential into various cell lineages and their capability to act as bioactive mediators inducing secondary cellular responses [2, 3]. Initially MSCs were thought to only differentiate and replace the respective cell source in the repair tissue environment, but now we know that MSCs can home to injured tissue and aid in tissue repair by the release of cytokines, antioxidants, trophic factors or other bioactive molecules [4-6]. The paracrine effects of MSCs and cell replacement of host tissue by MSC-derived cells are not mutually exclusive. Therefore investigations to improve MSC chondrogenic differentiation as well as the revealing of their paracrine effects in chondrogenic co-culture strategies are substantial to advance cartilage repair strategies.

In chapter four we introduce the general limitation of MSCs when used as autologous cell source to fill cartilage defects [7]. Only three donors out of twenty undergo sufficient amount of chondrogenesis ex vivo. Even though we demonstrate an approach to link MSC donor potential to the expression of mRNAs and miRNAS, we 
see the need for the identification of (a) strategies to improve chondrogenic potential of MSCs, (b) alternative cell combinations to improve chondrogenesis and (c) markers to select a priori MSC donors with high chondrogenic potential.

\subsection{Hypoxia to improve MSC performance and chondrogenic differentiation}

As described in the introduction the MSC stem cell niche is supposed to exhibit a hypoxic environment [8]. Therefore we believe that the oxygen tension during selection and expansion of MSCs is critical for optimal cell performance. In chapter five we demonstrate that continues hypoxic expansion can improve differentiation potential, delay senescence as well as alter the epigenetic profile of MSCs. MSCs cultured under hypoxic conditions have been described before to exhibit improved self-renewal and multipotency $[9,10]$, advanced differentiation potential [11, 12] and delayed senescence [13]. In this chapter we expand our knowledge by using three different genetic platforms for resolving the underlying mechanism of better MSC performance after hypoxic expansion. We reveal a significant different methylation profile of MSCs after long-term normoxic culture when compared to the hypoxic expanded MSCs. Additionally, mRNA profiling identified a panel of histone-related genes to be differently regulated. The iteration across the used platforms as well as the linking of regulated elements has been hardly achieved and requires the need for whole genome projects, as achieved in cancer biology [14]. On the one hand the altered methylation profile might result in the differential mRNA and miRNA regulation, but it is as well known that miRNA and mRNA levels have the potential to alter methylation profiles and other epigenetic modifications. For example, the cartilage specific miR-140 has been shown to target histone deacetylase 4 in mice [15].

Besides, the low oxygen tension can improve MSCs chondrogenic differentiation. A hypoxic environment marks cartilage with an oxygen concentration ranging from five to one percent. In chapter six we underline that MSC chondrogenesis under low oxygen tension is not only linked to improved matrix deposition and chondrogenic marker expression [16], but is as well connected to a more articular cartilage fingerprint of the newly formed tissue. Gawlitta et al. demonstrated recently that low oxygen can delay the often observed hypertrophic differentiation of MSCs in normoxic ex vivo conditions [17]. We are the first to link this delay in hypertrophic differentiation to an exclusive marker set of articular enriched genes and proteins: GREM1, FRZB, DKK1 and ABI3BP. The two identified antagonist of articular cartilage formation PANX3 and MMP13 were found to be down-regulated after hypoxic MSC differentiation $[18,19]$. An alternative to cell expansion and differentiation in hypoxia, can be the addition of small hypoxia mimicking compounds, like o-phenanthroline, to the culture medium. The results in chapter seven do show that these small molecules activate hypoxia signaling pathways and reduce catabolic matrix processes, but may have unwanted side effects. Hence safer compounds are needed to make hypoxia mimicking compounds more successful. 


\subsection{Co-culture of MSCs and chondrocytes for improved chondrogenesis}

The co-culture of MSCs and chondrocytes is seen as one option to optimise the current strategy of autologous chondrocyte implantation (ACI) [20]. For ACI chondrocytes are isolated from a non-load-bearing site of the joint in a first surgery, expanded $e x$ vivo and re-implanted in the defect site in a second surgery. Chondrocyte isolation and expansion is associated with de-differentiation and loss of chondrogenic potential and should therefore be limited [21]. To limit the use of chondrocytes as well as to moderate ACI from a two-step surgery to a one-step surgery the use of autologous MSCs was proposed. Next to the beneficial effect of chondrocyte cell number reduction, co-culture of MSCs and chondrocyte has been described to improve chondrogenic matrix formation [3]. In chapter nine we reveal a model to transfer the cell-based co-culture to a biomaterial assisted approach enabling for one-step surgery. Building blocks of MSC-loaded microcarriers are mixed with single cell chondrocytes. This co-culture model leads to improved chondrogenesis when compared to MSC- or chondrocyte-loaded microcarriers alone. In addition, this approach may contribute to more efficient culture expansion given the described positive effects of microcarriers in expansion of both MSCs and chondrocytes [22, 23].

In chapter eight we introduce the co-culture of MSCs and chondrocytes cultured in normoxia and hypoxia. Whereas normoxic co-culture leads to the described beneficial effect on chondrogenesis we were not able to proof this concept under hypoxic culture conditions. Therefore, we wanted to investigate on the likely altered expression profile of small molecules expressed by MSCs and chondrocytes in hypoxia and normoxia. Secondary ion mass spectroscopy- (SIMS) and matrix-assisted laser desorption/ionisation-(MALDI) imaging mass spectroscopy revealed different expression profiles of lipids in normoxic and hypoxic conditions. Next to higher levels of diacylglycerol we mainly assigned increased cholesterol levels to normoxic MSCcontaining pellets. This novel finding demonstrates cholesterol as a potential MSC factor involved in the improved chondrogenesis during the co-culture of MSCs and chondrocytes. Cholesterol was introduced before as regulator of chondrogenesis and endochondral ossification [24], but its definite biological role in the co-culture process has to be further researched. This study underlines that changes in lipid metabolism and resulting lipid profiles are one potential mechanism how cells react to environmental changes. Changes in lipid levels have been long linked to different malignancies of tumor cells in cancer biology [25]. Until now, lipid profilesare mainly neglected as marker for cell performance in tissue engineering or stem cell biology. We demonstrated that SIMS and MALDI imaging mass spectrometry provides a perfect platform for their investigation [26]. 


\subsection{Linking microRNA levels to MSC differentiation potential}

Recent research identified a major role of microRNAs in cellular processes. Slaby et al. were the first ones to describe miRNAs and their potential to modulate mRNA and protein levels in colorectal cancer. This directive publication pointed out that miRNAs have the potential to be a novel class of therapeutic targets [27]. This thesis introduces miRNAs in chapter four and five for the determination of environmental response, differentiation potential, chondrogenic differentiation state and the stem cell like properties of MSCs. Chapter four underlines that mRNA levels of MSC donors with high and low chondrogenic potential are not sufficiently distinct to determine prognostic markers. We provide evidence that miRNA profiles may have better prognostic value to identify MSC donors with high chondrogenic potential than global mRNA expression patterns [28]. Fold changes in mRNA expression between good and bad responders were rather small, while, at least in this limited donor set, differences in expression of miRNAs were more pronounced. The prognostic value of miRNA expression profiles for MSCs differentiation potential warrants further study. Nevertheless, genome wide expression profiling as well as miRNA profiling hinted at differences in TGF $\beta$ responsiveness in good and bad performing donors. Since TGF $\beta$ is the main driving force in currently exploited chondrogenic differentiation protocols $[29,30]$, sensitivity to TGF $\beta$ might be the underlying mechanism explaining donor variation in differentiation assays.

\subsection{Concluding remarks and future perspectives}

Functioning of tissue repair depends strongly on the initiation of regenerative processes including the recruitment of proper progenitor cells, the replacement of host cells and ultimately the repair of damaged tissue. Since cartilage has a limited intrinsic repair response after tissue injury, regenerative medicine approaches are needed. One progenitor cell source to repair cartilage defects are MSCs. MSC function is critically influenced by extrinsic signals derived from their natural habitat in the stem cell niche. Signals in the niche are ranging from cell-cell contact, cell-ECM interaction, soluble factors, and mechanical stress to low oxygen levels. The mimicking of signal cues experienced in the natural MSC environment is a valuable entry point to improve MSCs therapeutic performance. In this thesis we described two culture techniques to improve chondrogenic performance of MSCs for cartilage tissue engineering strategies. We demonstrated that low oxygen tension provides a key cue for the altering of MSC performance during expansion and differentiation. Furthermore we used a co-culture model of MSCs and chondrocytes to improve overall chondrogenesis in comparison to MSC or chondrocyte monoculture. Improved co-culture performance can be dependent on soluble/released factors as well as cell-cell contact.

Nevertheless, this thesis only includes limited cues of the cellular niche to improve MSC performance. Additional research has to determine more factors or combinations of those to further advance the use of MSCs in tissue engineering strategies. 


\section{References}

1. Friedenstein, A.J., S. Piatetzky, II, and K.V. Petrakova, Osteogenesis in transplants of bone marrow cells. Journal of embryology and experimental morphology, 1966. 16(3): p. 381-90.

2. Dominici, M., et al., Minimal criteria for defining multipotent mesenchymal stromal cells. The International Society for Cellular Therapy position statement. Cytotherapy, 2006. 8(4): p. 315-7.

3. Wu, L., et al., Trophic effects of mesenchymal stem cells increase chondrocyte proliferation and matrix formation. Tissue Eng Part A, 2011. 17(9-10): p. 1425-36.

4. Prockop, D.J., Repair of tissues by adult stem/progenitor cells (MSCs): controversies, myths, and changing paradigms. Molecular therapy : the journal of the American Society of Gene Therapy, 2009. 17(6): p. 939-46.

5. da Silva Meirelles, L., A.I. Caplan, and N.B. Nardi, In search of the in vivo identity of mesenchymal stem cells. Stem Cells, 2008. 26(9): p. 2287-99.

6. Doorn, J., et al., Therapeutic applications of mesenchymal stromal cells: paracrine effects and potential improvements. Tissue engineering. Part B, Reviews, 2012. 18(2): p. 101-15.

7. Mackay, A.M., et al., Chondrogenic differentiation of cultured human mesenchymal stem cells from marrow. Tissue Eng, 1998. 4(4): p. 415-28.

8. Mohyeldin, A., T. Garzon-Muvdi, and A. Quinones-Hinojosa, Oxygen in stem cell biology: a critical component of the stem cell niche. Cell Stem Cell, 2010. 7(2): p. 150-61.

9. Tamama, K., et al., Differential roles of hypoxia inducible factor subunits in multipotential stromal cells under hypoxic condition. J Cell Biochem, 2011. 112(3): p. 804-17.

10. Basciano, L., et al., Long term culture of mesenchymal stem cells in hypoxia promotes a genetic program maintaining their undifferentiated and multipotent status. BMC Cell Biol, 2011. 12: p. 12. 11. Adesida, A.B., A. Mulet-Sierra, and N.M. Jomha, Hypoxia mediated isolation and expansion enhances the chondrogenic capacity of bone marrow mesenchymal stromal cells. Stem Cell Res Ther, 2012. 3(2): p. 9 .

12. Yew, T.L., et al., Scale-up of MSC under hypoxic conditions for allogeneic transplantation and enhancing bony regeneration in a rabbit calvarial defect model. J Orthop Res, 2012.

13. Tsai, C.C., et al., Hypoxia inhibits senescence and maintains mesenchymal stem cell properties through down-regulation of E2A-p21 by HIF-TWIST. Blood, 2011. 117(2): p. 459-69.

14. Comprehensive molecular portraits of human breast tumours. Nature, 2012. 490(7418): p. 61-70.

15. Tuddenham, L., et al., The cartilage specific microRNA-140 targets histone deacetylase 4 in mouse cells. FEBS letters, 2006. 580(17): p. 4214-7.

16. Duval, E., et al., Hypoxia-inducible factor 1alpha inhibits the fibroblast-like markers type I and type III collagen during hypoxia-induced chondrocyte redifferentiation: hypoxia not only induces type II collagen and aggrecan, but it also inhibits type I and type III collagen in the hypoxiainducible factor 1alpha-dependent redifferentiation of chondrocytes. Arthritis Rheum, 2009. 60(10): p. $3038-48$.

17. Gawlitta, D., et al., Hypoxia Impedes Hypertrophic Chondrogenesis of Human Multipotent Stromal Cells. Tissue Eng Part A, 2012.

18. Leijten, J.C., et al., Gremlin 1, frizzled-related protein, and Dkk-1 are key regulators of human articular cartilage homeostasis. Arthritis Rheum, 2012. 64(10): p. 3302-12.

19. Leijten, J.C., et al., Hypoxia inhibits hypertrophic differentiation and endochondral ossification in explanted tibiae. PLoS One, 2012. 7(11): p. e49896.

20. Brittberg, M., et al., Treatment of deep cartilage defects in the knee with autologous chondrocyte transplantation. N Engl J Med, 1994. 331(14): p. 889-95.

21. Lin, Z., et al., Gene expression profiles of human chondrocytes during passaged monolayer cultivation. J Orthop Res, 2008. 26(9): p. 1230-7.

22. Frondoza, C., A. Sohrabi, and D. Hungerford, Human chondrocytes proliferate and produce matrix components in microcarrier suspension culture. Biomaterials, 1996. 17(9): p. 879-88.

23. Frauenschuh, S., et al., A microcarrier-based cultivation system for expansion of primary mesenchymal stem cells. Biotechnol Prog, 2007. 23(1): p. 187-93.

24. Deckelbaum, R.A., et al., Ihh enhances differentiation of CFK-2 chondrocytic cells and antagonizes PTHrP-mediated activation of PKA. Journal of cell science, 2002. 115(Pt 14): p. 3015-25.

25. Hakomori, S., Tumor malignancy defined by aberrant glycosylation and sphingo(glyco)lipid 
metabolism. Cancer research, 1996. 56(23): p. 5309-18.

26. Cillero-Pastor, B., et al., Time-of-Flight Secondary Ion Mass Spectrometry-Based Molecular Distribution Distinguishing Healthy and Osteoarthritic Human Cartilage. Analytical chemistry, 2012. 84(21): p. 8909-16.

27. Slaby, O., et al., MicroRNAs in colorectal cancer: translation of molecular biology into clinical application. Molecular cancer, 2009. 8: p. 102.

28. Guo, L., R.C. Zhao, and Y. Wu, The role of microRNAs in self-renewal and differentiation of mesenchymal stem cells. Exp Hematol, 2011. 39(6): p. 608-16.

29. Kang, S.W., et al., Increase of chondrogenic potentials in adipose-derived stromal cells by codelivery of type I and type II TGFbeta receptors encoding bicistronic vector system. J Control Release, 2012. 160(3): p. 577-82.

30. Bian, L., et al., Enhanced MSC chondrogenesis following delivery of TGF-beta3 from alginate microspheres within hyaluronic acid hydrogels in vitro and in vivo. Biomaterials, 2011. 32(27): p. 6425-34. 


\section{Curriculum Vitae}

Nicole Georgi was born at the $22^{\text {nd }}$ of March 1983 in Schlema, former German Democratic Republic. She received her pre-university diploma in 2001 at the Clemens Winkler Gymnasium Aue (Germany) and started her Biotechnology Bachelor studies at the Applied University of Sciences in Zittau (Germany) in the same year. After her Bachelor degree Nicole, obtained a position as research associate at the University Hospital Dresden, Germany (Prof. Gerhard Ehninger, Dr. Thomas Illmer) to continue her research involving the identification of markers for acute myeloid

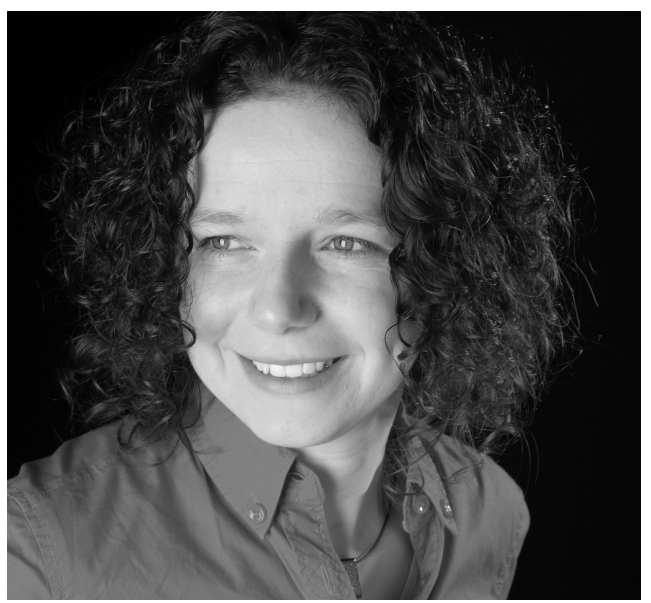
leukemia. In April 2008, Nicole received her Master of Science degree in Molecular Bioengineering from the Dresden University of Technology (Germany) after a nine months research visit in the Regenerative Medicine Lab of Prof. Dr. Dietmar Hutmacher (Brisbane, Australia). In November 2008, she started her PhD research at the departments of Tissue Engineering and Developmental BioEngineering at the University of Twente (The Netherlands) under the supervision of Prof. Marcel Karperien. From August 2011-December 2011, Nicole undertook part of her PhD research at the Cartilage Regeneration Laboratory (CRL) of Dr. Travis Klein (Brisbane, Australia). Her research in Twente and Brisbane was focussed on the optimisation of cell sources as well as cell culture conditions for the improvement of cartilage repair strategies. For her $\mathrm{PhD}$ research, Nicole received a scholarship of the German Academic Exchange Service and the Anna Fonds te Leiden as well as a Travel Award of the International Cartilage Repair Society. From Februar 2013, Nicole continues her scientific work as a Postdoctoral Fellow in the department of Molecular Nanofabrication (Dr. Pascal Jonkheijm), University of Twente (The Netherlands). 


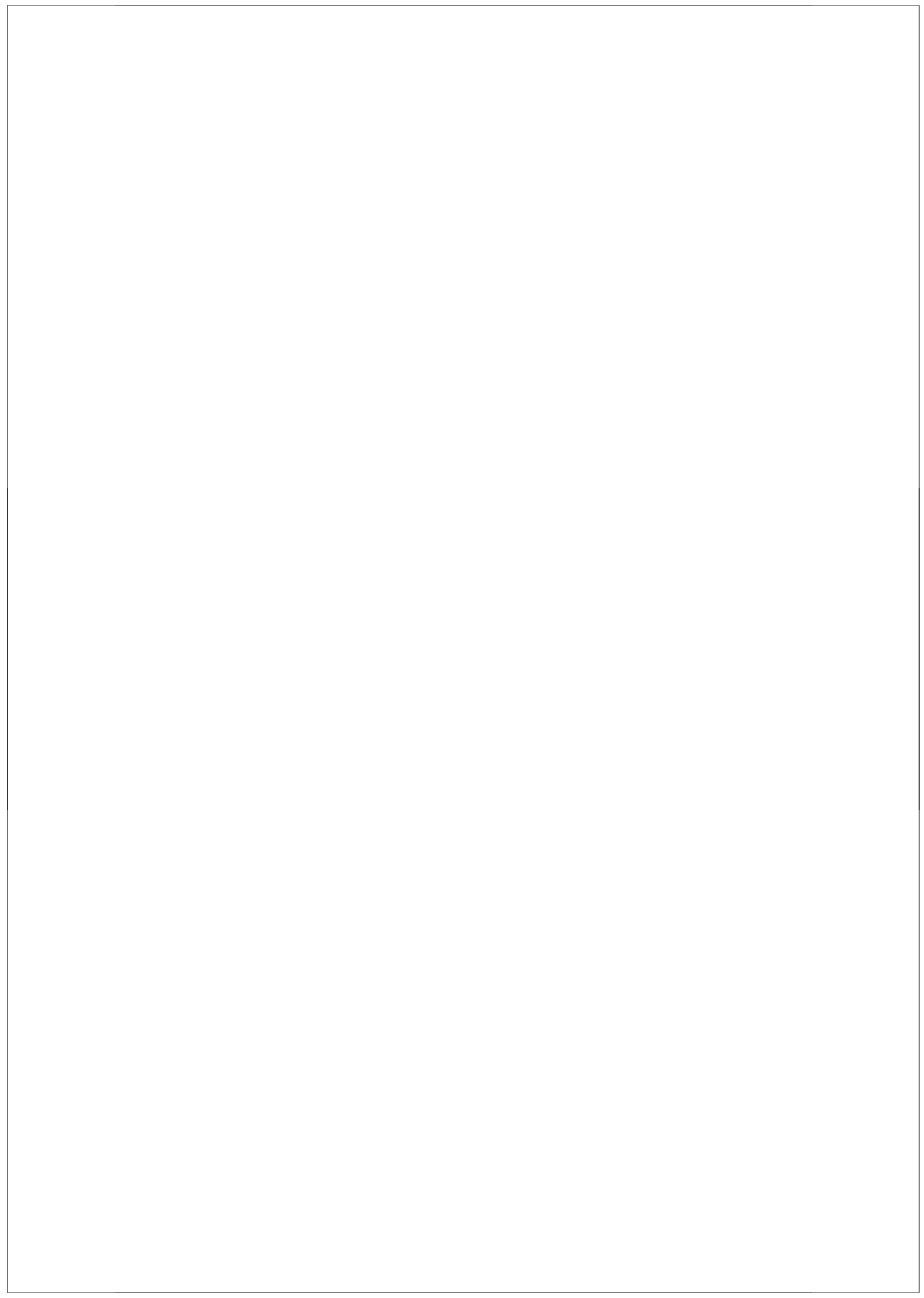




\section{List of Publications}

\section{Peer-reviewed papers}

Georgi N*, Leijten JC*, Wu L, van Blitterswijk CA, Karperien M. Cell Sources for Articular Cartilage Repair Strategies: Shifting from Monocultures to Cocultures. Tissue engineering. Part B, Reviews 2012.

Georgi N*, Moreira-Teixeira LS*, Leijten $\mathrm{J}^{*}$, Wu L, Karperien M. Cartilage tissue engineering. Endocrine development 2011; 21: 102-115.

Wu L, Leijten JC, Georgi N, Post JN, van Blitterswijk CA, Karperien M. Trophic effects of mesenchymal stem cells increase chondrocyte proliferation and matrix formation. Tissue engineering. Part A 2011; 17: 1425-1436.

Klein TJ, Rizzi SC, Reichert JC, Georgi N, Malda J, Schuurman W, et al. Strategies for zonal cartilage repair using hydrogels. Macromolecular bioscience 2009; 9: 1049-1058.

Marques Silva J, Georgi N, Costa R, Sher P, Reis R, van Blitterswijk C, Karperien M, Mano J. Nanostructured 3D constructs based on chitosan and chondroitin sulphate multilayers for cartilage tissue engineering. Accepted in PLOS ONE.

Georgi N, Schrobback K, Doran M, Klein TJ. Human chondrocyte cell line behavior in chondrogenic differentiation models. Submitted.

Georgi N, Taipaleenmaki H, Raiss CC, van Wijnen A, Groen N, Janeczek Portalska K, van Blitterswijk CA, Karperien M. microRNA levels as prognostic markers for chondrogenesis of MSC donors. Submitted.

Georgi N, van Blitterswijk CA, Karperien M. MSC or chondrocyte seeded microcarriers as building blocks for cartilage tissue engineering. Submitted.

Georgi N*, Landman EBM*, Klein T, van Blitterswijk CA, Karperien M. The effect of $o$-Phenanthroline as mediator of the hypoxic response in cartilage tissue engineering models. Submitted. 
Georgi N, Leijten $\mathrm{JCH}^{*}$, van Blitterswijk CA, Karperien M. Hypoxia steers chondrogenically differentiating MSCs towards an articular cartilage phenotype. Submitted.

Janeczek Portalska K, Groen N, Krenning G, Georgi N, Mentink A, van Blitterswijk CA, de Boer J. Donor variation and senescence in endothelial differentiation of human mesenchymal stromal cells. Submitted.

Leijten JCH, Landman EBM, Georgi N, Kip M, Jahr H, Post JN, van Blitterswijk CA, Karperien M. Transcriptional regulation of GREM1, FRZB and DKK1 by hypertrophic differentiation -regulated factors. Submitted.

Georgi N, Cillero Pastor B, Eijkel G, Kiss A, van Blitterswijk CA, Karperien $\mathrm{M}$. Cholesterol and phosphocoline as regulators of the chondrogenic response in co-cultures of MSCs and primary chondrocytes. In preparation.

Georgi N, Taipaleenmaki H, Leijten JCH, van Wijnen A, van Blitterswijk CA, Post JN, Karperien M. Epigenetic changes associate with improved performance of MSCs expanded in hypoxia. In preparation.

Georgi N, Schnittert J, van Blitterswijk CA, Karperien M. The influence of hypoxic expansion of human MSC on their performance in chondrogenic coculture. In preparation.

* authors contributed equally

\section{Abstracts selected for oral presentation}

Georgi N, Taipaleenmaki H, van Wijnen A, Groen N, Janeczek Portalska K, van Blitterswijk CA, J. de Boer, Post JN, Karperien M. MicroRNAs are prognostic markers for the chondrogenic potential of MSCs. OARSI, 2013, Philadelphia, United States.

Georgi N, van Blitterswijk, C, Karperien, M. MSC or chondrocyte seeded microcarriers as building blocks for cartilage tissue engineering. Annual meeting Dutch Society of Biomaterials and Tissue Engineering, 2012, Lunteren, The Netherlands.

Georgi N, van Blitterswijk CA, Karperien M. Hypoxic expansion of MSCs improves chondrogenicity and cell yield implications for the optimal use of MSCs in cartilage tissue engineering. International Cartilage Repair Society 10th World Congress, 2012 Montreal, Canada.

Georgi N, Klein T, Hutmacher D. Co-culture of Human MSCs and Chondrocytes on Nanofibre-Fibrin-Alginate Composites. 2nd International Congress on Stem Cells and Tissue Formation, 2008, Dresden, Germany. 
Georgi N, Klein T, Hutmacher D. Co-culture of Human MSCs and Chondrocytes on Nanofibre-Hydrogel Composites. 8th World Biomaterials Conference, 2008, Amsterdam, The Netherlands.

\section{Abstracts selected for poster presentations}

Georgi N, Kul B, Doran M, Hutmacher DW, Klein T. Triggering oxygen tension for improved cartilage matrix formation. IHBI inspirers, 2011, Brisbane, Australia.

Georgi N, Leijten JCH, van Blitterswijk CA, Karperien M. Influence of oxygen tension on differently performing MSC donors new implications for biomaterial based cartilage tissue engineering. Annual meeting German Biomaterials Society, 2010, Heiligenstadt, Germany.

Georgi N, van Blitterswijk CA, Karperien M. Culture of MSCs and chondrocytes in a disk cultures. TeRM SmartMix/BMM meeting, 2010, Ermelo, The Netherlands.

Georgi N, van Blitterswijk CA, Karperien M. Co-culture of fetal MSCs and chondrocytes in a transwell system. Annual meeting Dutch Society of Biomaterials and Tissue Engineering, 2009, Lunteren, The Netherlands.

Georgi N, Leijten JCH, Moreira Teixeira L, van Blitterswijk CA, Karperien M. Culture of fetal MSCs and fetal chondrocytes in a transwell system. Gordan research conference: Cartilage biology and pathology, 2009, Les Diablerets, Switzerland.

\section{Awards/ Scholarships}

International Cartilage Repair Society Travel Award. International Cartilage Repair Society 10th World Congress, 2012 Montreal, Canada.

Travel Scholarship of the German Academic Exchange Service (DAAD). 4 months lab visit Cartilage Regeneration Lab (Dr. Travis Klein), 2011, Brisbane, Australia.

Masterthesis Award of the German Biomaterials Society. 2008, Hamburg, Germany.

Biomaterials Student Travel Award. 8th World Biomaterials Conference, 2008, Amsterdam, The Netherlands. 


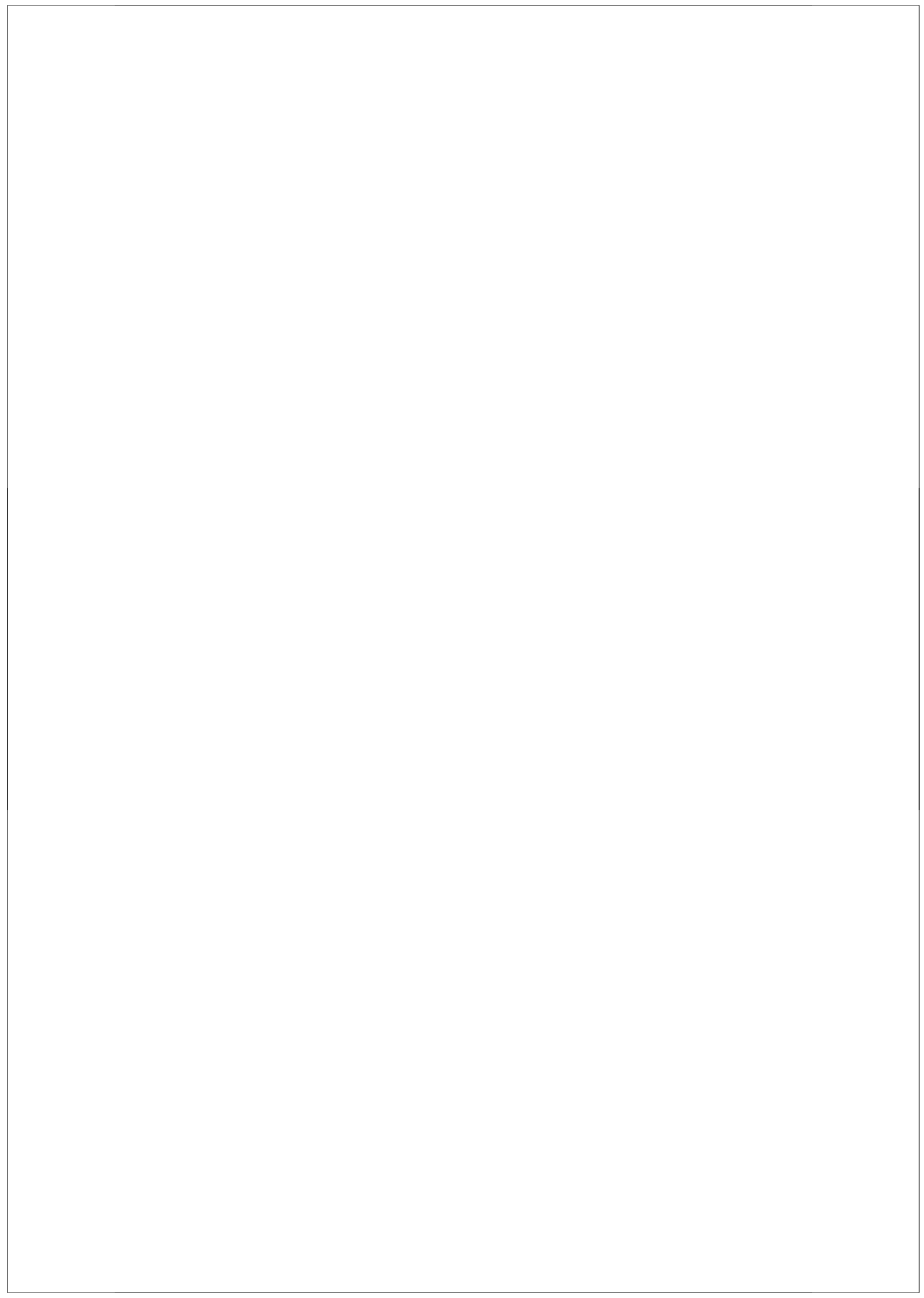




\section{Acknowledgement}

Finishing my $\mathrm{PhD}$ is another big step I take in my life. As with the most of us, there are a lot of people I feel very thankful for preparing, allowing and assisting me before and during this achievement.

First of all, I want to thank Marcel, my direct supervisor, and Clemens, my promoter, for giving me the opportunity to undertake research in their departments. You offered me a lot of scientific freedom and I enjoyed bringing my own ideas to life.

I want to thank as well Prof. Harrie Weinans, Prof. Wouter Dhert, Dr. Marco Helder, Prof. Dirk Grijpma and Prof. Leon Terstappen for being part of my graduation committee. I highly appreciate you taking the time to discuss my work.

Dietmar, I'm very grateful that you encouraged me to take this step in my career. I value the scientific trust, your honesty about my work as well as your hospitality whenever I was in Brisbane. You've been an amazing supervisor for me.

During my PhD, I was happy to collaborate with a lot of scientific outstanding, very friendly and lovely people:

Ron, thanks for the warm welcome at AMOLF. On the second day in your group, I was already part of the group BBQ. Thanks as well for fitting your agenda to my graduation day. Berta, you've been more than a collaborator. Thanks for all the (scientific) support and nice chats. Gert, analysing data was never so much fun. Let's start a new topic soon!

Andre, my stay in Worcester was short but impressive. I'm honored and happy that you proposed to be a member of my graduation committee. Thanks for taking all the efforts to be part of my committee. Hanna, you made my stay in Worcester very pleasant. Thanks for so much hospitality and for the efficient scientific collaboration. I hope we continue our collaboration.

Travis, you've already been part of my previous scientific step. This time, you are part of this thesis. Thanks for the very efficient and joyful stay in your group. I value your input on my work and hope we manage to find ground for future collaborations. Thanks as well to the whole Cartilage Regeneration Lab and Katy, my lovely housemate, for the great time we had together!

Prof. Brigitte Voit, as my mentor you shaped part of my scientific life. Thanks for your sudden input whenever I approach you. 
What would the time in Enschede have been without all the friends I got to know inside and outside of the lab?

Janneke and Angelito: it is great to have you not just as Pathmosburen. You are always there for us. Priceless! Jeroen and Lili, it seems like we share a lot of big events in our life: $\mathrm{PhD}$, marriage, children, cats and a lot of lovely dinners. Hopefully more to come! Karolina and Maciek, you've been the first we watched getting married, the first with a little baby and the ones with the biggest parties. I enjoyed so much being part of every event. Charlene and Alex, Sandra and Juan thank you for all the nice evenings, parties and chats. Mijke, you are the most bouncy and energetic office mate I had. Paul, my first housemate in Enschede youre always a ready listener and a great party man. You are adorable the way you are.

Ellie: starting the PhD almost at the same time, spending a lot of time in one office sharing happiness and frustration made us realize that we are more than just colleagues. Im happy that you are one of my paranymhs and I'm honored to be one of yours. A rewarding friendship.

Last but not least: to the current and previous members of the TR and DBE group - thanks for your support in lab issues, your chats inside and outside the lab, the fabulous labtrips with my first sailing experience (thanks Anne!) and the time we spent together.

After saying goodbye to my TR/DBE workplace, I was lucky to receive a very warm welcome in the MnF-group. I'm looking forward to my new scientific challenge and want to thank Pascal for giving me the opportunity and the trust to take this challenge in his group.

Silja, danke für die tolle Zeit, die wir zusammen in Enschede (und Den Haag) verbracht haben und noch verbringen werden. Unsere Unternehmungen, Ausflüge, Koch-, Backabende und Gespräche waren und sind eine Bereicherung.

Eine besondere Bereicherung sind langandauernde und erfrischende Freundschaften: Yvönne, das leben wäre nur halb so schön ohne dein Lachen und unsere Freundschaft. Claude, die WG-Zeiten bleiben unvergessen. Wally und Maria, die Erlebnisse des Masterstudiengang sind noch lebendig. Schön, dass wir noch immer Freude an neuen Wiedersehen haben. Nicole, danke für unsere bedingungslose Freundschaft über so viele Jahre und die Zusage als Paranymphe.

Den wohl größten Anteil an meiner Entwicklung und dem was ich heute bin, habt ihr: meine Eltern und Familie. Ich danke euch für eure Liebe und Unterstützung jeglicher Art.

Was wäre das Leben ohne meine eigene (noch) kleine Familie? Chris, danke für deine Liebe, dein Verständnis und die stetig warme Küche während des Schreibens dieser Arbeit. Emma, Ghandi und Gobi - ihr macht unser Leben einfach bunter. 